Universidad Nacional de La Plata

Facultad de Humanidades y Ciencias de la Educación

Secretaría de posgrado

Maestría en lingüística

Tesis presentada como requisito para la obtención del título de magíster en lingüística

\title{
La entonación en el discurso: solicitud y provisión de información en entrevistas en francés
}

\author{
Autora: Karina Ibañez \\ Directora: Dra. Luisa Granato \\ Co-Directora: Dra. Ana María Gentile
}




\section{Agradecimientos}

Quisiera expresar mi enorme gratitud a Luisa Granato quien no sólo dirigió esta tesis, sino que la hizo posible. Destaco especialmente su generosidad en lo académico, por su inestimable orientación y su excelente formación, pero también en su interés constante por poner a mi disposición su tiempo y su biblioteca personal para que pudiera llevar adelante mi trabajo. La confianza de Luisa, con la que conté desde antes de iniciar este camino, fue lo que me llevó adelante aún en momentos difíciles.

Mi reconocimiento asimismo a Ana María Gentile, por sus invaluables aportes y por su generosa predisposición a encauzar mi estudio.

Agradezco también a las personas que amable y desinteresadamente colaboraron con mi investigación: Roger, Laetitia, Monique, Claire, Aline, Clément, Nicolas, Frédéric, Angélique, Floriane, Ophélie, Catherine, Gilles, Samantha, Nathalie, Aurélie, Béatrix y Nadine.

Agradezco a mis colegas Valeria Liljesthröm, Daniela Spoto Zabala y Marina Grasso, por su valiosísimo apoyo y afectuosa contención. Y a mis amigas quienes, quizá sin saberlo, me brindaron momentos tan reconfortantes a lo largo de este proceso.

Un profundo agradecimiento a mi familia. A mis padres, quienes me enseñaron el valor del esfuerzo. A Ramiro y Valentina, por tantas tardes de juegos y paseos sin mamá. A Alejandro, a quien dedico esta tesis, por su aliento y su ayuda incondicionales. 


\section{Índice}

Página

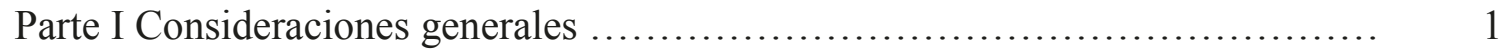

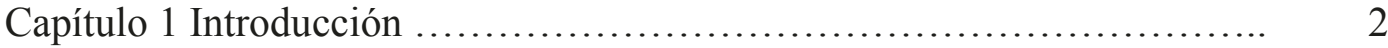

Capítulo 2 Estado de la cuestión ..................................... 6

Capítulo 3 Marco teórico ............................................. 19

Capítulo 4 Metodología ................................................ 26

Parte II Análisis ....................................................... 34

Capítulo 5 Emisiones que solicitan información ........................ 35

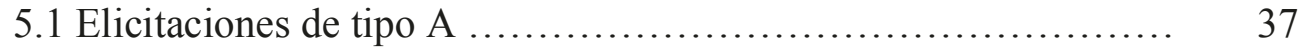

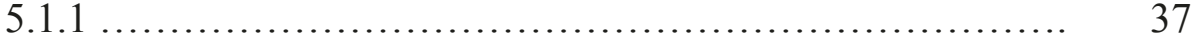

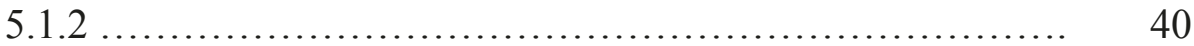

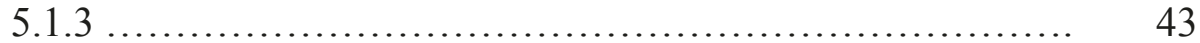

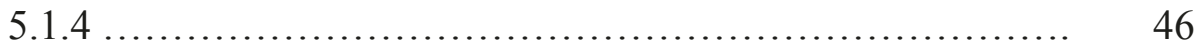

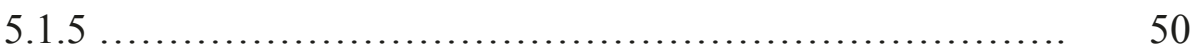

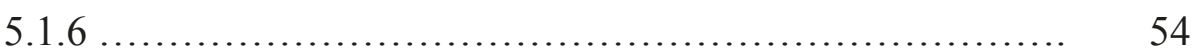

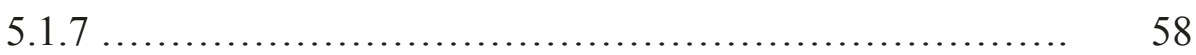

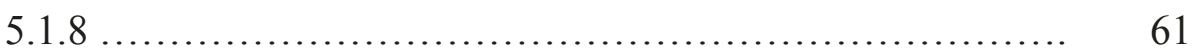

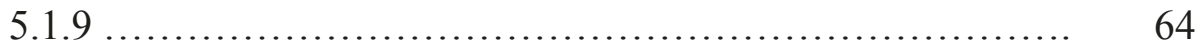

5.2 Elicitaciones de tipo B..................................... 72

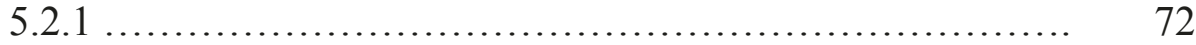

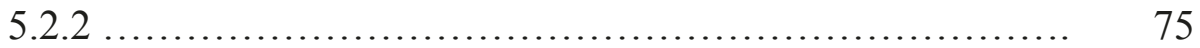

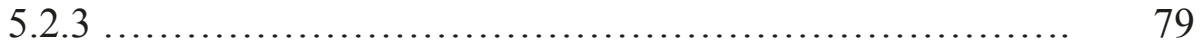

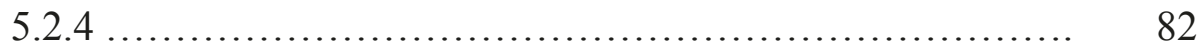

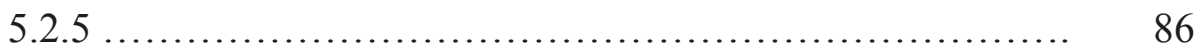

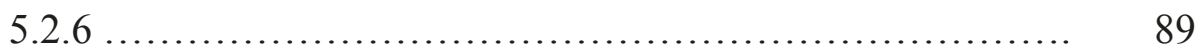

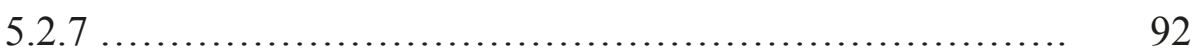

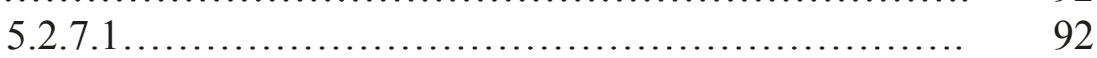

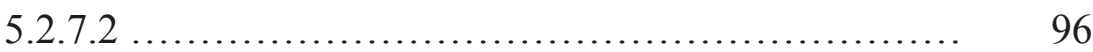

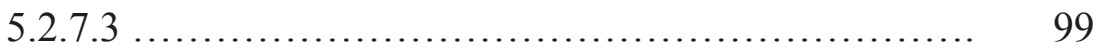

Capítulo 6 Reacciones a un pedido de información ..................... 110

6.1 Emisiones informativas de tipo A .......................... 112

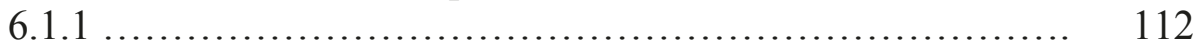

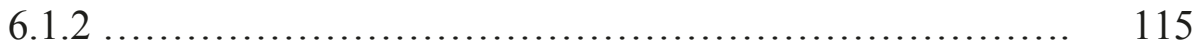

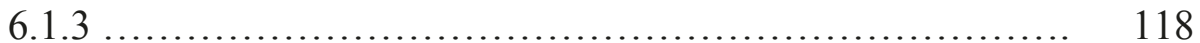

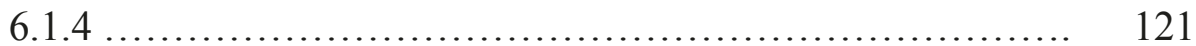

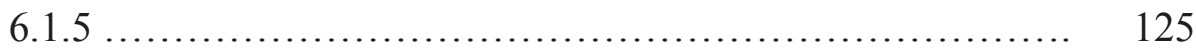

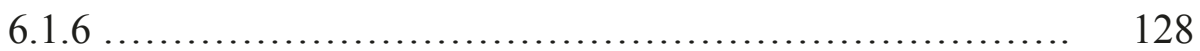

6.2 Emisiones informativas de tipo B $\quad 135$

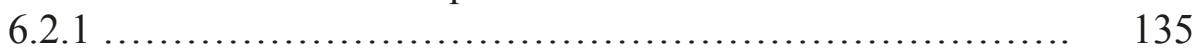

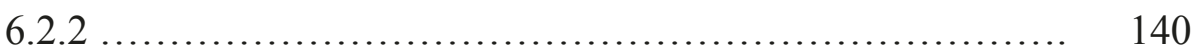




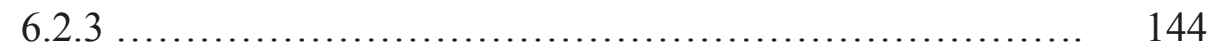

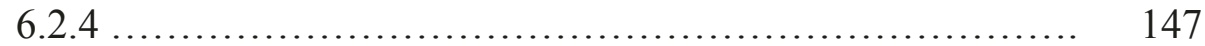

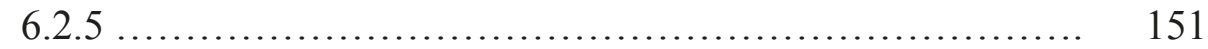

Capítulo 7 El Tono no interactivo ..................................... 159

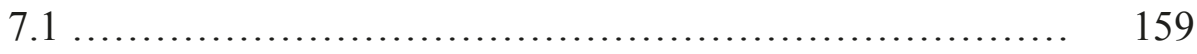

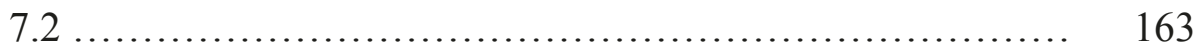

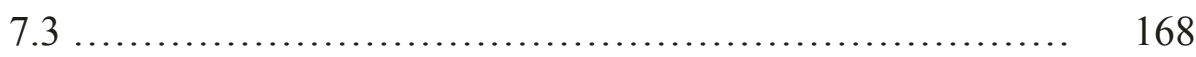

Parte III Reflexiones finales............................................. 177

Capítulo 8 Conclusiones .......................................... 178

Bibliografía .................................................... 182

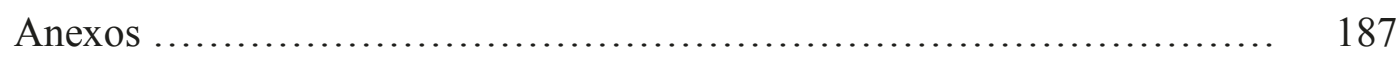




\section{Índice de gráficos}

Página

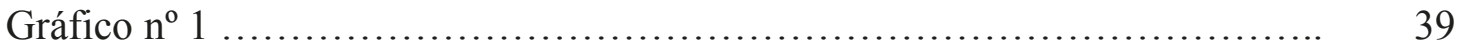

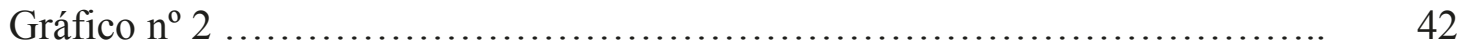

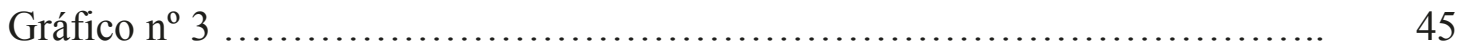

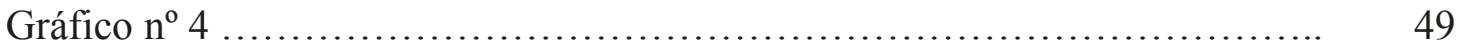

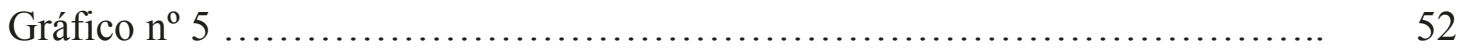

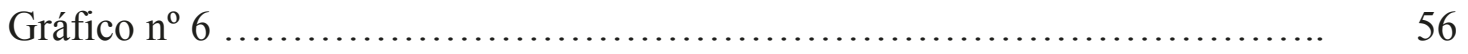

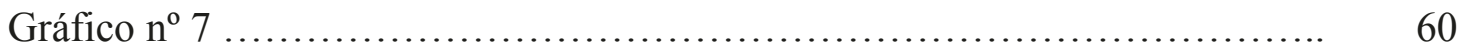

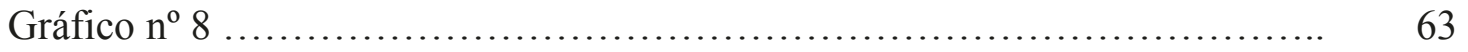

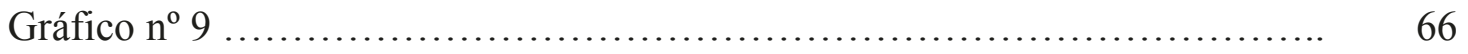

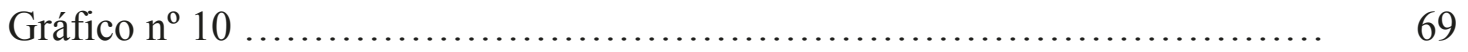

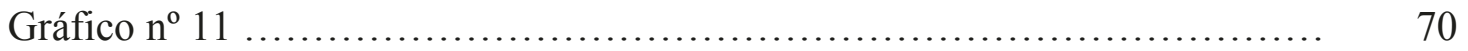

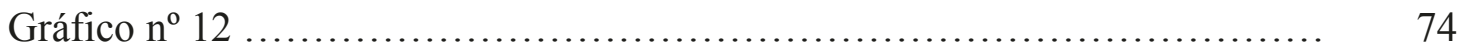

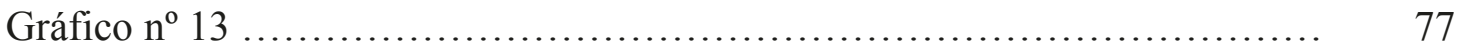

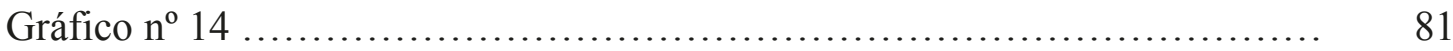

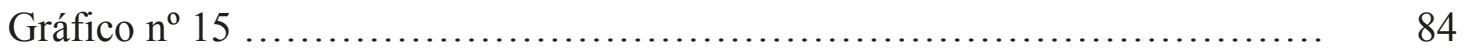

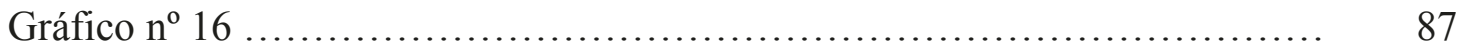

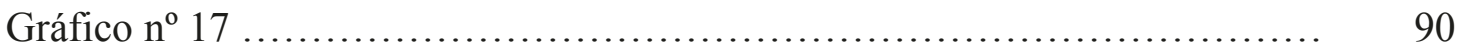

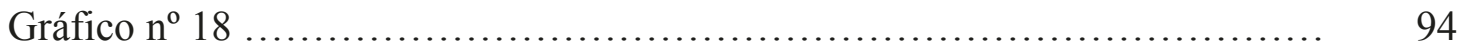

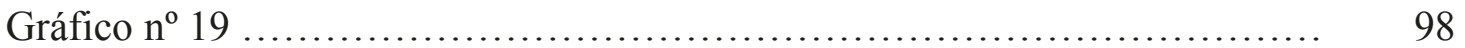

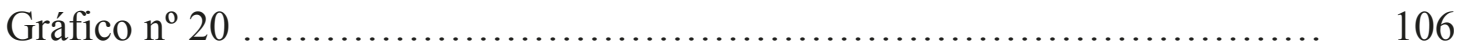

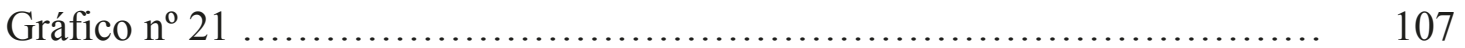

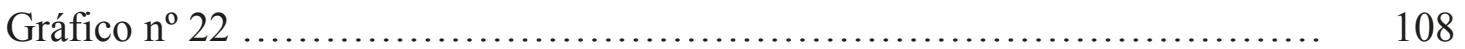

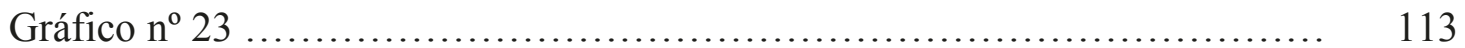

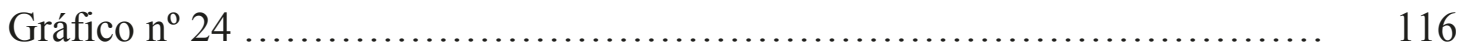

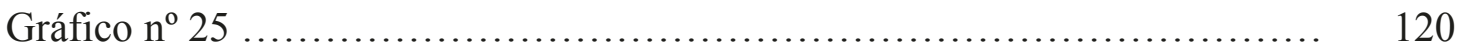

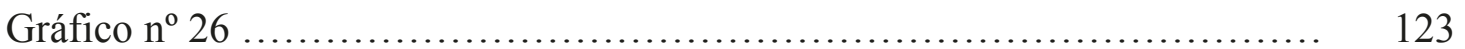

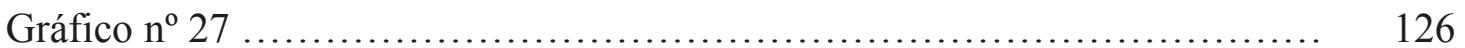

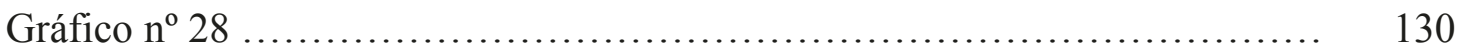

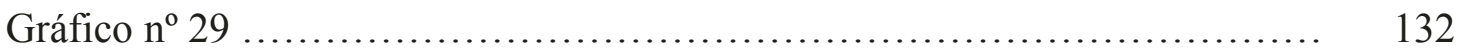

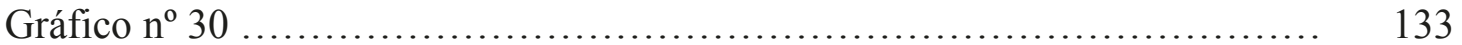

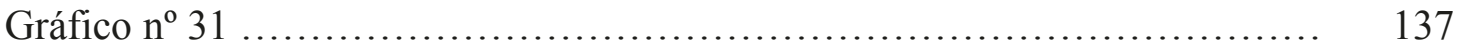




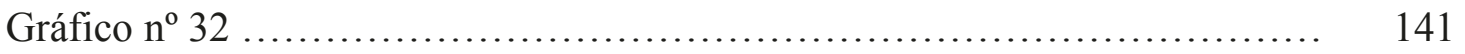

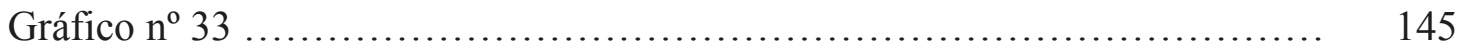

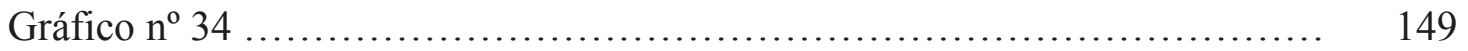

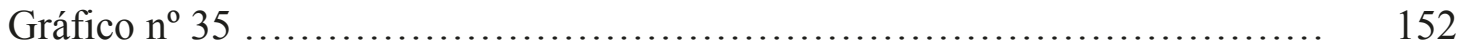

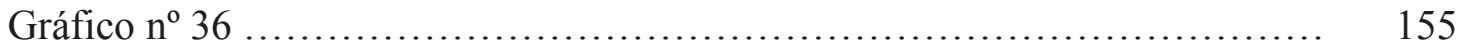

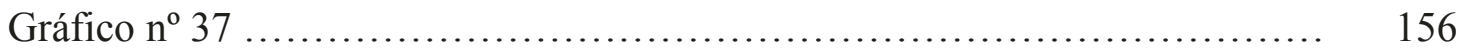

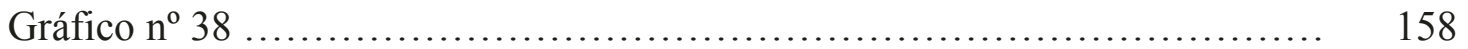

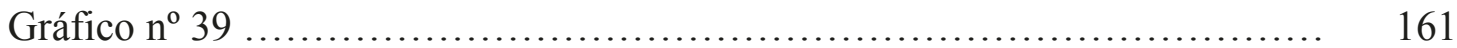

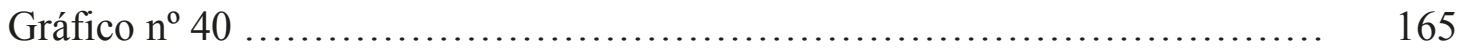

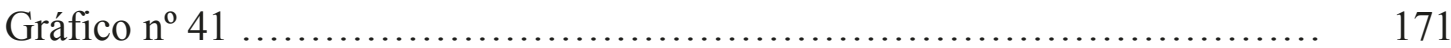

\section{Índice de cuadros}

Página

Cuadro $\mathrm{n}^{\mathrm{o}} 1$..................................................... 7

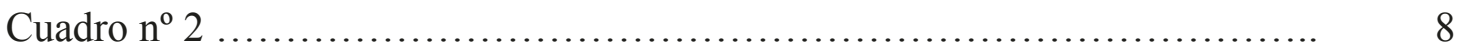

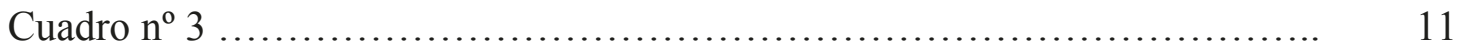

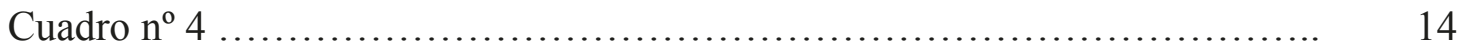

Cuadro $n^{0} 5$......................................................... 15

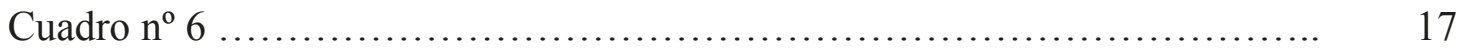

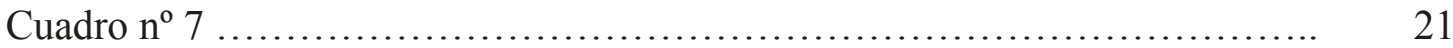

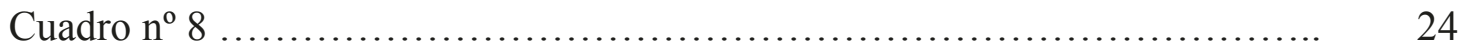

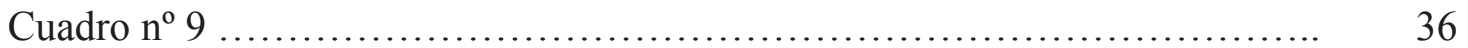

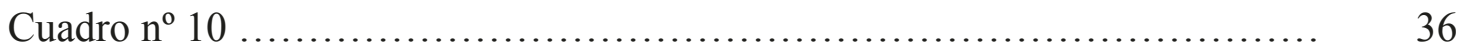

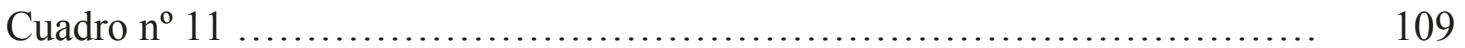

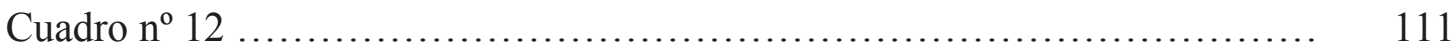

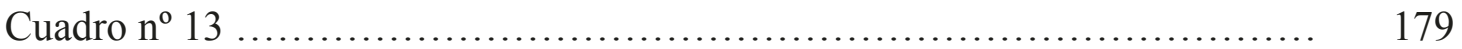


Parte I

Consideraciones generales 


\section{Capítulo 1}

\section{Introducción}

Este trabajo intenta analizar algunos aportes que la entonación realiza al significado del discurso en francés. Para lograr este objetivo, se examinarán emisiones que requieren información así como las respuestas que éstas generan en entrevistas semidirigidas llevadas a cabo por hablantes nativos de francés y registradas en un medio institucional de la ciudad de París. La inquietud de llevar a cabo un trabajo de esta naturaleza surge de la confluencia de dos áreas en las que me desempeño desde hace algunos años. En primer lugar, la de los estudios de la oralidad y, más particularmente, de la interacción verbal. Este ámbito de la lingüística se ha desarrollado con un gran impulso durante las últimas décadas del siglo $\mathrm{XX}$ y continúa aún hoy en expansión. Siguiendo las consideraciones de Eggins y Slade (1997) y de Kerbrat-Orecchioni (1992, 1996), es posible sintetizar algunas líneas de investigación. Desde el ámbito de la sociolingüística, son de gran relevancia los estudios iniciados por Hymes $(1972,1974)$ en etnografía del habla, por Gumperz (1982) en sociolingüística interaccional y por Labov $(1972,1996)$ en sociolingüística variacionista. Desde la etnometodología, los trabajos de Sacks, Schegloff y Jefferson (1974) Jefferson (1975, entre otros), inauguran el campo del Análisis de la conversación. Dentro de la lingüística y en la tradición estructuralista y funcionalista surgen a los estudios de la Escuela de Birmingham (Sinclair, Coulthard et al. 1978), de la Lingüística sistémico-funcional (vertiente desarrollada a partir de los trabajos de Halliday) y de la escuela de Ginebra (Roulet y otros). Desde el ámbito lógico-filosófico, son fundantes las contribuciones de la Teoría de los actos de habla (Austin, 1962 y Searle, 1994) y del principio de cooperación y sus máximas (Grice, 1975). Finalmente la perspectiva sociosemiótica, los trabajos de la Lingüística crítica y del Análisis crítico del discurso (Fairclough, 1992) han contribuido también al estudio de la interacción, y directamente relacionado con el contenido de esta tesis, se llevaron a cabo trabajos vinculados con la entonación del discurso.

En segundo lugar, en lo que hace a los estudios actuales de la entonación, distintos enfoques han contribuido a su desarrollo. Resultan de particular relevancia los abordajes 
que trascienden el análisis de la entonación en oraciones descontextualizadas para centrarse en la entonación del discurso.

En el marco de estos estudios, nuestro trabajo en el grupo de investigación dirigido por la Dra. Luisa Granato (FaHCE, UNLP) nos ha permitido iniciarnos en la exploración y el análisis de córpora de interacción informal. El enfoque sistémico y funcional adoptado posibilitó la comprensión y descripción de aspectos relevantes de esta forma de uso del lenguaje teniendo en cuenta su carácter situado y coconstruido. En trabajos realizados en el marco de este proyecto, nos abocamos fundamentalmente al análisis de las manifestaciones de la metafunción interpersonal, en lo referido al subsistema de evaluación con énfasis en la configuración prosódica de sus significados (Ibañez 2007, 2009; Grasso e Ibañez, 2010).

La práctica docente en las cátedras de Dicción Francesa 1 y 2 ha motivado el interés por profundizar el conocimiento de la entonación del francés, el de sus aportes a la producción y circulación de significados en la interacción y el de los subsistemas que pueden identificarse en el uso. En este ámbito, desarrollé algunos estudios desde el año 2009 referidos a las formas de abordaje de la entonación en los manuales de enseñanza del francés como lengua extranjera (Ibañez, 2010) y a los tipos de descripciones de la entonación más difundidos en estos inicios del siglo XXI (Ibañez, 2012).

La motivación para iniciar el presente trabajo surge entonces del interés en estos ámbitos de la lingüística al que se agrega asimismo el hecho de no haber encontrado, luego de una búsqueda exhaustiva de bibliografía, ninguna referencia a estudios llevados a cabo desde esta perspectiva pragmático-discursiva y sistémica.

El examen de un amplio corpus de francés parisino actual ha orientado nuestra atención hacia los aportes que la entonación puede agregar al desarrollo de la interacción en forma independiente de otros subsistemas de la lengua, tal como se planteó inicialmente para los estudios del inglés (Brazil, 1997). Por otra parte, la práctica de la enseñanza de diferentes aspectos de la oralidad en lengua francesa hace que la posibilidad de describir el carácter sistematizable de determinados valores entonativos se plantee como una perspectiva de gran interés. 


\section{Hipótesis y objetivos}

La observación de los textos con que se trabaja en la enseñanza del francés como lengua extranjera muestra la utilización de diferentes formas fonéticas en la realización de tipos de emisiones diversos. Hemos notado que las emisiones que tienden a generar información y aquellas que brindan la información, se pueden producir con parámetros entonativos diferentes que parecen agregar significados que también son diferentes. A partir de esta realidad nos formulamos la siguiente Hipótesis general.

- Es posible encontrar valores sistematizables en relación con los significados que la entonación agrega.

Dado que este trabajo centrará la atención en emisiones de elicitación y respuesta que se producen en las entrevistas del corpus, nos planteamos las siguientes hipótesis particulares.

Los aspectos entonativos mencionados a continuación inciden en el significado de las unidades tonales:

a) La altura tonal de las sílabas prominentes de las elicitaciones de información.

b) La dirección de la voz en las sílabas tónicas de las elicitaciones de información.

c) La altura tonal de las sílabas prominentes de las unidades informativas.

d) La dirección de la voz en las sílabas tónicas de las unidades informativas.

Sobre la base de estas hipótesis, se elaboraron los objetivos siguientes para la realización de este trabajo de tesis.

Objetivo general:

Comprobar si las características entonacionales inciden en los significados de las emisiones.

Objetivos particulares:

Identificar los Tonos que se utilizan en la emisión de los dos tipos de emisiones seleccionadas para su estudio.

- Identificar la variación en alturas tonales en la producción de las elicitaciones y de las emisiones informativas. 
- Comprobar si los cambios detectados en ambas variables producen cambios de significado.

- $\quad$ Describir los cambios observados.

- Llegar a la formulación de un sistema aplicable a la pronunciación del francés en relación con los dos tipos de actos comunicativos en estudio en el tipo de discurso analizado.

Esperamos que este trabajo contribuya al conocimiento de ciertas algunas entonativas en la interacción verbal y que resulte además una herramienta adecuada para su aplicación en la enseñanza del francés como lengua extranjera. 


\section{Capítulo 2}

\section{Estado de la cuestión}

El tratamiento de la entonación del francés ha dado lugar a numerosos estudios centrados en aspectos diversos de los contornos entonacionales. Los mismos se intensificaron especialmente a partir de la segunda mitad del siglo XX. Nos referiremos aquí a autores cuyas descripciones han aportado a la lingüística teórica así como también a su aplicación a la enseñanza del francés como lengua extranjera. Hacemos a continuación la presentación de algunas descripciones que abarcan todas las características que contribuyen a describir la entonación del francés y no nos detenemos en otros trabajos que, si bien son investigaciones rigurosas y muy conocidas, abordan únicamente aspectos determinados del tema. Entre ellos, se pueden mencionar estudios de Iván Fónagy $(1983,2000,2003)$ acerca de los aspectos pulsionales del habla; de Pierre Léon (1971, 1993), quien aborda la entonación desde el punto de vista fonoestilístico; de Anne Lacheret (2003, 2008), quien aborda el estudio de algunos aspectos pragmáticos y su caracterización prosódica, entre muchos otros.

Desde mediados de los años '60, Pierre Delattre propone abordar la entonación desde una perspectiva funcional con fines didácticos. Sus trabajos fueron fundantes en el análisis del valor lingüístico de la entonación del francés. Mediante una metodología inductiva y a partir de la observación de muestras de diferentes tipos de discurso, el autor de "Les dix intonations de base du français" (1966) y "L'intonation par les oppositions" (1969) define un sistema de diez formas entonativas. Las mismas son descritas fonéticamente de acuerdo con el sentido de la pendiente melódica, con los puntos de inicio y de conclusión (a través de un esquema con cuatro niveles de altura) y con la forma (recta, cóncava o convexa) de la curva entonativa. Delattre plantea la posibilidad de determinar un valor lingüístico por oposición de curvas en una forma similar a la oposición de fonemas. El análisis acústico y las pruebas perceptivas de contrastes de pares le permitieron vincular ciertas diferencias de forma con diferencias de significados percibidos. Tanto la descripción formal como las pruebas auditivas se 
realizan a partir de enunciados aislados, sin tener en cuenta su funcionamiento en el discurso interactivo.

Michel Martins-Baltar (1977) analiza la entonación del francés también con fines pedagógicos. Entre las funciones que describe, analiza como central la función enunciativa y menciona dos funciones periféricas (la sintáctica y la segmentadora) ambas relacionadas con la estructura sintáctica. El estudio distingue, a su vez, la participación de la entonación en la estructuración de los enunciados de acuerdo con tres niveles: el gramatical, el lógico y el psicológico. El autor utiliza esta descripción en el análisis de un manual para la enseñanza del francés como lengua extranjera. La descripción realizada por Martins-Baltar puede resumirse de la siguiente forma (ver cuadro $\left.n^{\circ} 1\right)$ :

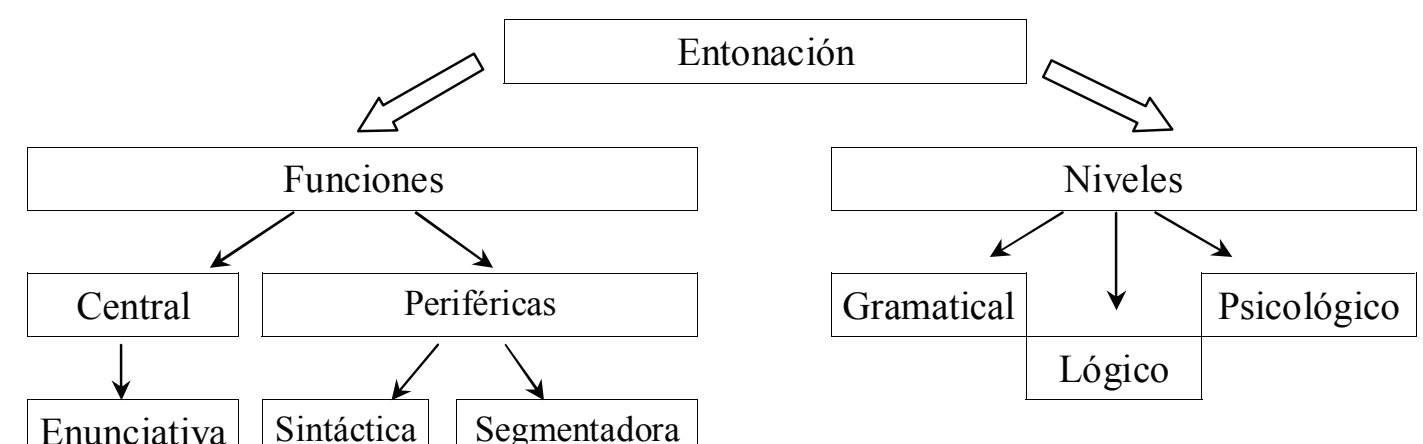

Cuadro $n^{\circ} 1$

El análisis de las funciones se lleva a cabo tomando como unidad el enunciado aislado, por lo cual no puede hablarse de funciones discursivas. Los valores de la función enunciativa son cotejados con la organización sintáctica de las secuencias a partir de la distinción fundamental entre modalidad asertiva e interrogativa.

El estudio propone así una lista de tipos de enunciados descritos fonéticamente de acuerdo con las fluctuaciones de $\mathrm{F}_{0}$ que tienen lugar en toda la emisión y no solamente en la sílaba prominente final. Se presentan, asimismo, precisiones en cuanto a las variaciones de intensidad. Se pone de manifiesto que el descenso de la melodía está asociado con la certeza acerca del contenido enunciado, con la conclusión del turno de habla o con el hecho de que lo dicho no es pasible de ser cuestionado, por ser información que sólo el locutor posee (y no el alocutario). Por el contrario, el ascenso marca cierta distancia con respecto a lo que se dice o una intención de continuar o de 
que el interlocutor continúe con el mismo tema del contenido (de poner el contenido emitido en consideración del alocutario).

Los trabajos de Mario Rossi $(1980,1987,1999)$ se inscriben en una teoría morfológica de la entonación. El autor adopta una perspectiva generativista desde la cual intenta establecer en forma deductiva un modelo para la entonación del francés (Rossi, 1999). El cuadro $n^{\circ} 2$ condensa la descripción de la entonación desarrollada por Rossi.

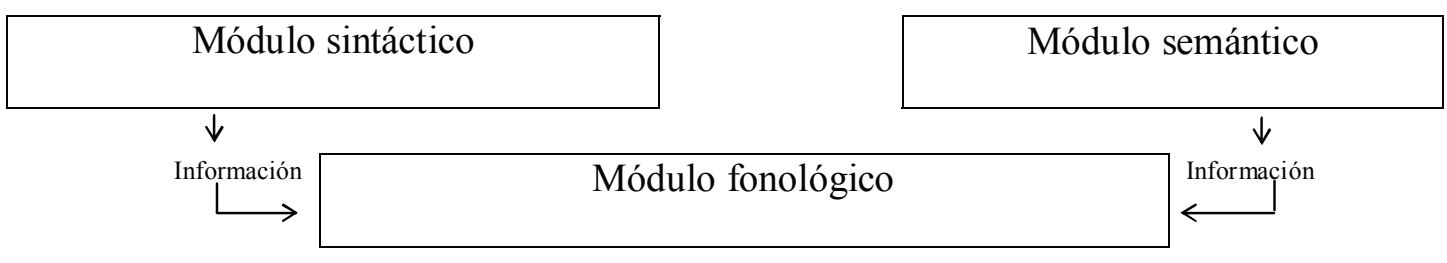

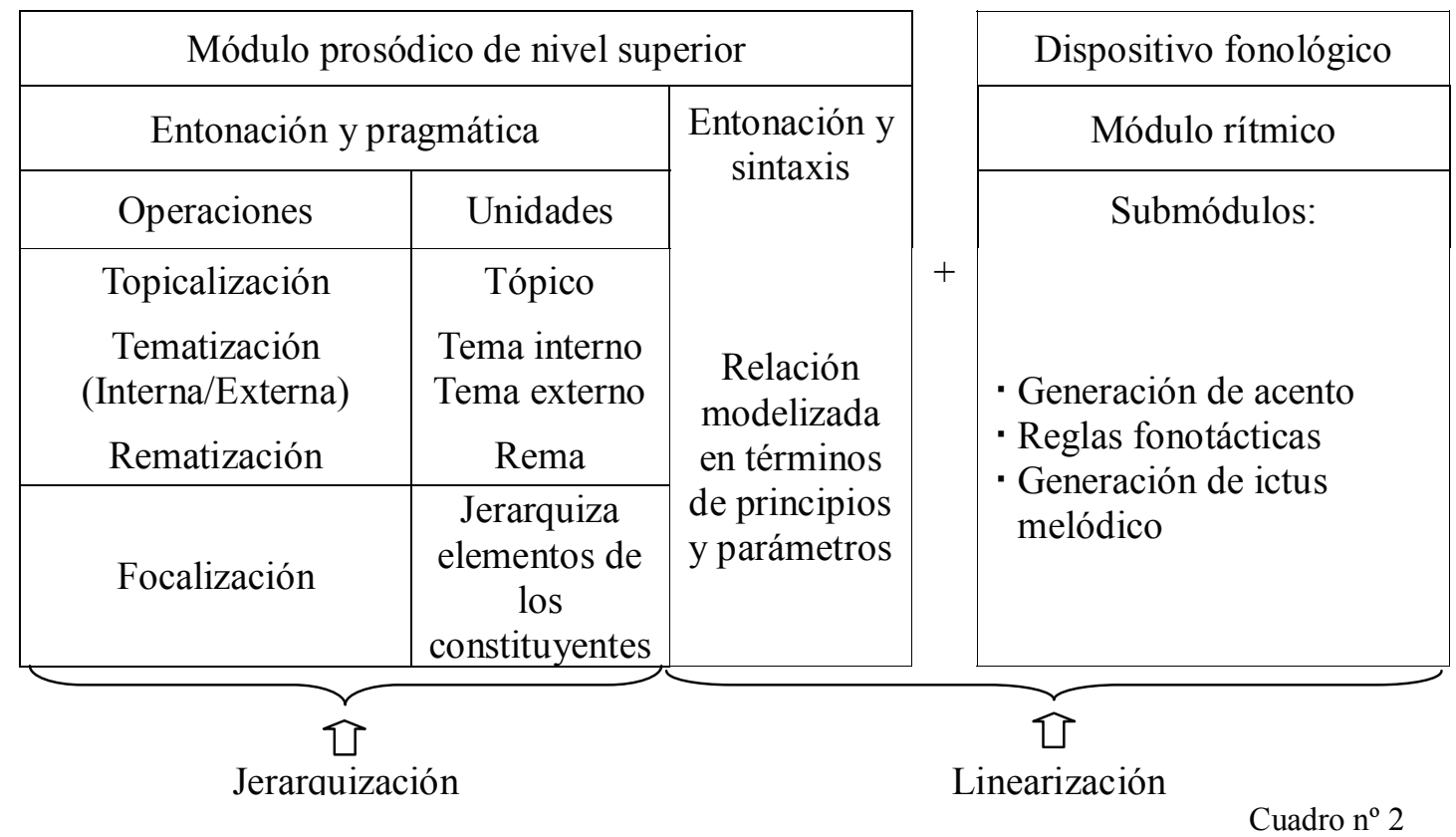

Rossi afirma la existencia de un módulo fonológico (del que forma parte la entonación) que opera en correlación con los módulos sintáctico y semántico "de los cuales recibe la información para constituirse" (Rossi, 1999:197).

El módulo fonológico da cuenta de operaciones que jerarquizan las partes del enunciado: la topicalización, la tematización interna y externa, la rematización y la 
focalización. Los segmentos marcados por estas operaciones son descritos teniendo en cuenta sus funciones y sus marcas prosódicas.

Por otra parte, el módulo incluye la "entonación sintáctica". A partir de la teoría chomskiana de Rección y ligamiento (Chomsky, 1981, 1987), Rossi describe la forma en la que la entonación dispone en el eje sintagmático la estructura jerárquica que constituye la sintaxis.

Finalmente, y sólo en el plano de la expresión, se formalizan las reglas del módulo rítmico, que no reciben información de los módulos sintáctico y semántico.

Esta construcción teórica permite a Rossi determinar un número limitado de morfemas entonativos, entendidos como signos lingüísticos hjemslevianos. Cada morfema se conforma por haces de rasgos distintivos o entonemas y está jerárquicamente determinado. El autor atiende a los parámetros de variación de la frecuencia fundamental $\left(\mathrm{F}_{0}\right)$, intensidad y tiempo (o en términos perceptivos: melodía, sonía y alargamiento). Los morfemas entonativos realizan de este modo funciones pragmáticas (tema, rema, tópico, foco) sintácticas (sujeto, paréntesis,...) o posicionales (continuativo, conclusivo) y operan en el ámbito de constituyentes de enunciados o de enunciados completos, pero su descripción se efectúa sin tener en cuenta el contexto de la emisión. El autor no realiza estudios de tipo discursivo.

Desde el enfoque morfológico de Rossi, se asocia el descenso melódico con la presentación de información nueva o con la idea de finalización del enunciado. Paralelamente, el ascenso marca la falta de conocimiento, de certeza respecto de lo que se dice o la presentación de información como conocida por los participantes.

Dentro del ámbito del generativismo, pero desde un enfoque lineal jerárquico, Albert Di Cristo y Daniel Hirst (Di Cristo y Hirst, 1997, 1998; Di Cristo, 2003) describen la entonación del francés mediante un dispositivo de tres niveles: el físico concreto y el nivel formal de abstracción con un nivel intermedio que los autores denominan fonológico de superficie, donde se opera la ‘señalización' de los objetos empíricos.

Sobre esta base, los autores describen un sistema entonativo del francés a través de diferentes patrones de entonación cuyo ámbito es la unidad entonativa, definida a partir de criterios sintácticos. En ella se distinguen asimismo las unidades tonal y rítmica, 
identificadas a partir de parámetros estrictamente tonales y acentuales. Su modalidad de análisis es global, dado que tienen en cuenta todas las sílabas de la emisión, no sólo las prominentes como lo hacen Rossi y Martin.

La descripción de Di Cristo y Hirst se circunscribe al nivel del enunciado tomado en forma aislada, por lo cual se margina toda consideración del contexto y del cotexto en el que el enunciado ocurre. Las formas así analizadas suelen distinguirse de acuerdo con la presencia, la ausencia o la posición de determinados ítems léxicos en la emisión (i.e. la oposición entre las preguntas parciales con palabra interrogativa al principio y con palabra interrogativa al final, ver cuadro $\mathrm{n}^{\mathrm{o}} 6$ ).

En los patrones detallados, se reiteran los movimientos ascendente, descendente, circunflejo y sostenido. Las diferencias entre los mismos atañen al nivel de arranque, la amplitud del movimiento melódico o las sílabas en las que opera el cambio en la dirección de la pendiente. Los patrones se asocian, a su vez, con diferentes planos de análisis lingüístico: modalidad, sintaxis, actitud/emoción, pragmática.

Desde una perspectiva definida por el autor como "fonosintáctica", Philippe Martin (2004, 2006, 2008, 2009) detalla la vinculación de la estructura entonativa y la estructura macrosintáctica del francés (Blanche-Benveniste, 2005; Blanche-Benveniste y Martin, 2011). El autor define la vinculación entre ambos planos en términos de “soberanía-asociación” y denomina "grupo acentual” a la unidad del plano sintáctico y "palabra prosódica", a la del plano prosódico.

A través de un procedimiento deductivo y tomando como base las modalidades de aserción y pregunta, el autor distingue los contornos melódicos con un principio fonológico. 


\begin{tabular}{|c|c|c|c|c|}
\hline \multirow{2}{*}{ Rasgo } & \multicolumn{4}{|c|}{ Ascendente } \\
\hline & \multicolumn{2}{|c|}{ - } & \multicolumn{2}{|c|}{+} \\
\hline Modalidades & \multicolumn{2}{|c|}{ Aserción } & \multicolumn{2}{|c|}{ Pregunta } \\
\hline \multirow{2}{*}{ Rasgo } & \multicolumn{2}{|c|}{ Amplio } & \multicolumn{2}{|c|}{ Amplio } \\
\hline & + & $+/-$ & + & $+/-$ \\
\hline \multirow[t]{2}{*}{ Rasgo } & \multicolumn{2}{|c|}{$\begin{array}{l}\text { Cloche (Ascendente } \\
\text { descendente) }\end{array}$} & \multicolumn{2}{|c|}{$\begin{array}{l}\text { Cloche (Ascendente } \\
\text { descendente) }\end{array}$} \\
\hline & - & + & - & + \\
\hline Modalidades & Orden & Evidencia & Sorpresa & Duda \\
\hline
\end{tabular}

Cuadro $n^{\circ} 3$

El cuadro $n^{\circ} 3$ resume los rasgos y modalidades presentados por Martin (2009): el rasgo ascendente permite distinguir la aserción de la pregunta $\mathrm{y}$, en cada una de estas variantes, el rasgo amplio distingue la orden de la evidencia y la sorpresa de la duda respectivamente.

En el interior de cada enunciado, se describen realizaciones entonativas que caracterizan los macrosegmentos presentados en el siguiente esquema:

$$
(\text { Prefijo })+\text { Núcleo }+(\text { Postfijo })+(\text { Sufijo })
$$

Los paréntesis encierran los elementos opcionales, por lo que únicamente el Núcleo es obligatorio.

Martin adopta para sus análisis las "transcripciones locales" que atienden únicamente a los movimientos efectuados en sílabas que considera "notables" como las sílabas acentuadas, sílabas iniciales y finales de las unidades sintácticas.

Los movimientos melódicos ascendentes se asocian, en esta teoría, con la continuidad del turno y con la pregunta, mientras que los descendentes se vinculan con la finalización del mismo. Los esquemas melódicos "planos" pueden vincularse tanto con la continuidad como con la finalización, dependiendo de la presencia o no de elementos de orden macrosintáctico (como el Postfijo). 
Las investigaciones realizadas por Piet Mertens (1997, 2004, 2006, 2009) tienen por objetivo la modelización de la entonación del discurso mediante un procedimiento deductivo a fin de aplicarla a la síntesis informática de la palabra. Para el autor, es la estructura acentual abstracta, definida con un criterio morfosintáctico, la que determina la estructura entonacional.

En sus estudios de fines de los años '90 y hasta 2004, el autor adopta como unidad de descripción el "morfema entonativos" pero, a diferencia de Rossi, lo define como "la secuencia de niveles tonales en una ubicación silábica determinada, en un contexto en el cual las ubicaciones se definen de acuerdo con la posición del acento" (Mertens 2002:1). Esta unidad es "una sucesión de sílabas en donde la última sílaba plena lleva un acento final' (Mertens, 2006:6). El autor reemplaza posteriormente este término por el de "grupo entonativo", que se distingue por contemplar la realización potencial de un acento inicial (Mertens, 2009:3).

El término "contorno" remite al movimiento melódico que tiene lugar en la unidad y que toma en cuenta algunos puntos relevantes: las sílabas inicial, penúltima y final, los acentos inicial y final. Por otra parte, se especifica que sólo la sílaba afectada por el acento final puede tener un tono dinámico. Las otras sílabas del grupo comportarán tonos estáticos.

El autor distingue cuatro niveles entonativos desde el extra $L$ hasta el extra $\mathrm{H}^{1}$ dentro del rango relativo de cada hablante. El análisis propuesto es local y progresivo de izquierda a derecha en el cual los elementos de la derecha ejercen dominio sobre los precedentes.

Los trabajos de Marandin $(2004,2006)$ dan cuenta de una interpretación de la entonación orientada interaccionalmente. El enfoque se ubica en los estudios de la gramática sintagmática nuclear (HPSG grammar). Se trata de una gramática de las construcciones, entendidas como constructos multidimensionales que combinan "principios generales del lenguaje con aspectos idiosincrásicos de cada lengua" (Marandin, 2006:1).

\footnotetext{
1

'L' representa Low (Bajo) y 'H' representa High (Alto).
} 
De acuerdo con las consideraciones de la teoría métrica autosegmental, se definen en primer lugar dos tonos (tones o pitch tones): L y H (Low y High). Cuando estos tonos están anclados en los límites de las frases prosódicas, el autor los denomina "tonos de frontera" (phrasal tones, boundary tones). Los "acentos melódicos" (pitch accents) se anclan en sílabas designadas según criterios métricos.

El "contorno" (contour) es descrito como la sucesión de al menos dos tonos. Se trata de una construcción que vincula un valor semántico pragmático con un reagrupamiento local de características entonativas. Siguiendo a Delattre y a Ladd, Marandin intenta dar cuenta de los significados de los contornos finales de las emisiones, a los cuales les atribuye el carácter de dialógico epistémicos.

Las emisiones se dividen en "all-focus utterances" (emisiones con foco amplio) y "utterances with narrow focus" (emisiones con foco reducido) de acuerdo con la coincidencia o no del ámbito de focalización y el límite derecho de la frase.

La primera jerarquía de contornos opone los contornos descendentes a los no descendentes de acuerdo con su carácter no polémico o polémico (noncontentious vs. contentious). Los primeros no anticipan ningún desacuerdo por parte del destinatario de la emisión. En afirmaciones, prevén un consentimiento mientras que, en preguntas, suponen un acuerdo sobre la pertinencia de la misma. Inversamente, los tonos no descendentes anticipan una posible resistencia del destinatario a acordar con el contenido de lo emitido. El hablante "asume que [su emisión] puede no ser compatible con lo que él asume como las creencias del destinatario" (Marandin, 2006:18).

A partir de estas distinciones iniciales, se identifican cuatro contornos finales: descendente, ascendente, ascendente descendente y descendente desde el pico de la penúltima sílaba plena (cuyo elemento vocálico no sea una e muda). Este modelo tiene la particularidad de no hacer referencia a la forma gramatical de las unidades analizadas. Tampoco se establecen distinciones funcionales que pudieran dar pistas de diferentes roles de las emisiones en el discurso.

Los estudios llevados a cabo por Morel y Danon-Boileau (Morel y Danon-Boileau, 1992, 1998; Morel, 2004, 2006) en el marco de la lingüística enunciativa realizan una interpretación de los niveles entonativos y sus variaciones. La atención de los autores se centra en la instancia de coenunciación descrita como un proceso de coconstrucción de 
sentido que realiza el enunciador a partir de la representación que él mismo posee de su coenunciador y del conocimiento que tienen en común.

La unidad de análisis adoptada es el párrafo entonativo, definido a través "de indicios de demarcación final: la caída conjunta de la melodía y la intensidad" (Morel, 2004:16). El mismo se compone de un elemento necesario -el rema - y dos elementos opcionales: el preámbulo temático (o preámbulo) y el postrema. La representación prosódica tiene en cuenta, asimismo, el nivel morfosintáctico.

De acuerdo con los autores, la altura del arranque (attaque) tiene un valor significativo en la interacción. De esta manera, se encuentran cuatro puntos de referencia en el análisis entonativo: la altura inicial y final, la altura final del preámbulo, la altura máxima del rema y la altura final del rema.

A partir de la identificación de la tesitura de cada hablante, se establecen dos rangos a los cuales se asigna un valor coenunciativo (ver cuadro $n^{0} 4$ ).

\begin{tabular}{|c|c|}
\hline Rango alto & $\begin{array}{r}\text { "Movimiento icónico de llamado al otro" } \\
\text { Consideración de la coenunciación. Actitud dialógica } \\
\text { (de convergencia o discordancia). }\end{array}$ \\
\hline Rango bajo & Repliegue sobre sí. Actitud monológica. \\
\hline
\end{tabular}

Cuadro $n^{\circ} 4$

Para estas distinciones de rango, se tiene en cuenta la totalidad del enunciado o párrafo entonativo. Asimismo, se toman en consideración los movimientos melódicos realizados en "las sílabas finales de los constituyentes discursivos" (Morel, 2006:136).

El cuadro $\mathrm{n}^{\circ} 5$ presenta en forma esquemática las conceptualizaciones de los diferentes autores. En primer lugar, se muestra el posicionamiento que se adopta para el examen de la entonación con respecto al nivel sintáctico. Como puede apreciarse, una amplia proporción de los modelos teóricos citados describe las formas que adquiere la entonación de acuerdo con las características sintácticas de las unidades analizadas.

La articulación entre sintaxis y entonación presenta, sin embargo, numerosas dificultades, fundamentalmente en el abordaje del discurso, lo cual ha llevado a algunos autores a realizar salvedades, como las que explicita Martin (2009). Inversamente, 
resulta marginal la elección metodológica de descartar toda relación con otros planos de análisis lingüístico, como es el caso de las teorías métricas y autosegmentales. Por otra parte, en necesario tener en cuenta que aun cuando se afirma una independencia absoluta respecto de otros niveles de análisis lingüístico, algunos estudios efectuados en este marco atienden al plano morfosintáctico para la delimitación de unidades (ver por ejemplo la determinación morfosintáctica de la unidad entonativa en Hirst y di Cristo).

\begin{tabular}{|c|c|c|c|c|c|}
\hline \multirow{2}{*}{ Autor } & \multicolumn{2}{|c|}{$\begin{array}{c}\text { Relación } \\
\text { entonación / } \\
\text { sintaxis } \\
\end{array}$} & \multirow{2}{*}{$\begin{array}{l}\text { Unidad de análisis y } \\
\text { Ámbito de realización }\end{array}$} & \multicolumn{2}{|c|}{$\begin{array}{l}\text { Descripción del } \\
\text { movimiento } \\
\text { melódico }\end{array}$} \\
\hline & $\begin{array}{l}\text { Vincula } \\
\text {-ción }\end{array}$ & $\begin{array}{l}\text { Indepen- } \\
\text { dencia }\end{array}$ & & $\begin{array}{l}\text { Todas } \\
\text { las } \\
\text { silabas }\end{array}$ & $\begin{array}{l}\text { Silabas } \\
\text { prominen- } \\
\text { tes }\end{array}$ \\
\hline Delattre & $\mathrm{X}$ & & Enunciado & $X$ & \\
\hline $\begin{array}{c}\text { Martins- } \\
\text { Baltar }\end{array}$ & $\mathrm{X}$ & & Enunciado & $\mathrm{X}$ & \\
\hline Rossi & $\mathrm{X}$ & & $\begin{array}{c}\text { "morfema entonativo" / } \\
\text { Enunciado o } \\
\text { constituyentes de } \\
\text { enunciados }\end{array}$ & & $\mathrm{X}$ \\
\hline $\begin{array}{l}\text { Hirst y Di } \\
\text { Cristo }\end{array}$ & & $\mathrm{X}$ & $\begin{array}{c}\text { "unidad entonativa" / } \\
\text { Enunciado o } \\
\text { constituyentes de } \\
\text { enunciados }\end{array}$ & $\mathrm{X}$ & \\
\hline Martin & $\mathrm{X}$ & & $\begin{array}{l}\text { "palabra prosódica"/ } \\
\text { Enunciado o grupo } \\
\text { acentual. }\end{array}$ & & $\mathrm{X}$ \\
\hline Mertens & $\mathrm{X}$ & & "grupo entonativo" & & $\mathrm{X}$ \\
\hline Marandin & & $X$ & "contorno" / Emisión & & $X$ \\
\hline $\begin{array}{l}\text { Morel y } \\
\text { Danon- } \\
\text { Boileau }\end{array}$ & $\mathrm{X}$ & & $\begin{array}{l}\text { "párrafo entonativo"/ } \\
\text { enunciado o secuencias } \\
\text { de enunciados }\end{array}$ & $\mathrm{X}$ & \\
\hline
\end{tabular}

Cuadro $n^{\circ} 5$

La segunda de las columnas principales resume las unidades de análisis adoptadas en cada perspectiva como así también el segmento de habla en el que las mismas operan. Se constata que, en la mayor parte de los estudios, el ámbito de realización de las diferentes unidades de análisis, se circunscribe al enunciado o a partes de enunciados. Entre las descripciones estudiadas, sólo la de Morel y Danon-Boileau (1998) toma en consideración una unidad más amplia: el "párrafo entonativo". 
Finalmente, la tercera columna da cuenta del tipo de descripción del movimiento melódico, el cual presenta también divergencias en lo referido a las secuencias silábicas que son tenidas en cuenta como significativas. Esta variable opone perspectivas que atienden al movimiento realizado a lo largo de todas las sílabas de una secuencia y estudios que únicamente consideran significativo el movimiento operado en sílabas salientes. En este último caso, se atiende específicamente a las sílabas prominentes finales de grupos y, en algunas perspectivas, como la de Morel y Danon-Boileau, se examinan asimismo los rangos tonales utilizados. Este análisis coincide así en algunos casos con las variables de los subsistemas de Arranque y Terminación descritas por Brazil y Granato.

La síntesis que proponemos en el cuadro $n^{\circ} 6$ ilustra, para todas las perspectivas, el movimiento que se describe en la sílaba tónica. Allí, puede visualizarse el tipo de significados mencionados en cada descripción así como los valores asociados con las distintas curvas.

Las formas melódicas corresponden, como precisáramos más arriba, al movimiento de $\mathrm{F}_{0}$ que tiene lugar sólo en la sílaba prominente final de grupo. A modo de ilustración, mencionamos el caso de la "declarativa básica no enfática" en los estudios de Hirst y Di Cristo. La misma refiere al movimiento melódico de ascenso y posterior descenso que ocurre a lo largo de un enunciado. En la elaboración de esta síntesis consideramos solamente el descenso final que corresponde a la sílaba tónica.

Es necesario también precisar que no en todos los trabajos citados se han mencionado distinciones funcionales entre emisiones que solicitan información y emisiones que proveen información. Más precisamente, son sólo los estudios de Martins-Baltar los que distinguen sistemáticamente entre estas dos funciones. En otros estudios, se constatan algunas menciones funcionales referidas al carácter interactivo o no interactivo del discurso, aunque las mismas no son sistemáticas. Por consiguiente, los significados presentados pueden referirse a emisiones de elicitación o bien a emisiones informativas.

La vinculación que se establece entre la configuración entonacional y la sintáctica implica que, en muchas ocasiones, el significado es descrito haciendo referencia a las funciones que determinadas unidades sintácticas cumplen en el discurso. Tal es el caso de las menciones al significado de 'pregunta', 'interrogación o 'aserción', entre otros. 


\begin{tabular}{|c|c|c|c|c|c|}
\hline \multirow{2}{*}{ Autor } & \multicolumn{5}{|c|}{ Significado } \\
\hline & Tipo & $\nabla$ & $\searrow$ & $\widehat{\Delta}$ & $\longrightarrow$ \\
\hline Delattre & $\begin{array}{l}\text { ENUNCIATIVO } \\
\text { SINTÁCTICO } \\
\end{array}$ & Pregunta & $\begin{array}{c}\text { Finalidad / pregunta } \\
\text { parcial }\end{array}$ & Implicación & Paréntesis / eco \\
\hline Martin-Baltar & $\begin{array}{l}\text { FUNCIÓN DE } \\
\text { UNIDADES } \\
\text { SINTÁCTICAS } \\
\end{array}$ & $\begin{array}{c}\text { Ignorancia / imposibilidad } \\
\text { de juzgar }\end{array}$ & Adición de información & $\begin{array}{l}\text { Consideración / } \\
\text { evidencia }\end{array}$ & - \\
\hline Rossi & $\begin{array}{c}\text { SINTÁCTICO } \\
\text { PRAGMÁtICO }\end{array}$ & Interrogación & Final de aserción & - & Paréntesis \\
\hline $\begin{array}{l}\text { Hirst y Di } \\
\text { Cristo }\end{array}$ & $\begin{array}{l}\text { ENUNCIATIVO } \\
\text { SINTÁCTICO } \\
\text { ACTITUDINAL } \\
\text { PRAGMÁTICO }\end{array}$ & $\begin{array}{c}\text { Pregunta / pregunta parcial } \\
\text { con palabra interrogativa al } \\
\text { final }\end{array}$ & $\begin{array}{l}\text { Declarativa básica } \\
\text { / tema pospuesto / } \\
\text { pregunta parcial con } \\
\text { palabra interrogativa al } \\
\text { principio }\end{array}$ & - & - \\
\hline Martin & $\begin{array}{l}\text { ENUNCIATIVO } \\
\text { SINTÁCTICO } \\
\text { ACTITUDINAL } \\
\end{array}$ & Pregunta & Aserción & Evidencia & Postfijo \\
\hline Mertens & PRAGMÁTICO & $\begin{array}{c}\text { Presentación de } \\
\text { información conocida }\end{array}$ & Pedido de confirmación & Focalización & - \\
\hline Marandin & $\begin{array}{l}\text { ACTITUDINAL } \\
\text { PRAGMÁTICO }\end{array}$ & $\begin{array}{l}\text { Negativa a ceder en la } \\
\text { propia posición }\end{array}$ & $\begin{array}{c}\text { Información planteada } \\
\text { como no sujeta a } \\
\text { discusión }\end{array}$ & $\begin{array}{l}\text { Anticipación de } \\
\text { disenso sin } \\
\text { voluntad de ceder }\end{array}$ & - \\
\hline $\begin{array}{l}\text { Morel y } \\
\text { Danon- } \\
\text { Boileau }\end{array}$ & $\begin{array}{l}\text { ACTITUDINAL } \\
\text { ENUNCIATIVO }\end{array}$ & $\begin{array}{l}\text { Búsqueda de consenso a } \\
\text { partir de una discrepancia } \\
\text { reconocida }\end{array}$ & $\begin{array}{l}\text { Finalidad / repliegue } \\
\text { monológico / búsqueda } \\
\text { de confirmación }\end{array}$ & $\begin{array}{l}\text { Presunción de } \\
\text { acuerdo / planteo } \\
\text { no sujeto a } \\
\text { discusión }\end{array}$ & $\begin{array}{c}\text { Ausencia de } \\
\text { consideración del } \\
\text { interlocutor. Ruptura en } \\
\text { el desarrollo discursivo } \\
\text { del enunciado. }\end{array}$ \\
\hline
\end{tabular}


Asimismo, son numerosas las referencias a significados locales de tipo actitudinal con los que se relacionan diferentes curvas entonativas. Las actitudes y emociones tienen un tratamiento dispar y se pone de manifiesto la complejidad de intentar proveer descripciones exhaustivas de las mismas.

Se puntualiza, por otra parte, que no todas las perspectivas consideran la curva correspondiente al ascenso-descenso. Las que sí lo hacen, asocian este movimiento melódico con significados de tipo local: evidencia, implicación, negativa a ceder en una posición, presentación de una información como no sujeta a discusión, focalización. Sin hacer referencia a significados generalizables.

Ninguno de los modelos a los cuales nos hemos referido estudia los aportes de la entonación de las emisiones en discurso con excepción de las consideraciones ya mencionadas realizadas por Martins-Baltar y Morel y Danon-Boileau. 


\section{Capítulo 3}

\section{Marco teórico}

Los estudios de la entonación efectuados por Brazil (1992, 1995, 1997) para la lengua inglesa y por Granato $(1999,2005)$ para el español, plantean la posibilidad de describir sistemas entonativos con un enfoque funcional y pragmático discursivo. Esta perspectiva se propone dar cuenta de los significados que la entonación aporta al discurso en forma independiente de otros niveles de análisis lingüístico. Se trata entonces de la definición de significados generales y constantes que se desprenden de las elecciones que realiza el hablante en un número relativamente reducido de aspectos que conciernen a la prominencia, la altura tonal y el sentido de la pendiente melódica. Por consiguiente, este enfoque no contempla los significados locales que pueden asociarse con las características entonativas, así como las expresiones de actitudes y emociones sino que se ciñe a lo que hay en común a todos ellos.

Se trata de una teoría que busca despojar el estudio de matices de significado, en pos de una descripción global y general de un sistema. Como señala Mario Rossi (1999) quien, desde otra perspectiva teórica se plantea la definición de un sistema para la entonación del francés, la formalización implica una mirada sobre el objeto que trasciende lo particular. Esta mirada se basará en las realizaciones particulares, pero está necesariamente llamada a trascenderlas.

El planteo de un sistema fonológico de entonación del discurso supone la determinación de un conjunto cerrado de variables o elementos organizados en subsistemas, que se definen negativamente respecto de los demás elementos que los componen. Es a través del examen de la oposición de significados que los interactuantes realizan que Brazil propone determinar el valor de cada uno de los elementos en cada subsistema, realizando así una descripción lingüística de los fenómenos entonativos.

Brazil y Granato definen, de este modo, un modelo que se revela especialmente apto para dar cuenta del aporte de la entonación al discurso interactivo. Brazil (1992) da cuenta de la diferencia de la organización entonativa de la lectura y del discurso interactivo. En la lectura, el locutor está implicado con la oralización de un discurso preconcebido cuya evolución no dependerá de elementos contextuales. En la interacción 
verbal, en cambio, tanto el hablante al producir su discurso, como el oyente al descodificarlo, lo hacen agrupando la información en unidades interpretadas como un todo. En este caso, el autor realiza una distinción funcional entre emisiones de “elicitación” y emisiones informativas (Brazil, 1997). Se trata de una distinción que no se basa en la estructuración sintáctica de las emisiones sino en su valor dentro del discurso. En efecto, una distinción funcional permite agrupar unidades con diversas características léxicas y sintácticas que comparten una misma función en el lenguaje interactivo.

Los interactuantes tienen en cuenta el carácter de "progresión paso a paso" que produce cada emisión. Por consiguiente, cada unidad será al mismo tiempo condicionada y condicionante del avance del discurso. Las unidades de análisis adoptadas por este modelo, que se definen como bloques de información, se denominan "unidades tonales", denominación que equivale a expresiones usadas en otras descripciones como "unidades entonativas" o "grupos fónicos". La unidad tonal es el ámbito en el que se realizan los subsistemas de Prominencia, Arranque, Terminación y Tono. Se trata de un segmento de habla que puede incluir una o más sílabas prominentes de las cuales sólo la última presenta un movimiento melódico o pendiente, denominado Tono.

El subsistema de Prominencia distingue sílabas que presentan nociones nuevas de otras que presentan nociones dadas, distinción que se concreta mediante el uso de sílabas prominentes y sílabas no prominentes respectivamente. Dado que la perspectiva de la entonación del discurso se ocupa de las opciones significativas realizadas por el hablante, no se tienen en cuenta las prominencias potenciales que se han señalado en aproximaciones no discursivas y que, en términos de Garde (1962) pertenecen a unidades "accentogènes" (o pasibles de recibir un acento). Una sílaba prominente tiene entonces un valor significativo de contraste respecto de las sílabas adyacentes producto de la intención comunicativa del hablante en el momento de la emisión. Dentro de una unidad tonal, la cantidad de sílabas prominentes permite distinguir entre unidades simples (en las cuales hay una sola sílaba prominente) y unidades extendidas (en las cuales hay más de una sílaba prominente).

Los significados propios de los subsistemas de Arranque y Terminación vinculan las unidades con secuencias anteriores y posteriores respectivamente. En el caso de los grupos fónicos simples, el Arranque, la Terminación y el Tono se realizan sobre la misma sílaba, la sílaba tónica. Cuando se trata de grupos extendidos, el Arranque se 
realiza sobre la primera sílaba prominente de la secuencia, que recibe el nombre de sílaba de Arranque. Las elecciones en estos subsistemas conciernen a la altura tonal de sílabas prominentes. Un Arranque realizado en nivel alto transmite significados de contraste respecto de la unidad anterior. Si el mismo se realiza en nivel medio, expresa la adición de información, mientras que, realizado en nivel bajo, el Arranque presenta una relación de equivalencia entre la unidad proferida y la anterior.

Por su parte, el subsistema de Terminación, que se realiza siempre sobre la última sílaba prominente, puede transmitir tres situaciones diferentes en cuanto a las expectativas respecto de las intervenciones siguientes. El hablante expresa la ausencia de expectativas mediante la elección del nivel tonal bajo. Por el contrario, cuando se selecciona una Terminación en nivel medio o alto, se manifiestan determinadas expectativas respecto de la continuidad de la interacción verbal: mediante la elección de nivel medio, el hablante espera concordancia con lo que se ha expresado y la elección de un nivel alto proyecta expectativas de un posicionamiento diferente del planteado.

Por último, el subsistema de Tono define significados diferentes mediante elecciones de movimientos melódicos que tienen lugar en la última sílaba prominente de la unidad tonal, la sílaba tónica. Las descripciones realizadas para el inglés y para el español dan cuenta de cinco movimientos posibles:

Ascendente; descendente; ascendente-descendente; descendente-ascendente; sostenido.

Los mismos se resumen en tres Tonos:

\begin{tabular}{|c|c|}
\hline Tonos & Movimientos melódicos \\
\hline \multirow{2}{*}{ Proclamatorio } & descendente \\
\cline { 2 - 2 } & ascendente-descendente \\
\hline \multirow{2}{*}{ Referido } & ascendente \\
\cline { 2 - 2 } & descendente-ascendente \\
\hline Neutral & sostenido \\
\hline
\end{tabular}

Cuadro $n^{\circ} 7$

Cabe destacar que, como puede observarse en el cuadro $n^{0} 7, \operatorname{los}$ Tonos Proclamatorio y Referido cuentan con dos realizaciones posibles que comparten el mismo movimiento melódico final. 
El Tono Neutral se utiliza únicamente en emisiones no interactivas. Brazil (1997) distingue así entre lo que denomina "orientación oblicua" y "orientación directa". La orientación oblicua del discurso no interactivo se utiliza cuando el hablante no está comprometido con otro participante sino con un texto y su contenido. Esta postura se señala mediante el uso de los Tonos Neutral y Proclamatorio: el Tono Neutral señala que el texto no concluye aún, mientras que el Tono Proclamatorio indica un final potencial en el texto. De modo que si el Tono Neutral aparece dentro de una conversación, implica que momentáneamente el hablante ha dejado de lado la actitud interactiva.

En el discurso de orientación directa, se plantean dos instancias: la solicitud de información y la provisión de información.

Los significados producidos por las elecciones en este subsistema se refieren a lo que el autor denomina significados generales y sociales. En su análisis de las emisiones que transmiten información en el discurso en inglés y en relación con el significado general, Brazil sostiene que la transmisión de un contenido no compartido con el interlocutor se señala con el uso de un Tono Proclamatorio y el contenido presentado como compartido se marca con un Tono Referido.

También es posible, desde el punto de vista social, indica posicionamientos entre el emisor y el receptor, de modo que cuando el hablante desea proyectar que habla sólo por sí mismo, utiliza un Tono Proclamatorio y cuando incluye al receptor, utiliza el Tono Referido. Brazil denomina separateness (separación) y togetherness (inclusión) a la proyección de estos significados.

En relación con las emisiones que requieren información (elicitaciones), Brazil distingue dos significados básicos: señala que cuando la elicitación se produce con desconocimiento de la respuesta se acompaña con el Tono Proclamatorio; cuando se tiene una respuesta posible en mente y sólo se busca confirmación, el hablante selecciona el Tono Referido.

Asimismo, el autor se refiere a la proyección del dominio discursivo por parte de los hablantes en los dos tipos de emisiones y sostiene que tal dominio puede manifestarse a partir del uso de las variantes ascendente y ascendente-descendente de los Tonos Referido y Proclamatorio respectivamente. Por su parte, cuando no se intenta ejercer este dominio discursivo, las variantes seleccionadas son la descendente-ascendente y la descendente. 
En su estudio sobre el español, Granato (2005) sintetiza los resultados de su investigación como puede verse en el cuadro $n^{\circ}$ 8. Se observa en la última columna de la derecha la forma fonológica asociada con cada Tono representada por flechas. Las mismas se refieren al movimiento de la pendiente melódica sobre la sílaba tónica.

En dicho cuadro, puede apreciarse que se distingue, ante todo, la orientación del significado del discurso. En el discurso interactivo, o de orientación directa, se plantean dos instancias: la solicitud de información y la provisión de información. Dentro de las emisiones que solicitan información, o elicitaciones, Granato detecta que, en español, el Tono Referido señala la ignorancia de la información que se solicita mientras que, con el Tono Proclamatorio, el hablante manifiesta tener un cierto conocimiento de la respuesta que espera de su interlocutor. Por consiguiente, ambos Tonos se agregan significados opuestos a los que agregan en inglés.

En las emisiones en que el hablante provee información, se distinguen asimismo los significados generales y sociales. En un primer nivel de aproximación, los significados generales de la unidad informativa oponen el conocimiento que se presenta como no compartido por los interlocutores, acompañado por un Tono Proclamatorio al conocimiento presentado como compartido a través de un Tono Referido. Puede apreciarse entonces que esta variable proyecta significados comunes tanto en inglés como en español. Paralelamente, en cuanto a los significados sociales, el Tono Proclamatorio manifiesta que el hablante toma distancia respecto de los interlocutores, mientras que el Tono Referido plantea un acercamiento a los demás interactuantes.

En una segunda instancia de aproximación, las dos realizaciones del Tono Proclamatorio permiten distinguir entre el conocimiento que el locutor plantea como no compartido con sus oyentes, a través del uso de la variante descendente, y el conocimiento que es doblemente nuevo: tanto para sí mismo, como para los demás participantes del intercambio. Este último está acompañado por la variante ascendentedescendente. 
Subsistema de Tono (Granato 1999, 2005)

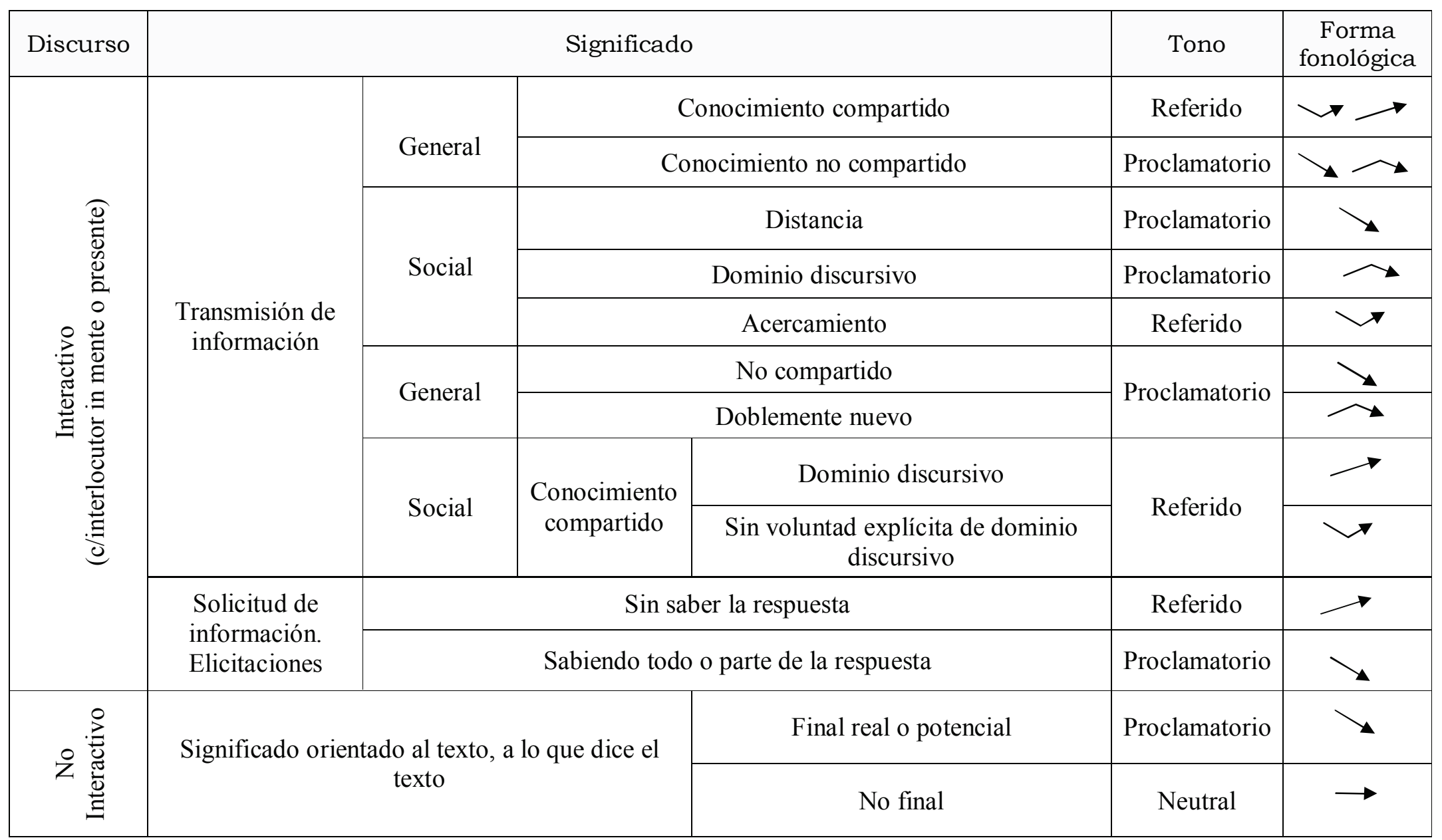


Paralelamente, las dos variantes de los Tonos Referido y Proclamatorio establecen diferencias entre un posicionamiento de dominio del discurso, que expresa el deseo de continuar hablando, y un posicionamiento no dominante que no expresa la voluntad de hacerlo. Estos significados se proyectan mediante las variantes ascendente y ascendente-descendente.

Vemos entonces que esta perspectiva teórica permite dar cuenta de la forma en que el hablante transmite significados generales y sociales a través de elecciones realizadas en cada subsistema. Es importante resaltar que es posible explotar el sistema, es decir que dichas elecciones tienen vinculación con la intencionalidad del locutor y no con un estado efectivo de cosas. La mirada está puesta en la forma en que se saca provecho del sistema para lograr un propósito comunicativo determinado. Del mismo modo, los demás participantes pueden, en todo momento, manifestar por medio del mismo sistema y de las elecciones en las mismas variables su grado de acuerdo o desacuerdo con lo planteado. De esta forma, se logra el avance de la interacción.

Es desde esta perspectiva teórica que nos proponemos realizar nuestra investigación para determinar de qué modo utilizan los interactuantes francófonos las distintas formas fonológicas de la entonación del francés. Nuestro planteo propone examinar la entonación en relación con su función en la interacción. Una descripción lingüística como la que nos proponemos implica ir más allá de los significados locales para estudiar las características generalizables del significado que la entonación aporta al discurso. El enfoque que adoptamos es pragmático discursivo y sistemático; implica elaborar un sistema que, como tal, contiene subsistemas con elementos que se describen negativamente respecto de los otros elementos dentro de dicho sistema. 


\section{Capítulo 4}

\section{Metodología}

\subsection{Etapas de realización}

En la elaboración de esta tesis se siguieron los siguientes pasos.

1. Escucha, selección y recolección del corpus.

2. Catalogación y regularización del corpus. Numeración de textos y líneas.

3. Selección bibliográfica y lectura de bibliografía pertinente.

4. Preparación y realización de pruebas perceptivas.

5. Análisis de los resultados de dichas pruebas.

6. Interpretación de los resultados de las pruebas perceptivas.

7. Medición acústica de fragmentos a analizar.

8. Interpretación de resultados de pruebas acústicas.

9. Cotejo de resultados de pruebas de percepción y mediciones acústicas.

10. Análisis de los resultados obtenidos.

11. Redacción del trabajo final.

\subsection{Corpus}

El estudio se llevó a cabo sobre la base de una selección de fragmentos pertenecientes al CFPP2000 (Corpus de français parlé parisien des années 2000). Dicho corpus fue recolectado por S. Branca-Rosoff et al. de la universidad de París 3, Sorbonne Nouvelle, en diferentes distritos de París y su área metropolitana durante la primera década del signo XXI. Se trata de entrevistas semidirigidas realizadas a parisinos de diferente edad, sexo, categoría sociocultural, nivel educativo, lugar de origen y lugar de residencia. Los intercambios tienen una duración promedio de 1 hora 18 minutos, lo cual totaliza 38 horas 54 minutos, y fueron grabados en audio en los sitios donde alguno de los participantes reside.

Los temas abordados en estas entrevistas giran en torno a las particularidades de la vida en cada distrito: servicios, características edilicias, aspectos idiosincrásicos de los habitantes, comparación con otras épocas y con otros distritos, autopercepción, etc. Las 
conversaciones se desarrollan en un clima general ameno y distendido y, aunque el entrevistador tiene una lista de posibles preguntas a realizar, las mismas no condicionan el desarrollo del intercambio en forma estricta, ya que existe un margen importante para la incorporación de preguntas que deriven del desarrollo mismo de la interacción.

Se seleccionaron para el análisis 8 fragmentos de una duración promedio de 4'11" en los que participan un total de 3 entrevistadores y 19 entrevistados, de entre 15 y 88 años, residentes en 5 distritos de París y su aglomeración. El Anexo n ${ }^{0} 1$ incluye, en primer lugar, información detallada acerca de las edades de los participantes, sus lugares de residencia y sus profesiones $\mathrm{u}$ ocupaciones. En segundo lugar, se presenta la transcripción de cada una de las secuencias seleccionadas para el análisis ${ }^{2}$. Esta elección atendió a nuestro interés por incluir hablantes pertenecientes a diferentes grupos etarios y categorías socioculturales que residían en diferentes distritos de París.

Tuvimos en cuenta asimismo el grado de participación e implicación de los hablantes en la entrevista. En los fragmentos seleccionados, el intercambio es fluido entre todos los interactuantes y las emisiones de solicitud de información e información seleccionadas para su estudio no siempre son producidas por el entrevistador y el entrevistado respectivamente sino que, a veces, son los entrevistados quienes producen elicitaciones y los entrevistadores quienes brindan la información.

El examen minucioso de los fragmentos dio lugar a la selección de 124 emisiones que fueron posteriormente divididas en dos grandes grupos. El criterio central para su selección es pragmático discursivo, dado que a menudo la forma sintáctica de las emisiones no da cuenta fehaciente de su función en la interacción, como puede apreciarse en el siguiente ejemplo:

B.D. : [...] et l'adresse de l'appartement était dix place du Trocadéro + y la dirección del departamento era plaza del Trocadéro número diez.

S.B.-R.C. : (rire bref) - voilà (risa breve) - y sí.

$\rightarrow \quad$ R.C.: comme quartier chic + t'es sûre que c'était chic ? (rire) como barrio elegante $+¿$ Seguro que era elegante? (risa)

B.D. : quand on m'a dit l'adresse j'étais là 'non mais tu t' trompes on a rendez-vous place du Troca- non non c'est dix place du Trocadéro c'est

\footnotetext{
${ }^{2}$ Las mismas cuentan con números de línea que son posteriormente mencionados en los análisis de cada caso y permiten remitir fácilmente a la transcripción.
} 
l'adresse où" voilà +

cuando me dijeron la dirección me quedé "no pero estás equivocado nos

encontramos en plaza del Trocadéro número di-“" "no no es plaza del

Trocadéro número diez es la dirección donde" y sí +

CFPP2000 [11-03] Blanche_Duchemin_F_25_Reine_Ceret_F_60_11 ${ }^{\mathrm{e}}$

(Líneas 270-275)

La emisión de R.C.: "t'es sûre que c'était chic?" tiene una forma interrogativa. Sin embargo, ni la persona a quien se dirige la intervención ni el resto de los participantes consideran que la hablante solicita una información y que es necesario proveerla.

A la inversa de lo que ocurre en el fragmento anterior, observamos una secuencia con forma declarativa en el inicio del siguiente intercambio. En momentos en que describen las guerras entre colegios de Mardi Gras, la entrevistadora pronuncia:

\footnotetext{
$\rightarrow \quad$ S.B. : farine et oufs harina y huevos

O.K. : ouais

se
A.D. : farine et oufs harina y huevos

O.K. : farine et oufs ouais harina y huevos se
}

[CFPP2000] [03-01] Ozgur_Kiliç_H_32_alii_3 ${ }^{\mathrm{e}}$

(Líneas 148-151)

En la continuidad de la interacción, se pone de manifiesto que la entrevistadora, a pesar de utilizar una construcción declarativa, no afirma que la batalla se hacía con harina y huevos sino, por el contrario, desea que se le dé esa información o que se confirme si efectivamente era así.

Esta distinción funcional permite trascender la organización léxica y sintáctica de las emisiones. Así, la muestra seleccionada consta de emisiones de diferentes configuraciones sintácticas y léxicas, porque lo que interesa en nuestro estudio es indagar acerca de qué significados funcionales se le atribuyen y qué tienen en común.

Para la selección de las elicitaciones, se recurrió entonces a la interpretación de las secuencias siguientes en las que los interlocutores proveían información en reacción con la emisión precedente. Las emisiones que proporcionan información se reconocieron a 
partir del análisis de las intervenciones en las que los participantes reaccionaban a elicitaciones y se identificaron en ellas diferentes partes.

Se seleccionaron para nuestro estudio las secuencias en las que el hablante aporta la información solicitada o una información en reacción con una solicitud formulada previamente. Se incluyen, del mismo modo, emisiones en las que el hablante se refiere a su estado de conocimiento acerca del tema sobre el cual se le solicitó información, como por ejemplo la emisión de O.K.: j'en sais rien. ("no sé nada de eso"). (CFPP2000 [03-01] Ozgur_Kiliç_H_32_alii_3 ${ }^{\mathrm{e}}$ Línea 156).

Dado que se constató que, por lo general, el contenido informativo de las intervenciones que proveen información se sitúa en las primeras unidades del turno de habla de los participantes, nos detendremos en el análisis de la emisión inicial.

\subsection{Métodos}

\subsection{1}

A partir de las consideraciones de Quivy y Van Campenhoudt (1995), utilizamos en una parte importante de nuestra labor técnicas pertenecientes al "análisis de contenido" o a lo que se conoce generalmente como "metodología cualitativa" (Silverman, 2001). Los autores antes mencionados detallan tres variantes de esta metodología que fueron puestas en juego en este estudio: "el análisis temático", "el análisis formal” y "el análisis estructural".

El "análisis temático", se refiere a las interpretaciones sociales vinculadas con determinadas realizaciones en el discurso; el mismo implica explícitamente los juicios de sujetos consultados para tal fin.

También se llevó a cabo un "análisis formal”, específicamente en lo referido a la determinación de características entonativas de las secuencias estudiadas.

Finalmente, se utilizó al "análisis estructural" con el fin de detectar las características generales de la vinculación entre determinados elementos de la entonación y los significados percibidos por los hablantes.

No obstante, siguiendo lo expuesto por Angouri (2010), nuestra práctica no se limitó a los procedimientos englobados en esta metodología. Utilizamos de técnicas propias del análisis llamado cualitativo, como del denominado cuantitativo, en lo que la autora 
denomina la "aproximación del pragmático"3. De este modo, las técnicas utilizadas para el estudio incluyeron la observación, la elaboración de entrevistas, la interpretación y el micro análisis de las muestras para la selección del corpus, la realización de pruebas perceptivas y la interpretación de los datos de estas pruebas, lo que permitió detectar y cotejar significados. Por su parte, el análisis de las características entonativas se desarrolló por medio de mediciones y comparaciones.

La determinación de unidades se llevó a cabo en función de las dos etapas anteriores (la interpretación y la medición) para lo cual se requirieron nuevamente las técnicas de observación e interpretación. Finalmente, se recurrió a algunos exámenes porcentuales para determinar las características entonativas dominantes para cada grupo de emisiones examinado.

\subsubsection{Pruebas perceptivas}

Se confeccionaron grillas en las que se agruparon 70 ocurrencias de elicitaciones y 54 ocurrencias de emisiones informativas, enumeradas ${ }^{4}$ y ordenadas de acuerdo con su aparición en los textos. Estos fragmentos fueron utilizados para realizar las pruebas perceptivas. Para las mismas, se entrevistó en forma individual a 18 individuos francohablantes de entre 21 y 64 años procedentes de Francia metropolitana de los cuales se provee información detallada en el Anexo $n^{\circ} 2$.

Los sujetos escucharon cada fragmento en forma integral y luego las emisiones puntuales en el orden en que aparecían en el texto y se les solicitó que dijeran qué significados atribuían a las mismas. Las personas contaron con la mayor libertad para su respuesta ya que no se les dio ninguna pista acerca de los significados potenciales, a fin de que las respuestas fueran lo más espontáneas posibles. El Anexo $n^{\circ} 3$ presenta detalles de la modalidad utilizada para las pruebas perceptivas como así también las preguntas que se formularon a los sujetos participantes.

La grabación en audio y posterior transcripción de estas pruebas perceptivas constituyen la primera parte de los datos de nuestro estudio. Las respuestas obtenidas fueron agrupadas en grillas (como la que presentamos a continuación) en las que se puso especial atención a los comentarios referidos a la circulación de información y a la

\footnotetext{
${ }^{3}$ Nuestra traducción.

${ }^{4}$ La numeración de las emisiones aparece precedida de "S", para las emisiones que solicitan información y "P" para las que proveen información.
} 
gestión de la interacción.

Ejemplo de grilla de entrevistas para tests perceptivos

\begin{tabular}{|l|l|l|c|}
\hline $\mathrm{N}^{\mathrm{o}}$ & $\begin{array}{c}\mathrm{N}^{\mathrm{o}} \text { de línea } \\
\text { transcripción }\end{array}$ & Emisión & $\begin{array}{c}\text { Comentarios de sujetos francófonos acerca de } \\
\text { significados de las emisiones }\end{array}$ \\
\hline & & & \\
\hline
\end{tabular}

\subsubsection{Análisis acústico}

Para dar cuenta de las características entonativas, se realizó un análisis de variación de $\mathrm{F}_{0}$ en las sílabas tónicas y de altura de $\mathrm{F}_{0}$ en sílabas de Arranque. Dicho análisis se complementó con la delimitación de las unidades en que se dividen las secuencias, la identificación de las sílabas prominentes. Se definieron así la forma de las curvas encontradas en las sílabas tónicas y los valores alcanzados por la $\mathrm{F}_{0}$. Se utilizó, para este examen, el programa PRAAT ${ }^{5}$ de análisis de la señal sonora.

En el cuerpo de la tesis se podrán observar los gráficos de las emisiones y su transcripción. En algunos de ellos, las variaciones de $F_{0}$ correspondientes a otro hablante (como en el caso de algunas superposiciones) alteran la curva producida por el otro hablante, por lo que no siempre pueden tenerse en cuenta. Es por eso que se especifican muy claramente los encabalgamientos en la interacción.

Los gráficos incorporados al Análisis cuentan con una especificación previa de valores de altura tonal, sílabas prominentes, Tonos empleados y valores de $\mathrm{F}_{0}$.

\footnotetext{
${ }^{5}$ Paul Boersma y David Weenink del Instituto de Ciencias Fonéticas de la Univesidad de Amsterdam.
} 
A continuación presentamos un gráfico de ejemplo de PRAAT con referencias que detallan la información que contiene:

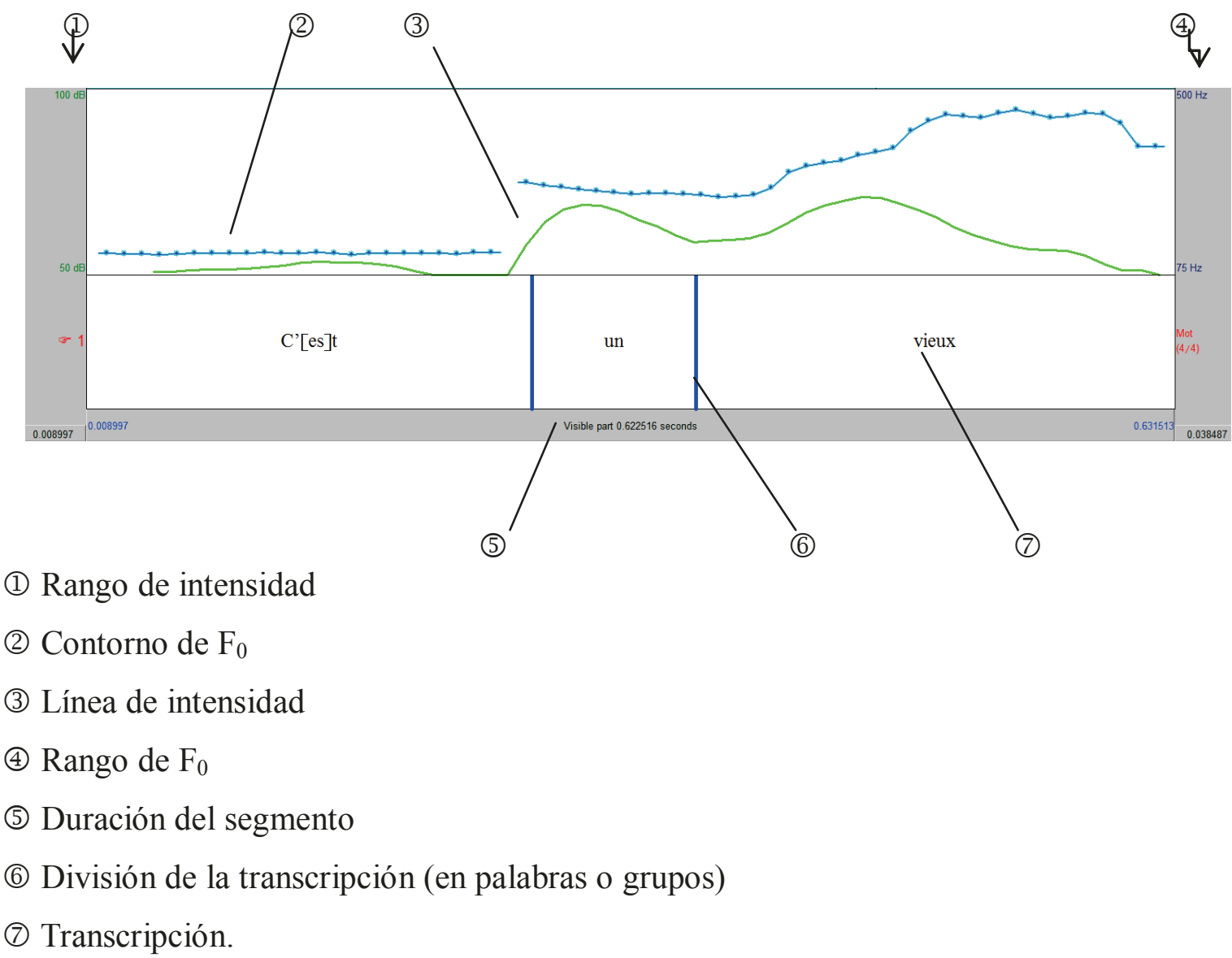

\subsubsection{Convenciones para la transcripción}

La transcripción del corpus se tomó asimismo del sitio de CFPP2000 realizando sólo algunas correcciones referidas la identidad de los hablantes y a la puntuación. El interés por conservar la transcripción original radica en que la misma es el producto de la escucha y la interpretación de sujetos francohablantes.

Precisamos, a continuación los símbolos utilizados en las transcripciones del corpus tal como fue extraído del sitio de CFPP2000:

\footnotetext{
$+\quad$ Pausa breve

+ Pausa prolongada

- Turnos de habla superpuestos

$\mathrm{X}$ Fragmentos ininteligibles

( ) Fragmento superpuesto breve o realizaciones extralingüísticas (risas, tos, etc.)

: $\quad$ Alargamiento vocálico
} 
Convenciones utilizadas en el cuerpo del trabajo

[ ] Segmento de habla superpuesto

$\mathrm{Hz} \quad \mathrm{Hertz}$
(A) Nivel tonal alto (o altura tonal alta)
(M) Nivel tonal medio (o altura tonal media)
(B) Nivel tonal bajo (o altura tonal baja)
(P) Tono Proclamatorio
(N) Tono Neutral
(R) Tono Referido 
Parte II

Análisis 


\section{Capítulo 5}

\section{Emisiones que solicitan información}

Tal como se explicó en la Metodología, se seleccionaron secuencias que solicitan información tratando de abarcar la mayor variedad posible de formas gramaticales e incluyendo emisiones con diferente extensión. Las mismas fueron luego sometidas, como ya dijimos, a la interpretación de sujetos francohablantes y se distinguieron dos grupos. En cada uno, se incluyen aquellas ocurrencias con rasgos comunes en relación con las interpretaciones obtenidas. Presentaremos a continuación el análisis de estos dos grupos a los que denominaremos en forma provisoria Elicitaciones de tipo A y de tipo B respectivamente.

Como expusiéramos en el Marco teórico de este trabajo, acuñamos el término "elicitación" (Brazil, 1997) utilizado también para los estudios del español (Granato 1998, 2005) y no el de 'pregunta', porque no se refiere específicamente a unidades que exhiben una estructura interrogativa sino a emisiones cuya función es generar información más allá de la sintaxis utilizada.

La literatura que presentamos en el Estado de la cuestión describe mayoritariamente las elicitaciones atendiendo a su configuración léxicogramatical:

- Presencia de palabras interrogativas: comment (cómo), que/quoi (qué), qui (quién), où (dónde), pourquoi (por qué), quand (cuándo).

- Su ubicación: al principio o al final de la secuencia.

Algunas descripciones distinguen asimismo las preguntas totales (o 'questions') y las preguntas parciales (o 'interrogations').

Como ya mencionamos en el capítulo de Estado de la cuestión, las características entonativas que se asocian en los trabajos consultados dividen las elicitaciones en dos grandes grupos, como se grafica en el cuadro $\mathrm{n}^{\circ} 6$. De este modo, a las preguntas totales o que no incluyen palabras interrogativas se les atribuye una entonación ascendente. Inversamente, se asume que las preguntas parciales o que incluyen un ítem léxico interrogativo están acompañadas por una entonación descendente. 


\begin{tabular}{|c|c|}
\hline Tipo de secuencias & Patrón entonativo \\
\hline $\begin{array}{c}\text { Preguntas totales o sin palabras } \\
\text { interrogativas }\end{array}$ & entonación ascendente \\
\hline $\begin{array}{c}\text { Preguntas parciales o con palabras } \\
\text { interrogativas al principio }\end{array}$ & entonación descendente \\
\hline
\end{tabular}

Cuadro $n^{\circ} 9$

Recordamos asimismo que Martins-Baltar atribuye a la entonación ascendente el significado funcional de ignorancia, duda, imposibilidad de verificar o de juzgar. Respecto de las curvas descendentes, Morel y Danon-Boileau señalan que su función es la de buscar confirmación.

En lo que respecta al español, los estudios de Granato sobre el español rioplatense (1998, 2005) dan cuenta de las siguientes correspondencias entre elecciones en el subsistema de Tono y tipos de elicitación de información:

\begin{tabular}{|c|c|}
\hline \multicolumn{2}{|c|}{ Emisiones de elicitación } \\
\hline $\begin{array}{c}\text { Tono } \\
\text { Ascendente } \\
\text { Ascendente-descendente }\end{array}$ & Descendente \\
\hline $\begin{array}{c}\text { Búsqueda de información que no se } \\
\text { posee }\end{array}$ & $\begin{array}{c}\text { Búsqueda de confirmación de } \\
\text { información que se posee }\end{array}$ \\
\hline
\end{tabular}

Cuadro $n^{\circ} 10$, basado en Granato, 2005:100

Las emisiones con cuya presentación expondremos el Análisis se presentarán comenzando por una breve descripción del contexto en el que cada una de ellas aparece. Seguidamente, se mencionarán los resultados obtenidos para la interpretación de esa secuencia en las pruebas perceptivas así como un reagrupamiento de los mismos en función de los aspectos generales que comparten. A estas menciones, seguirá el análisis de las características entonativas y los gráficos del análisis acústico y se culminará con una discusión acerca de las vinculaciones entre significado y forma. 


\subsection{Elicitaciones de tipo A}

Presentaremos en este primer apartado el examen de emisiones de elicitación de información en las que pueden observarse diferencias en cuanto a la estructuración gramatical, al tipo de pregunta (total o parcial) y a su extensión. Las mismas fueron agrupadas a partir de la identificación de rasgos comunes en los significados que vehiculizan, obtenidos en las pruebas perceptivas.

\section{1 .1}

La emisión que exponemos a continuación es pronunciada por una hablante con un final ascendente en momentos en que se hace referencia a un hombre que no está presente y con quien una de las participantes de la conversación tuvo un entredicho. El comentario de Anne, superpuesto con parte del relato que está realizando Jeanne M., motiva la siguiente intervención de Farah.

S61:

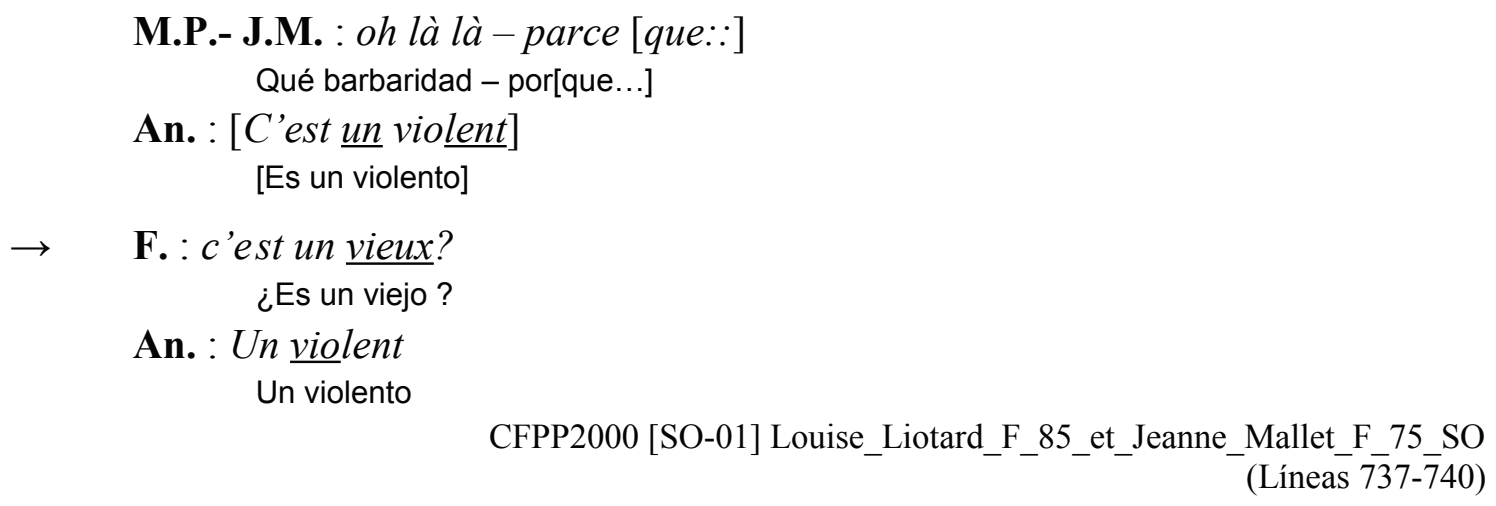

Consultados acerca de los significados que pueden interpretarse en esta emisión, los sujetos participantes de las pruebas perceptivas realizaron los siguientes comentarios:

Elle ne sait pas, elle a des préjugés.

No sabe, tiene prejuicios.

Elle ne suit pas le récit.

No sigue el relato.

Elle n'a pas bien compris.

No entendió bien.

Elle n'a pas bien écouté. "C'est un vieux?" No escuchó bien. “¿Es un viejo?”

Elle veut savoir, elle pose une question parce qu'elle ne comprenait pas.

Quiere saber, hace una pregunta porque no entendía. 
Elle n'a pas compris et pose la question parce ce qu'elle ne comprend pas ce qu'elle croit entendre.

No entendió y hace la pregunta porque no entiende lo que cree haber oído.

Elle a besoin de comprendre sil y a une différence de culture et aussi une différence générationnelle.

Necesita entender si hay una diferencia cultural y generacional también.

$C$ 'est une question et elle attend vraiment une réponse.

Es una pregunta y ella espera realmente una respuesta.

On continue dans l'identification $d u$ personnage, on essaie de l'identifier. Elle comprend pas ce qui a été dit donc elle répète.

Siguen en la identificación del personaje. Se intenta identificarlo. Ella no entiende lo que se dijo, lo repite.

Elle a mal entendu.

Oyó mal.

On voit que la personne n'a pas bien compris, elle a fait une association avec "violent » « vieux » et que ça la surprendrait que ce soit un vieux.

Se ve que la persona no entendió bien, asoció violento y viejo y la sorprendería que fuera un viejo.

Elle ne sait pas.

No sabe.

Elle demande un complément d'information. "C'est ça que vous avez dit, 'c'est un vieux?'”

Pide información complementaria. “¿Es eso lo que usted dijo, 'es un viejo'?”

En las interpretaciones provistas, se observan referencias a diferentes significados que transmite la hablante:

a) ignora la información que solicita a su interlocutora: «Elle ne sait pas » « Elle a besoin de comprendre... »

"No sabe", "Necesita entender..."

b) no comprendió bien el contenido del comentario precedente: «Elle ne suit pas le récit. «Elle n'a pas bien compris » «Elle n’a pas bien écouté. » «... elle ne comprenait pas. » «Elle n'a pas compris... « «... parce ce qu'elle ne comprend pas... » «Elle comprend pas... » «Elle a mal entendu ... « «On voit que la personne n'a pas bien compris... »

"No sigue el relato." "No entendió bien." "No escuchó bien." "... no entendía." "No entendió" "... porque no entiende..." "No entiende..." "Escuchó mal..." "Se ve que la persona no entendió bien..." 
Gráfico $\mathrm{n}^{\circ} 1$

S61:

J.M. : [parce que: ]

A. : [/ (A) c'est un violent (M) / ]*

(R)

$\rightarrow$ F. : /(A) c'est un vieux (450)/

CFPP2000 [SO-01] Louise Liotard F 85 et Jeanne Mallet F 75 SO (Líneas 737-740)

* El encabalgamiento de turnos impide la medición con PRAAT.

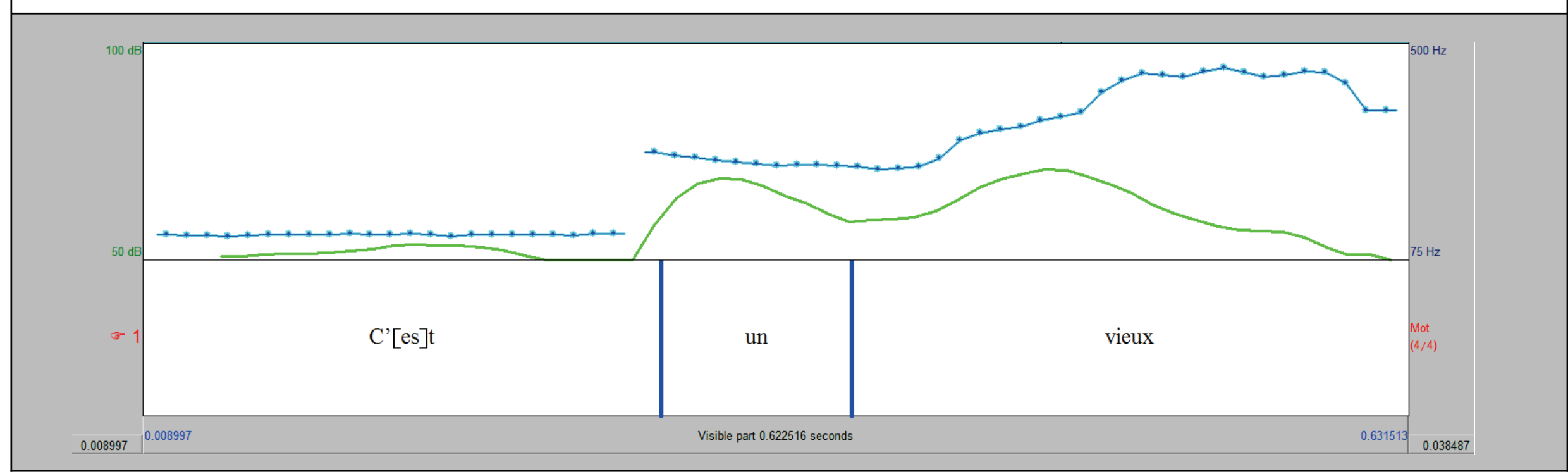


c) desea que su interlocutora le provea la información: «Elle veut savoir, elle pose une question... » «... et pose la question... « "C'est une question et elle attend vraiment une réponse. » «... elle demande un complément d'information... $\gg$

"Quiere saber, hace una pregunta..." "... y hace la pregunta..." "Es una pregunta y ella espera realmente una respuesta." "... pide un complemento de información...”

El análisis acústico arroja los siguientes resultados (ver gráfico $\mathrm{n}^{\circ} 1$ ). Se trata de una emisión realizada con una unidad tonal simple y con Tono Referido. El Arranque y la Terminación de la misma se efectúan en un nivel alto sobre el ítem "vieux", que alcanza los $450 \mathrm{~Hz}$. Debemos puntualizar que no es posible medir con el programa PRAAT el Arranque de la unidad precedente, a saber, la medida de la sílaba prominente " $u n$ " en la intervención previa de Anne "c'est un violent", a causa del encabalgamiento de turnos que mencionáramos anteriormente. Sin embargo, tanto el análisis perceptivo como el gráfico muestran en forma clara la diferencia de altura entre las líneas melódicas de las dos emisiones y permite determinar que la altura tonal del Arranque de la emisión de Farah, "C'est un vieux?", tiene un nivel alto.

Recordemos que la literatura referida a la entonación del francés detallada en el Estado de la cuestión describe este tipo de emisiones como preguntas totales y les atribuye un patrón entonativo ascendente. Examinaremos a continuación una elicitación que corresponde a las denominadas preguntas parciales.

\section{1 .2}

En la siguiente secuencia, una hablante de edad avanzada describe las molestias que le ocasiona un vecino del piso de arriba de su edificio. El entrevistador reacciona y pronuncia las siguientes emisiones con una entonación ascendente:

S58:

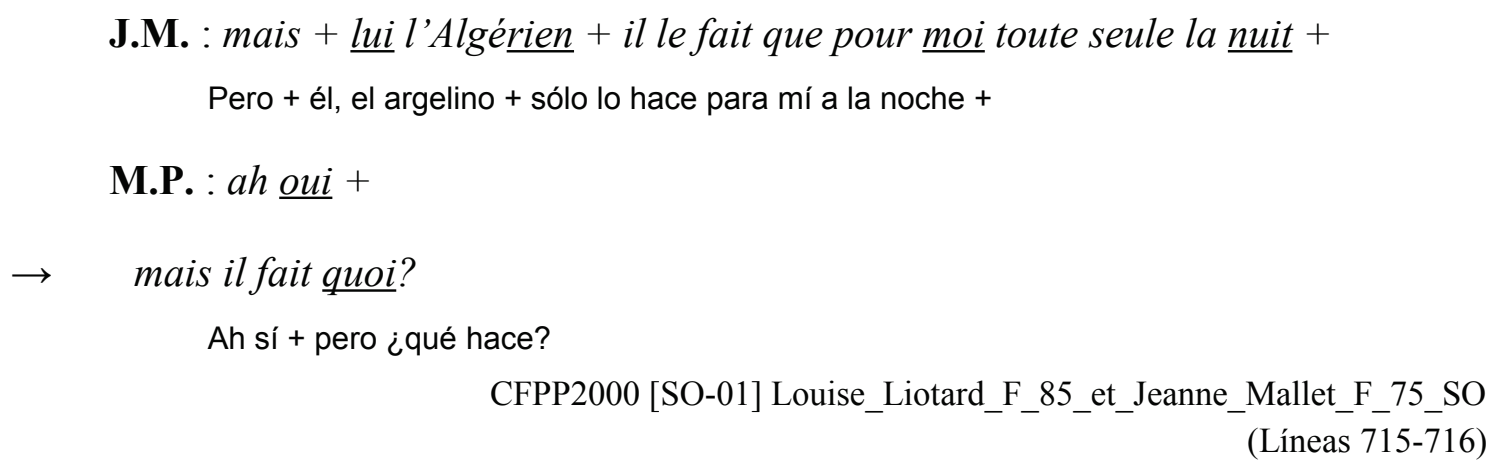

J.M. : mais + lui l'Algérien + il le fait que pour $\underline{\text { moi }}$ toute seule la nuit + Pero + él, el argelino + sólo lo hace para mí a la noche +

M.P. : ah $\underline{o u i}+$

$\rightarrow \quad$ mais il fait quoi?

Ah sí + pero ¿qué hace?

CFPP2000 [SO-01] Louise_Liotard_F_85_et_Jeanne_Mallet_F_75_SO

(Líneas 715-716) 
Los sujetos consultados en las pruebas perceptivas atribuyeron los siguientes significados a la emisión en cuestión:

C'est une volonté d'explication.

Es un deseo de explicación.

L'insistance sur le «quoi » montre justement qu'il y a un fossé, une distance entre les deux générations.

La insistencia en el "qué" muestra que hay una brecha, una distancia entre las dos generaciones.

Il pose la question parce qu'il ne comprend pas.

Hace la pregunta porque no entiende.

Il a perdu le fil du récit et il demande.

Perdió el hilo del relato y pregunta.

Il veut savoir.

Quiere saber.

Il pose la question. Il n'a pas attendu qu'elle termine pour poser sa question.

Hace la pregunta. No esperó a que ella terminara para hacer su pregunta.

Il demande de quoi elle parle. Il pose une question.

Pregunta de qué está hablando ella. Hace una pregunta.

Il pose la question un peu déçu de la dérive de l'interview et qu'il a perdu le fil.

Hace la pregunta un poco decepcionado por el rumbo de la entrevista y además porque perdió el hilo.

Il essaie de suivre mais il y a des choses qu'il a besoin de comprendre pour pouvoir espérer continuer de la suivre.

Trata de seguir [a su interlocutora] pero hay cosas que necesita comprender para poder tener expectativas de seguirla.

Il demande des précisions.

Pide precisiones.

Il n'a pas compris. Il lui manque un élément pour comprendre, et il demande " il fait quoi ».

No entendió. Le falta un elemento para comprender y pregunta "¿qué hace?"

Il veut savoir, en fait « dis-moi un peu plus ».

Quiere saber, de hecho « decime un poco más"

$C$ 'est une recherche d'information.

Es una búsqueda de información.

Il est curieux de savoir ce que l'homme fait pour la déranger.

Tiene curiosidad por saber lo que el hombre hizo para molestarla. 
Gráfico $\mathrm{n}^{\circ} 2$

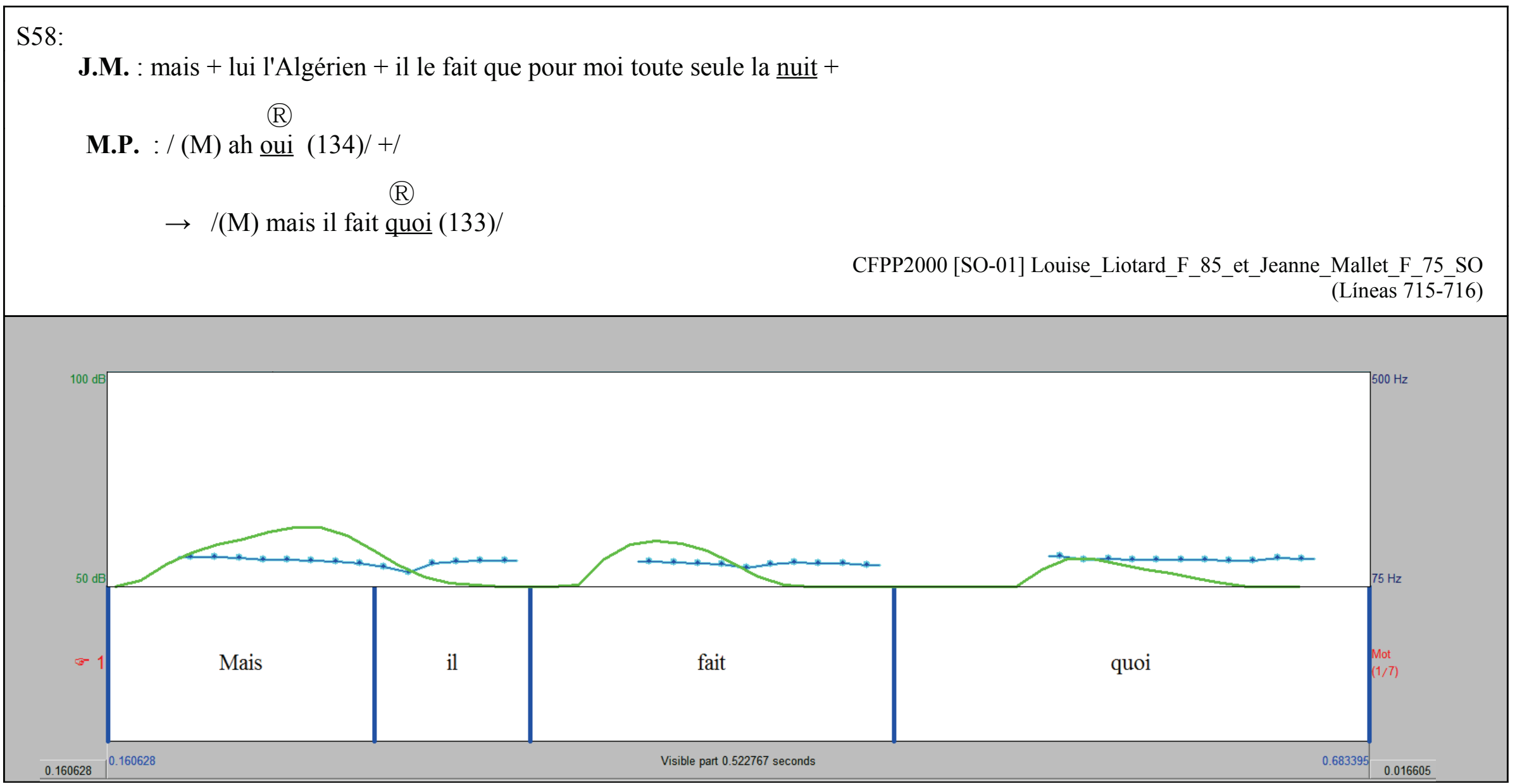


Las referencias citadas pueden agruparse de acuerdo con los siguientes puntos:

a) El hablante manifiesta la falta de una información: «... parce qu’il ne comprend pas. » «Il a perdu le fil du récit... « «... il y a des choses qu'il a besoin de comprendre...» «Il n'a pas compris. Il lui manque un élément pour comprendre ... »

"... porque no comprende." "Perdió el hilo del relato..." "hay cosas que necesita comprender..." "No entendió. Le falta un elemento para comprender"

b) El hablante desea que su interlocutora le provea una información: «C'est une volonté d'explication. " «Il pose la question... » en dos oportunidades « ... et il demande. " en dos oportunidades «Il veut savoir. " «Il demande de quoi elle parle. Il pose une question. » «Il demande des précisions. » « ... et il demande 'il fait quoi'. " "Il veut savoir, en fait 'dis-moi un peu plus'. " "C'est une recherche d'information. " "Il est curieux de savoir... »

"Es un deseo de explicación." "Hace la pregunta..." "... y pregunta." "Quiere saber." "Pregunta de qué está hablando ella. Hace una pregunta." "Pide precisiones." "Quiere saber, de hecho 'decime un poco más"” "Es una búsqueda de información." "Tiene curiosidad de saber..."

En cuanto a sus características entonativas (expuestas en el gráfico $\mathrm{n}^{\circ} 2$ ), esta elicitación presenta, como la anterior, una única unidad tonal simple. Tanto el Tono, como el Arranque y la Terminación se realizan por consiguiente sobre el elemento "quoi". El Tono es Referido y la altura tonal de Arranque y Terminación tiene un nivel medio (el movimiento de $\mathrm{F}_{0}$ llega a los $133 \mathrm{~Hz}$ ), dado que la altura tonal del Arranque precedente se sitúa en $134 \mathrm{~Hz}$ (en el ítem “oui”).

La bibliografía consultada, y en particular los trabajos de Hirst y di Cristo (1998), asocian las elicitaciones de este tipo con la entonación ascendente. Estas emisiones son descritas como preguntas parciales con palabra interrogativa al final.

\section{1 .3}

La solicitud de información que presentamos ahora corresponde, en la literatura, a la categoría ya mencionada de preguntas parciales. Sin embargo, esta emisión no contiene palabras interrogativas. Adèle ha sido interrogada a propósito de la forma de vestir de los jóvenes de su distrito. Luego de su intervención, Francine pronuncia la elicitación que retenemos para el análisis: 
S26:

A. : et les jeunes ? alors les jeunes ça dépend + mais euh + bah ils s'habillent un peu comme tous les jeunes quoi bah + la mode des jeunes

¿y los jóvenes? a ver los jóvenes depende + pero eh + y bue se visten un poco como todos los jóvenes eh + la moda de los jóvenes

$\rightarrow \quad$ F. : c'est-à-dire?

¿es decir?

CFPP2000 [07-02] Lucie_da_Silva_F_22_7

(Líneas 219-221)

Las interpretaciones de esta intervención obtenidas en las pruebas perceptivas son las siguientes:

Elle demande de définir. Elle attend une réponse.

Pide que defina. Espera una respuesta.

Elle a l'air de dire 'là, tu ne réponds pas' Comme quand tu dis 'mais encore?'

Parece decir 'ahí no estás respondiendo'. Como cuando decimos '¿y entonces?'

Elle cherche à la faire préciser.

Trata de hacerla precisar.

C'est une demande de précision 'dis-nous ce que ça veut dire'.

Es un pedido de precisión 'decinos lo que quiere decir eso'.

Elle insiste parce qu'elle veut sa réponse.

Insiste porque quiere su respuesta.

Je crois qu'elle cherche à avoir plus de précisions.

Creo que busca tener más precisiones.

Elle veut savoir vraiment comment s'habillent les jeunes. Elle veut que l'autre le dise.

Quiere saber realmente cómo se visten los jóvenes. Quiere que la otra lo diga.

C'est une interrogation, on lui demande d'être plus descriptive.

Es una pregunta, se le pide que sea más descriptiva.

Elle est en train de prendre le relais. Elle lui dit qu'il leur faut plus d'information.

Está tomando la posta. Le dice que necesitan más información.

Ça signifie 'Qu'est-ce que ça veut dire?' je pense.

Significa ‘¿Qué quiere decir eso?' me parece.

Elle veut que l'autre précise.

Quiere que la otra precise.

"Explique-moi ce que pour toi 'les jeunes' signifie. Quelle est ta figuration de la mode des jeunes dans ta tête. ”

“Explicame lo que significa para vos 'los jóvenes'. Qué idea de la moda de los jóvenes tenés en tu cabeza."

Elle dit 'donne-moi plus de détails pour que je comprenne ce que tu veux me dire'. 
Gráfico $\mathrm{n}^{\circ} 3$

S26:

A.: / ils s'habillent un peu/ comme tous les jeunes quoi / bah / + /(A) la mode des jeunes (297) /

(R)

$\rightarrow \quad$ F.: /(A) c'est à d[i:re] (494)/

[07-02] Lucie_da_Silva_F_22_7 $7^{\mathrm{e}}$ (Líneas 219-221)

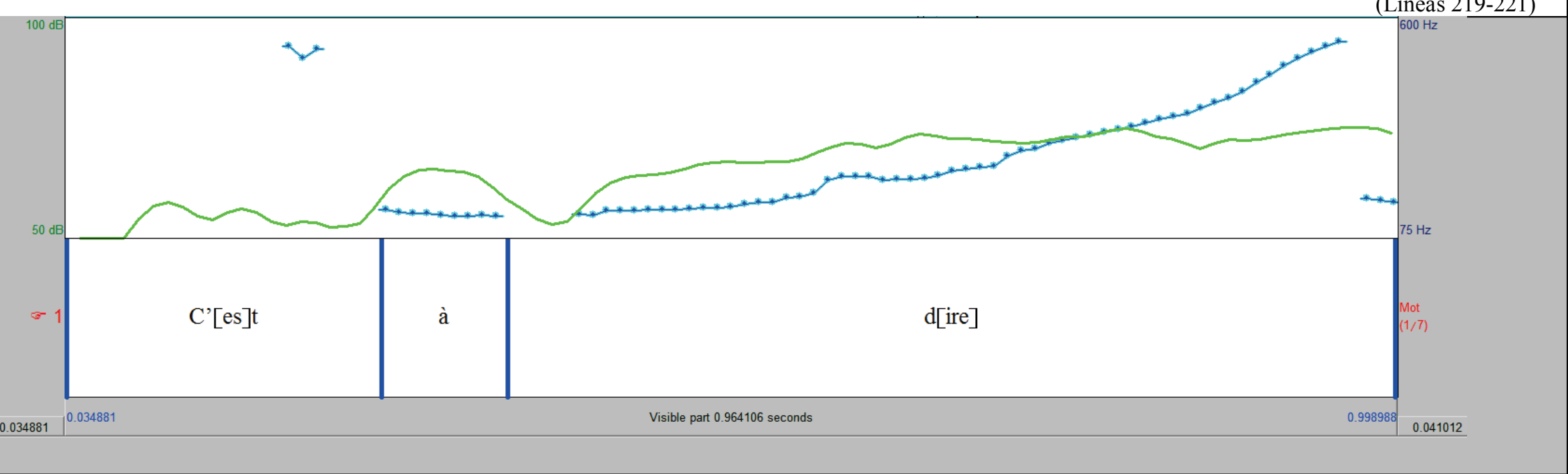


Le dice 'dame más detalles para que yo comprenda lo que querés decirme.

Puede apreciarse que, de acuerdo con la interpretación de los sujetos, la hablante manifiesta:

a) La voluntad de saber: «Elle demande de définir. Elle attend une réponse. » « Elle cherche à la faire préciser. » « ... elle cherche à avoir plus de précisions. » «C'est une demande de précision. » «Elle veut savoir vraiment ... » « Elle lui dit qu'il leur faut plus d'information. »

"Pide que defina. Espera una respuesta." "Busca hacerla precisar." "... busca tener más precisiones." "Es un pedido de precisión" "Quiere saber realmente..." "Le dice que necesitan más información."

b) El deseo de que su interlocutora brinde la información: «Elle veut que l'autre le dise. » «... on lui demande d'être plus descriptive. » «Elle veut que l'autre précise. " "'Explique-moi ce que pour toi 'les jeunes' signifie. Quelle est ta figuration de la mode des jeunes dans ta tête.' "

"Quiere que la otra lo diga." "... se le pide que sea más descriptiva." "Quiere que la otra precise." "Explicame lo que significa para vos 'los jóvenes. Cuál es tu figuración de la moda de los jóvenes en tu cabeza'."

c) La apreciación de que la información proporcionada previamente no es suficiente: "Elle a l'air de dire 'là, tu ne réponds pas' " "Elle insiste parce qu'elle veut sa réponse.» «Elle dit 'donne-moi plus de détails pour que je comprenne ce que tu veux me dire'. "

"Parece decir 'ahí no estás respondiendo'." "Insiste porque quiere su respuesta." "Le dice 'dame más detalles para que yo comprenda lo que querés decirme."

En lo referido a sus características entonativas, que pueden observarse en el gráfico $\mathrm{n}^{\circ} 3$, la emisión comprende una unidad tonal simple en la que el hablante elige el Tono Referido. El Arranque y la Terminación, realizados en la sílaba tónica, "dire”, tienen un nivel alto respecto del Arranque precedente ubicado en el ítem "jeunes" (297 Hz) de la intervención de Adèle. El punto máximo medido a través de PRAAT sobre la sílaba “dire” se ubica en $494 \mathrm{~Hz}$. Se percibe que la curva melódica continúa ascendiendo aún más, pero su medición se hace imposible por el encabalgamiento con el turno que sigue.

\section{1 .4}

A diferencia de las elicitaciones presentadas hasta aquí, la emisión que examinamos a continuación está constituida por una unidad tonal extendida. La misma consta de más 
de una sílaba prominente y en consecuencia el Arranque se realiza en la primera de ellas.

La joven Blanche D. describe un distrito de París que ha visitado hace poco. La entrevistadora toma la palabra para solicitar que dé una información puntual.

S33:

Bl.D. : ah la la j'aime pas du tout j'aime pas l'ambiance mais c'est vraiment j'aime pas + hhh + j' peux pas décrire mais [c'est ::]

Ay no me gusta para nada no me gusta el ambiente pero es realmente no me gusta + (suspiro) + no puedo describir pero [es...]

$\rightarrow$ S.B. : [tu en dirais au] tant des gens ? + + ¿Dirías lo mismo de la gente?

[CFPP2000] [11-03] Blanche_Duchemin_F_25_Reine_Ceret_F_60_11 (Líneas 283-285)

Al ser consultados acerca de los significados que se desprenden de esta emisión, los sujetos de las pruebas perceptivas aportaron las siguientes consideraciones:

C'est une question. Elle vise à aller plus loin.

Es una pregunta. Ella pretende ir más lejos.

Elle pose la question pour savoir si la fille est vraiment matérialiste à ce point-là.

Hace la pregunta para saber si la chica es verdaderamente materialista hasta ese punto.

Elle donne un sens, une direction à la conversation. Ça invite l'autre à être critique.

Le da un sentido, una dirección a la conversación. Eso invita a la otra a ser crítica.

Elle a envie de savoir si la fille pense que les gens sont aussi détestables que les lieux.

Tiene ganas de saber si la chica piensa que la gente es tan detestable como el lugar.

C'est une question politiquement correcte.

Es una pregunta políticamente correcta.

L'intervieweuse veut que la fille parle des gens, du milieu riche.

Le entrevistadora quiere que la chica hable de la gente, del mundo rico.

Elle pose la question pour ramener la gamine au monde des personnes, pour essayer de voir ce qu'elle pense de la société.

Hace la pregunta para llevar a la chica al mundo de las personas, para tratar de ver lo que piensa sobre la sociedad.

Elle est intéressée et elle ne sait pas ce que la fille va répondre.

Está interesada y no sabe lo que la chica va a responder.

Elle veut pousser encore un peu plus loin la conversation. Elle voudrait savoir pour les gens.

Quiere llevar un poco más lejos la conversación. Quisiera saber de la gente. 
C'est pas une question innocente. C'est une question qui a déjà la réponse, avec sa petite voix 'T'en dirais autant des gens?', tu vois, c'est 'oui', évidemment.

No es una pregunta inocente. Es una pregunta que ya tiene la respuesta, con su vocecita ‘¿Dirías lo mismo de la gente?', ves es 'si', obviamente.

On veut savoir. On essaie d'aller plus loin. Elle essaie de savoir vraiment ce qu'elle pense sur quelque chose de matériel, la petite aussi. On sent une connotation péjorative dans la question.

Quiere saber. Intenta ir más lejos. Trata de saber lo que la chiquita piensa acerca de algo material también. Se siente una connotación peyorativa en la pregunta.

Elle est intéressée pour savoir plus du quartier. C'est une curiosité sans aucune idée préconçue. Je pense qu'elle veut savoir.

Está interesada en saber más del barrio. Es una curiosidad sin ninguna idea previa. Creo que ella quiere saber.

L'intervieweuse veut savoir si elle n'aime pas non plus les gens qui habitent le quartier. La entrevistadora quiere saber si tampoco le gusta la gente que vive en el barrio.

Los significados giran nuevamente en torno de los puntos que detallamos:

a. La hablante expresa la voluntad de saber: «C'est une question. Elle vise à aller plus loin. » "Elle pose la question pour savoir si... " « Elle a envie de savoir si... » "Elle est intéressée et elle ne le sait pas ce que la fille va répondre. » « Elle voudrait savoir... " "Elle est intéressée pour savoir plus [...] C'est une curiosité sans aucune idée préconçue. Je pense qu'elle veut savoir. " " L'intervieweuse veut savoir si... »

"Es una pregunta. Ella pretende ir más lejos." "Hace la pregunta para saber si..." "Tiene ganas de saber si..." "Está interesada y no sabe lo que la chica va a responder." "Quisiera saber..." "Está interesada en saber más [...]. Es una curiosidad sin ninguna idea previa. Creo que ella quiere saber." "La entrevistadora quiere saber si..."

b. La hablante expresa su deseo de que la joven responda a su solicitud de información: «... savoir si la fille est vraiment matérialiste à ce point-là. » «L'intervieweuse veut que la fille parle des... « «Elle a envie de savoir si la fille pense que ... » « ... pour ramener la gamine au monde des personnes, pour essayer de voir ce qu'elle pense de ... » «... savoir si elle n'aime pas non plus les gens qui habitent le quartier. "

“ ... saber si la chica es verdaderamente materialista hasta ese punto." "Le entrevistadora quiere que la chica hable de ..." "Tiene ganas de saber si la chica piensa que la gente ..." "... para llevar a la chica al mundo de las personas, para tratar de ver lo que piensa sobre..." "saber si tampoco le gusta la gente que vive en el barrio." 
Gráfico $n^{\circ} 4$

S33 :

(P)

B.D. : [...] ah là là j'aime pas du tout j'aime pas l'ambiance mais c'est vraiment j'aime pas + hhh + (A) j' peux pas décrire (302) mais [c'est : ]/

(R)

$\rightarrow$ S.B. : / (A) [tu en dirais au]tant des gens $(436)(\mathrm{A}) /$

[CFPP2000] [11-03] Blanche_Duchemin_F_25_Reine_Ceret_F_60_11 ${ }^{\mathrm{e}}$ (Líneas 283-285)

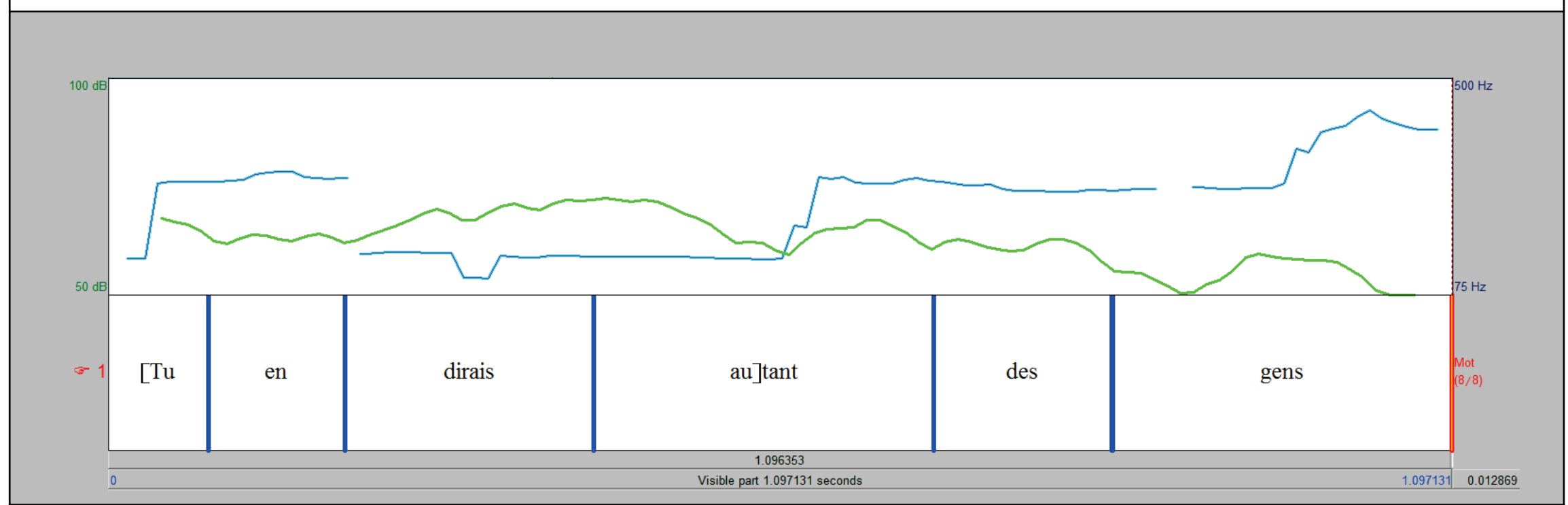


Uno de los sujetos interpretó además que la entrevistadora tiene una idea de la respuesta que va a recibir ("C'est pas une question innocente. C'est une question qui a déjà la réponse ..."1). Entre las ideas evocadas por el sujeto, el hecho de resaltar que 'no es una pregunta inocente' está vinculado, a nuestro entender, con significados de tipo local referidos a las connotaciones socioeconómicas y culturales que implicaría la elicitación. No obstante, todos los demás participantes de las pruebas perceptivas asociaron la elicitación con la ignorancia de la respuesta que se solicita.

El análisis acústico del segmento, que puede visualizarse en el gráfico $n^{\circ} 4$, permite establecer que la emisión se compone, como adelantáramos, de una unidad tonal extendida. La sílaba de Arranque "rais" tiene un nivel alto que se determina en forma perceptiva, dado que la superposición de turnos impide medir la curva de $\mathrm{F}_{0}$ por medio de PRAAT. La hablante utiliza un Tono Referido que culmina en $436 \mathrm{~Hz}$, sobre el ítem léxico "gens". La Terminación tiene, por consiguiente, un nivel alto.

Las emisiones que presentamos hasta ahora fueron realizadas en una única unidad tonal. Mostraremos a continuación elicitaciones que se realizan con una extensión mayor.

\section{1 .5}

La secuencia en la que tiene lugar la siguiente emisión se inicia con un pedido a las entrevistadas de que detallen sus desplazamientos diarios. Como reacción a ese pedido, Julie T. formula a su vez una elicitación dirigida a la entrevistadora:

S45:

S.B. : un jour où vous bougez un peu ++ alors " $j$ ' suis sortie d'la maison [K.T. : $m h \mathrm{mh}$ ] à telle heure j'ai fait comme ça »

[...] un día en el que se mueven un poco ++ entonces "salí de la casa [K.T. : mh mh] a tal hora, hice asi"

$\rightarrow \quad$ J.T. : ben alors jour de semaine ou : le wee[k-end ?]

¿pero entonces día de semana o : el fin de [semana?]

\section{S.B. : [ $\underline{\text { Comme }] \text { vous voulez }}$}

[Como] quieran.

CFPP2000[11-04] Julie_Teixeira_F_18_Katia_Teixeira_F_15_11 ${ }^{\mathrm{e}}$

(Líneas 534-537)

En las pruebas perceptivas, la secuencia dio lugar a los siguientes comentarios de los sujetos francófonos:

Elle pose une question, parce que pour elle, 'bouger', c'est le week-end.

\footnotetext{
1 "No es una pregunta inocente. Es una pregunta que ya tiene la respuesta..."
} 
Hace la pregunta porque para ella 'moverse' es el fin de semana.

Elle redemande à l'intervieweuse pour avoir des précisions, pour savoir exactement la réponse qu'elle va donner.

Vuelve a preguntarle a la entrevistadora para tener precisiones, para saber exactamente la respuesta que va a dar.

Elle cherche à préciser pour répondre correctement à ce qui est demandé.

Intenta precisar para responder correctamente a lo que se le preguntó.

Elle cherche à savoir plus précisément ce que la dame demande.

Intenta saber más precisamente lo que la mujer le pregunta.

Elle pose une question pour préciser la demande de l'intervieweuse.

Hace una pregunta para precisar la pregunta de la entrevistadora.

Elle pose une question pour savoir, le ton monte sur 'semaine' et sur 'week-end'.

Hace una pregunta para saber, el tono sube en 'semana' y en 'fin de semana'.

Elle demande si c'est bien ce qu'elle a compris que l'intervieweuse voulait dire. "Estce que c'est ça que vous me demandez?».

Pregunta si está bien lo que interpretó que la entrevistadora quería decir. “¿Es esto lo que usted me pregunta?"

On voit qu'elle n'a pas très bien compris la question. Elle demande un peu plus d'information parce que c'est pas clair. Pendant ce temps déjà elle réfléchit à sa réponse.

Se ve que no comprendió muy bien la pregunta. Pide un poco más de información porque no es claro. Mientras tanto, ya está pensando en su respuesta.

Elle n'a pas très bien compris la question. Donc, elle demande un peu plus d'information, parce que c'est pas très clair.

No entendió muy bien la pregunta. Entonces, pide un poco más de información porque no está muy claro.

Justement c'est l'intonation de voix [de la question de l'intervieweuse] ce qui choque les deux sœurs. Elle demande une confirmation parce qu'elle est interloquée par la façon de poser la question.

Justamente es la entonación de la voz [de la pregunta de la entrevistadora] lo que sorprende a las dos hermanas. Pide una confirmación porque está sorprendida por la forma de hacer la pregunta.

La question l'a surprise. Pour gagner du temps, elle essaie de savoir si au moins on peut choisir entre la semaine ou le week-end. Elle cherche de l'aide de l'intervieweuse.

La pregunta la sorprendió. Para ganar tiempo, trata de saber si al menos se puede elegir entre la semana o el fin de semana. Busca ayuda de la entrevistadora.

Elle marque qu'il y a une grande différence. Elle veut savoir ce que la dame souhaite savoir. 
Gráfico $n^{\circ} 5$

S45:

S.B.: /alors / j' suis sortie /d'la maison / à telle heure / (M) j'ai fait (167) comme ça (183) (M) /

(R)

(R)

$\rightarrow \quad$ J.T. : / (A) ben alors jour de semaine $(384)$ / (M) ou : le wee[k-end]*/

CFPP2000[11-04]Julie_Teixeira_F_18_Katia_Teixeira_F_15_11 ${ }^{\mathrm{e}}$

(Líneas 534- 537)

* El encabalgamiento de turnos impide la medición de altura tonal.

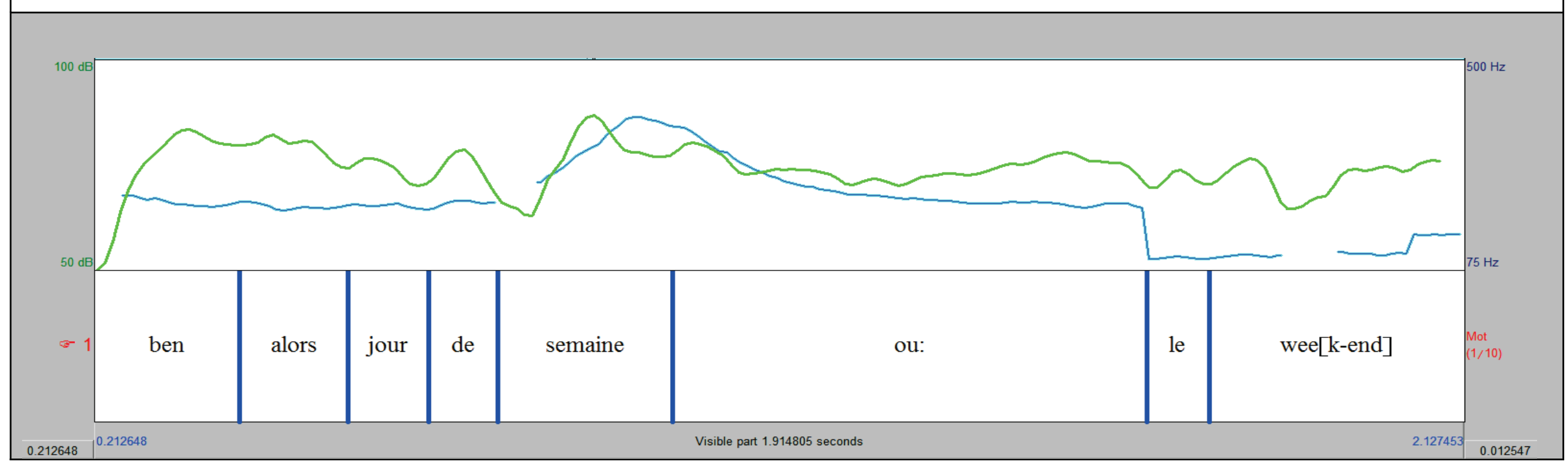


Marca que hay una gran diferencia. Quiere saber lo que la señora desea saber.

Los conceptos proporcionados por los sujetos comparten la percepción de los significados que detallamos a continuación:

a) La hablante manifiesta su desconocimiento y su necesidad de obtener una información puntual: « ... pour savoir exactement la réponse qu'elle va donner. » «Elle cherche à préciser .... « « Elle cherche à savoir plus précisément ce que la dame demande. » «... pour préciser la demande de l'intervieweuse. » «On voit qu'elle n'a pas très bien compris la question. » «Elle veut savoir ce que la dame souhaite savoir. »

“... para saber exactamente la respuesta que va a dar." "Busca precisar..." "Busca saber más precisamente lo que la mujer le pregunta." "... para precisar la pregunta de la entrevistadora." "Se ve que no comprendió muy bien la pregunta." "Quiere saber lo que la mujer desea saber."

b) La hablante desea que su interlocutora le provea la información: «Elle pose une question... » «Elle redemande à l'intervieweuse pour avoir des précisions... » «Elle demande... » «Elle demande un peu plus d'information parce que c'est pas clair. » " Donc, elle demande un peu plus d'information... » « ... elle essaie de savoir si... » «Elle cherche de l'aide de l'intervieweuse. »

"Hace la pregunta..." "Vuelve a preguntar a la entrevistadora para tener precisiones..." "Pregunta..." "Pide un poco más de información porque no es claro." "Entonces, pide un poco más de información..." "...trata de saber si..." "Busca ayuda de a entrevistadora."

El análisis acústico del segmento, reflejado en el gráfico $n^{\circ} 5$, da cuenta de una emisión realizada con dos unidades tonales simples. El Arranque y la Terminación de la primera unidad, situados en la sílaba "maine", se realizan en nivel alto, con una altura tonal de $384 \mathrm{~Hz}$, muy superior a la del Arranque precedente (pronunciado por S.B. sobre el elemento léxico "fait", que se ubica en $167 \mathrm{~Hz}$ ). La segunda unidad tiene un Arranque y una Terminación en nivel medio cuya altura no puede precisarse por el encabalgamiento mencionado.

En ambas unidades, la hablante utiliza el Tono Referido. Más aún, uno de los sujetos de las pruebas perceptivas fue sensible a los dos movimientos melódicos: «le ton monte sur 'semaine' et sur 'week-end'. » (“El tono sube en 'semana' y en 'fin de semana"”). Sin embargo, la primera se percibe con mayor claridad que la segunda, que se produce en superposición con el comienzo del turno siguiente. Podría suponerse que la interlocutora reacciona entonces a los significados proyectados por la primera realización de Tono. 
Este tipo de emisiones ha sido descrito por Di Cristo (1998) como preguntas alternativas y el autor atribuye a las mismas un patrón entonativo realizado sobre dos unidades tonales en las que se suceden los movimientos melódicos ascendente y descendente respectivamente. Observamos en el corpus elicitaciones que responden al patrón descrito por este autor, como en el ejemplo que vemos a continuación:

$$
\text { (R) } \mathrm{P}
$$

B.D. : t'as raté ta jeunesse ou quoi ?

¿no tuviste infancia o qué?

[CFPP2000] [03-01] Ozgur_Kiliç_H_32_alii_3 ${ }^{\mathrm{e}}$

(Líneas 130-131)

En el caso de la emisión de Julie T., el patrón entonativo no coincide con la descripción de Di Cristo para el francés. No hubo registro por parte de los participantes de la prueba perceptiva en cuanto a la falta de naturalidad de esta emisión, lo cual puede vincularse con el hecho de que el hablante transmite el desconocimiento de la respuesta que solicita en ambas unidades tonales.

\section{1 .6}

A continuación, nos centraremos en una elicitación que puede encuadrarse en lo que ha sido descrito como pregunta parcial y que se inicia con una palabra interrogativa. La misma tiene lugar en momentos en que las entrevistadas describen la vestimenta usual de los jóvenes del $7^{\circ}$ distrito de París, luego de lo cual la entrevistadora realiza esta intervención en la que se aprecia también un ascenso melódico:

S29:

L.dS. : tee-shirt chemise

remera camisa

$\rightarrow \quad$ F.L. : comment ça s'appelle ces chaus $\underline{\text { sures ? }}$

¿cómo se llaman esos zapatos?

A. : les Schmooves

los Schmooves

CFPP2000 [07-02] Lucie_da_Silva_F_22 $7^{\mathrm{e}}$

(Líneas 251-253)

Entre los comentarios vertidos por los sujetos en las pruebas perceptivas acerca de esta emisión, podemos citar:

Elle pose une question.

Hace una pregunta.

Elle demande de l'information sans plus. 
Pide simplemente información.

Elle demande parce que ça ne lui dit rien.

Pregunta porque eso no le dice nada.

Elle n'a pas compris. Elle demande une répétition.

No entendió. Pide una repetición.

C'est une demande de répéter, parce qu'elle n'a pas compris.

Es un pedido de repetición, porque no comprendió.

Elle n'a pas compris le mot donc elle demande de répéter.

No entendió la palabra, entonces pide que repitan.

Elle est surprise, par ce mot qu'elle en connaît pas et parce que c'est une référence importante.

Está sorprendida porque es una palabra que no conoce y porque es una diferencia importante.

Elle vient d'un autre monde et elle est un peu noyée dans cette masse d'information et elle pose une question.

Viene de otro mundo y está un poco ahogada en esta masa de información y hace una pregunta.

On voit qu'elle n'a pas très bien compris.

Se ve que no entendió muy bien.

Elle ne connaît pas du tout, elle connaît pas le mot.

No los conoce para nada, no conoce la palabra.

Elle veut savoir, elle n'a pas compris le mot donc elle demande.

Quiere saber, no entendió la palabra entonces pregunta.

Elle ne connaît pas. Ça doit être la première fois qu'elle entend parler de ce modèle.

Ça l'intéresse.

No conoce. Debe ser la primera vez que escucha hablar de ese modelo. Le interesa.

Dans le ton de l'intervieweuse vraiment, elle découvre. Elle n'a jamais entendu parler de ce mot et elle veut une confirmation qu'elle a bien compris dans la description que c'était des chaussures pointues...

Por el tono de la entrevistadora, ella comienza a descubrir [algo]. Nunca oyó hablar de esa palabra y quiere una confirmación de que entendió bien por la descripción que eran zapatos puntiagudos.

Elle ne connaît pas.

No los conoce. 
Gráfico $n^{\circ} 6$

S29 :

(P)

L.dS. : / (A) tee-shirt (267) chemise (213) (M) /

(R)

(R)

F.L. : /(A) comment ça s'appelle (321) / (A) ces chaussures (352) /

CFPP2000 [07-02] Lucie_da_Silva_F_22_7 ${ }^{\mathrm{e}}$ (Líneas 251-253)

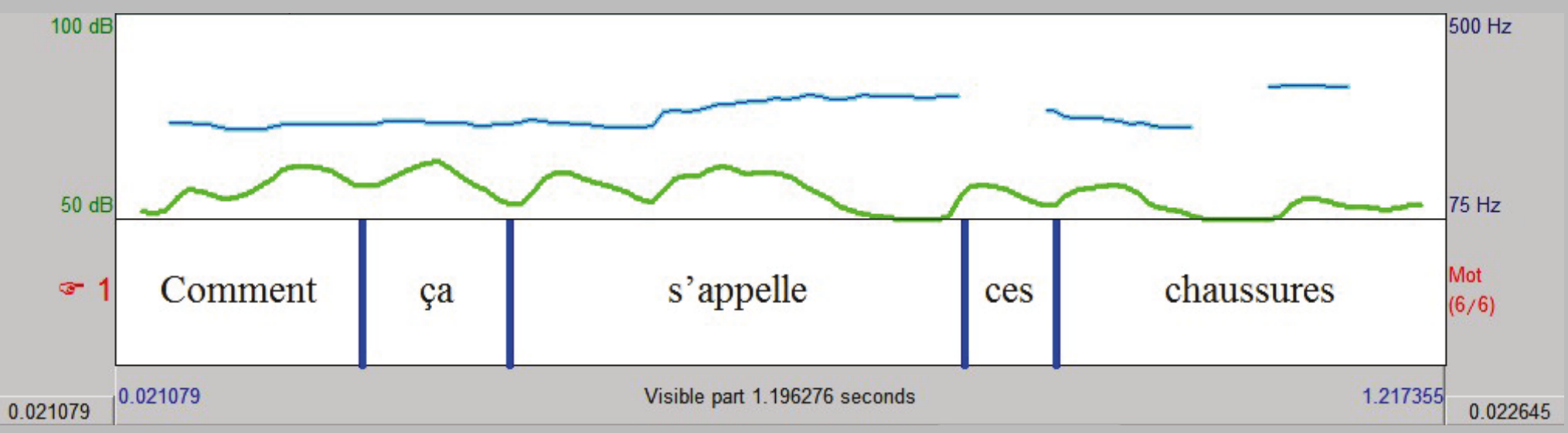


Es posible observar que las interpretaciones de los sujetos en las pruebas perceptivas refieren a:

a) la falta de comprensión de una información provista anteriormente: « elle n’a pas compris » ("no entendió") en tres ocasiones.

b) la falta de conocimiento del elemento acerca del cual se solicita información: « ... ça ne lui dit rien... » «Elle veut savoir... » « Elle ne connaît pas », este último concepto es citado en cuatro oportunidades.

“... eso no le dice nada" "Quiere saber ..." "No los conoce..."

c) el carácter novedoso de la información que se solicita: «... elle découvre. Elle n'a jamais entendu parler de....» « Ça doit être la première fois qu'elle entend parler de...» « Elle est surprise... »

“... ella comienza a descubrir [algo]. Nunca oyó hablar de ..." "Debe ser la primera vez que escucha hablar de..." "Está sorprendida..."

d) la intención de que las interlocutoras provean la información que falta: «Elle pose une question » en dos ocasiones, «Elle demande de l'information ... » « elle demande une répétition/de répéter $\gg$.

"Hace una pregunta." "Pide información..." "Pide una repetición/ que le repitan".

El análisis acústico de la emisión permite determinar que la intervención consta de dos unidades tonales simples (ver gráfico $n^{\circ}$ 6). Su cotejo con el Arranque de la unidad precedente ("shirt", de la emisión de Lucie dS., que alcanza $213 \mathrm{~Hz}$ ) permite determinar que tanto el Arranque como la Terminación de la primera unidad, situados ambos en la sílaba "pelle", tienen un nivel alto (su altura tonal es de $321 \mathrm{~Hz}$ ). Lo mismo ocurre con el Arranque y la Terminación de la segunda unidad, realizados en la sílaba "sures", cuya altura tonal alcanza los $352 \mathrm{~Hz}$. En ambas unidades entonativas se reitera el Tono Referido.

Recordemos que este tipo de preguntas parciales con una palabra interrogativa al principio han sido asociadas en la literatura con un esquema entonativo descendente. La elección de lo que en el marco de nuestro estudio denominamos Tono Proclamatorio es frecuente en francés. Consideramos que esta elección se vincula con cierto aspecto de la información solicitada que quien formula la elicitación conoce o cree conocer.

En lo que respecta a nuestros datos, no contamos con elicitaciones de este tipo que sean pronunciadas con Tono Proclamatorio. Constatamos entonces que el Tono Referido es 
también usual en estos casos, dado que estas realizaciones son efectuadas e interpretadas por francohablantes. En secuencias como la pronunciada por Julie T., el Tono Referido acentúa el carácter no negociado de la información que se solicita. Una vez más, vemos que la estructura sintáctica de las emisiones no es determinante en las elecciones relacionadas con los patrones entonativos utilizados.

\section{1 .7}

En la elicitación que exponemos a continuación, Etienne S. trata de recordar los animales que veía en la Plaza du Temple cuando era niño. En ese momento, Ozgur K. interviene y solicita una información puntual a su amigo con un ascenso melódico al final:

S9:

E.S. : [...] mais à part les canards euh ... [...] pero a parte de los patos eh ...

$\rightarrow \quad$ O.K. : Mais t'y allais souvent toi au square du Temple? ¿Pero ibas muy seguido vos a la plaza del Temple?

[CFPP2000] [03-01] Ozgur_Kiliç_H_32_alii_3 $3^{\mathrm{e}}$

(Líneas 88-89)

Los sujetos consultados acerca de los significados que se desprenden de la escucha de esta emisión, proveyeron las siguientes consideraciones:

C'est une question avec beaucoup de surprise.

Es una pregunta con mucha sorpresa.

Il pose une question. Il a l'air étonné.

Hace una pregunta. Parece sorprendido.

Il est étonné. C'est marrant le ton qu'il emploie. Il y a moins de connivence que précédemment.

Está sorprendido. Es gracioso el tono que emplea. Hay menos complicidad que antes.

Il lui demande parce qu'il ne s'en souvient pas.

Le pregunta porque no se acuerda.

Il veut vraiment savoir si son copain y allait souvent. Ou bien, il mésestime son copain, c'est pour dire "tu connais rien, quoi». Dans les deux cas, ça demanderait une réponse.

Realmente quiere saber si su amigo iba seguido ahí. O bien, subestima a su amigo, como queriéndole decir "no conocés nada". En los dos casos, se esperaría una respuesta.

$C$ 'est une interrogation.

Es una interrogación. 
Énormément de surprise. "Tu ne me l'as jamais dit! Comment je ne connais pas les moindres détails de ta vie?! »

Muchísima sorpresa. “iNunca me lo dijiste! ¿¡Cómo es que no conozco los mínimos detalles de tu vida?!"

Il est un peu étonné. Il cherche à avoir une réponse parce que lui, ça ne l'a pas marqué, alors que son copain s'en souvient très bien.

Está un poco sorprendido. Busca tener una respuesta porque eso él no lo registró en cambio amigo se acuerda muy bien.

Il est étonné. Il le dit avec beaucoup de surprise. Il veut que son copain lui dise s'il y allait parce qu'apparemment ce n'est pas un lieu sûr où on puisse aller quand on est jeune.

Está asombrado. Lo dice con mucha sorpresa. Quiere que su compañero le diga si iba ahí porque aparentemente no es un lugar muy seguro para ir cuando se es chico.

Il est étonné du fait qu'il ne savait pas quelque chose de son ami. Il lui demande d'expliquer « comment ça se fait ».

Está sorprendido por el hecho de que no sabía algo de su amigo. Le pide que explique "cómo puede ser".

Là, il y a comme un doute. L'air de dire "Comment tu sais qu'il y avait des canards au square du Temple?»

Ahí hay como una duda. Es como decir “¿Cómo sabías que había patos en la plaza del Temple?"

Nuevamente, la mayor parte de los significados que se atribuyeron a la emisión estuvieron relacionados con:

a. El desconocimiento de una información por parte de quien formula la elicitación: «Il y a moins de connivence que précédemment. » «... il ne s'en souvient pas. » «Il veut vraiment savoir si ... » « ' [...] Comment je ne connais pas les moindres détails de ta vie?!'» «ça ne l'a pas marqué, alors que son copain s'en souvient très bien. " «... il ne savait pas quelque chose de son ami. »

"Hay menos complicidad que antes." "... no se acuerda." "Realmente quiere saber si..." "[...] ¿¡Cómo es que no conozco hasta los más mínimos detalles de tu vida?!” "...eso él no lo registró en cambio su amigo se acuerda muy bien." "... no sabía algo de su amigo."

b. El deseo de que la persona a quien se dirige brinde la información: «... ça demanderait une réponse. " "Il cherche à avoir une réponse... " "Il veut que son copain lui dise si... » "Il lui demande d'expliquer... » 
Gráfico $\mathrm{n}^{\circ} 7$

S9:

E.S. : /(M) à part les canards (135) euh /

(R)

(R)

$\rightarrow$ O.K. : / (A) mais t'y allais souvent (301)/(A) toi au square du Temple (299) /

[CFPP2000] [03-01] Ozgur_Kiliç_H_32_alii_3 (Líneas 88-89)

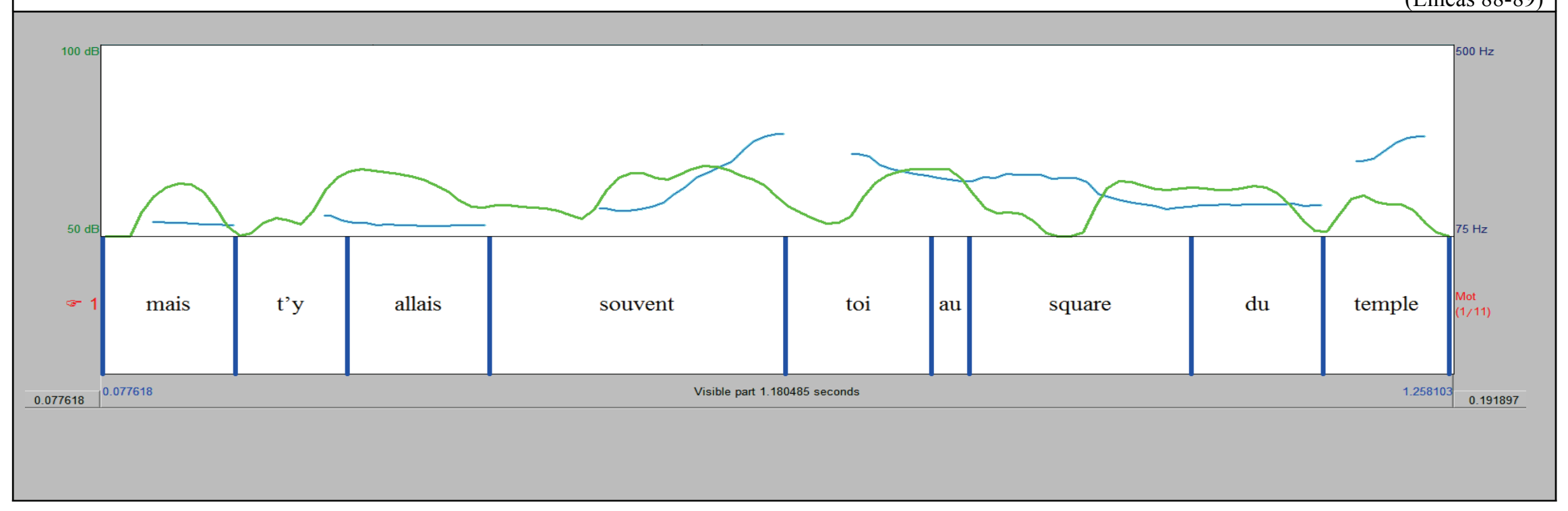


“... se esperaría una respuesta." "Busca tener una respuesta..." "Quiere que su compañero le diga si..." "Le pide que explique..."

Más aún, a las interpretaciones que asocian la elicitación de información con algún tipo de categoría sintáctica o funcional («C'est une question... » "C'est une interrogation. $»^{2}$ ) se agrega la sensibilidad de casi todos los sujetos a los significados de sorpresa por el desconocimiento de la información que transmite la emisión de Ozgur K. (« ... avec beaucoup de surprise. " «Il a l'air étonné. " «Il est étonné» "Énormément de surprise. » " '[...] Comment je ne connais pas les moindres détails de ta vie?!' " «Il est un peu étonné. » «Il le dit avec beaucoup de surprise. » " 'comment ça se fait' »³).

En lo que refiere a sus características entonativas, el hablante realiza la emisión con dos unidades tonales simples en las que se reitera el Tono Referido. En la primera, el Arranque y la Terminación se realizan sobre la sílaba tónica "vent" y tienen un nivel alto. El movimiento melódico alcanza los $301 \mathrm{~Hz}$, por encima del arranque precedente de Étienne, situado en $135 \mathrm{~Hz}$. En tanto, el Arranque y la Terminación de la segunda unidad, realizados sobre la sílaba tónica que conforma el elemento léxico "Temple" tienen un nivel tonal también alto cuyo extremo se sitúa en $299 \mathrm{~Hz}$.

Al tratarse de una emisión que puede enmarcarse en la categoría mencionada de preguntas totales, puede decirse que el patrón entonativo que expusimos coincide en general con las descripciones provistas en la bibliografía analizada acerca del tema.

Respecto de los significados ligados a la idea de sorpresa, los mismos pueden asociarse a la altura tonal Alta indicada tanto por Brazil para el inglés como por Granato para el español como vehiculizadora de contraste. Por otra parte, el significado local de sorpresa no puede desvincularse del significado más general de falta de conocimiento que se percibe en forma unánime en las pruebas perceptivas.

\section{1 .8}

La secuencia que nos ocupa cuenta, como la anterior, con dos unidades tonales y reitera asimismo el ascenso melódico final. Blanche D. realiza un comentario acerca de los jóvenes de su distrito. Su madre, reacciona y efectúa el siguiente pedido de información:

\footnotetext{
2 "Es una pregunta..." "Es una interrogación."

3 “... con mucha sorpresa." "Parece sorprendido" "Está asombrado.” "Muchísima sorpresa.” “[... ] ¿Cómo es que no conozco hasta los más mínimos detalles de tu vida?!”" "Está un poco sorprendido" "Lo dice con mucha sorpresa" "“... cómo puede ser..."
} 
S27:

L.dS. : dans l'septième c'est très rare de voir euh: un groupe de jeunes en jogging ça par contre + j'avoue en el séptimo distrito en cambio es raro ver ehhh un grupo de jóvenes en jogging + confieso

$\rightarrow \quad$ A. : de quoi + c'est très ?

¿qué + es muy?

[CFPP2000] [07-02] Lucie_da_Silva_F_22_7

(Líneas 222-225)

Las impresiones de los sujetos, a partir de la escucha de la emisión que nos ocupa, son las siguientes:

La mère n'a pas compris. Elle demande à sa fille de répéter.

La madre no entendió. Le pide a su hija que repita.

C'est une demande d'explication, la femme n'a pas compris ce que la fille disait.

Es un pedido de explicación, la mujer no entendió lo que decía la chica.

Elle n'a pas compris parce que l'autre parle tellement vite...

No entendió porque la otra habla tan rápido...

Elle lui demande de répéter ses mots.

Le pide que repita sus palabras.

C'est une question parce que la fille parle très vite et elle rit, alors ce n'est pas clair.

Es una pregunta porque la chica habla muy rápido y se ríe, entonces no es claro.

Elle reprend le début de la phrase et elle attend que l'autre complète. Elle fait la moitié du travail pour récupérer l'information de perdu.

Retoma el inicio de la frase y espera que la otra complete. Hace la mitad del trabajo para recuperar la información perdida.

La dame demande de répéter. Elle veut savoir ce que l'autre avait dit en riant.

La señora le pide que repita. Quiere saber lo que la otra había dicho riéndose.

Elle ne comprend pas. Elle n'a pas entendu à cause de la prolifération de personnes qui prennent la parole.

No entiende. No escuchó por la proliferación de personas que toman la palabra.

Elle demande de répéter. Elle reprend sa fille.

Pide que repita. Retoma [las palabras de] su hija.

C'est juste « J'ai pas bien compris ce que tu me dis ». Pour qu'elle répète en fait.

Es simplemente « No entendí lo que me decís". En realidad, para que ella repita.

Sa fille prend la parole et parle très rapidement. La femme demande alors de répéter.

Su hija toma la palabra muy rápidamente. Entonces, la mujer le pide que repita. 
Gráfico $\mathrm{n}^{\circ} 8$

S27:

L.dS. : dans l'septième c'est très rare de voir euh: un groupe de jeunes en jogging ça par contre +/ (M) j'avoue (240)/ (R) (R)

$\rightarrow \quad$ A. : /(A) de quoi (392) / (A) c'est très : (279)/

[CFPP2000] [07-02] Lucie_da_Silva_F_22_7 $7^{\mathrm{e}}$ (Líneas 222-225)

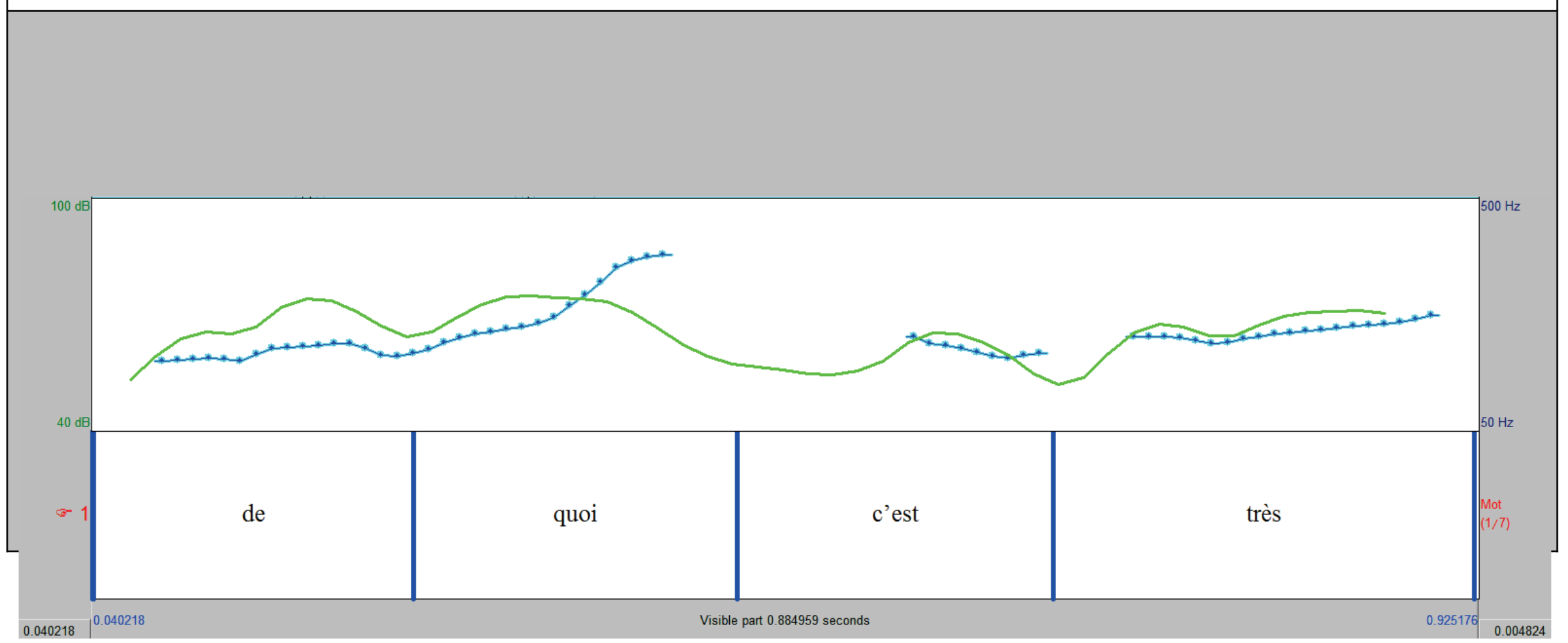


Los significados que se atribuyen a la emisión reiteran características que hemos señalado en las pruebas perceptivas de las emisiones analizadas hasta aquí:

a. La expresión de un vacío de información por parte de la hablante: « La mère/la femme n'a pas compris... « «... pour récupérer l'information de perdu.» «Elle veut savoir ce que l'autre avait dit... » «Elle ne comprend pas. Elle n'a pas entendu...» « C'est juste 'J'ai pas bien compris ce que tu me dis' »

"La mujer/La madre no entendió." “...para recuperar la información perdida." "Quiere saber lo que la otra había dicho..." "No comprende. No escuchó..." "Es simplemente 'No entendí lo que me decís"

b. El deseo de que su interlocutor brinde esa información: «Elle demande à sa fille de répéter. " «C'est une demande d'explication...» «Elle lui demande de répéter ses mots. » «... elle attend que l'autre complète. » «... pour qu'elle répète.» «L L femme demande alors de répéter. »

"Le pide a su hija que repita." "Es un pedido de explicación..." "Le pide que repita sus palabras." "... espera que la otra complete.” “... para que repita." "Entonces, la mujer le pide que repita.”

En lo referido a sus características entonativas, en el gráfico $n^{\circ} 8$ puede observarse que esta elicitación está compuesta por dos unidades tonales simples. La primera sílaba prominente - de Arranque y tónica -, sobre ítem léxico “quoi” culmina en $392 \mathrm{~Hz}$. Observamos que tanto el Arranque como la Terminación de esta unidad se sitúan en un nivel alto. Estos valores surgen del cotejo de esta altura tonal con la de la unidad precedente, "j'avoue", pronunciada por Lucie dS. La sílaba "voue" tiene nivel tonal medio, situado en $240 \mathrm{~Hz}$. En cuanto a la segunda unidad, la altura tonal de Arranque y Terminación situados en la sílaba tónica "très" tiene asimismo un nivel alto (que concluye en $279 \mathrm{~Hz}$ ). En las dos unidades la hablante utiliza el Tono Referido.

\section{1 .9}

La última secuencia con la que ilustramos las elicitaciones de tipo A está compuesta por tres unidades entonativas. La misma puede definirse como una pregunta parcial y presenta una palabra interrogativa al final de la primera unidad. La joven Blanche D. cuenta una anécdota a propósito de un bar de su distrito y, en momentos en que está concluyendo la misma, su madre interviene para realizar esta elicitación: 
S37 :

Bl.D. : voilà [donc déjà d'emblée]

Entonces ya de una

$\rightarrow \quad$ R.C. : [et il est où ce $\underline{\text { bar] }}$ [ma fille?]

¿y dónde está ese bar, hija?

Bl.D. : [c'est $\underline{\text { rue }}]$ Amelot

en la calle Amelot

[11-03] Blanche_Duchemin_F_25_Reine_Ceret_F_60_11

(Líneas 374-376)

Las pruebas perceptivas con los sujetos francohablantes permitieron obtener los siguientes comentarios acerca de esta elicitación:

Elle ne sait pas. Et elle aimerait y aller, donc elle veut savoir où est le bar.

No sabe. Le gustaría ir, entonces quiere saber dónde está el bar.

Elle y est vachement intéressée "Et il est où, ce bar? ", elle demande pour aller voir.

Está súper interesada " ¿Y dónde es el bar?", pregunta para ir a ver.

Elle est intéressée, elle veut savoir où est le bar.

Está interesada. Quiere saber dónde está el bar.

Elle est curieuse. Elle montre de l'intérêt.

Tiene curiosidad. Muestra interés.

Elle demande une information supplémentaire qui montre qu'elle est intéressée par ce que dit sa fille.

Pide más información demostrando así que está interesada en lo que dice su hija.

Elle connaît pas du tout, mais elle veut savoir.

No lo conoce para nada, pero quiere saber.

Elle pose la question avec plein de curiosité. Elle veut savoir.

Hace la pregunta con mucha curiosidad. Quiere saber.

Elle lui pose une question, ça montre son intérêt.

Le hace una pregunta, eso muestra su interés.

On voit qu'elle a très envie d'y aller, alors, elle demande de lui en donner l'adresse.

Se ve que tiene muchas gansa de ir, entonces, le pide que le dé la dirección.

«Non, je te crois pas! J'ai jamais vu, comment est-ce possible! » Elle montre de

l'étonnement.

“¡No, no te creo! ¡Nunca lo vi, cómo puede ser!” Muestra sorpresa.

Elle approuve sa fille dans sa façon de parler, mais en même temps, elle attend de savoir où est le bar.

Está de acuerdo con la forma de hablar de su hija pero, al mismo tiempo, espera saber dónde está el bar. 


\section{Gráfico ${ }^{\circ} 9$}

S37 :

Bl.D. : / (A) voilà [donc déjà d'emblée]/
(R)
(R)
(P)

$\rightarrow$ R.C.: [/ (A) et il est où / (A) ce bar /] [/ (M) ma fille $/ *$ ]

BI.D. : [c'est rue] Amelot

[11-03] Blanche_Duchemin_F_25_Reine_Ceret_F_60_11 ${ }^{\mathrm{e}}$

(Líneas 374-376)

* La medición de las alturas tonales a través de PRAAT se hace imposible por los encabalgamientos de turnos.

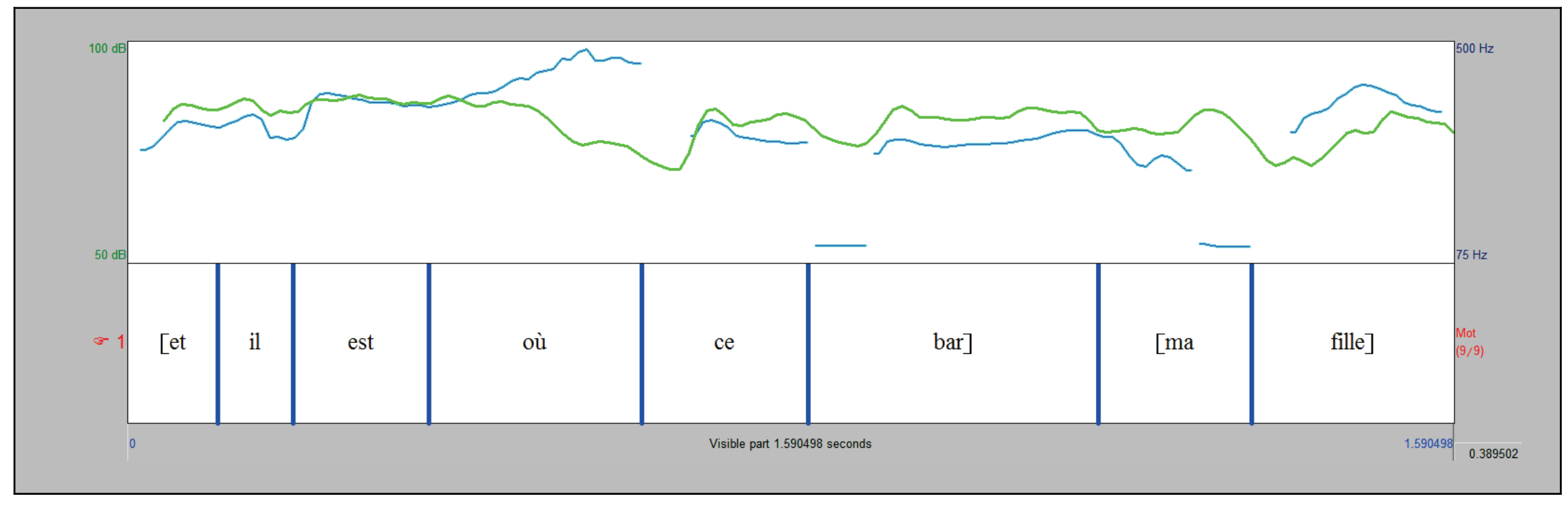


Elle n'est pas au courant sur ce que fait sa fille. C'est un peu un regret et en même temps curiosité, en même temps envie de savoir.

No está al tanto de lo que hace s hija. En cierta forma lo lamenta y, al mismo tiempo, tiene curiosidad y, al mismo tiempo, ganas de saber.

Elle veut savoir où passe ses soirées sa fille et 'ma fille' apporte de la proximité.

Quiere saber a dónde sale su hija y "hija" da más intimidad [a la intervención].

Elle lui pose la question parce qu'elle a envie de savoir. Peut-être qu'elle voudrait y aller.

Le hace la pregunta porque tiene ganas de saber. Quizá porque quiere ir.

Una vez más encontramos como ejes centrales de los significados percibidos por los sujetos:

a) La ignorancia de una información por parte del hablante: " Elle ne sait pas. " « Elle connaît pas du tout,... » « '[...] J'ai jamais vu...' » « Elle n'est pas au courant sur ce que fait sa fille. »

"No sabe." " “[...]Nunca lo vi..." "No está al tanto de lo que hace s hija."

b) El deseo de saber: «elle veut savoir où est le bar » «Elle y est vachement intéressée. " "Elle est intéressée, elle veut savoir où est le bar. " "Elle est curieuse. Elle montre de l'intérêt. » « ... elle est intéressée par ce que dit sa fille. » « ... avec plein de curiosité. Elle veut savoir. " « ... ça montre son intérêt. » « ... elle attend de savoir où est le bar. " « ... en même temps curiosité, en même temps envie de savoir. " "Elle veut savoir... "

“... quiere saber dónde está el bar." "Está súper interesada” "Está interesada. Quiere saber dónde está el bar." "Tiene curiosidad. Muestra interés." “... está interesada por lo que dice su hija." “... con mucha curiosidad. Quiere saber.” "...eso muestra su interés.” “... espera saber dónde está el bar.” “... al mismo tiempo, tiene curiosidad y, al mismo tiempo, ganas de saber." "Quiere saber ...”

c) El deseo de que su interlocutora le provea la información: « Elle demande une information supplémentaire... " " Elle pose la question 》 " Elle lui pose une question... » «... elle demande de lui en donner l'adresse. " « Elle lui pose la question... »

"Pide más información..." "Hace la pregunta" "Le hace una pregunta." "... le pide que le dé la dirección." "Le hace la pregunta..."

Presentamos a continuación las características acústicas de esta elicitación:

Como puede apreciarse en el gráfico $n^{\circ} 9$, se trata de una emisión compuesta por tres unidades tonales simples. El Arranque y la Terminación de la primera unidad, ubicados 
en la sílaba tónica "où", se realizan en nivel alto (que, recordamos, surge de la comparación de su altura tonal con la altura tonal del Arranque previo, en este caso, el de la emisión "Voilà." de Blanche D.). El nivel tonal alto se reitera en el Arranque y la Terminación de la unidad siguiente "ce bar". En tanto, la tercera y última unidad, " $m a$ fille" tiene una altura tonal Media. En los tres casos, la superposición de las intervenciones hace imposible medir las alturas de $\mathrm{F}_{0}$ en $\mathrm{Hz}$, por lo cual se recurrió únicamente al análisis perceptivo para dar cuenta de estos niveles.

En cuanto a las elecciones en el subsistema de Tono, la hablante utiliza dos Tonos Referidos y finaliza con un Tono Proclamatorio. Los corchetes del gráfico dan cuenta de que las dos primeras unidades se superponen con el turno previo de Blanche ("donc déjà d'emblée") que Reine interrumpe. Al mismo tiempo, la reacción de Blanche al pedido de información se inicia al finalizar la secuencia compuesta por las dos primeras unidades ("Et il est où, ce bar"). La joven reacciona, entonces, a las dos secuencias realizadas por Reine con Tono Referido.

El recuento de estas emisiones nos permitió determinar porcentualmente las características entonativas predominantes. Presentaremos entonces su distribución atendiendo a las realizaciones en los subsistemas de Arranque, Terminación y Tono. Para ello, operamos una simplificación en la descripción del Arranque y la Terminación, dado que las mismas fueron examinadas en detalle en la presentación de cada secuencia analizada. En esta instancia, nos referimos al Arranque que se vincula con la unidad precedente (realizada, con mayor frecuencia en nuestros datos por un hablante diferente). En las emisiones realizadas con más de una unidad, se trata únicamente del primer Arranque. Del mismo modo, consideramos la Terminación que se proyecta hacia las emisiones siguientes de otros participantes, que en emisiones extensas es la Terminación de la última unidad. 


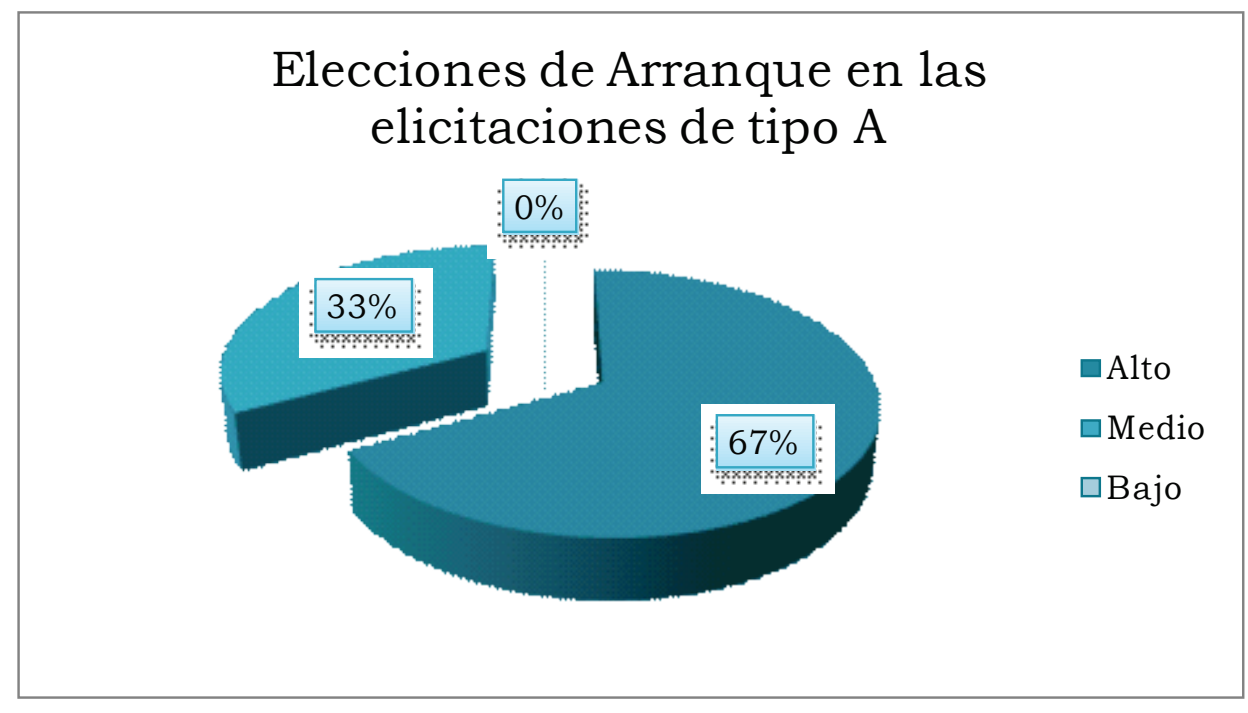

Gráfico $n^{\circ} 10$

Como podemos apreciar en el gráfico $\mathrm{n}^{\circ} 10$, el Arranque se realiza mayoritariamente en nivel alto: $67 \%$ de las ocurrencias analizadas, frente a 33\% para Arranques en nivel medio (no se registraron ocurrencias con Arranque en nivel bajo). Si se tiene en cuenta que el Arranque en nivel alto se asocia al contraste con la unidad anterior, y la elección de nivel medio evoca la adición de información, notamos que en la mayor parte de las ocurrencias el hablante podría buscar distinguir claramente la elicitación que va a formular de lo dicho anteriormente. La adición de información en forma más armónica representaría entonces la elección por defecto, debido a la ausencia en nuestros datos de elicitaciones que fueran presentadas como equivalentes a lo dicho anteriormente, significado que transmite el nivel bajo en el Arranque.

En cuanto a las elecciones realizadas en el subsistema de Terminación, en el 69\% de las emisiones estudiadas los hablantes optaron por el nivel alto, mientras que en el $31 \%$, se registraron Terminaciones en nivel medio. No se contabilizaron ocurrencias de Terminaciones en nivel bajo. Los valores mencionados pueden visualizarse en el gráfíco $\mathrm{n}^{\circ} 11$. 


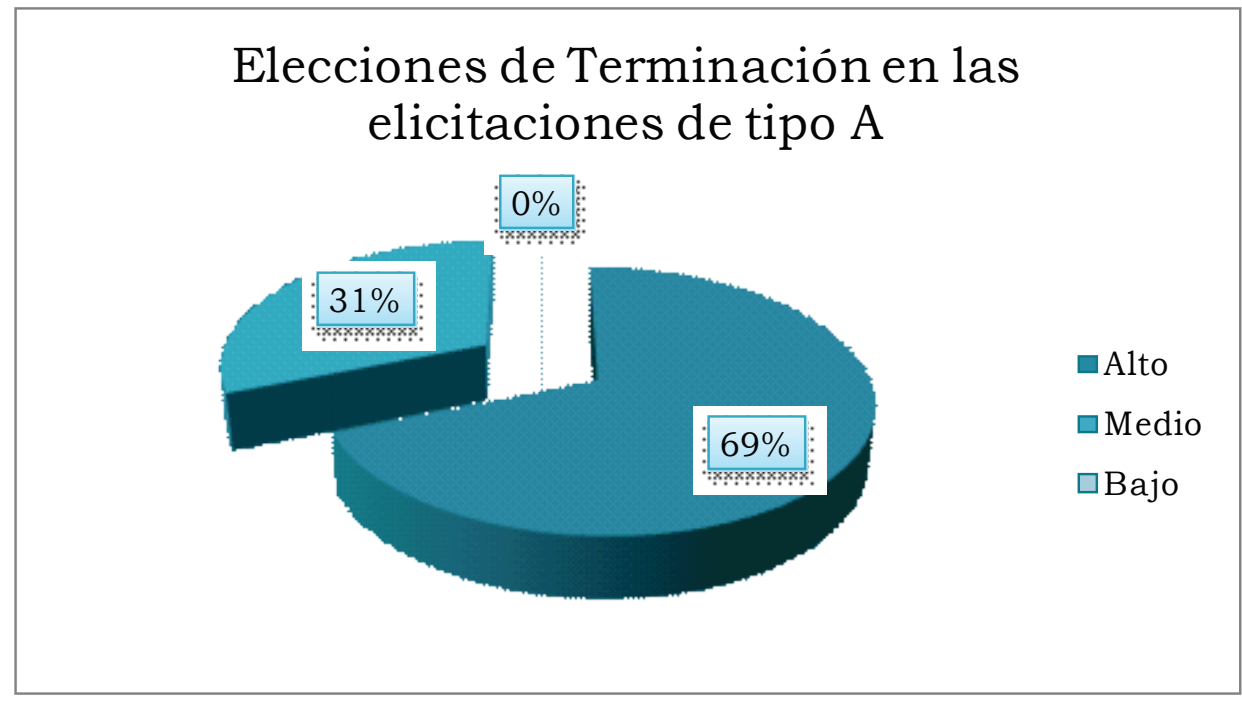

Gráfico ${ }^{\circ} 11$

La elección de una Terminación alta proyecta, recordemos, expectativas de que el interlocutor realice la emisión siguiente con un Arranque también alto. El hablante invita así a que la emisión siguiente se presente en oposición clara a otra respuesta posible. Este tipo de significados es denominado 'Adjudicación' por Brazil. Por su parte, la Terminación realizada en nivel medio, transmite expectativas de que el interlocutor concuerde con lo dicho. En el caso de las elicitaciones de información, se aprecia que el locutor espera que la información provista conserve la armonía con lo que plantea. Finalmente, dado que la Terminación en nivel bajo expresa la ausencia de expectativas respecto de a unidad siguiente, puede interpretarse que en estas elicitaciones ese significado sería contrario a la intención de obtener una información.

En las elecciones en el subsistema de Tono se aprecia mayor coincidencia que en los dos subsistemas que acabamos de presentar. En las elicitaciones presentadas en este apartado, se observa una notable coincidencia en la utilización del Tono Referido.

Hemos observado que en las solicitudes de información que agrupamos como elicitaciones de tipo A, se evidencia una gran variedad de configuraciones sintácticas y emisiones con diferente extensión. Como reseñáramos al principio de ese apartado, la literatura atribuye a estas variedades diferentes patrones entonativos relacionados fundamentalmente con el movimiento melódico y asociados específicamente con la estructura sintáctica de que se trate (descrito en la bibliografía mencionada al iniciar la presentación de las elicitaciones). La mayor parte de los autores asocian el significado atribuido a la pendiente melódica ascendente con la estructura sintáctica de las 
denominadas preguntas totales o preguntas parciales que concluyen con una palabra interrogativa (ver cuadro $n^{\circ} 6$ del Estado de la cuestión).

Los resultados obtenidos en el análisis de nuestros datos muestran que el significado general que transmite la curva entonativa ascendente es el de ignorancia de la información que se solicita. Se evidencia así que el significado que agrega la curva entonativa descrita se aplica a cualquier configuración léxico-gramatical que cumpla la función de elicitación de información. 


\subsection{Elicitaciones de tipo B}

En el conjunto de las emisiones que buscan generar información, se detectó un grupo cuyas interpretaciones no coinciden con las obtenidas para las elicitaciones de tipo A. Aunque la cantidad de ocurrencias en este grupo es menor, las regularidades en los significados detectados por los sujetos permiten identificarlo claramente como un subconjunto con características propias que detallaremos a continuación.

\section{2 .1}

Examinaremos en primer lugar una emisión realizada con una unidad tonal simple. Una hablante interviene en un intercambio en el que sus interlocutoras intentan precisar el tiempo transcurrido desde la muerte de un ex intendente de su comuna. Luego de que Louise L. y Anne realizaran su contribución, Jeanne M. reacciona por medio de una intervención cuya entonación es descendente:

S69:

L.L. : oh oui il y a [une quarantaine d'années]

oh sí, hace [unos cuarenta años]

An.: [à peu près]

más o menos

L.L. : oui

sí

$\rightarrow \quad$ J.M. : [tant que ça ?]

¿Tantos?

M.P. : $[\mathrm{mm}]$

$\mathrm{mhm}$

CFPP2000 [SO-01] Louise_Liotard_F_85_et_Jeanne_Mallet_F_75_SO

(Líneas 816-818)

Cabe precisar que Mat P., el entrevistador, interviene superponiéndose al comentario de Jeanne [" $\mathrm{mm}$ "], como lo indican los corchetes.

Consultados por la interpretación que dan a esta emisión, los sujetos realizaron los siguientes comentarios:

Elle ne pensait pas que c'était il y a si longtemps.

No creía que fuera hace tanto tiempo.

Elle demande, mais elle pense le contraire. 
Pegunta, pero piensa lo contrario.

Elle n'arrive pas à réaliser que tout ce temps c'est écoulé.

No logra tomar conciencia de que pasó todo ese tiempo.

Elle n'est pas si sûre de ça.

No está tan segura de eso.

Elle demande de confirmer parce qu'elle est surprise.

Pide que le confirmen porque está sorprendida.

Elle met l'interrogative à la fin, mais on pourrait dire que c'est de la surprise.

Pone un punto de interrogación al final. Podría decirse que es sorpresa.

Il y a une espèce d'incrédulité à accepter le fait que le temps passe très vite.

Hay una especie de incredulidad en aceptar el hecho de que el tiempo pasa muy rápido.

On sent qu'elle est sceptique. Elle n'y croit pas.

Se siente que es incrédula. Ella no lo cree.

Pas tellement dans le genre question, mais plutôt « $\mathrm{mm} \mathrm{mm}$, pas une quarantaine d'années. Tu te trompes. »

No tanto en la categoría pregunta, sino « $\mathrm{mm} \mathrm{mm}$, no unos cuarenta años. Te equivocás."

Elle n'est pas sûre que ce soit vraiment pour ces années-là. Elle met en doute la parole de la dame qui sort l'information.

No está segura de que sea realmente por esos años. Pone en duda la palabra de la mujer que da la información.

Elle n'a pas vu le temps passer, "je ne pensais pas que c'était si loin ».

No vio pasar el tiempo, "no creí que hubiera pasado tanto tiempo".

Podemos apreciar que los significados percibidos giran en torno a los ejes que detallamos a continuación:

a) La hablante pone de manifesto un desfasaje entre la información que recibe y la que tiene en mente: "Elle ne pensait pas que c'était il y a si longtemps. " "Elle n'arrive pas à réaliser... "Elle n'a pas vu le temps passer. 'je ne pensais pas que c'était si loin'»

"No creía que fuera hace tanto tiempo." "No logra tomar conciencia de..." "No vio pasar el tiempo, "no creí que hubiera pasado tanto tiempo."'

b) La hablante pide una confirmación: " Elle demande de confirmer... » "Pide que le confirmen..."

c) La hablante tiene una idea de la información que solicita: «... elle pense le contraire. » «Elle n'est pas si sûre de ça. » «Il y a une espèce d'incrédulité... » «On sent qu'elle est sceptique. " «Elle n'y croit pas.» "'Mm mm, pas une quarantaine d'années. Tu te trompes.'” 
Gráfico $n^{\circ} 12$

S69 :

L.L. : oh oui il y a [une quarantaine d'années]

An.: [à peu près]

L.L. : /(M) $\underline{\text { oui }}(174) /$

(P)

$\rightarrow \quad$ J.M. : [/(A) tant que ça $(209) /]$

CFPP2000 [SO-01] Louise_Liotard_F_85_et_Jeanne_Mallet_F_75_SO

(Líneas 816-818)

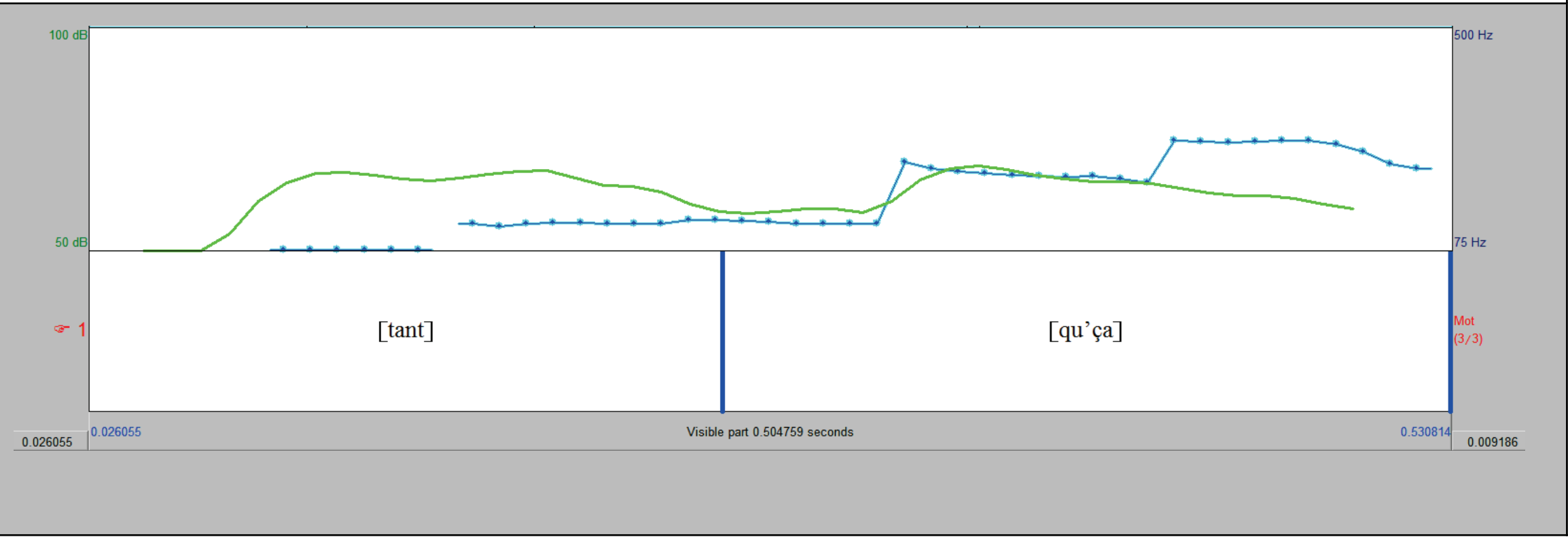


«Elle n'est pas sûre que ce soit vraiment pour ces années-là. » "Elle met en doute la parole de... »

"... piensa lo contrario." "No está tan segura de eso." "Hay una especie de incredulidad..." "se siente que es escéptica" "No lo cree." "'mm mm, no unos cuarenta años. Te equivocás." "No está segura de que sea realmente por esos años. Pone en duda la palabra de..."

Los resultados del análisis acústico, presentados en el gráfico ${ }^{\circ} 12$, señalan que se trata de una unidad tonal simple, ya que consta de una única sílaba prominente, la sílaba tónica "ça". La altura tonal del Arranque y la Terminación tiene un nivel alto, que concluye en $209 \mathrm{~Hz}$, muy por encima de los $174 \mathrm{~Hz}$ de la unidad precedente de Louise. El tono utilizado por la hablante es Proclamatorio.

Recordemos que este tipo de emisiones es descrito en la bibliografía bajo el rótulo de preguntas totales y se las asocia con un patrón entonativo ascendente. La emisión que analizamos en el apartado siguiente podría agruparse en la misma categoría.

\section{2 .2}

En esta secuencia, la entrevistadora ha solicitado información acerca de alimentos exóticos que las entrevistadas hayan descubierto en su distrito. Ante esta solicitud, Adèle realiza a su vez una elicitación de información:

S20:

F.L. : des aliments des fruits un peu exotiques ou des euh: Alimentos frutas un poco exóticos o eh...

$\rightarrow \quad$ A. : des choses nouvelles ? + +

¿Cosas nuevas?

[CFPP2000] [07-02] Lucie_da_Silva_F_22_7

(Líneas 177-179)

Interrogados acerca de esta emisión, los participantes de las pruebas perceptivas manifestaron los significados que enumeramos a continuación:

Elle n'a pas compris la question. Elle pense que c'est impossible de trouver quoi que ce soit de nouveau.

No entendió la pregunta. Piensa que es imposible encontrar algo nuevo.

Soit elle se dit 'j'ai pas compris la question' soit elle a compris, mais elle se dit 'Pourquoi elle demande ça?'

O bien se dice 'no entendí la pregunta' o bien entendió, pero se dice ‘¿Por qué pregunta eso?'

Elle ne comprend pas du tout la question. Ça ne lui paraît pas pertinent.

No comprende para nada la pregunta. No le parece pertinente. 
C'est une question qui paraphrase ce qu'a dit l'autre.

Es una pregunta que parafrasea lo que dijo la otra.

Elle a besoin de savoir si vraiment c'est ça « est-ce que j'ai bien compris?».

Necesita saber si realmente es eso « ¿Comprendí bien?"

Elle résume et elle demande la confirmation à l'intervieweuse.

Resume y pide la confirmación a la entrevistadora.

Elle fait office d'interprète, elle cherche à faciliter la transmission du message pour que les autres comprennent ce que l'intervieweuse veut savoir.

Hace oficio de intérprete, busca facilitar la transmisión del mensaje para que las demás comprendan lo que la entrevistadora quiere saber.

Elle exprime la surprise par rapport à la question posée.

Expresa la sorpresa respecto de la pregunta que le hicieron.

Elle a bien compris la question, mais elle cherche à faciliter la compréhension du message.

Entendió bien la pregunta, pero busca facilitar la comprensión del mensaje.

Elle essaie de voir un peu où veut en venir l'intervieweuse. Elle essaie d'aller un peu dans la direction de l'intervieweuse.

Trata de entender adónde quiere llegar la entrevistadora. Trata de ir en el mismo sentido que la entrevistadora.

Elle n'a pas compris la question, elle demande des explications. Elle demande à ce que l'intervieweuse soit un peu plus explicite.

No entendió la pregunta, pide explicaciones. Pide que la entrevistadora sea más explícita.

On voit que la question a été ratée, que la fille n'a pas compris.

Se ve que la pregunta fue fallida, que la chica no comprendió.

Elle demande une confirmation. "Tu me demandes sur les choses nouvelles, c'est ça?»

Pide una confirmación. “¿Me preguntás acerca de las cosas nuevas, es eso?”

C'est un étonnement par rapport à la question. Ça ne lui est même pas venu à l'esprit.

Es un desconcierto con respecto a la pregunta. Eso ni si quiera se le cruzó por la cabeza.

Elle veut que l'intervieweuse lui confirme si elle doit répondre sur des choses nouvelles.

Quiere que la entrevistadora le confirme si tienen que responder acerca de cosas nuevas.

Los sujetos manifiestan que la hablante busca una confirmación por parte de la entrevistadora: "Elle a besoin de savoir si vraiment c'est ça 'est-ce que j'ai bien compris?' " « ... elle demande la confirmation à l'intervieweuse. » " Elle demande une confirmation 'Tu me demandes sur les choses nouvelles, c'est ça?' " "Elle veut que l'intervieweuse lui confirme si... » (“Necesita saber si realmente es eso ‘Comprendí bien?” 
Gráfico $n^{\circ} 13$

S20:

F.L.: des aliments des fruits un peu exotiques/(M) ou des euh (180)/

(P)

$\rightarrow \quad$ A. : /(A) des choses nouvelles (219)/

[CFPP2000] [07-02] Lucie_da_Silva_F_22_7

(Líneas 177-179)

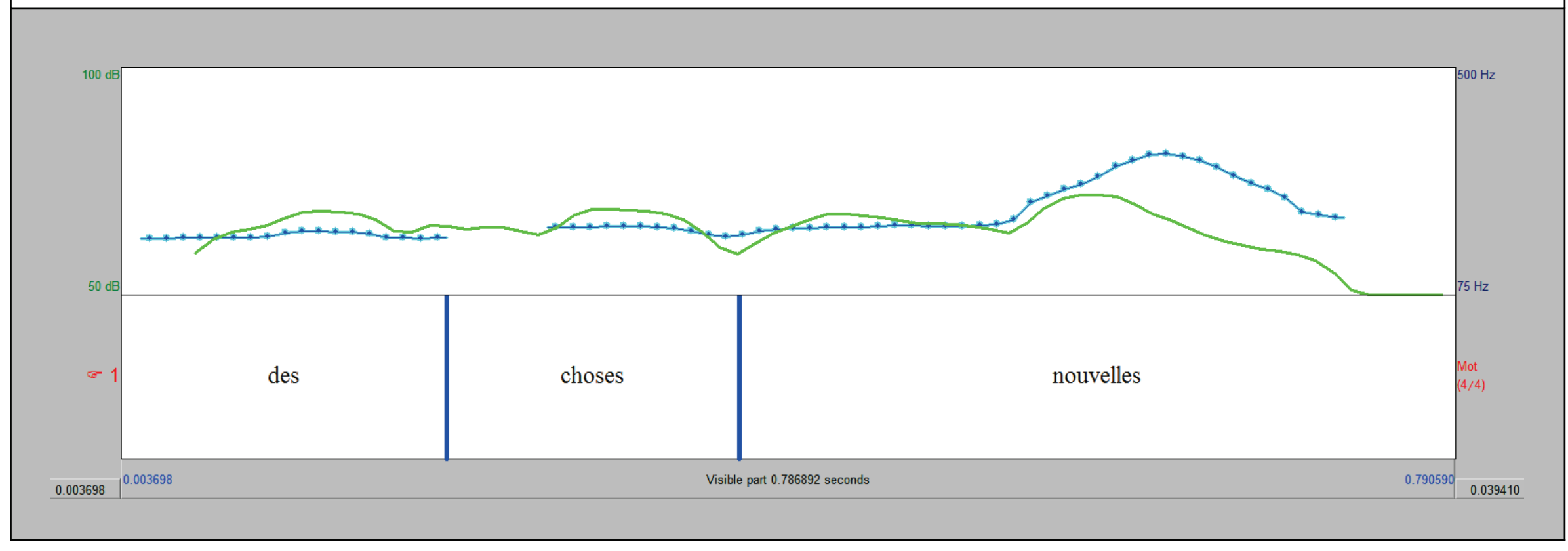


“...pide la confirmación a la entrevistadora." "Pide una confirmación. ‘¿Me preguntás acerca de las cosas nuevas, es eso?"” "Quiere que la entrevistadora le confirme si...")

Algunos sujetos señalan el hecho de que la hablante propone algo a la consideración de la entrevistadora a fin de que ésta apruebe o especifique su pedido: «C'est une question qui paraphrase ce qu'a dit l'autre. " "Elle fait office d'interprète, elle cherche à faciliter la transmission du message... » «Elle essaie d'aller un peu dans la direction de l'intervieweuse. \ (Es una pregunta que parafrasea lo que dijo la otra." "Hace oficio de intérprete, busca facilitar la transmisión del mensaje..." "Trata de ir en el mismo sentido que la entrevistadora.")

En varias oportunidades, se hace referencia a la falta de comprensión de la hablante que realiza la elicitación. Pero sólo en una de las interpretaciones, se entiende que, en verdad, la información no se ha concretado. El resto de las apreciaciones que citan la falta de comprensión, se asocian con el desconcierto entre lo que se entendió, y el grado de pertinencia que se atribuye a aquello que se entendió: «Elle n'a pas compris la question. Elle pense que c'est impossible de trouver quoi que ce soit de nouveau. " «Soit elle se dit 'j'ai pas compris la question' soit elle a compris, mais elle se dit 'Pourquoi elle demande ça?'》 "Elle ne comprend pas du tout la question. Ça ne lui paraît pas pertinent. » «C'est un étonnement par rapport à la question. Ça ne lui est même pas venu à l'esprit. »

"No entendió la pregunta. Piensa que es imposible encontrar algo nuevo." "O bien se dice "no entendí la pregunta' o bien entendió, pero se dice ‘¿Por qué pregunta eso?"' "No comprende para nada la pregunta. No le parece pertinente." "Es un desconcierto con respecto a la pregunta. Eso ni si quiera se le cruzó por la cabeza."

De este modo, se desprende que, mayoritariamente, los comentarios de los sujetos sugieren que la hablante posee una determinada idea de la respuesta que espera obtener por parte de la entrevistadora.

Como puede observarse en el gráfico $\mathrm{n}^{\circ} 13$, el análisis acústico determinó que Adèle realiza su emisión en una única unidad entonativa simple. Tanto el Arranque como la Terminación se producen sobre la sílaba prominente de la unidad, "velles", y exhiben un nivel alto (la curva melódica alcanza los $337 \mathrm{~Hz}$ y culmina en $219 \mathrm{~Hz}$ ). Se observa un claro contraste con la altura tonal baja del Arranque y la Terminación de la unidad precedente (“ou des euh") pronunciada por la entrevistadora, situada en $180 \mathrm{~Hz}$. El Tono utilizado es Proclamatorio. 
Las emisiones analizadas hasta ahora constan de una unidad tonal simple. En el apartado que sigue, nos ocuparemos de una elicitación realizada en una unidad tonal extendida.

\section{2 .3}

En momentos en que Blanche D. relata una anécdota, su padre, Jean-Pierre, interviene para realizar la siguiente elicitación de información:

S32 :

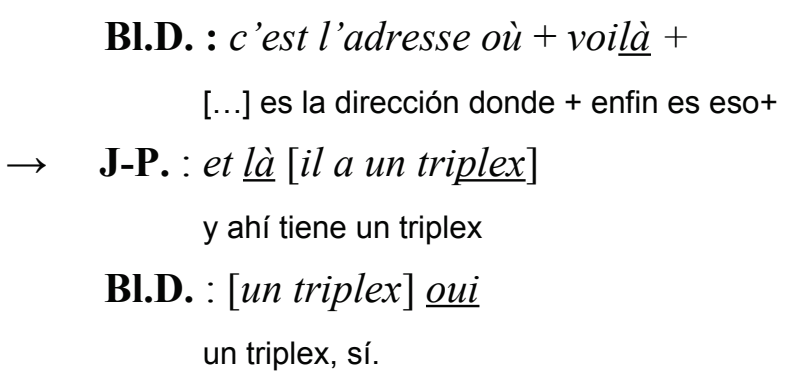

[CFPP2000] [11-03] Blanche_Duchemin_F_25_Reine_Ceret_F_60_11 $1^{\mathrm{e}}$

(Líneas 276-277)

Luego de escuchar esta secuencia, los sujetos participantes de las pruebas perceptivas aportaron las siguientes impresiones acerca de la elicitación de Jean-Pierre:

Il est étonné et demande à sa fille de confirmer ce qu'elle avait dit.

Está asombrado y pide a su hija que confirme lo que había dicho.

Il demande une confirmation.

Pide una confirmación.

Il exprime un tout petit peu de fascination. En même temps, Le fait de marquer ta surprise normalement ça amène l'autre à expliquer un peu.

Expresa un poquitito de fascinación. Al mismo tiempo, el hecho de mostrar tu sorpresa normalmente lleva al otro a explicar un poco.

Il hallucine, le père. Il montre qu'il est surpris.

Está alucinando, el padre. Muestra que está sorprendido.

Il demande de confirmer si on a bien compris. C'est un commentaire qui aide à clarifier pour le reste des personnes.

Pide que le confirmen si se entendió bien. Es un comentario que ayuda a clarificar para el resto de las personas.

C'est l'étonnement, on voit qu'il est surpris. On voit qu'il est presque sceptique. On dirait qu'il a besoin qu'on lui reconfirme vraiment cette information.

Es asombro, se ve que está sorprendido. Se ve que casi no le cree. Pareciera que necesita que le reconfirmen otra vez realmente esa información.

C'est plutôt de la surprise. 
Es más bien sorpresa.

Il veut confirmer.

Quiere confirmar.

Le ton c'est pour confirmer ce que dit sa fille. Il veut qu'elle confirme.

El tono es para confirmar lo que dice su hija. Quiere que ella confirme.

Il reprend ce que dit sa fille pour que sa fille lui confirme bien, qu'il a bien entendu. Il y a un peu d'étonnement que sa fille connaisse ce milieu.

Retoma lo que dijo su hija para que su hija le confirme bien que oyó bien. Hay un poco de asombro por el hecho de que su hija conozca ese medio.

Ce qu'il dit, c'est plutôt « Et ben, dis-donc, vraiment il a un triplex ? 》

Lo que dice es más bien "Eh, decime, ¿realmente tiene un triplex?"

Puede observarse que los sujetos son sensibles a los siguientes significados transmitidos por la emisión:

a) El hablante solicita una confirmación de la información: "Il est étonné et demande à sa fille de confirmer ce qu'elle avait dit. " "Il demande une confirmation. " "Il demande de confirmer si on a bien compris. " «On dirait qu'il a besoin qu'on lui reconfirme vraiment cette information. " «Il veut confirmer. " "Le ton c'est pour confirmer ce que dit sa fille. Il veut qu'elle confirme. " "Il reprend ce que dit sa fille pour que sa fille lui confirme bien... » "Está asombrado y pide a su hija que confirme lo que había dicho." "Pide una confirmación." "Pide que le confirmen si se entendió bien." "Pareciera que necesita que le reconfirmen realmente esa información." "El tono es para confirmar lo que dice su hija. Quiere que ella confirme." "Retoma lo que dijo su hija para que su hija le confirme bien..."

b) El hablante tiene una idea del tipo de respuesta que solicita: « Ce qu'il dit, c'est plutôt 'Et ben, dis-donc, vraiment il a un triplex?' »

"Lo que dice es más bien 'Eh, decime, ¿realmente tiene un triplex?”

En más de una oportunidad, los sujetos evocaron significados asociados con la sorpresa («Il est étonné... " "Il hallucine, le père. Il montre qu’il est surpris. " "C'est l'étonnement, on voit qu'il est surpris. » «C'est plutôt de la surprise. " «Il y a un peu d'étonnement $\ldots »^{1}$ ). Este significado no es generalizable, pero es interesante lo que uno de los sujetos expresa acerca del mismo: «Il exprime un tout petit peu de fascination. En même temps, le fait de marquer ta surprise normalement ça amène l'autre à

\footnotetext{
1 “Está asombrado..." "Está alucinando, el padre. Muestra que está sorprendido." "Es asombro, se ve que está sorprendido." "Es más bien sorpresa." "Hay un poco de asombro..."
} 
Gráfico ${ }^{\circ} 14$

S32 :

BI.D. : /(M) voilà (203)/

(P)

$\rightarrow$ J-P. : / (A) et là (228) il a [un triplex (111) (M) /]

Bl. D. : [un tri]plex oui

[CFPP2000] [11-03] Blanche_Duchemin_F_25_Reine_Ceret_F_60_11 (Líneas 276-277)

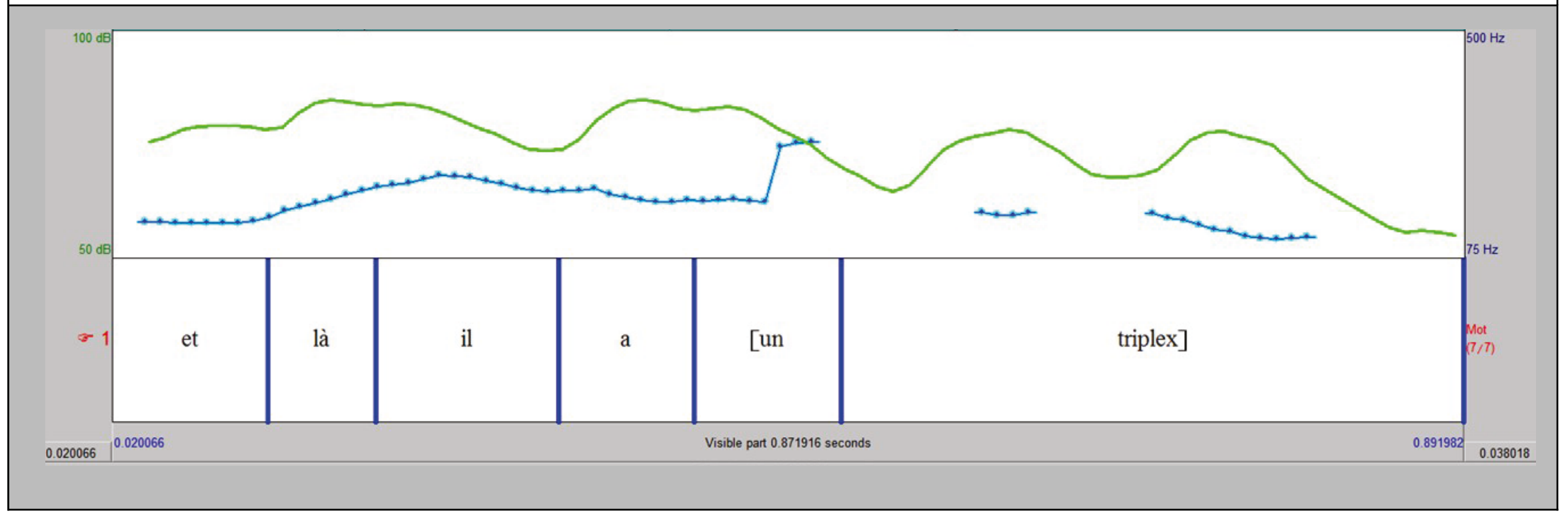


expliquer un peu. $»^{2}$ La relación entre la expresión de la sorpresa y la búsqueda de confirmación fue puesta de manifiesto en las pruebas perceptivas a propósito de otras elicitaciones similares.

Como adelantáramos al inicio de este párrafo, el análisis acústico permitió determinar que el hablante realizó esta elicitación en una unidad tonal extendida (ver gráfico $\mathrm{n}^{\circ} 14$ ). El Arranque de la unidad precedente, que corresponde al ítem "voilà" (203 Hz) pronunciado por Blanche D., tiene un nivel medio. Cotejándolo con esta unidad, vemos el Arranque de la emisión de Jean-Pierre, realizado sobre el ítem "là" es alto y alcanza los $228 \mathrm{~Hz}$. En tanto, la Terminación situada en la sílaba tónica "plex" tiene un nivel tonal medio (situado en $111 \mathrm{~Hz}$ ). El Tono elegido por el hablante es Proclamatorio.

Como señaláramos en otra oportunidad (5.1.7), la evocación frecuente de la sorpresa expresada en esta emisión puede vincularse con la elección de un nivel tonal alto del Arranque. Tanto en inglés (Brazil, 1995) como en español (Granato 2005), se ha señalado que la elección de un nivel alto en el Arranque vehiculiza un significado general de contraste. Teniendo en cuenta significados de otros niveles de análisis lingüístico y elementos propios del conocimiento del mundo de los hablantes (en este caso, la ubicación geográfica de la plaza citada, el estatuto socioeconómico del $16^{\circ}$ distrito de París, los valores de los inmuebles ubicados allí), los hablantes asocian este significado general con el significado más local de sorpresa.

\section{2 .4}

En esta secuencia, Florence L. ha solicitado información acerca de determinados productos disponibles en el mercado. Cuando las entrevistadas finalizan su intervención, ella realiza la elicitación que exponemos a continuación:

S 22:

$$
\begin{aligned}
& \text { F. : ouais } \\
& \text { se } \\
& \text { F.L. : d'accord }+ \\
& \text { de acuerdo }+ \\
& \text { autre } \underline{\text { chose }}+\underline{\text { non }} \\
& \text { otra cosa }+ \text { no }
\end{aligned}
$$

\footnotetext{
2 "Expresa un poquitito de fascinación. Al mismo tiempo, el hecho de mostrar tu sorpresa normalmente lleva al otro a explicar un poco."
} 
Las pruebas perceptivas arrojaron los siguientes datos a propósito de la elicitación de información de Florence L.:

C'est une question.

Es una pregunta.

Elle demande s'il y a autre chose " que vous voudriez dire là-dessus ».

Ella pregunta si hay otra cosa "que ustedes quisieran decir sobre eso".

Elle pose la question. "Vous n'avez rien trouvé d'autre? "Un peu pour les provoquer, pour qu'elles parlent.

Hace la pregunta "¿No encontraron ninguna otra cosa?" Un poco para incitarlas a que hablen.

Elle leur demande, mais pour elle, elles n'ont rien découvert d'autre.

Les pregunta, pero cree que no descubrieron nada más.

Elle attend une réponse et elle pose la question par la négative. Elle s'imagine déjà qu'elles vont dire «non ».

Espera una respuesta y hace la pregunta por la negativa. Ya se imagina que van a decir "no".

C'est une question fermée. Elle est presque sûre qu'on a fait déjà le tour de la question, elle veut juste se rassurer.

Es una pregunta cerrada. Está casi segura de que ya se agotó el tema, sólo quiere asegurarse.

C'est pour dire que c'est fini, la conversation est terminée et elle attend que l'autre dise 'oui'.

Es para decir que se terminó, la conversación se terminó y espera que la otra diga "si".

Elle demande.

Pregunta.

Elle clôt pour passer à la question suivante. Avec la question, elle propose de passer à autre chose.

Cierra para pasar a la pregunta siguiente. Con la pregunta, propone pasar a otra cosa.

Elle demande une confirmation (si c'est vrai qu'on a fait le tour de la question).

Pide una confirmación (si es cierto que se agotó la pregunta).

Elle essaie de laisser un ton ouvert tout en fermant. "Autre chose, non? " l'air de dire "il y a rien d'autre. "

Trata de dejar un tono abierto aún cuando está cerrando. "¿Otra cosa?, no" como diciendo "No hay nada más."

En estos comentarios, se ponen de relieve dos significados generales a los cuales los sujetos fueron sensibles: 
Gráfico ${ }^{\circ} 15$

S22 :

F.L. : /(M) d'accord (194)/

$$
\text { (R) (P) }
$$

$\rightarrow \quad /(\mathrm{A})$ autre chose $(287) /(\mathrm{M})$ non $(187) /$

[CFPP2000] [07-02] Lucie_da_Silva_F_22_7

(Líneas 195-196)

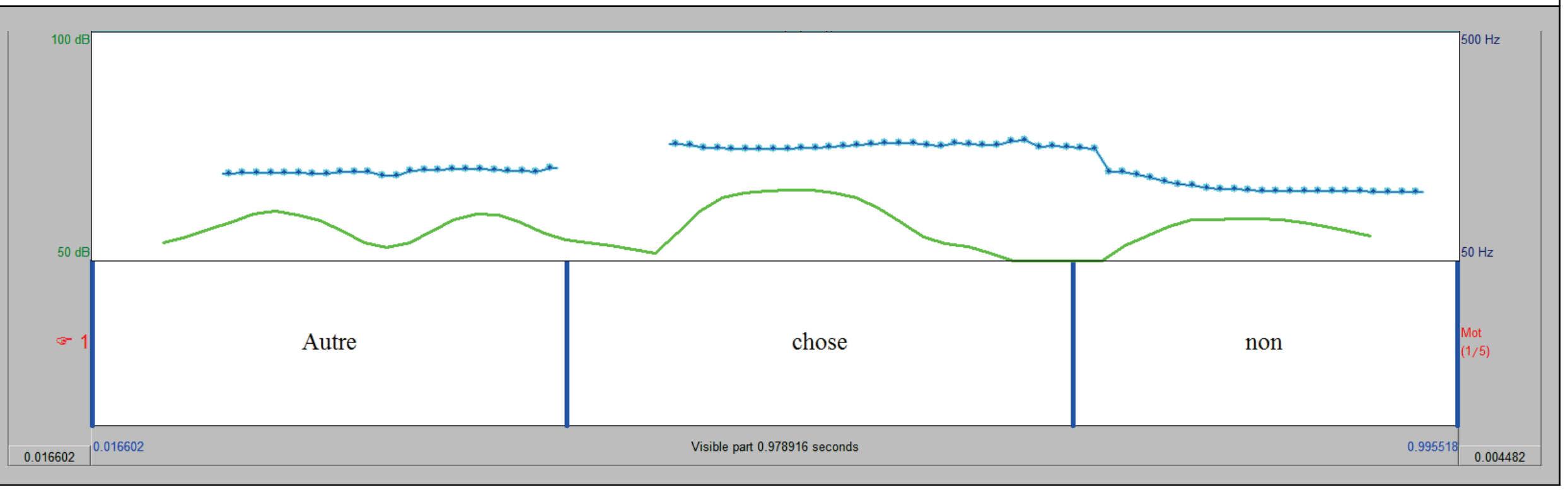


a. La entrevistadora solicita una información a sus entrevistadas: "C'est une question. " "Elle demande s'il y a... " «Elle pose la question. " «Elle leur demande, ... » «Elle attend une réponse...»

"Es una pregunta." "Ella pregunta si hay..." "Hace la pregunta." "Les pregunta, ..." "Espera una respuesta, ..."

b. La entrevistadora tiene una determinada respuesta in mente para la elicitación que realiza: « ... mais pour elle, elles n'ont rien découvert d'autre. » " Elle s'imagine déjà qu'elles vont dire 'non'. " «C'est une question fermée. Elle est presque sûre qu'on a fait déjà le tour de la question, elle veut juste se rassurer. $»$ »... elle attend que l'autre dise 'oui'... » « Elle demande une confirmation (si c'est vrai qu'on a fait le tour de la question). " «Elle essaie de laisser un ton ouvert tout en fermant. 'Autre chose, non ?' l'air de dire 'il y a rien d'autre.'” “ ...pero cree que no descubrieron nada más." "Ya se imagina que van a decir "no." "Es una pregunta cerrada. Está casi segura de que ya se agotó el tema, sólo quiere asegurarse." “... espera que la otra diga 'sí'." "Pide una confirmación (si es cierto que se agotó la pregunta)." “Trata de dejar un tono abierto aún cuando está cerrando. ‘¿Otra cosa?, no’ como diciendo 'No hay nada más."”

En cuanto a las características acústicas, Florence L. realiza la elicitación de información en dos unidades entonativas simples, como vemos en el gráfico $\mathrm{n}^{\circ} 15$. El Arranque y la Terminación de la primera unidad, realizados sobre la sílaba tónica "chose" tienen un nivel alto $(287 \mathrm{~Hz})$. El mismo surge del cotejo con la emisión precedente de la misma hablante "d'accord" cuyo Arranque tiene un nivel medio (194 Hz). La segunda unidad presenta un Arranque y una Terminación realizados en nivel medio sobre el ítem léxico "non" (187 Hz). La hablante elige el Tono Referido para la primera unidad y el Tono Proclamatorio para la segunda.

Puede observarse que los significados agrupados en el apartado (a) se asemejan a los significados que prevalecen en las elicitaciones con respuesta no conocida analizados en el capítulo anterior, en las que es constante la elección del Tono Referido. En tanto, los significados incluidos en el apartado (b) son afines a los que se evocaron en forma predominante en las emisiones analizadas en el presente capítulo. Es posible que las divergencias entre estas interpretaciones se deban a que los sujetos respondieron o bien al Tono Referido de la primera unidad, o bien al Tono Proclamatorio de la segunda. No obstante, son los significados asociados con el pedido de confirmación los que se 
imponen, lo cual permite inferir que, en la percepción de los sujetos, prevaleció la realización de Tono con la que Florence finaliza su emisión.

\section{2 .5}

Examinamos a continuación una emisión realizada también en dos unidades tonales simples. Este fragmento tiene lugar cuando Jeanne M. describe el pueblo de su infancia. El comentario de que viajó allí hace poco tiempo, motiva la siguiente intervención de Anne:

S65:

J.M. : j'y suis allée donc lundi dernier fui entonces el lunes pasado

L.L. : $(X X X)$

$\rightarrow \quad$ A. : mais ça a dû changer hein depuis

Pero debe haber cambiado eh desde entonces

CFPP2000 [SO-01] Louise_Liotard_F_85_et_Jeanne_Mallet_F_75_SO

(Líneas 767-769)

Las pruebas perceptivas realizadas sobre esta emisión arrojaron las siguientes consideraciones:

Elle présente une évidence.

Presenta una evidencia.

Elle cherche une confirmation. Elle cherche à savoir ce qui a changé.

Busca una confirmación. Busca saber lo que cambió.

Elle imagine bien que ça a changé parce que les gens quittent la campagne.

Ya se imagina que cambió porque la gente está abandonando el campo.

C'est comme une remarque, mais elle pose une question. C'est orienté.

Es como una observación, pero hace una pregunta. Está orientada.

Elle pose la question avec une petite note d'humour peut-être.

Hace la pregunta con una pequeña nota de humor quizá.

C'est un genre de question qui n'en est pas une. C'est ce genre de lieu commun qui appelle à la complicité. Plus qu'une vraie question sur ce sujet-là, c'est une manière de faire un lien dans la conversation.

Es un tipo de pregunta que en realidad no es tal. Es ese tipo de lugar común que llama a la complicidad. Más que una verdadera pregunta sobre ese tema, es una manera de establecer un vínculo en la conversación.

Elle attend une réponse avec le « hein?».

Espera una respuesta con el « ¿eh ?»

Elle pose la question mais elle connaît déjà la réponse. 
Gráfico ${ }^{\circ} 16$

S 65:

J.M. : /(B) j'y suis allée (124) donc lundi dernier (197) (M)/

L.L. : $(\mathrm{XXX})$

$\rightarrow$ A. : / (A) mais ça a dû changer (249) / (M) hein depuis (160) /

CFPP2000 [SO-01] Louise Liotard F 85 et Jeanne Mallet F 75 SO (Líneas 767-769)

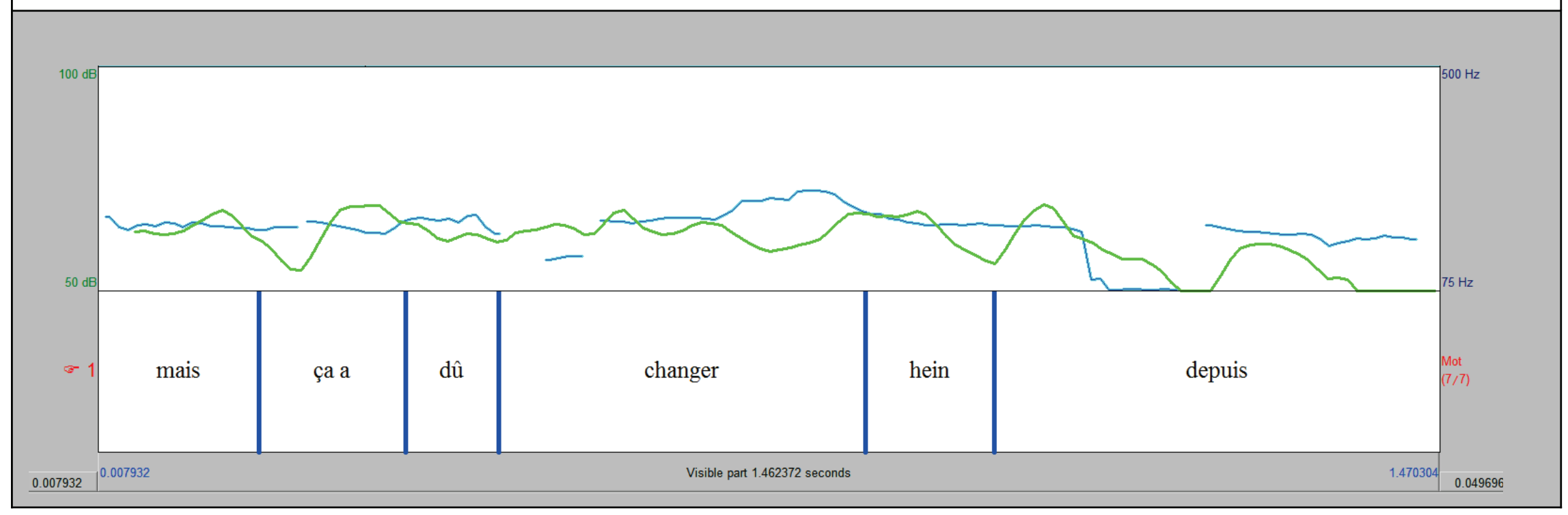


Hace una pregunta, pero ya conoce la respuesta.

Elle s'imagine bien la scène et elle demande une confirmation. "Je suis sûre à 100\% que tu vas me répondre 'oui'. "

Se imagina claramente la escena y pide una confirmación. "Estoy $100 \%$ segura de que me vas a responder 'si'”'.

Dans l'intonation, c'est pas qu'elle connaît le lieu mais elle fait une déduction avec l'âge qu'elles ont.

Por la entonación, no es que conoce el lugar sino que hace una deducción en función de la edad que tienen.

Elle suppose que ça a changé, comme partout.

Supone que cambió, como en todas partes.

Las interpretaciones citadas hacen referencia a las siguientes situaciones:

a) La hablante conoce o cree conocer la respuesta. «Elle présente une évidence. » «Elle imagine bien que ça a changé... " « ... elle connaît déjà la réponse. » « ... 'je suis sûre à 100\% que tu vas me répondre oui'. " « Elle s'imagine bien la scène... » « ... elle fait une déduction... » « Elle suppose que ça a changé... ».

"Presenta una evidencia." "Busca una confirmación." "Ya se imagina que cambió..." “...ya conoce la respuesta." "Estoy $100 \%$ segura de que me vas a responder "sí". "Se imagina claramente la escena..." "... hace una deducción..." "Supone que cambió..."

b) La hablante busca un tipo determinado de respuesta: "Elle cherche une confirmation. » en dos oportunidades «C'est orienté. » «C'est ce genre de lieu commun qui appelle à la complicité. »

"Busca una confirmación" "Está orientada." "Es ese tipo de lugar común que llama a la complicidad."

c) La hablante busca de todas formas que el interlocutor responda. «Elle pose la question... » «Elle attend une réponse... »

"Hace la pregunta, ..." "Espera una respuesta..."

El análisis acústico, que puede apreciarse en el gráfico $n^{\circ} 16$, permite observar que la elicitación está compuesta por dos unidades tonales simples. El Arranque y la Terminación de la primera unidad, situados en la sílaba tónica "ger", tienen un nivel alto y se ubican en $249 \mathrm{~Hz}$ (recordemos que el nivel alto se determina a partir del cotejo de esta unidad con el Arranque de la unidad anterior, "j’y suis allée donc lundi dernier" pronunciada por Jeanne, donde la $\mathrm{F}_{0}$ se sitúa en $124 \mathrm{~Hz}$ ). En cuanto a la segunda unidad, su Arranque y su Terminación, sobre la sílaba tónica "puis", se realizan en nivel bajo y 
culminan a una altura de $160 \mathrm{~Hz}$. En cuanto a las elecciones en el subsistema de Tono, Anne reitera en las dos unidades el Tono Proclamatorio.

Puede apreciarse que, en este caso, las interpretaciones han sido más coincidentes entre sí que las que analizamos para la emisión de 5.2.4. Esto puede vincularse al hecho de que, en esta emisión, los dos Tonos realizados son Proclamatorios.

\section{2 .6}

Para concluir con el análisis de este grupo de elicitaciones de información, presentamos una emisión más extensa, compuesta por tres unidades tonales. Como en la totalidad de las emisiones presentadas hasta ahora en este capítulo, la intervención exhibe una entonación final descendente. En momentos en que la entrevistada describe su forma de hablar, Sonia B. interviene para realizar la siguiente elicitación:

S 35:

B.D. : non de parler oui très différent aussi + c'est $\underline{\underline{\hat{u}} r}+c$ 'est $\underline{\mathrm{s} \hat{u} r}$ No de hablar sí muy diferente también + seguro + seguro

$\rightarrow \quad$ S.B. : mais en même temps tu n' parles pas comme les petits gamins qui ratent leurs études de ton quartier

Pero al mismo tiempo no hablás como los chiquitos a los que les va mal en la escuela de tu barrio

[CFPP2000] [11-03] Blanche_Duchemin_F_25_Reine_Ceret_F_60_11

(Líneas 303-305)

Los sujetos consultados en las pruebas perceptivas manifestaron las siguientes impresiones a propósito de esta elicitación:

Elle insiste sur le sujet de la différence.

Insiste sobre el tema de la diferencia.

Elle veut lui faire admettre qu'elle est différente des jeunes défavorisés du $11^{\text {ème }}$.

Quiere hacerle admitir que ella es diferente de los jóvenes desfavorecidos del distrito 11.

Elle essaie de la pousser dans le sens inverse que précédemment. Elle cherche à lui faire corriger son propos.

Trata de empujarla un poco en el sentido inverso al de antes. Busca hacerle corregir sus conceptos.

C'est une interpellation, elle veut la faire réagir et je pense qu'elle est sûre qu'elle a raison.

Es una interpelación, quiere hacerla reaccionar y pienso que está segura de que tiene razón.

$C$ 'est une question avec une réponse évidente après derrière.

Es una pregunta con una respuesta evidente detrás. 
B.D. : non de parler oui très différent aussi + c'est $\underline{\text { surr }}+/ c^{\prime}$ 'est $\underline{\text { sûr }}\left(228^{*}\right) /$

$\rightarrow$ S.B. : /(A) mais en même temps (251) tu n' parles pas comme les petits: (180) (M) / (M) gamins (203) qui ratent leurs études (174) (M) /

/(M) de ton quartier (198)/

[CFPP2000] [11-03] Blanche_Duchemin_F_25_Reine_Ceret_F_60_11 $\mathrm{e}^{\mathrm{e}}$ (Líneas 303-305) * Medida determinada perceptivamente debido a la intensidad extremadamente baja que imposibilita la medición exacta con PRAAT.

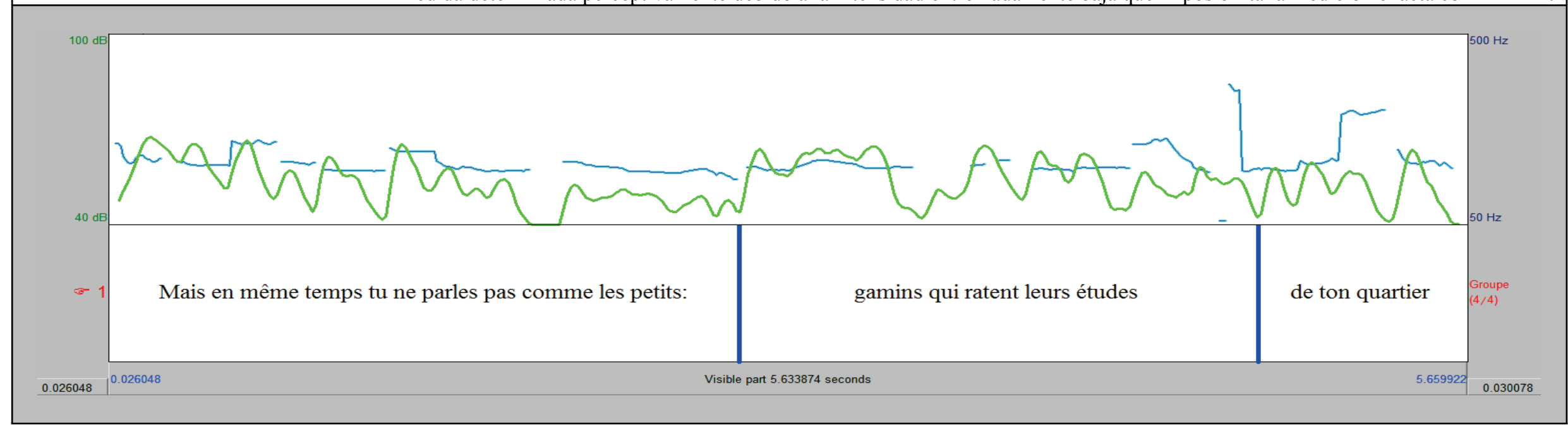


C'est plus pour meubler que blanc plus qu'autre chose.

Es más para rellenar el silencio que para otra cosa.

Elle renforce encore, elle remet une couche sur la différence entre nous et eux.

Refuerza, aún más, agrega algo más sobre las diferencias entre nosotros y ellos.

Elle lui pose la question " tu t'identifies linguistiquement où? 》.

Le hace la pregunta “¿Dónde te identificás lingüísticamente?”

Il y a un petit peu d'ironie. Elle essaie de la faire réagir. Il faut qu'elle pense bien ce qu'elle dit, elle la titille.

Hay un poquito de ironía. Trata de hacerla reaccionar. Es necesario que piense bien en lo que dice, ella la provoca.

Ce n'est pas une question, elle constate que cette fille ne parle pas comme les gens pauvres de son quartier. Elle veut lui faire accepter qu'elle n'a pas la même condition que d'autres jeunes de son quartier. "

No es una pregunta, constata que esta chica no habla como la gente pobre de su barrio. Le quiere hacer aceptar que ella no tiene la misma condición que otros jóvenes de su barrio.

Estos comentarios coinciden en la evocación de los siguientes significados:

a. La hablante solicita un determinado tipo de respuesta a su interlocutora : «Elle veut lui faire admettre qu'elle ... » "Elle cherche à lui faire corriger son propos. » « ... je pense qu'elle est sûre qu'elle a raison. » "C'est une question avec une réponse évidente après derrière. " "Elle veut lui faire accepter que...»

"Quiere hacerle admitir que ella..." "Busca hacerle corregir sus conceptos.” “... pienso que está segura de que tiene razón." "Es una pregunta con una respuesta evidente detrás." "Le quiere hacer aceptar que..."

Se evidencia, asimismo, que algunos sujetos apelan a la categoría de 'pregunta' para definir la emisión y establecen una diferencia respecto de la misma. En otros términos, se señala que esta emisión no constituye una pregunta genuina ( $C$ 'est une interpellation. " "C'est plus pour meubler que blanc plus qu'autre chose. " «Ce n'est pas une question... $\left.»^{3}\right)$.

El gráfico $n^{\circ} 17$ expone el análisis acústico de la emisión para la cual la hablante elige, como adelantamos, una secuencia de tres grupos fónicos: dos extendidos y uno, el último, simple. El Arranque de la primera unidad se realiza en el ítem "temps" con un nivel tonal alto $(251 \mathrm{~Hz})$; puede apreciarse entonces que es superior al de la unidad precedente pronunciada por Blanche (“c'est sûr” que se ubica aproximadamente en 228

\footnotetext{
3 “Es una interpelación..." "Es más para rellenar el espacio que para otra cosa." "No es una pregunta, ..."
} 
$\left.\mathrm{Hz}^{4}\right)$. Su Terminación recae en la sílaba tónica "tits" y tiene un nivel medio (180 Hz). En cuanto a la segunda unidad, Tanto su Arranque (sobre la sílaba "mins" cuya altura es de $203 \mathrm{~Hz}$ ) como su Terminación (sobre la sílaba tónica "tudes", que culmina en 174 $\mathrm{Hz}$ ) son realizados en nivel medio. La tercera unidad entonativa de la secuencia, exhibe un Arranque y una Terminación efectuados sobre la sílaba tónica "tier" y tienen asimismo un nivel medio $(198 \mathrm{~Hz})$. En cuanto a las elecciones realizadas por Sonia B. en el subsistema de Tono, puede observarse que a la primera unidad es realizada con tono Neutral y siguen dos grupos pronunciados con Tono Proclamatorio.

5.2.7 Incidencia de otros niveles lingüísticos en las interpretaciones

El grupo de emisiones que ilustramos en este apartado motivó interpretaciones similares entre los sujetos de las pruebas perceptivas sin necesariamente estar acompañadas de características entonativas comunes. Más precisamente, al dar sus impresiones acerca de estas secuencias, los sujetos parecen coincidir en que son las elecciones realizadas en otros niveles de organización lingüística, en este caso, el nivel léxico, las que se imponen por sobre las elecciones realizadas a nivel entonativo. La literatura examinada en el Estado de la cuestión describe las elicitaciones que nos ocupan aquí bajo la denominación de "questions de confirmation" (Hirst y di Cristo: 1998). Presentaremos algunas secuencias para ilustrar nuestro análisis.

\section{2 .7 .1}

En primer lugar, exponemos una elicitación pronunciada por la entrevistadora luego de que los entrevistados se refirieran a los hábitos que compartían en su paso por el colegio.

S17 :

B.D. : [...] et tout c' 'qui colle et tout c'qui tâche enfin

$\mathrm{Y}$ todo lo que se pega y todo lo que mancha en fin

$\rightarrow \quad$ S.B. : C'est un peu fini non?

¿Medio que no se hace más no?

[CFPP2000] [03-01] Ozgur_Kiliç_H_32_alii_3 ${ }^{\mathrm{e}}$

(Líneas 154-155)

Los significados que los sujetos atribuyeron a esta emisión se detallan a continuación:

Elle demande. Elle partage une constatation.

\footnotetext{
${ }^{4}$ Esta medida es aproximada / perceptiva, ya que la emisión concluye con una intensidad extremadamente baja que imposibilita la medición exacta con PRAAT.
} 
Pregunta. Comparte una constatación.

Elle veut savoir simplement.

Quiere saber simplemente.

Elle cherche à les faire parler du moment présent.

Busca hacerlos hablar del momento presente.

Elle demande si ça continue dans l'actualité. Elle pose une question pour réorienter la discussion.

Pregunta si eso se sigue haciendo en la actualidad. Hace una pregunta para reorientar la discusión.

Elle demande, mais la question est dirigée dans le sens que pour elle, c'est fini. Elle leur demande leur avis.

Pregunta, pero la pregunta está orientada en el sentido de que para ella, ya no se hace más. Les pregunta su opinión.

On a l'impression qu'elle sort cette question parce qu'elle est vraiment glauque.

Da la impresión de que esta pregunta se le acaba de ocurrir, porque es realmente rara.

"Est-ce que on voit plus trop ça? »... Elle boucle et réoriente. "Moi, je propose autre chose... »

“¿Ya no se ve demasiado?”... cierra y reorienta [el tema de conversación]. "Yo propongo otra cosa..."

C'est une question avec un "non?» Elle insiste un peu sur la réponse qui est évidente.

Es una pregunta con un "¿no?" Insiste un poco en la respuesta que es evidente.

Elle a donné la réponse avant de poser la question.

Dio la respuesta antes de hacer la pregunta.

On demande une confirmation.

Se pide una confirmación.

C'est un doute dans une interrogation. Elle attend quelque chose, elle attend une réponse. Elle sait pas en fait.

Es una duda en una interrogación. Ella espera algo, espera una respuesta. No sabe, de hecho.

Elle pense que c'est fini mais elle veut savoir si c'est bien fini.

Piensa que no se hace más, pero quiere saber si efectivamente no se hace más.

Las interpretaciones provistas comparten los siguientes significados:

a. La hablante conoce o cree conocer la información que espera obtener de sus interlocutores: « Elle partage une constatation. » «... pour elle, c'est fini. » «Elle insiste un peu sur la réponse qui est évidente. » «lle a donné la réponse avant 
Gráfico ${ }^{\circ} 18$

S17 :

\section{(P)}

B.D. : et tout c'qui colle / (M) et tout c'qui tâche (133) enfin/

(R)

$\rightarrow$ S.B. : /(A) C'est un peu fini (381) non /

[CFPP2000] [03-01] Ozgur_Kiliç_H_32_alii_3 ${ }^{\mathrm{e}}$ (Líneas 154-155)

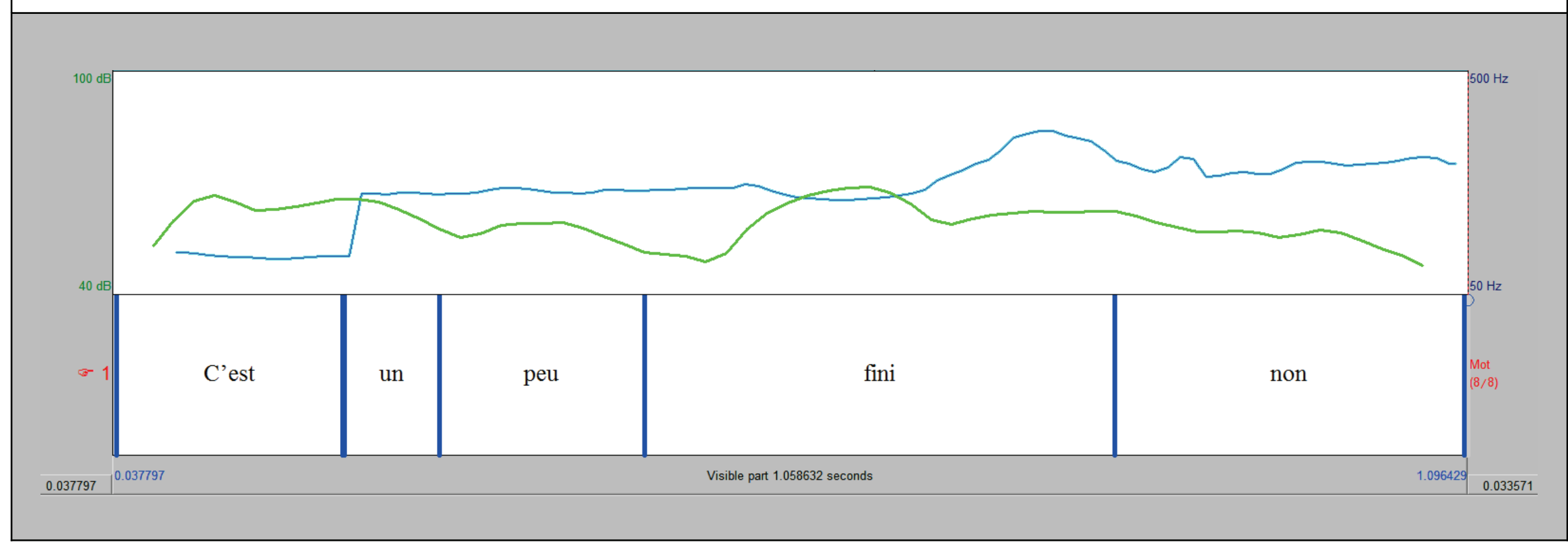


de poser la question. " «Elle pense que c'est fini mais elle veut savoir si c'est bien fini.

"Comparte una constatación." "... para ella, ya no se hace más." "Insiste un poco en la respuesta que es evidente." "Dio la respuesta antes de hacer la pregunta." "Piensa que no se hace más, pero quiere saber si efectivamente no se hace más."

b. La hablante espera generar un tipo de información determinado: «... mais la question est dirigée... » "On demande une confirmation. » "Elle cherche à les faire parler du moment présent. »

"...pero la pregunta está orientada..." Se pide una confirmación." "Busca hacerlos hablar del momento presente."

c. La hablante busca de todas formas generar información: «Elle demande. » (en dos oportunidades) «Elle veut savoir simplement.» «Elle demande si ... » «C'est un doute dans une interrogation. Elle attend quelque chose, elle attend une réponse. »

"Pregunta." "Quiere saber simplemente." "Pregunta si..." "Es una duda en una interrogación. Ella espera algo, espera una respuesta."

Cabe destacar que un sujeto atribuye explícitamente el significado de la emisión a la presencia del ítem léxico “non": "C'est une question avec un 'non ?' Elle insiste un peu sur la réponse qui est évidente. $\rangle^{5}$

El gráfico $\mathrm{n}^{\circ} 18$ permite visualizar las características entonacionales de este emisión realizada en una unidad tonal simple. Teniendo en cuenta que el grupo anterior pronunciado por Benoît D. tiene un Arranque situado en $133 \mathrm{~Hz}$, se deduce que el Arranque y la Terminación de la elicitación de Sonia B. tienen un nivel alto a $381 \mathrm{~Hz}$ (estos parámetros se realizan en la sílaba tónica “ni"). En este caso, el Tono elegido por la hablante es Referido.

Vemos en esta elicitación, que la forma entonativa es diferente de las analizadas hasta ahora en 5.2. Más precisamente, se trata aquí de una emisión realizada con Tono Referido y seguida del ítem léxico "non", que en este caso no es prominente. Como vimos en el apartado 5.1, esta realización de Tono estuvo frecuentemente asociada con el significado de que el hablante ignora la información que solicita a su interlocutor. En el caso de esta emisión de Sonia B., los sujetos interpretan, en general que ella no ignora la información que espera de sus entrevistados, y atribuimos esta interpretación a la

\footnotetext{
“Es una pregunta con un ‘¿no?’. Insiste un poco en la respuesta que es evidente”.
} 
existencia del 'non' utilizado habitualmente para pedir confirmación de información conocida.

A continuación, presentaremos una emisión realizada en una unidad tonal extendida.

\section{$5 \cdot 2.7 .2$}

En esta secuencia, Lucie dS. acaba de emitir un comentario acerca de sus mascotas. A continuación, Adèle asiente y Francine formula a su vez una elicitación de información:

S18 :
A. : ouais
se

$\rightarrow \quad$ F. : toi tu sors pas (a)vec ton hamster hein?

vos no salís con tu hámster ¿eh?

[CFPP2000] [07-02] Lucie_da_Silva_F_22_7

(Líneas 168-169)

Los comentarios de los sujetos a propósito de esta elicitación fueron los siguientes:

Dans ce type de questions, on a l'impression que celui qui pose la question ne veut pas vraiment de réponse. Elle cherche la confirmation dans son intervention.

En este tipo de preguntas, da la impresión de que el que hace la pregunta no quiere realmente una respuesta. Busca la confirmación en su intervención.

Elle pose la question. Mais c'est une évidence.

Hace la pregunta. Pero es evidente.

Ce n'est pas une question sérieuse.

No es una pregunta en serio.

Elle veut faire une blague.

Quiere hacer una broma.

C'est une blague.

Es una broma.

C'est une note d'humour.

Es una nota de humor.

C'est une interrogation qui a déjà la réponse. Ça limite la liberté de réponse de l'interlocuteur. On est tout de suite dans la contrainte, on contraint l'autre à aller à un autre sens d'emblée.

Es una pregunta que ya tiene la respuesta. Eso limita la libertad de respuesta del interlocutor. En seguida uno está condicionado, se condiciona al otro a ir directamente hacia un determinado sentido.

Elle pose la question, mais elle connaît déjà la réponse.

Hace la pregunta, pero ya conoce la respuesta. 
C'est un commentaire un peu ironique. Pour moi, cela ne demande pas une réponse.

Es un comentario un poco irónico. Para mí, no pide una respuesta.

C'est un commentaire avec de l'humour. Il donne le ton de l'interview qui commence légère et avec de l'humour.

Es un comentario con humor. Da el tono de la entrevista que empieza superficial y con humor.

C'est un peu ironique.

Es un poco irónico.

Elle ne pose pas vraiment la question, elle le sait.

No hace realmente la pregunta, lo sabe.

Elle sait que l'autre va répondre 'non', évidemment.

Sabe que la otra va a responder 'no', obviamente.

Los significados evocados en estas reacciones ponen de manifiesto que la hablante tiene una idea precisa de la respuesta que espera de su interlocutora: « [...] on a l'impression que celui qui pose la question ne veut pas vraiment de réponse. Elle cherche la confirmation dans son intervention. " «C'est une interrogation qui a déjà la réponse. Ça limite la liberté de réponse de l'interlocuteur.» «Elle pose la question, mais elle connaît déjà la réponse. » « ... elle le sait. » "Elle sait que l'autre va répondre 'non', évidemment. »

“... da la impresión de que el que hace la pregunta no quiere realmente una respuesta. Busca la confirmación en su intervención." "Es una pregunta que ya tiene la respuesta. Eso limita la libertad de respuesta del interlocutor." "Hace la pregunta, pero ya conoce la respuesta." "... lo sabe." "Sabe que la otra va a responder 'no', obviamente."

Sin embargo, el hecho de que el hablante tenga una respuesta in mente, no invalida la elicitación. La misma se asocia, en las interpretaciones de los sujetos, con rótulos gramaticales que refieren a los tipos de emisiones utilizados habitualmente para solicitar información: «Dans ce type de questions... » «Elle pose la question. 》 « Ce n'est pas une question sérieuse. " «C'est une interrogation... " «Elle ne pose pas vraiment la question... »

"En este tipo de preguntas..." "Hace la pregunta." "No es una pregunta en serio." "Es una interrogación..." "No hace realmente la pregunta,..."

Se observan también alusiones al tono humorístico de la elicitación, pero este tipo de significados locales se desprenden del contenido semántico de la secuencia ("no salís con tu hámster'). Recordamos que aunque hacemos mención a este tipo de significados, 
Gráfico n ${ }^{\circ} 9$

S18 :

A. : / (M) ouais (169)/

(P)

$\rightarrow \quad$ F.: /(M) toi (210) tu sors pas (a)vec ton hamster (246) hein (A)/

[CFPP2000] [07-02] Lucie_da_Silva_F_22_7 $7^{\mathrm{e}}$ (Líneas 168-169)

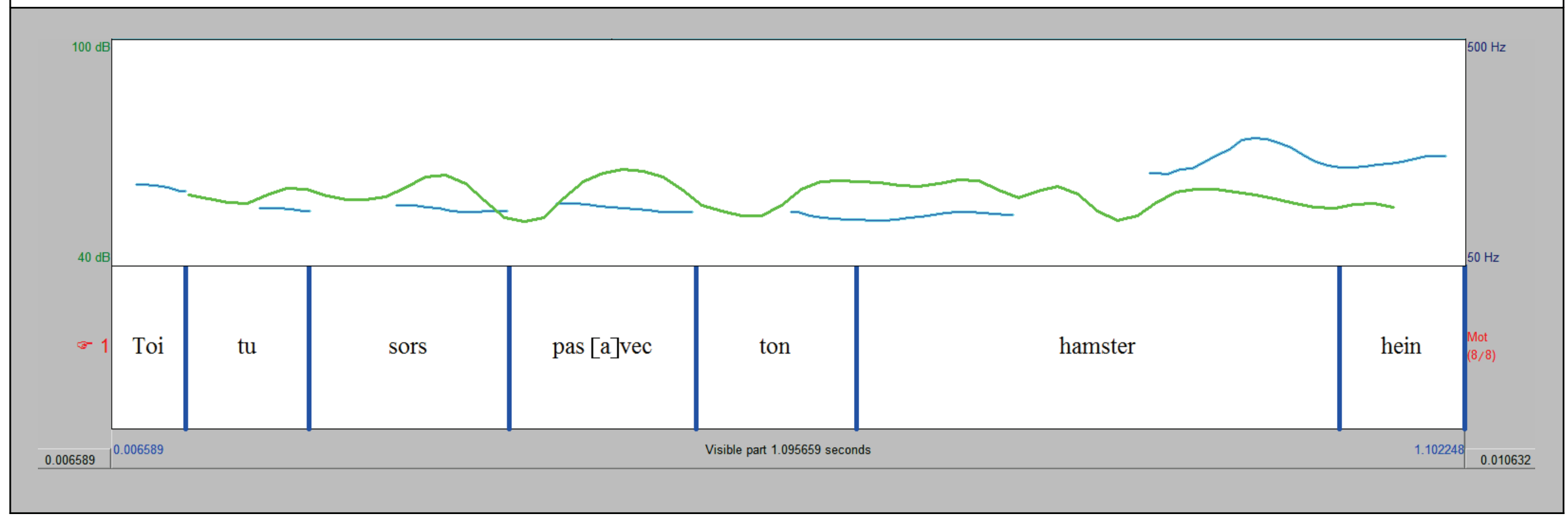


los mismos no pueden ser generalizables y, por consiguiente, no es dable considerarlos desde la perspectiva de trabajamos.

Puede observarse por otra parte, que, en el nivel léxico-gramatical otro componente acentúa los significados de conocimiento de la respuesta que se solicita. Se trata de la forma negativa en la que se presenta la emisión, la cual no parece ser la forma natural de una pregunta cuya respuesta se ignora. Si además de tener una entonación ascendente, la unidad fuera proferida en forma afirmativa, el significado discursivo sería totalmente diferente del transmitido en esta secuencia.

El análisis acústico de la emisión permite determinar las características entonativas de esta emisión realizada, como adelantáramos, en una unidad tonal extendida (ver gráfico $\mathrm{n}^{\circ}$ 19). El Arranque se sitúa en el elemento "toi" y tiene un nivel medio $(210 \mathrm{~Hz})$ en comparación con el Arranque precedente sobre el ítem "ouais" realizado por Anne que tiene un nivel bajo $(169 \mathrm{~Hz})$. Por su parte, la Terminación se realiza en la sílaba tónica "ter" y tiene un nivel tonal alto $(246 \mathrm{~Hz})$. La hablante utiliza en su elicitación el Tono Referido.

El examen acústico permite además constatar que el ítem léxico con el que finaliza la emisión, (en este caso, "hein") no es prominente, tal como ocurría con "non" en el ejemplo anterior (5.2.7.1). Precisamos asimismo que la sílaba que se encuentra entre paréntesis ha sido omitida en la emisión (o bien, la misma ha sido asimilada por la sílaba precedente, que termina con el mismo fonema, /a/) por lo que no se contabiliza como una sílaba efectivamente realizada.

La secuencia que analizaremos en el apartado siguiente es una unidad de extensión aún mayor que cuenta con dos unidades entonativas.

\section{$5 \cdot 2.7 .3$}

Esta elicitación se produce en momentos en que Jeanne M. habla acerca de su lugar de origen. Otra participante de la entrevista, Louise L. recuerda entonces que Jeanne es oriunda del mismo departamento que Mitterrand y, luego de que ésta asiente, Louise agrega las siguientes emisiones:

S66

L.L. : oui c'est pour ça que vous vous êtes: 
sí es por eso que ustedes se:

J.M. : oui + oui oui ++

sí+ sí sí ++

$\rightarrow \quad$ L. L. : vous l'avez connu non? +

usted lo conoció ¿no?

CFPP2000 [SO-01] Louise_Liotard_F_85_et_Jeanne_Mallet_F_75_SO

(Líneas 773-775)

En las pruebas perceptivas, las interpretaciones que obtuvimos para esta secuencia fueron las siguientes:

Elle relance pour la faire parler.

Ella insiste para hacerla hablar.

Elle demande pour lui faire dire si elle a connu Mitterrand voire plus.

Pregunta para hacerla decir si conoció a Mitterrand e incluso algo más.

Elle veut confirmer et aussi la faire parler.

Quiere confirmar y también hacerla hablar.

Elle veut savoir si l'autre a connu Mitterrand. Soit elle sait la réponse, soit elle la déduit. Comme elle le dit, elles en ont déjà parlé.

Quiere saber si la otra conoció a Mitterrand. Ella sabe la respuesta, o bien la deduce. Por como lo dice, ellas ya hablaron de eso.

Elle sait déjà qu'elle l'a connu. Mais elle pose la question sur un ton... ça pourrait être même une remarque. Mais elle pose la question.

Sabe que ella lo conoció. Pero hace la pregunta con un tono... podría ser incluso un comentario.

Pero hace la pregunta.

Evidemment, elle sait que l'autre a connu Mitterrand. Elle veut que l'autre raconte, parce que c'est intéressant.

Evidentemente, sabe que la otra conoció a Mitterrand. Quiere que la otra mujer cuente, porque es interesante.

C'est une réponse en regroupant des informations qu'elle a entendues. Au lieu de le penser dans sa tête, elle le dit oralement. En vérifiant qu'elle se trompe pas en même temps.

Es una respuesta que agrupa informaciones que ella ha escuchado. En lugar de pensarlo en su cabeza, lo dice oralmente. Verificando al mismo tiempo que no se equivoca.

Avec ce "non?", c'est toujours la question qui entraîne la réponse.

Con ese "¿no?", es siempre la pregunta que conlleva la respuesta.

"C'est évident, s'il est du pays ». Pas comme quelque chose d'improbable mais plutôt comme quelque chose de tout à fait possible.

"Es evidente, si es del lugar". No como algo improbable, sino más bien como algo totalmente posible. 
C'est un «non » qui veut dire « oui ». C'est « Je suppose que vous l'avez connu. »

Es un no que quiere decir sí. Es "Supongo que usted lo conoció."

On a l'impression qu'elle lui dit ça parce qu'elle le sait, elles ont dû en parler avant.

Da la impresión de que ella le dice eso porque lo sabe, probablemente hablaron antes de eso.

Je pense qu'elle savait, ou elle s'en doutait.

Pienso que ella lo sabía o lo sospechaba.

On peut douter, on peut dire "Vous m'aviez dit une fois que vous l'avez connu » pour qu'elle raconte aux autres. Ou bien c'est vraiment une interrogation, mais dans ce 'non' il y a 'oui, vous l'avez certainement connu'.

Se puede sospechar, se puede decir "Usted me había dicho una vez que usted lo conoció" para que les cuente a los demás. O bien es realmente una interrogación, pero en ese "no", hay un "sí, usted seguramente lo conoció."

Estas interpretaciones ponen de manifiesto que los hablantes son sensibles a significados comparables a los expuestos en los apartados anteriores:

a. La hablante conoce o cree conocer la respuesta que espera obtener de su interlocutora: "Elle veut confirmer...» «Soit elle sait la réponse, soit elle la déduit. » «Evidemment, elle sait que ... « « Comme elle le dit, elles en ont déjà parlé. 》 "Elle sait déjà qu'elle l'a connu. " «C'est une réponse en regroupant des informations qu'elle a entendues (...) En vérifiant qu'elle se trompe pas en même temps. " " 'C'est évident, s'il est du pays'. Pas comme quelque chose d'improbable mais plutôt comme quelque chose de tout à fait possible. " «On a l'impression qu'elle lui dit ça parce qu'elle le sait, elles ont dî en parler avant. "» « Je pense qu'elle savait, ou elle s'en doutait."

"Quiere confirmar..." "Ella sabe la respuesta, o bien la deduce." "Evidentemente, sabe que..." "Es una respuesta que agrupa informaciones que ella ha escuchado. (...) Verificando al mismo tiempo que no se equivoca." 'Es evidente, si es del país'. No como algo improbable, sino más bien como algo totalmente posible." "Da la impresión de que ella le dice eso porque lo sabe, probablemente hablaron antes de eso." "Pienso que ella lo sabía o lo sospechaba."

b. La hablante espera generar un tipo de información determinado: «Elle relance pour la faire parler. " "Elle demande pour lui faire dire si elle a connu Mitterrand voire plus. " «... et aussi la faire parler. " «Elle veut que l'autre raconte, parce que c'est intéressant. " " ... pour qu'elle raconte aux autres. " "Ella insiste para hacerla hablar." "Pregunta para hacerla decir si conoció a Mitterrand e incluso algo más." “... y también hacerla hablar." "Quiere que la otra mujer cuente, porque es interesante." "... para que les cuente a los demás." 
c. La hablante realiza un pedido de información: «... Mais elle pose la question.» «Ou bien c'est vraiment une interrogation... »

“... Pero hace la pregunta." "O bien es realmente una interrogación..."

Son también considerables las referencias a la significación de elementos de orden léxico. En este caso, como en 5.2.7.1, se trata del ítem "non": «Avec ce 'non ?', c'est toujours la question qui entraîne la réponse. " «C'est un 'non' qui veut dire 'oui', c'est 'Je suppose que vous l'avez connu.'” «... mais dans ce 'non' il y a 'oui, vous l'avez certainement connu'. $»^{6}$

En cuanto a sus características entonativas, el gráfico $n^{\circ} 20$ exhibe la emisión de una elicitación realizada en dos unidades tonales simples. El Arranque y la Terminación de la primera unidad, ubicados en la sílaba tónica " $n u$ ", tienen un nivel alto que culmina en $212 \mathrm{~Hz}$ (recordemos que el Arranque de la unidad precedente de Jeanne M., realizado sobre el ítem "oui" se sitúa en $92 \mathrm{~Hz}$ ). Por su parte, el Arranque y la Terminación de la segunda unidad, realizados sobre el elemento "non" (que es al mismo tiempo la sílaba tónica) tienen una altura tonal media $(176 \mathrm{~Hz})$. Se aprecia asimismo que el Tono elegido para la primera unidad es Proclamatorio, mientras que en la segunda unidad la hablante opta por un Tono Referido. El gráfico permite visualizar de igual modo el encabalgamiento que afecta la secuencia “connu, non?”. Aquí, la línea melódica que se delinea de manera bastante clara se interrumpe parcialmente, sin afectar no obstante la visualización del conjunto de la emisión y de las realizaciones de Arranque, Terminación y Tono.

Señalamos, para terminar, que el examen arroja la existencia de dos sílabas tónicas consecutivas al final de la frase (“connu, $\underline{n o n}$ ?"). A este respecto, muchos autores sostienen que en francés no es posible encontrar este tipo de secuencias (reglas de colisión de acento de Martin: 2009 y de Di Cristo: 1998 y 2004, por citar sólo algunos). Sin embargo, entendemos que tanto la velocidad de elocución pausada de la emisión (que se pone de manifiesto en el alargamiento de ambas sílabas tónicas) como la pausa que las separa, posibilitan que se distingan claramente dos unidades y que, como se visualiza en el gráfico, esta emisión de Louise L. cuente con una sucesión de dos sílabas tónicas.

\footnotetext{
6 “'Con ese '¿no?', es siempre la pregunta que conlleva la respuesta." "Es un no que quiere decir sí. Es 'Supongo que usted lo conoció."” 'pero en ese 'no', hay un ‘sí, usted seguramente lo conoció.'
} 
El análisis de las instancias incluidas en este apartado pone de relieve el vínculo existente entre la función de la emisión y los significados de elementos de orden léxico tales como 'non' y 'hein'. Más aún, en muchas oportunidades este vínculo fue explicitado por los sujetos participantes de las pruebas perceptivas. En su examen acerca de las denominadas "question tags" del inglés, Brazil (1978) detalla la forma en que se vinculan los sistemas de significados de la gramática y los de la entonación. El autor señala que los distintos niveles de análisis lingüístico posibilitan elecciones por parte de los hablantes que no siempre vehiculizan los mismos significados. Cuando esto ocurre, la elección operada por el hablante en un nivel puede prevalecer sobre las realizadas en otros. Es por ello que, aunque no es nuestro propósito abordar este nivel léxico-gramatical, proponemos una somera descripción de dichos recursos.

El diccionario del CNRTL designa a este uso de "non" como un elemento de pregunta retórica. Luego de una pregunta afirmativa, invita a una respuesta afirmativa. Luego de una pregunta negativa, invita a confirmar esa negación. En lo que refiere al ítem "hein", el mismo diccionario define esta función como la de una "partícula pragmática" que insta al interlocutor a expresar su acuerdo con lo dicho.

Como mencionamos anteriormente, algunos autores como Hirst y Di Cristo (1998) describen estas emisiones desde una perspectiva que explora la función de estructuras sintácticas bajo la denominación de preguntas totales para confirmación. En ellas, la secuencia previa al elemento léxico que los autores denominan "terminator" ("non" “hein" " $n$ 'est-ce pas") está realizada con el patrón descrito para la modalidad de declarativa simple, básica no enfática: "ascendente-descendente o circunfleja” (Hirst y Di Cristo, 1998:204). Recordemos que los patrones entonativos presentados en este modelo atienden al movimiento de $\mathrm{F}_{0}$ en todas las sílabas de la emisión y no sólo en las prominentes.

Retomando las consideraciones de Brazil (1978), entendemos que las emisiones analizadas hasta aquí corresponden a lo que el autor describe como intercambios en los que existe un flujo de información iniciado por el hablante pero que, en el caso de completarse, esa información procedería del interlocutor a quien la elicitación va dirigida. Por ello, sostenemos que en este grupo de emisiones existe una respuesta in mente en quien formula la elicitación. El sujeto requiere una confirmación de la información que ya posee (aunque la convicción de poseer la información fuera luego

7 "no" "eh" "no es así" 
desmentida por su interlocutor). Como mostramos en las pruebas perceptivas, las emisiones del apartado 5.2.7 transmiten en forma predominante este significado.

Si tenemos en consideración las elicitaciones presentadas en este apartado, se constata que no puede afirmarse la existencia de una constante en las características entonativas. En las secuencias que presentan un único grupo fónico, detectamos la realización de Tono Referido. Sin embargo, se encontraron emisiones con más de un grupo fónico. En estos casos, el ítem léxico utilizado como "terminator" (término utilizado por Hirst y Di Cristo) o 'tag' está separado del resto de la secuencia y es acompañado por un Tono Referido, mientras que la unidad precedente puede presentar Tono Referido o Proclamatorio (como en 5.2.7.3 o como indican Hirst y Di Cristo 1998) sin que esto afecte la interpretación que se hace del conjunto de la emisión.

Esto permite deducir entonces que el significado de las unidades examinadas aquí no se desprende del aporte de la entonación sino, como lo demuestran las pruebas perceptivas, de la presencia de los ítems léxicos mencionados. Por este motivo, estas emisiones se consideran como un caso diferente en el que, como ya dijimos, la incidencia de las elecciones léxicas se impone con fuerza sobre el significado que otorga la entonación. Por consiguiente, estas elicitaciones no son tenidas en cuenta al analizar la relación existente entre la interpretación y las características entonativas, dado que no permiten dar cuenta de la contribución de una contribución constante de la entonación al significado del discurso.

Del total de las elicitaciones seleccionadas para el estudio, las que culminan con estos elementos y presentan esta preponderancia de significados aportados por el léxico en la interpretación sumaron un total del 7\%.

Como una conclusión parcial de nuestro trabajo, analizando en su conjunto las elicitaciones de tipo B, constatamos que todas las ocurrencias agrupadas en este capítulo transmiten el significado de que el hablante tiene una determinada respuesta in mente al momento de solicitar información. En algunas oportunidades, los sujetos de las pruebas perceptivas definieron las secuencias apelando a la categoría que cumple normalmente la función de generar información "c'est une question" pero agregaron apreciaciones tales como "pour orienter" "pour lui faire dire", "c'est pas une vraie question" con las que definen intenciones particulares de estas emisiones asociadas con una determinada

\footnotetext{
8 "es una pregunta"

9 "para orientar" "para hacerle decir" "no es una verdadera pregunta".
} 
expectativa o conocimiento que se atribuye a quien las pronuncia. No obstante, estas consideraciones no invalidan la intención del hablante de obtener una respuesta por parte del interlocutor. Asimismo, las elicitaciones se enmarcan en su totalidad en lo que ha sido descrito como "preguntas totales". No encontramos en nuestros datos preguntas parciales que vehiculicen este tipo de significados.

Si nos remitimos a la descripción realizada por diferentes autores que mencionamos en el Estado de la cuestión, observamos que no abundan las referencias a este tipo de elicitaciones para el francés. Sólo en los estudios de Martins-Baltar, Mertens y Morel y Danon-Boileau se detallan algunas características que coinciden con nuestra descripción. En el trabajo de Martins-Baltar, se describe un patrón entonativo descendente en preguntas asociado con la intención de verificar lo que cree haber escuchado por parte del interlocutor (Martins-Baltar, 1978:48), es decir, que la elicitación incluye en este caso la respuesta. Por su parte, tanto Mertens como Morel y Danon-Boileau vinculan el descenso en la melodía con la búsqueda de confirmación cuando no se ha comprendido bien. Vemos entonces que, para estos autores, el hablante que utiliza esta configuración entonacional para realizar una elicitación, tiene también un tipo de respuesta in mente y la expectativa de que el interlocutor la confirme.

Desde el punto de vista de sus características entonativas, se constata que, con excepción de las emisiones agrupadas en 5.2.7 cuyas particularidades discutiéramos más arriba, todas las emisiones agrupadas como elicitaciones de tipo B están realizadas con un Tono Proclamatorio. Esta constatación coincide con las consideraciones de Mertens y de Morel y Danon-Boileau, quienes asocian el patrón melódico descendente con la búsqueda de confirmación.

Las realizaciones en el subsistema de Arranque, por su parte, tienen predominantemente una altura tonal alta: el 71\% de las emisiones fueron se situaron en este nivel. En tanto, un 29\% de Arranques se realizó en nivel medio, y no se detectaron ocurrencias en las que se optara por el nivel bajo, como se observa en el gráfico $n^{\circ} 20$. Recordemos que la elección de nivel alto en este subsistema transmite significados de contraste, mientras que los Arranques con nivel medio agregan información. El valor de contraste podría vincularse con la intención de dominar la gestión del intercambio a fin de obtener información. 


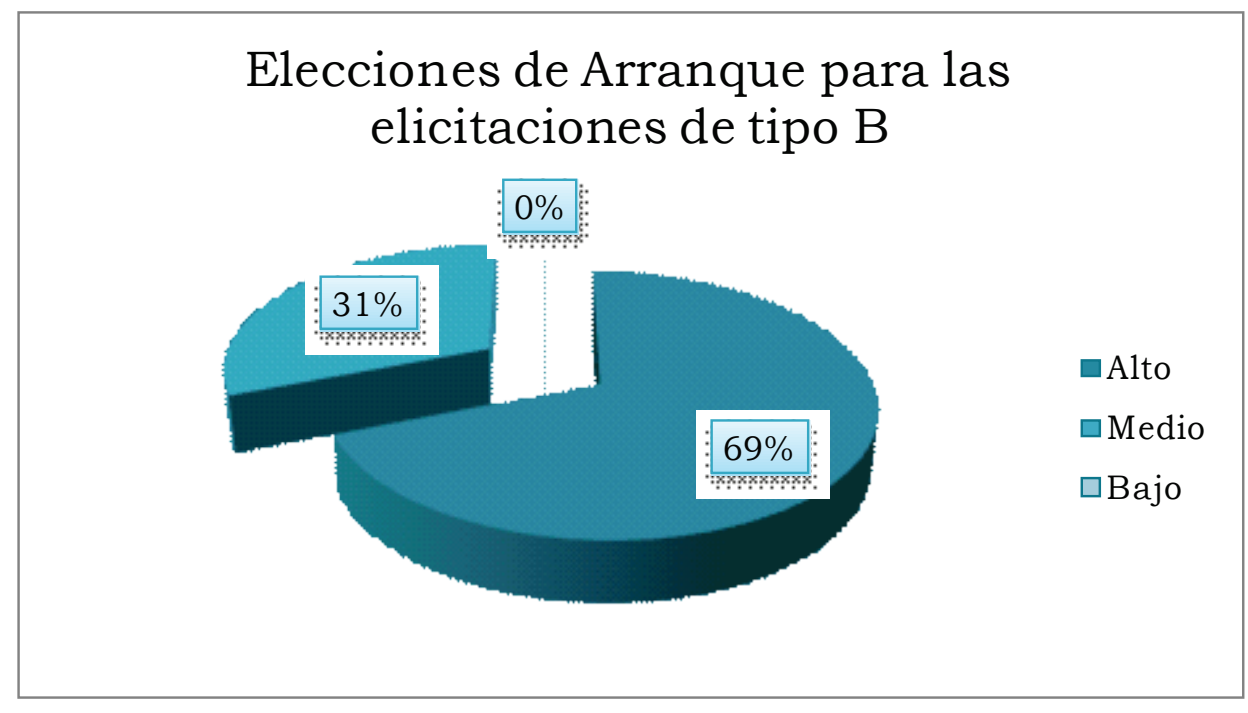

Gráfico $n^{\circ} 20$

En cuanto a la Terminación, pudo constatarse una preferencia por el nivel medio (77\% de las emisiones, frente al $23 \%$ de Terminaciones en nivel alto) plasmada en el gráfico $\mathrm{n}^{\mathrm{o}} 21$. Recordemos que este subsistema proyecta expectativas respecto de la altura tonal del próximo Arranque y, por consiguiente, expectativas referidas a la posición que adoptará el interlocutor al tomar la palabra. El predominio de la Terminación en nivel medio puede vincularse con una intención frecuente de que el interlocutor complete el intercambio brindando la información esperada. Con la elección de Terminación alta, en tanto, el locutor expresa que tiene en cuenta la posibilidad de que el interlocutor plantee en su emisión una opinión independiente. Tal como ocurría con las elicitaciones de tipo A, los hablantes no han utilizado el nivel bajo en la Terminación, lo cual puede atribuirse al hecho de que quien solicita información no carece de expectativas sobre la continuidad del intercambio, siendo la falta de expectativas el significado la Terminación baja. 


\section{Elecciones de Terminación para las elicitaciones de tipo B}

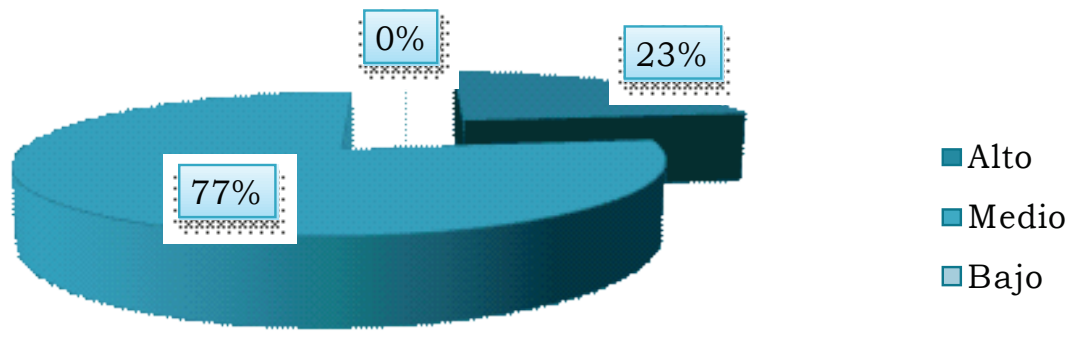

Gráfico $n^{\circ} 21$

En las pruebas perceptivas, los sujetos francohablantes fueron fundamentalmente sensibles al grado de conocimiento proyectan los hablantes que solicitan información. Esta variable de significado permitió establecer la diferencia entre las elicitaciones de tipo A y las de tipo B. Sin embargo, al indagar en los posibles correlatos entre estos significados y las características entonativas examinadas, se aprecia que los valores de Altura tonal no permiten una distinción taxativa entre los dos tipos de emisiones que solicitan información.

Si se tienen en cuenta las opciones del subsistema de Arranque, el análisis expuesto demuestra que el nivel tonal alto predomina en ambos tipos de elicitaciones. En cuanto a las elecciones de Terminación, las mismas no son concluyentes dado que, si bien las elicitaciones de tipo A exhiben cierto predominio del nivel alto sobre el nivel medio, y en las de tipo B esta tendencia se invierte, en ningún caso se excluyen las opciones contrarias y no nos arriesgaríamos a hablar de una tendencia constante.

Inversamente a lo que ocurre en esos dos subsistemas, es posible observar que la elección de Tono que realiza el locutor es un elemento pertinente para distinguir los tipos de emisiones en las que se solicita información y para precisar qué incidencia tiene la entonación en la distinción de significados. Este parámetro codifica el estado de conocimiento que se atribuye al hablante y aporta un significado relevante en el intercambio como es el de determinar si quien ha solicitado una información tiene o no una idea de la respuesta que espera.

El significado agregado por la entonación es uniforme e independiente del contenido léxico-gramatical de la emisión, como pudo establecerse en el análisis que presentamos. 
El gráfico $\mathrm{n}^{\circ} 22$ representa el examen de las ocurrencias de realizaciones de Tono y los significados asociados por los sujetos de las pruebas perceptivas.

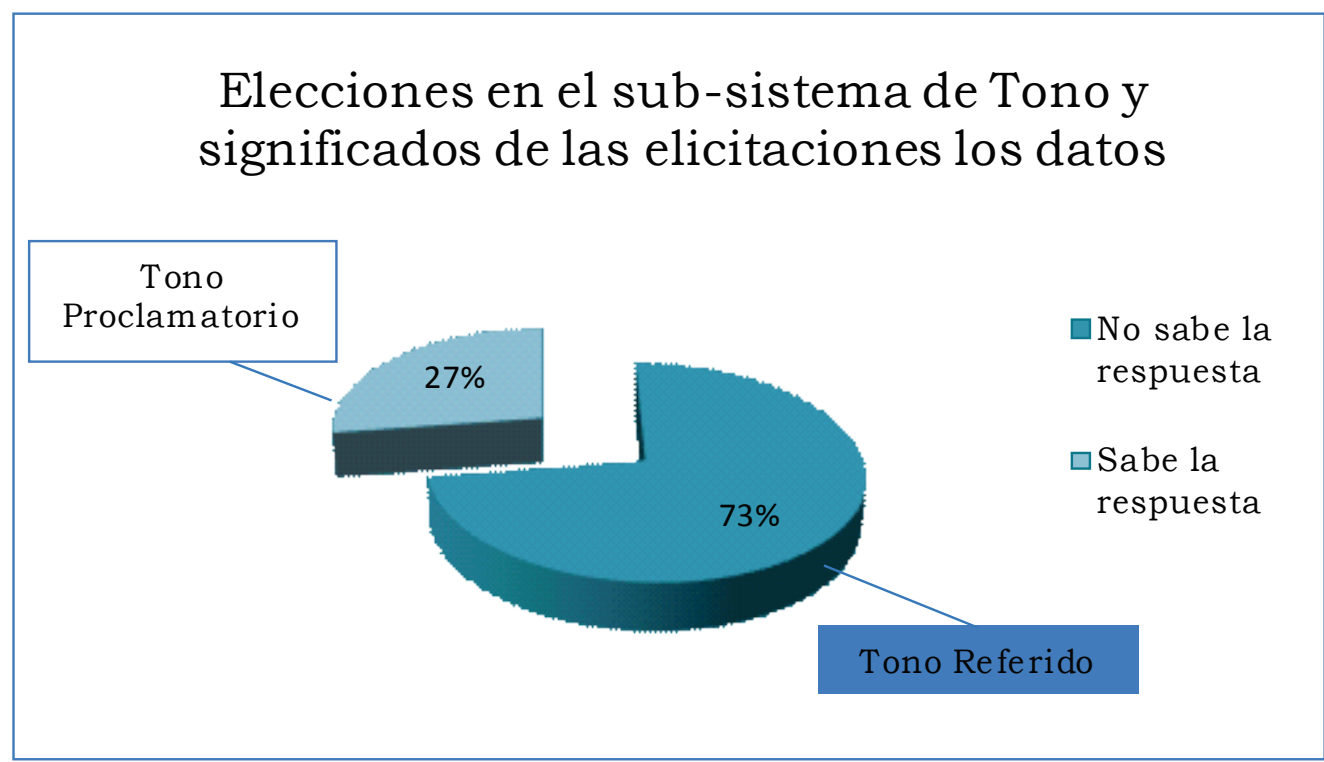

Gráfico $n^{\circ} 22$

El estudio porcentual de las emisiones que solicitan información permitió apreciar que, en nuestros datos, prevalecen las elicitaciones en las que se considera que el hablante ignora la respuesta que solicita. Como dijimos, excluidas las emisiones que se interpretaron predominantemente por su contenido léxico, sobre un total de 66 elicitaciones de información, el $80 \%$ se consideraron como emisiones realizadas por un locutor que desconoce la respuesta. En tanto, el 20\% de las ocurrencias fueron interpretadas como solicitudes de información que el locutor conoce o cree conocer.

Para resumir el análisis llevado a cabo hasta ahora, presentamos el cuadro $\mathrm{n}^{\mathrm{o}} 11$ en el que se correlacionan los dos tipos fundamentales de elicitaciones definidos en las pruebas perceptivas y las características entonativas de cada uno de ellos.

Como puede apreciarse, en todos los casos en que los hablantes emplearon Tono Proclamatorio, los sujetos de las pruebas perceptivas interpretaron que tenía una respuesta in mente. Paralelamente, la elección de Tono Referido fue siempre asociada al desconocimiento de la respuesta por parte del hablante. 
Significados atribuidos a las emisiones que solicitan información y características entonativas asociadas

\begin{tabular}{|c|c|c|c|}
\hline \multirow{3}{*}{$\begin{array}{l}\text { Significado } \\
\text { atribuido }\end{array}$} & \multicolumn{3}{|c|}{ Características entonativas } \\
\hline & \multicolumn{2}{|c|}{ Altura tonal } & \multirow{2}{*}{ Tono } \\
\hline & Arranque & Terminación & \\
\hline $\begin{array}{l}\text { Sin respuesta in } \\
\text { mente }\end{array}$ & $\begin{array}{c}\text { Predominantemente } \\
\text { alto }\end{array}$ & $\begin{array}{c}\text { Predominantemente } \\
\text { alto }\end{array}$ & Referido \\
\hline $\begin{array}{c}\text { Con respuesta in } \\
\text { mente }\end{array}$ & $\begin{array}{l}\text { Predominantemente } \\
\text { alto }\end{array}$ & $\begin{array}{l}\text { Predominantemente } \\
\text { medio }\end{array}$ & Proclamatorio \\
\hline
\end{tabular}

Cuadro ${ }^{\circ} 11$

Es necesario destacar que los significados que el hablante transmite mediante la elección en cualquiera de los subsistemas entonativos pueden presentar diferencias respecto de los que se desprenden de recursos de otros niveles, como el sintáctico o el léxico. La entonación ofrece, como vimos, subsistemas de opciones independientes entre sí y las opciones elegidas son significativas por poseer un valor dentro de cada subsistema. No se trata aquí de respetar reglas de formación correcta. El hablante selecciona opciones en diferentes subsistemas que pueden ser concordantes o no. En los casos en que los significados de diferentes subsistemas no coinciden, hay prevalencia de uno sobre los demás.

A su vez, es importante señalar la posibilidad de explotar el sistema para lograr transmitir determinados significados de acuerdo con el propósito comunicativo. Cada participante de la interacción tiene así libertad de elección respecto de la forma en que presenta las emisiones en su discurso. A su vez, como vimos en varias oportunidades, los sujetos son sensibles a estas elecciones y tienen en cuenta que la intención comunicativa es independiente de criterios de verdad. Como señala Brazil, los interactuantes pueden explotar el sistema prosódico y presentar algo que es conocido como si no lo fuera; presentar una elicitación cuya respuesta fuera conocida como no conocida o viceversa. 


\section{Capítulo 6}

\section{Reacciones a un pedido de información}

Las emisiones que presentaremos en los capítulos que siguen están motivadas por una elicitación de información que se ha realizado previamente en el intercambio. Tomamos en cuenta aquellas expresiones que presentan una información en relación con lo solicitado. Recordamos que, como expusimos en el Marco teórico, las mismas tienen por función completar el acto informativo, en términos de Granato (2005).

Tal como procedimos en el análisis de las elicitaciones, agruparemos en forma provisoria las instancias analizadas en emisiones de tipo A y de tipo B, atendiendo a la distinción de dos grandes grupos de significados identificados en las pruebas perceptivas.

Recordemos que, como pudimos observar en el cuadro $n^{\circ} 6$ (Estado de la cuestión), los autores que hacen referencia a este tipo de emisiones, las describen desde otras perspectivas bajo el rótulo de frases asertivas o declarativas. En numerosos casos, se hace referencia a segmentos constituyentes de enunciados, con la denominación de "final" o "finalidad". A diferencia de las elicitaciones de información, los autores consultados no incluyen en el análisis comentarios referidos a las características sintácticas de las secuencias. Hirst y Di Cristo y Martins-Baltar precisan, para algunos casos, el carácter contrastivo a través de términos como "aserción perentoria" (MartinsBaltar), "declarativa enfática" (Hirst y Di Cristo). Otros refieren a la percepción de un desacuerdo con otros participantes de la interacción (Marandin, Morel y DanonBoileau). En cuanto a las significaciones provistas, podemos mencionar las siguientes como las más cercanas a la búsqueda de significados sistematizables que nos planteamos: 
$\underline{\text { Significaciones asociadas al movimiento melódico según Martins-Baltar y Morel y }}$ Danon-Boileau

\begin{tabular}{|c|c|c|}
\hline $\begin{array}{c}\text { Subsistema } \\
\text { de Tono } \\
\text { (enfoque } \\
\text { discursivo) }\end{array}$ & $\begin{array}{c}\text { Movimiento } \\
\text { melódico }\end{array}$ & \multicolumn{1}{|c|}{ Significado asociado } \\
\hline Proclamatorio & Descendente & $\begin{array}{l}\text { Aserción informativa } \\
\text { Agrega información (Martins- } \\
\text { Baltar, 1977) }\end{array}$ \\
\hline Referido & Ascendente & $\begin{array}{l}\text { Duda - imposibilidad de verificar } \\
\text { (Martins-Baltar, 1977) }\end{array}$ \\
\hline Neutral & Sostenido & $\begin{array}{l}\text { Ausencia de toda consideración de } \\
\text { la coenunciación. Ruptura del } \\
\text { desarrollo discursivo del enunciado. } \\
\text { (Morel y Danon-Boileau, 1998) }\end{array}$ \\
\hline
\end{tabular}

Cuadro $n^{\circ} 12$

El cuadro $n^{\circ} 12$ menciona en la columna de la izquierda los Tonos detectados en nuestros datos de emisiones informativas. La columna central detalla los movimientos melódicos que son tenidos en cuenta en las descripciones consultadas $y$, finalmente, la columna de la derecha menciona significados asociados en las perspectivas de MartinsBaltar y de Morel y Danon-Boileau. 


\subsection{Emisiones informativas de tipo A}

Seleccionamos para el análisis, como explicáramos en la Metodología, emisiones que presentan diferentes configuraciones en el plano sintáctico. Los aspectos que nos permiten agruparlas son las interpretaciones provistas por los sujetos francófonos. Como en el caso de las elicitaciones, presentaremos en el análisis emisiones con una extensión creciente.

\section{1 .1}

La siguiente secuencia muestra la emisión que efectúa una hablante en reacción a un pedido de información que analizáramos en 5.1.9 Reine, la madre de Blanche, le pide información sobre la localización del bar del que está hablando y la joven responde:

P 27:

R.C. : et il est où ce bar [ma fille?]

¿Y dónde está ese bar hija?

$\rightarrow \quad$ Bl.D. : [c'est rue] Amelot

en la calle Amelot

CFPP2000 [11-03] Blanche_Duchemin_F_25_Reine_Ceret_F_60_11 ${ }^{\mathrm{e}}$

(Líneas 375-376)

Los sujetos participantes de las pruebas perceptivas, aportaron los siguientes comentarios acerca del significado de esta emisión:

Elle donne l'information demandée.

Da la información solicitada.

Elle répond à la question de l'autre.

Responde a la pregunta de la otra.

Elle fournit l'information, c'est tout.

Provee la información, es todo.

Elle donne l'information qu'on lui demande.

Da la información que se le pide.

Elle donne l'adresse que sa mère lui avait demandée.

Da la dirección que su madre le había pedido. 


\section{Gráfico $n^{\circ} 23$}

P27:

(R)

(R)

(P)

R.C. : [/ (A) et il est où $(*) /(\mathrm{A})$ ce bar $\left.\left(310^{*}\right) /\right][/(\mathrm{M})$ ma fille $(*) /]$

(P)

$\rightarrow$ B.D. : [/(A) c'est rue (390)] Amelot (304) (M)/

[11-03] Blanche_Duchemin_F_25_Reine_Ceret_F_60_1 $1^{\mathrm{e}}$

(Líneas 375-376)

* El encabalgamiento hace imposible la medición de altura tonal con PRAAT.

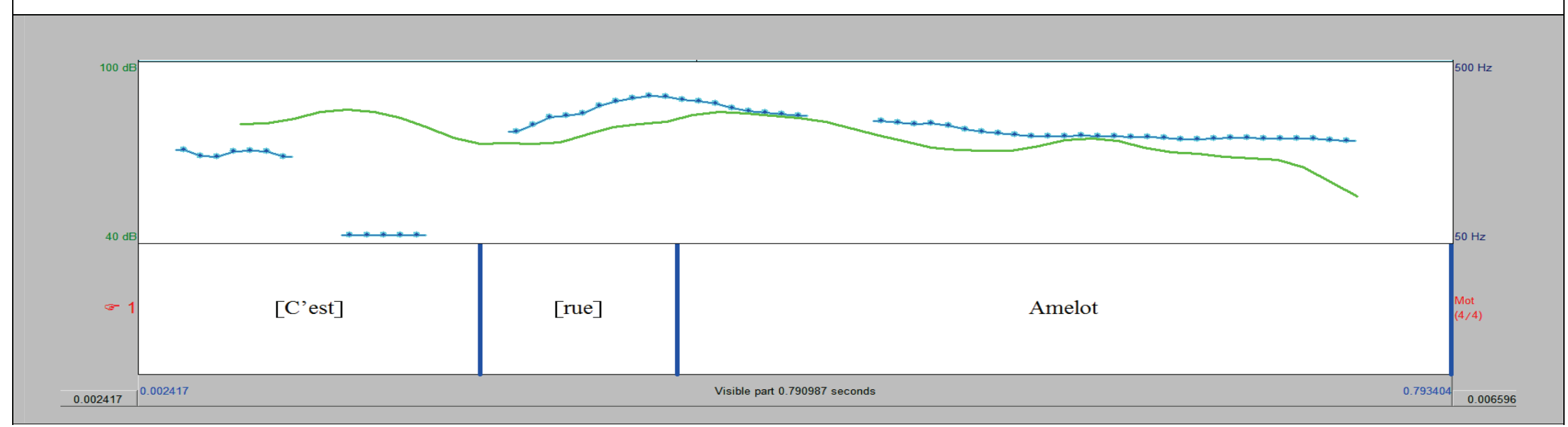


Elle répond à la question.

Responde a la pregunta.

C'est juste la réponse que l'autre lui avait demandée, l'adresse du bar.

Es sólo la respuesta que la otra mujer le había pedido, la dirección del bar.

$C$ 'est la réponse à la question de la mère.

Es la respuesta a la pregunta de la madre.

Elle répond et donne l'information, puis elle continue.

Responde y da la información, después continúa.

Elle donne la réponse à sa mère.

Le da la respuesta a su madre.

Elle est catégorique. Elle n'a rien à cacher à sa mère. Le ton est catégorique; c'est «Tu veux savoir ?... Ben, je te le dis ».

Es categórica. No tiene nada que esconderle a su madre. El tono es categórico; es "¿Querés saber?... Bueno, te lo digo".

Elle lui donne l'adresse.

Le da la dirección.

C'est juste la réponse, l'adresse que sa mère voulait savoir.

Es sólo la respuesta, la dirección que su madre quería saber.

Las apreciaciones provistas muestran, en forma unánime, que la hablante provee la información que le ha sido solicitada: " Elle donne l'information demandée. " "Elle répond à la question ... » en dos ocasiones «Elle fournit l'information... » « Elle donne l'adresse que sa mère lui avait demandée. " «C'est juste l'information que sa mère lui a demandée. " "C'est juste la réponse que l'autre lui avait demandée... " «C'est la réponse à la question de la mère. » «Elle répond et donne l'information ... « «Elle donne la réponse à sa mère. " "'Tu veux savoir ?... Ben, je te le dis.' " "Elle lui donne l'adresse. 》 " C'est juste la réponse, l'adresse que sa mère voulait savoir. »

"Da la información solicitada." "Responde a la pregunta..." "Provee la información..." "Da la información que se le pide." "Da la dirección que su madre le había pedido." "Es sólo la respuesta que la otra mujer le había pedido..." "Es la respuesta a la pregunta de la madre." "Responde y da la información..." "Le da la respuesta a su madre.” “¿Querés saber?... Bueno, te lo digo.” "Le da la dirección." "Es sólo la respuesta, la dirección que su madre quería saber.

Al observar los datos del análisis acústico, que presentamos en el gráfico $\mathrm{n}^{\circ} 23$, constatamos que se trata de una emisión realizada en una única unidad tonal extendida. Blanche inicia la emisión antes de que su madre concluya su elicitación, por lo que el segmento "c'est rue" se superpone con "ma fille" pronunciado por Reine. 
El Arranque de la emisión informativa de Blanche, ubicado en el elemento "rue", es alto, puede apreciarse que su altura tonal es de $390 \mathrm{~Hz}$. Este nivel tonal se determina, recordemos, por comparación con el Arranque precedente, en este caso, el de la unidad de Reine "ce bar" cuya altura es de aproximadamente 310 Hz. La Terminación, localizada en la sílaba tónica "lot" tiene un nivel medio, dado que su altura tonal concluye en $304 \mathrm{~Hz}$. El movimiento melódico de la sílaba tónica "lot" es el propio de un Tono Proclamatorio.

Recordamos que los autores consultados dan a este tipo de emisiones la denominación de "aserción” (Martins-Baltar, 1978) o “declarativa básica no enfática” (Hirst y Di Cristo, 1998).

\section{1 .2}

Presentamos a continuación una emisión informativa realizada también en una unidad tonal extendida. Luego de que Benoît D. solicita la confirmación de una información puntual acerca de los patos que había en la plaza del Temple, Étienne S. pronuncia una emisión que responde a tal solicitud y la culmina con un descenso melódico.

P 7:

B.D. : canards + ¿au square?

Patos + en la plaza?

$\rightarrow \quad$ E.S. : toujours au square du Temple

Sí claro, en la plaza del Temple

[CFPP2000] [03-01] Ozgur_Kiliç_H_32_alii_3 $3^{\mathrm{e}}$

(Líneas 85-86)

Las pruebas perceptivas permitieron obtener las siguientes interpretaciones acerca de lo significados de esta emisión:

Il se souvient qu'il y avait des canards au Square du Temple et le rappelle à l'autre.

Se acuerda que había patos en la plaza del Temple y se lo recuerda al otro.

Il affirme. Il dit à son copain ce qu'il lui avait demandé. Il est certain.

Afirma. Le dice a su amigo lo que le había preguntado. Está seguro.

Il confirme et il reste dans cette connivence avec les autres copains du groupe.

Confirma y sigue en esa complicidad con los demás del grupo.

Il insiste et confirme ce qu'il avait dit. Il évoque des choses qu'il ne dit pas. Il y a une complicité énorme, plein de non-dits.

Insiste y confirma lo que había dicho. Evoca cosas que no dice. Hay una complicidad enorme,

muchos implícitos. 


\section{Gráfico ${ }^{\circ} 24$}

P7:

(R)

B.D. : canards + / (A) au square (236)

(P)

$\rightarrow \quad$ E.S. : /(A) toujours (183) au square du Temple (102) (B)/

[CFPP2000] [03-01] Ozgur_Kiliç_H_32_alii 3c (Líneas 85-86)

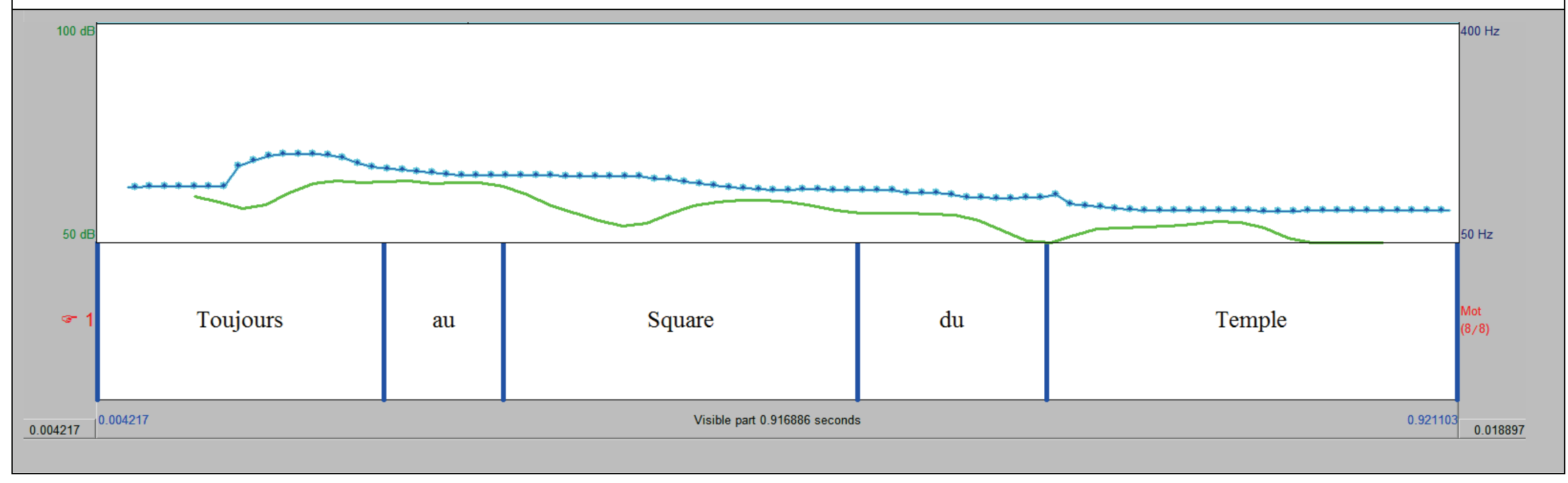


Il réaffirme. Comme de l'ironie un peu.

Reafirma. Como con un poco de ironía.

C'est une précision géographique sans émotion.

Es una precisión geográfica sin emoción.

Il joue le jeu. Après avoir rigolé, on précise.

Sigue el juego. Después de bromear, precisamos.

Il confirme, c'est une confirmation d'information.

Confirma. Es una confirmación de información

Il lui répond et réaffirme l'information qu'il avait donnée.

Responde y reafirma la información que había dado.

Il insiste, il confirme " Justement au square du Temple, il y a, des, canards. " Insiste y confirma "Precisamente, en la plaza del Temple, hay, patos."

Il confirme.

Confirma

Il confirme qu'il y avait des canards au Square du Temple.

Confirma que había patos en la plaza del Temple.

Estos comentarios se pueden agrupar de acuerdo con os siguientes significados:

a) El hablante provee una información que no se hallaba hasta el momento en el conocimiento común: "Il se souvient qu’il y avait des canards au Square du Temple et le rappelle à l'autre. » "Il affirme. Il dit à son copain ce qu'il lui avait demandé. » «C'est une précision géographique sans émotion. » «... on précise. » "Se acuerda que había patos en la plaza del Temple y se lo recuerda al otro." "Afirma. Le dice a su amigo lo que le había preguntado." "Es una precisión geográfica sin emoción.” "... precisamos.”

b) El hablante responde a la solicitud de confirmación: «Il confirme... » en seis oportunidades «Il réaffirme. » « ... c'est une confirmation d'information. » «Il lui répond et réaffirme l'information qu'il avait donnée. » "Confirma...” "Reafirma.” “...es una confirmación de información.” "Responde y reafirma la información que había dado."

Las características entonativas de esta emisión pueden visualizarse en el gráfico $\mathrm{n}^{\mathrm{0}} 24$. Como puede observarse, la misma está realizada con una unidad tonal extendida. El cotejo del Arranque con el Arranque de la unidad anterior de Benoît muestra un desfase importante en cuanto a los rangos melódicos y la intensidad. La elicitación "au Square" de Benoît tiene un Arranque Alto que alcanza los $236 \mathrm{~Hz}$. Aunque el rango de voz de Étienne es más grave y la intensidad de su elocución es mucho menor, puede percibirse que el Arranque de su emisión, situado en la sílaba "jours" (en $183 \mathrm{~Hz}$ ) tiene también un nivel alto. 
En cuanto al subsistema de Terminación, realizado sobre la sílaba tónica "Temple", el hablante elige un nivel bajo $(102 \mathrm{~Hz})$. Al respecto, cabe precisar que la perspectiva de Brazil no contempla el pasaje de un nivel tonal alto a uno bajo o viceversa. No obstante, la percepción de la fluctuación melódica de la secuencia permite detectar estas elecciones. Más aún, la elección de Arranque alto es consecuente con el significado general de contraste, dado que Étienne quiere responder de este modo reafirmando algo que Benoît parece cuestionar con su elicitación. Asimismo, la elección de una Terminación baja no proyecta expectativas respecto de la continuidad del diálogo, ya que la misma provee la información requerida $y$, por consiguiente, puede interpretarse que el hablante cierra el ciclo iniciado por la elicitación.

Finalmente, mencionamos que Étienne elige el Tono Proclamatorio para realizar su contribución.

Hasta ahora, analizamos en este apartado dos emisiones realizadas con un único grupo fónico. A continuación, presentaremos el análisis de una emisión más extensa, formada por dos unidades tonales.

\section{1 .3}

Al hacer referencia a las guerras de Mardi Gras que tenían lugar entre varios colegios, la entrevistadora pregunta a Augustin D. si él iba al colegio Victor Hugo. Otro de los participantes responde negativamente y luego Augustin realiza su contribución con una emisión que finaliza también con un descenso melódico:

P8:

E.S. : $\underline{\text { non }}$

No

O.K. : [T'en as $\underline{e u}$ ?]

[¿Tuviste?]

$\rightarrow \quad$ A.D. : [Moi j'étais à C] Couperin moi [Yo estaba en el C] Couperin.

CFPP2000 [03-01] Ozgur_Kilic_H_32_alii_3 $3^{\mathrm{e}}$

(Líneas 126-128)

Precisamos asimismo que, cuando Augustin responde, se produce un encabalgamiento con la intervención de Ozgur, quien a su vez pregunta “ $T$ 'en as eu?" para saber si había participado de las guerras entre colegios. 
A continuación, transcribimos los comentarios realizados por los sujetos en lo que respecta a esta emisión:

Il précise le nom du collège. Il insiste dessus.

Precisa el nombre del colegio. Insiste en eso.

Il marque la différence par rapport aux autres.

Marca la diferencia con respecto a los otros.

Il précise parce qu'il n'était pas à ce collège, il était à Couperin.

Precisa que él no estaba en ese colegio, estaba en el Couperin.

Il précise et il s'exclut du groupe à ce moment-là.

Precisa y se excluye del grupo en ese momento.

Il corrige, parce que l'intervieweuse avait mal compris.

Corrige, porque la entrevistadora había entendido mal.

C'est une précision.

Es una precisión.

Les autres ne se souvenaient peut-être pas et il précise qu'il était à Couperin.

Los otros tal vez no se acordaban quizá y él precisa que estaba en el Couperin.

Il signale qu'il ne fait pas partie de la bande. Il n'a pas la même toile de fond.

Señala que no es parte de la barra. No tiene el mismo telón de fondo.

Il précise parce qu'il n'était pas dans le même collège que les autres.

Precisa que no estaba en el mismo colegio que los otros.

Il donne l'information. Et c'est pour cela que les autres ne savaient pas s'il avait vécu les guerres de collège. Il vient d'un autre collège.

Da la información. Y es por eso que los otros no sabían si él había vivido las guerras de colegio. Él viene de otro colegio.

Il corrige l'intervieweuse. Il n'était pas à Victor Hugo, mais à Couperin.

Corrige a la entrevistadora. Él no estaba en el Víctor Hugo, sino en el Couperin.

Il affirme, il donne l'info. "Attention, il faut pas me confondre, moi j'étais Couperin ».

Afirma, da la información. "Atención, no hay que confundirme, yo estaba en el Couperin"

Il confirme qu'il était à Couperin, parce qu'apparemment tous n'étaient pas dans le même collège.

Confirma que él estaba en el Couperin, porque aparentemente no estaban todos en el mismo colegio.

Il donne la précision à l'a dame: "Moi j'étais pas dans le même collège, le mien s'appelait Couperin ».

Le da la precisión a la señora: "Yo no estaba en el mismo colegio, el mío se llamaba Couperin." 
Gráfico $\mathrm{n}^{\circ} 25$

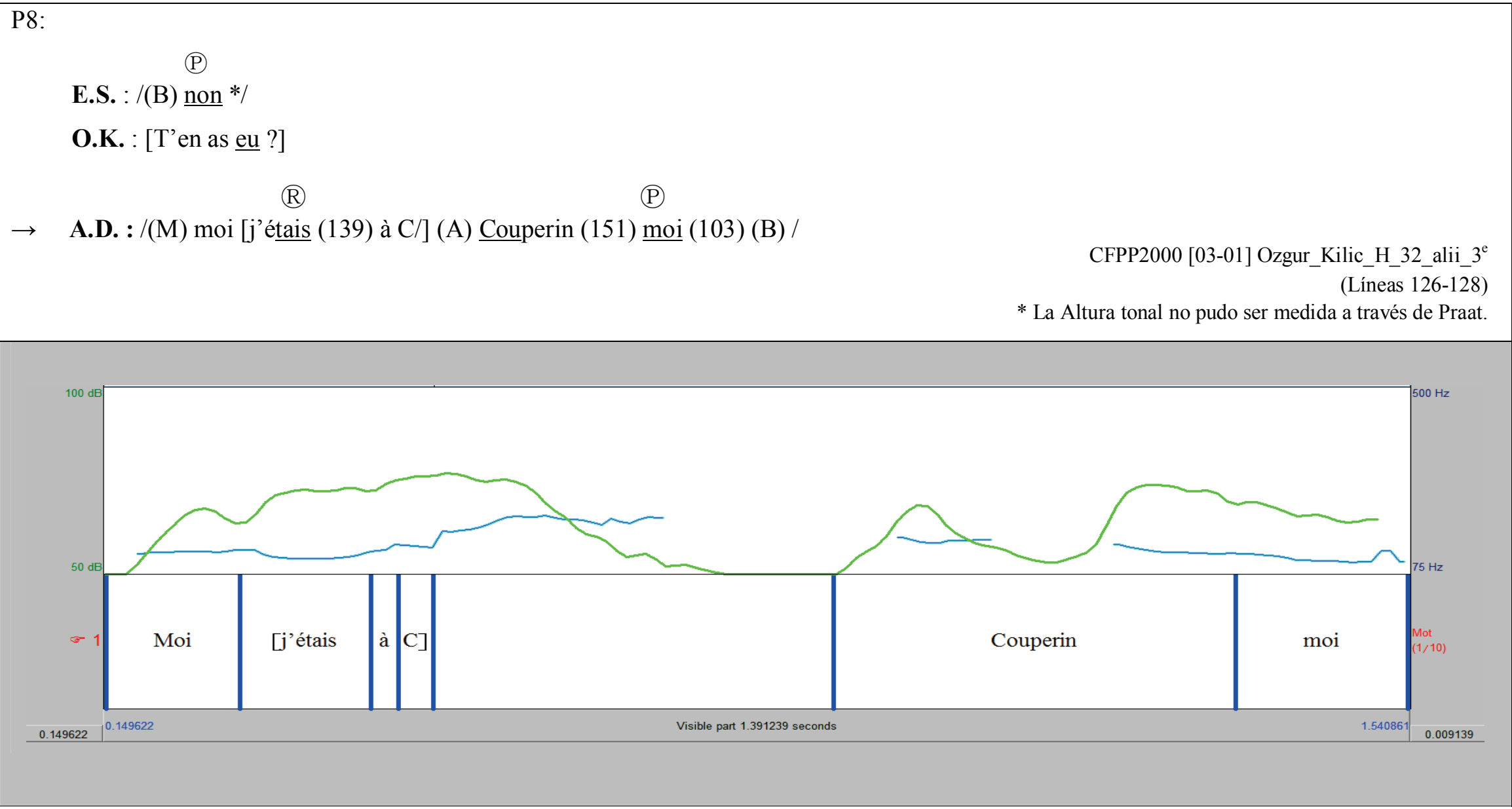


Los significados a los que los sujetos fueron sensibles pueden agruparse de la siguiente manera:

a) El hablante da una precisión: "Il précise le nom du collège. " "Il marque la différence par rapport aux autres. » "Il précise parce qu'il ...» «Il précise ... » «C'est une précision. " «... il précise qu'il ... » en dos de los comentarios «Il confirme qu'il ...» "Il donne la précision à la dame... » "Precisa el nombre del colegio." "Marca la diferencia con respecto a los otros." "Precisa que él..." "Precisa..." "Es una precisión." "... él precisa que..." "Confirma que él..." "Le da la precisión a la señora..."

b) La información no se encontraba hasta ese momento en el conocimiento común de los interlocutores: «Il corrige, parce que l'intervieweuse avait mal compris. » «Les autres ne se souvenaient peut-être pas ...» «Et c'est pour cela que les autres ne savaient pas s'il... « «Il corrige l'intervieweuse.» «Il affirme, il donne l'info. 'Attention, il faut pas me confondre, moi (...)' ").

"Corrige, porque la entrevistadora había entendido mal." "Los otros tal vez no se acordaban..." "Y es por eso que los otros no sabían si él..." "Corrige a la entrevistadora." "'Atención, no hay que confundirme, yo (...)"

En cuanto a sus características entonativas, que podemos visualizar en el gráfico $\mathrm{n}^{\mathrm{o}} 25$, la emisión presenta dos unidades tonales: una simple y una extendida consecutivamente. Ambas están separadas por una pausa y la primera se encuentra afectada por el encabalgamiento que mencionáramos más arriba. El Arranque y la Terminación de esta primera unidad se realizan en la sílaba tónica "tais" y tienen un nivel medio (139 Hz). Para el caso puntual del nivel de Arranque, recordamos que el Arranque precedente de la emisión “non" de Étienne S. no ha podido medirse a través de PRAAT. Sin embargo, se percibe que su nivel tonal es bajo.

En tanto, Augustin efectúa la segunda unidad con un Arranque en nivel alto, en la sílaba “Cou” (151 Hz) y con una Terminación en nivel bajo (el movimiento melódico finaliza en $103 \mathrm{~Hz}$ ). Puntualizamos aquí que Brazil no contempla en su modelo una transición que "salte" niveles tonales, es decir, que una Terminación baja siga un Arranque alto. No obstante, el contraste percibido entre el nivel tonal del Arranque y el de la Terminación de esta unidad es muy notorio, lo cual permite, teniendo en cuenta el significado expresado, determinar que la Terminación no se realiza en nivel medio, sino bajo. 
El hablante opta por el Tono Referido para la primera unidad y por el Proclamatorio para la segunda. Se constata además que en el primer grupo, afectado por la superposición de turnos, el hablante suspende su emisión. Se produce una pequeña pausa de 435 centisegundos (durante la cual Ozgur finaliza su intervención) y luego Étienne completa la unidad informativa.

Desde la léxico-gramática, la reiteración del pronombre tónico 'moi' (que Augustin realiza en dos oportunidades en esta secuencia) se asocia con un procedimiento enfático (Charaudeau, 1992). En su descripción de la entonación, Martins-Baltar (1977) precisa que la aserción perentoria está también acompañada por una entonación descendente y que la misma vehiculiza un significado de presentación de información que no sería compartida por los participantes del intercambio. Sería entonces posible caracterizar esta emisión como una frase declarativa enfática y constatar que la descripción de Martins-Baltar coincide con nuestras observaciones.

La emisión informativa que presentamos a continuación cuenta también con dos unidades tonales.

\section{1 .4}

La intervención que exponemos se produce luego de que se abordara el tema de los perros y la suciedad que dejan en las calles. La entrevistadora realiza una elicitación a la cual Ozgur responde de la siguiente manera:

P4:

\section{S.B. : donc + chiens $\underline{\text { merde }}$ \\ Entonces + perros mierda}

$\rightarrow \quad$ O.K. : ouais chiens égal euh ouais à Paris oui

Sí perros igual eh se en París sí.

[CFPP2000] [03-01] Ozgur_Kiliç_H_32_alii_3 ${ }^{\mathrm{e}}$

(Líneas 61-62)

Los sujetos participantes de las pruebas perceptivas expresaron las siguientes impresiones respecto de la emisión de Ozgur:

Il affirme qu'à Paris les chiens salissent les trottoirs.

Afirma que en París los perros ensucian las veredas.

$C$ 'est une confirmation.

Es una confirmación

Il acquiesce à son discours [celui de l'enquêtrice]. 
Asiente su discurso [el de la entrevistadora].

Il répond et il précise.

Responde y precisa.

Il valide ce que l'intervieweuse a proposé.

Valida lo que propuso la entrevistadora.

Ce que l'intervieweuse voulait dire en fait, c'est « chiens égal merde » Et lui, il affirme le «égal».

Lo que la entrevistadora quería decir en realidad es "perros igual mierda". Y él afirma el "igual".

Il est d'accord, mais il s'empresse de préciser que c'est pour Paris.

Está de acuerdo, pero se apura a precisar que es para París.

Il lui confirme.

Le confirma.

Il est obligé d'admettre ce que dit l'intervieweuse, mais il sent qu'il faut préciser.

Está obligado a admitir lo que dice la entrevistadora, pero siente que es necesario precisar.

Il limite l'affirmation de l'intervieweuse mais, en même temps, il confirme aussi.

Limita la afirmación de la entrevistadora pero, al mismo tiempo, confirma también.

Il reprend ce qu'elle a dit et en plus en situant géographiquement la situation. Il est sûr de lui en le disant.

Retoma lo que ella dijo, situando geográficamente la situación, además. Está seguro de sí mismo cuando lo dice.

Il confirme.

Confirma.

Il confirme ce qu'elle avait dit.

Confirma lo que ella le había dicho.

Il confirme l'information qu'on lui avait demandée.

Confirma la información que le habían pedido.

Il confirme et précise que c'est à Paris.

Confirma y precisa que es en París. 
Gráfico ${ }^{\circ} 26$

P4

(P)

(P)

S.B.: /(M) donc (219) / (M) chiens merde (182)/

(N)

(P)

$\rightarrow$ O.K. : /(M) ouais (133) chiens égal euh: (108) (M) /(B) ouais à Paris oui (93)/

[CFPP2000] [03-01] Ozgur_Kiliç_H_32_alii_3 (Líneas 61-62)

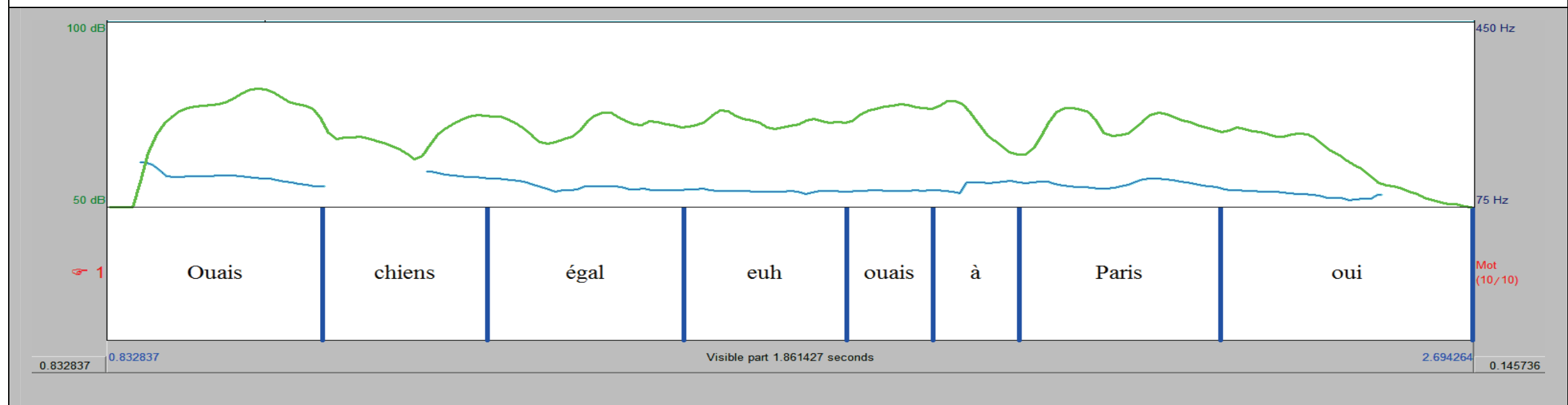


Los significados expresados en estos comentarios comparten las siguientes características:

a) La presentación por parte del hablante de una información nueva: "Il affirme qu'à Paris les chiens salissent les trottoirs. » «... et il précise. » «... il s'empresse de préciser que... » «... mais il sent qu’il faut préciser. » «Il limite l'affirmation de l'intervieweuse...» «Il reprend ce qu'elle a dit et en plus en situant géographiquement la situation.» «...et précise que c'est à Paris. »

"Afirma que en París los perros ensucian las veredas." "... y precisa." "pero se apura a precisar que..." "... pero siente que es necesario precisar." "Limita la afirmación de la entrevistadora..." "Retoma lo que ella dijo, situando geográficamente la situación, además." "y precisa que es en París."

b) La respuesta del hablante a un pedido de confirmación: " C'est une confirmation.» «Il acquiesce à son discours [celui de l'enquêtrice]. " «Il répond...» «Il valide ce que l'intervieweuse a proposé. » « Ce que l'intervieweuse voulait dire en fait, c'est 'chiens égal merde' Et lui, il affirme le 'égal'. » "Il est d'accord, ... " «Il lui confirme.» «Il est obligé d'admettre ce que dit l'intervieweuse, ... « «... il confirme aussi. » «Il confirme.» en cuatro oportunidades.

"Es una confirmación." "Asiente su discurso [el de la entrevistadora]." "Responde... Valida lo que propuso la entrevistadora." "Lo que la entrevistadora quería decir en realidad es "perros igual mierda'. Y él afirma el 'igual'." "Está de acuerdo..." "Le confirma." "Está obligado a admitir lo que dice la entrevistadora..." “... confirma también." "Confirma...” en cuatro oportunidades

El análisis acústico, que puede visualizarse en el gráfico $n^{\circ} 26$, permitió determinar que la misma es realizada en dos unidades tonales. La primera unidad es extendida y su Arranque se realiza en un nivel medio, sobre el ítem léxico "ouais" (133 Hz). El nivel tonal se estableció por comparación con el Arranque precedente de la emisión de Sonia “chiens merde" situado sobre el último ítem léxico, con una altura tonal de $182 \mathrm{~Hz} .{ }^{17} \mathrm{La}$ terminación tiene asimismo un nivel medio, realizdo sobre el ítem "euh", que alcanza los $108 \mathrm{~Hz}$. La segunda unidad es simple y cuenta con un Arranque y una Terminación en nivel bajo $(93 \mathrm{~Hz})$ realizada sobre el ítem léxico "oui”.

Las elecciones de Tono que opera el hablante son el Tono Neutral y el Tono Proclamatorio para la primera y la segunda unidad respectivamente.

\footnotetext{
${ }^{17}$ Recordemos que es necesario tener en cuenta en estos casos que los rangos de $\mathrm{F}_{0}$ femeninos son frecuentemente más agudos que los masculinos.
} 
La emisión que nos ocupa en el apartado siguiente tiene dos unidades tonales extendidas que también utilizan el descenso melódico final.

6.1 .5

La secuencia que expondremos ahora concluye un intercambio en el que la entrevistadora solicita información acerca de las frutas exóticas que pueden encontrarse en los comercios del distrito. Luego de haber mencionado una fruta, Lucie dS. realiza la intervención que sigue en forma superpuesta con otras emisiones de Anne y de Francine:

P 15 :

F. : On en a goûté mais : + on n'a pas aimé [c't espèce de de truc énorme là]

Lo probamos pero: + no nos gustó [esa especie de de cosa enorme]

A. : [C'est quoi? un fruit?]

[¿Qué es? ¿una fruta?]

$\rightarrow \quad$ L.dS. : [Si ça je si s ce j’aij'j'ai dé]couvert ça dans un supermarché ouais.

[Sí eso sí s eso yo he y yo des]cubrí eso en un supermercado se.

CFPP2000 [07-02] Lucie_da_Silva_F_22_7 ${ }^{\mathrm{e}}$

(Líneas 192-194)

Consultados acerca de los significados asociados con esta intervención de Lucie, los sujetos manifestaron los siguientes conceptos:

Elle affirme sans passion. Ça ne les a pas marquées.

Afirma sin pasión. Eso no las marcó.

Elle dit ça, "Ah, oui, maintenant que j'en parle, je me rappelle... » ça répond quandmême parce que l'intervieweuse avait demandé s'ils avaient découvert quelque chose.

Ella dice eso "Ah, sí, ahora que lo menciono, me acuerdo..." de todas formas eso responde porque la entrevistadora había preguntado si habían descubierto algo.

Elle répond juste pour entretenir l'échange 'je ne coupe pas la communication'.

Responde sólo para mantener el intercambio "no corto la comunicación".

Ça c'est informatif. Il n'y a pas d'intention de dire autre chose que où elle a trouvé ça.

Eso es informativo. No hay intención de decir otra cosa más que dónde encontró eso.

Elle répond à l'intervieweuse, à la question de l'intervieweuse, enfin.

Responde a la entrevistadora, a la pregunta de la entrevistadora, al fin.

C'est une affirmation.

Es una afirmación. 


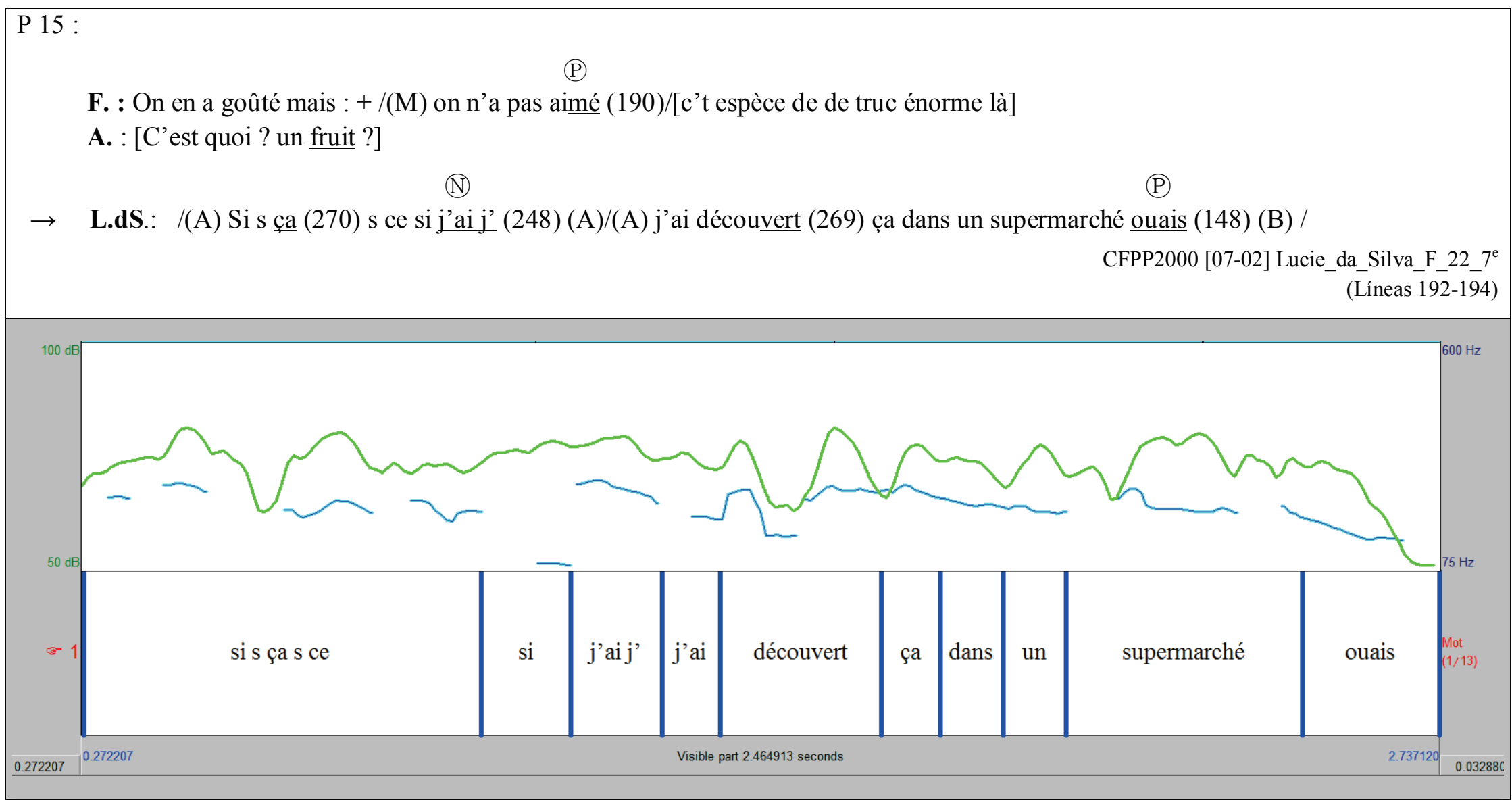


Elle comprend ce dont il s'agit [la question de l'intervieweuse]. Elle exprime son soulagement parce qu'elle peut donner une réponse. Ce qui est dit passe en arrière plan.

Comprende de lo que se trata [la pregunta de la entrevistadora]. Expresa su alivio por poder dar una respuesta. Lo que dice pasa a segundo plano.

Elle reprend la question antérieure. Et elle finit par conclure qu'elle a bien découvert quelque chose de nouveau.

Retoma la pregunta anterior. Termina reconociendo que, efectivamente, descubrió algo nuevo.

C'est par rapport à la question qui avait été posée avant. Elle confirme et puis elle ajoute qu'elle l'a découvert dans un supermarché.

Es con respecto a la pregunta que había sido hecha antes. Confirma y después agrega que lo descubrió en un supermercado.

Elle confirme. Et en même temps, elle clôt le sujet.

Confirma. Al mismo tiempo, cierra el tema.

Elle confirme par le biais du pomélo qu'il y a quelque chose d'exotique. Comme si la mémoire lui revenait.

Confirma a través del pomelo que hay algo exótico. Como si le viniera a la memoria.

Oui, c'est probable, oui. «Ah, si, si! Maintenant que tu me dis, j'ai découvert ça dans un supermarché. "

Sí, es probable, sí. "Ah, sí, sí! Ahora que me decís, descubrí eso en un supermercado."

Esos comentarios pueden agruparse de acuerdo con los siguientes significados que comparten:

a) La información que la hablante aporta es nueva: «'Ah, oui, maintenant que j'en parle, je me rappelle'... » «Ça, c'est informatif. Il n'y a pas d'intention de dire autre chose que où elle a trouvé ça» « .... et puis elle ajoute qu'elle l'a découvert dans un supermarché. » «Elle confirme...» «Elle confirme par le biais du pomélo qu'il y a quelque chose d'exotique. Comme si la mémoire lui revenait. » «'Ah, si, si! Maintenant que tu me dis, j’ai découvert ça dans un supermarché'. »

"'Ah, sí, ahora que lo menciono, me acuerdo..." "Eso es informativo. No hay intención de decir otra cosa que dónde encontró eso." "...y después agrega que lo descubrió en un supermercado." "Confirma..." "Confirma a través del pomelo que hay algo exótico. Como si le viniera a la memoria." "'Ah, sí, sí! Ahora que me decís, descubrí eso en un supermercado."”

b) La información responde a la solicitud de información que había expresado la entrevistadora: «... ça répond quand-même parque que l'intervieweuse avait demande s'ils avaient découvert quelque chose. » «Elle répond... » « Elle répond 
à l'intervieweuse, à la question de l'intervieweuse, enfin. » «Elle exprime son soulagement parce qu'elle peut donner une réponse. 》 « Elle reprend la question antérieure. Et elle finit par conclure qu'elle a bien découvert...» «C'est par rapport à la question qui avait été posée avant. Elle confirme... »

“...de todas formas eso responde porque la entrevistadora había preguntado si habían descubierto algo." "Responde..." "Responde a la entrevistadora, a la pregunta de la entrevistadora, al fin." "Expresa su alivio por poder dar una respuesta." "Retoma la pregunta anterior. Termina reconociendo que, efectivamente, descubrió..." "Es con respecto a la pregunta que había sido hecha antes. Confirma..."

Respecto del análisis acústico (ver gráfico $n^{0}$ 27), precisamos que, además del encabalgamiento con otras intervenciones, la emisión de Lucie presenta la particularidad de un falso comienzo que dificulta el análisis de la primera parte de la misma. Esta situación se invierte, dado que el final de la emisión es muy evidente. Prueba de ello es, además, que las interpretaciones de los sujetos no fueron dubitativas. El Arranque de la primera unidad se ubica en la sílaba "ça" y tiene un nivel alto situado en $270 \mathrm{~Hz}$, mientras que el Arranque de la unidad precedente, pronunciada por Francine (“on n'a pas aimé”), alcanza los $190 \mathrm{~Hz}$. La Terminación se realiza sobre la secuencia “j'ai j” y tiene también un nivel alto $(248 \mathrm{~Hz})$. La segunda unidad cuenta asimismo con un Arranque en nivel alto $(269 \mathrm{~Hz})$, realizado sobre la sílaba "vert" y con una Terminación en nivel Bajo, ubicada en la sílaba tónica "ouais" (148 Hz). La hablante produce un Tono Neutral en la primera unidad y un Tono Proclamatorio en la segunda.

Cerraremos este capítulo con el análisis de una emisión más extensa, que incluye tres unidades entonativas.

\title{
6.1 .6
}

Gabriel P., cuyos hijos asisten a la misma escuela a la que él fue cuando era niño, es interrogado acerca de si hubiera sido posible encontrar a sus propios maestros en la institución. En reacción a la elicitación, el entrevistado realiza la siguiente emisión:

P43:

\author{
G.P. : [non non $]$ \\ No no \\ F.L. : [Ça aurait] pu? \\ ¿Podría haber sido?
}


$\rightarrow \quad$ G.P. : ouais ouais ça aurait pu mais non non ils sont tous partis ils sont ils sont plus là- $\underline{\text { bas }}+$

Se se podría haber sido pero: no no todos se fueron ya no ya no están más ahí.

[CFPP2000] [13-01] Gabriel_Pujade_H_40_13 ${ }^{\mathrm{e}}$

(Líneas 699-702)

Las pruebas perceptivas permitieron obtener los siguientes comentarios acerca del significado de esta intervención:

Il affirme nettement qu'ils ne sont plus au collège.

Afirma claramente que ya no están en el colegio.

Il répond sans plus.

Responde sin más.

Il pense et il cherche pourquoi non, puis, il le dit.

Piensa y busca por qué no, después lo dice.

Il répond à la question.

Responde a la pregunta.

Il répond en justifiant son affirmation. On voit qu'il s'est renseigné.

Responde justificando su afirmación. Se ve que se informó.

Il répond et il dit pourquoi.

Responde y dice por qué.

Il réfléchit, puis il répond.

Piensa y después responde.

Encore une réponse très calme, très claire, mais complètement lisse. Il répond à la question de la dame.

Otra respuesta muy serena, muy clara, pero completamente insípida. Responde a la pregunta de la señora.

Là, il cherche à donner l'information.

Ahí busca dar la información.

Il lui répond quand-même, comme si c'était une question. Mais je pense qu'il reprend.

" Ça aurait pu, c'est vrai, t'as raison..."

Le responde de todas formas, como si fuera una pregunta. Pero creo que lo que hace es retomar

"Podría haber sido, es cierto, tenés razón..."

Le « oui, non non " c'est pour garder vraiment le fil de l'interlocution. Le récepteur qui dit oui, et puis non non. " Oui, je comprends ta question, mais non non, je vais te répondre vraiment à la question ».

El "sí, no no" es para conservar realmente el hilo de la interlocución. El receptor que dice "sí", y después "no no". "Sí, entiendo tu pregunta, pero no no, te voy a responder realmente a la pregunta".

Dans le ton qu'il emploie, on se doute qu'il a fait des recherches. Il justifie pourquoi ses instits ne sont pas là. 
Gráfico $\mathrm{n}^{\circ} 28$

P43 :

(

F.L. : /[ (A) ça aurait $] \underline{\mathrm{pu}}(305) /$

(R)

$\rightarrow$ G.P. : /(A) oui oui ça aurait pu (208)/(M) mais (165) non non ils sont tous partis (M)*/

(P)

(M) ils sont (146) ils sont plus là-bas (122) (B) /

[CFPP2000] [13-01] Gabriel_Pujade_H_40_13 ${ }^{\mathrm{e}}$ (Líneas 699-702)

* No puede ser medido por Praat por la presencia de ruido.

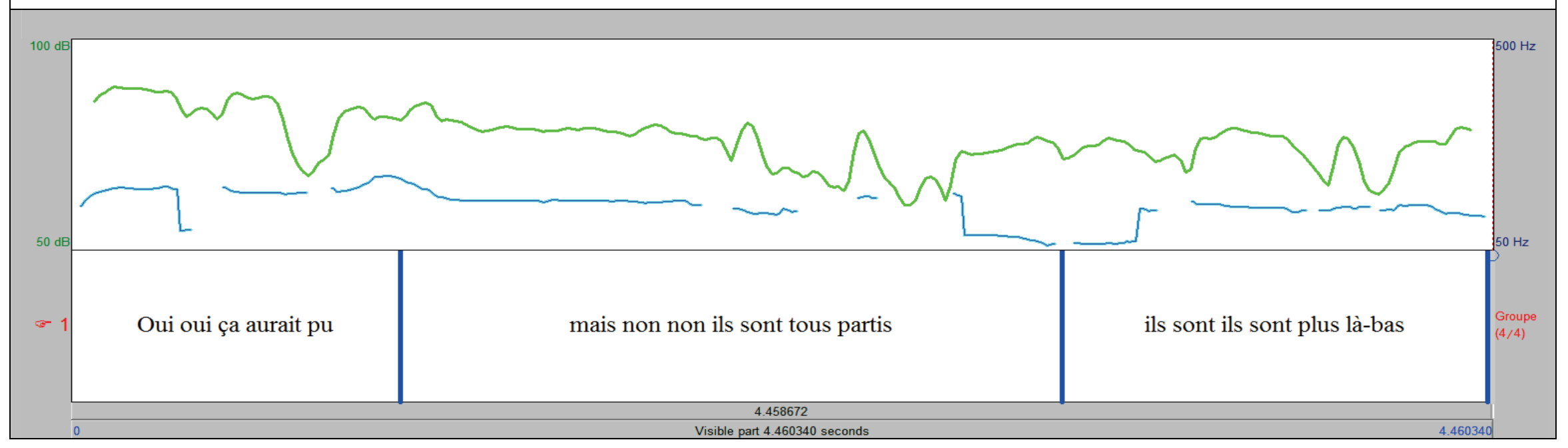


Por el tono que emplea, uno se da cuenta de que investigó. Justifica por qué sus maestros no están ahí.

Il répond à la question. Il n'y a pas de sous-entendus.

Responde a la pregunta. No hay nada implícito.

Las impresiones obtenidas manifiestan dos aspectos generales del significado de la emisión:

a) El hablante da una información: "Il affirme nettement qu'ils ne sont plus au collège. » «... et il cherche pourquoi non, puis, il le dit. » «... en justifiant son affirmation. On voit qu'il s'est renseigné. » «... et il dit pourquoi. » «Là, il cherche à donner l'information. » «Dans le ton qu'il emploie, on se doute qu'il a fait des recherches. Il justifie pourquoi ses instits ne sont pas là. »" "Afirma claramente que ya no están en el colegio." “... y busca por qué no, después lo dice.” “... justificando su afirmación. Se ve que se informó." "... y dice por qué." "Ahí busca dar la información." "Por el tono que emplea, uno se da cuenta de que investigó. Justifica por qué sus maestros no están ahí."

b) La información responde a la elicitación de la entrevistadora: «Il répond » en ocho oportunidades « '... je vais te répondre vraiment à la question'».

"Responde" "“... te voy a responder realmente a la pregunta."”

Como puede apreciarse en el gráfico $\mathrm{n}^{\mathrm{o}} 28$, el análisis acústico muestra que la emisión de Gabriel P. consta de una unidad tonal simple seguida por dos unidades extendidas. El Arranque y la Terminación de la primera unidad se realizan, consecuentemente, sobre la sílaba tónica " $p u$ " y tienen un nivel Alto $(208 \mathrm{~Hz})$. El valor de Arranque surge de su comparación con el Arranque de la unidad precedente de Florecne L. en la unidad léxica " $p u$ " (305 Hz). Nuevamente, es necesario recordar que la gran diferencia de altura en Hertz entre ambos Arranques se debe a la disparidad entre los rangos femenino y masculino de los participantes, por lo que se establece que la emisión de Gabriel tiene un Arranque alto aun cuando su altura es casi $100 \mathrm{~Hz}$ menor que la de Florence.

En la segunda unidad, "mais non non ils sont tous partis", el hablante realiza un Arranque en nivel medio $(165 \mathrm{~Hz})$ sobre el elemento "mais", nivel tonal que se reitera en la Terminación de la unidad. La misma, así como el inicio de la tercera unidad, se encuentran afectadas por la presencia de ruido, como consta en el gráfico y su altura no pudo ser medida con PRAAT.

La tercera unidad, "ils sont ils sont plus là-bas" cuenta también con un Arranque en nivel Medio, en la primera realización del ítem "sont" (146 Hz). En tanto la 
Terminación es efectuada sobre la sílaba tónica "bas" con una altura tonal baja de 122 Hz.

En lo referido a las realizaciones de Tono, Gabriel realiza la primera unidad con Tono Referido y las dos últimas unidades con Tono Proclamatorio.

A modo de síntesis de lo expuesto en este capítulo, presentaremos el examen porcentual del conjunto de las emisiones en lo referido a las elecciones en tres subsistemas estudiados.

En cuanto a las elecciones operadas en el subsistema de Arranque, el gráfico $\mathrm{n}^{\mathbf{0}} 29$ Expone los porcentajes de ocurrencias por cada uno de los tres niveles del subsistema.

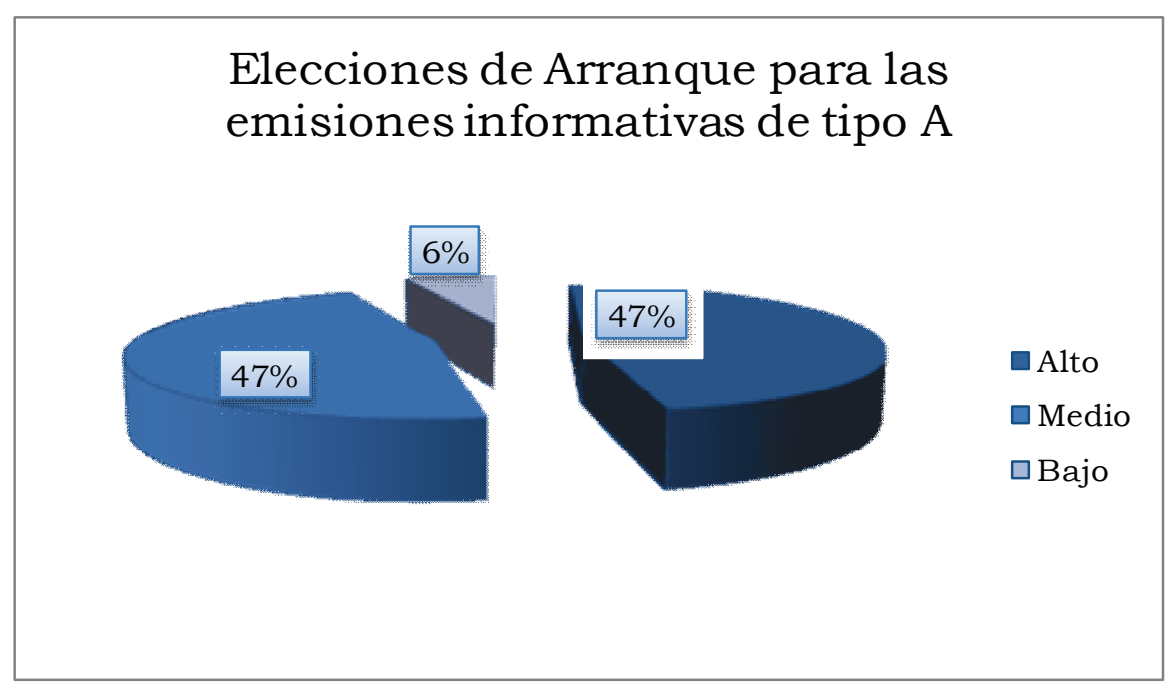

Gráfico $n^{\circ} 29$

Podemos observar que, en este grupo de emisiones informativas, los Arranques en nivel alto tienen tanta incidencia como los que se realizan con nivel medio: ambos representan el $47 \%$ de las elecciones. Los Arranques en nivel bajo, por su parte, totalizan el 6\% de las realizaciones. Cabe recordar que las elecciones en este subsistema no pueden escindirse de las realizaciones de Arranque de la unidad precedente. Como lo afirman Brazil para el inglés y Granato para el español, las opciones del subsistema parecen expresar significados referidos al grado de armonía o de contraste existente entre la emisión en curso y la precedente; fundamentalmente aquellos que fueron expresados por los interlocutores al momento de solicitar la información a la que estas emisiones responden. Recordamos entonces que la elección de Arranque en nivel alto manifiesta contraste. En nuestros datos, esta elección fue frecuentemente motivada por 
la Adjudicación expresada en la intervención previa con una Termianción alta. Inversamente, los Arranques en nivel medio, expresan la adición de información. En las pruebas perceptivas, recordemos, fueron numerosas las referencias a la actitud colaborativa del hablante quien, con su aporte informativo, cubre las expectativas planteadas en la elicitación. Por último, la elección de Arranque en nivel bajo, que tuvo una mínima incidencia en los datos, transmite significados que ponen a lo dicho en relación de equivalencia con lo manifestado anteriormente, por lo que puede apreciarse que el hablante porta la información también de un modo concordante con la elicitación previa. Comprobamos entonces que la incidencia de emisiones que brindan información planteando un contraste es casi tan importante como la de aquellas que simplemente responden al pedido de información con el aporte solicitado.

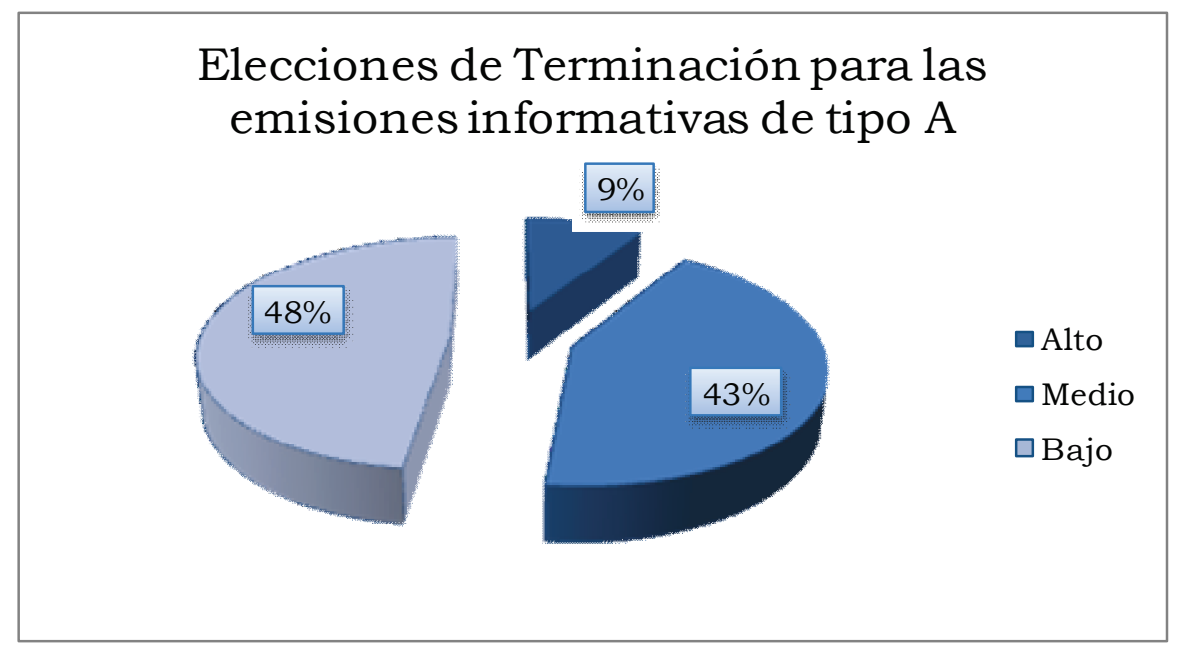

Gráfico $n^{\circ} 30$

En lo referido a las opciones en el subsistema de Terminación, plasmadas en el gráfíco $n^{\circ} 30$, se constata una leve preferencia de la realización de nivel bajo, que representó el $48 \%$ de las ocurrencias. Las mismas expresan, en coincidencia con los estudios del inglés y del español, ausencia de expectativas con respecto a la continuidad del intercambio, por lo cual puede pensarse que, como comentáramos en el análisis de 2.1.2, una vez provista la información, se entiende que se cierra una secuencia iniciada con la elicitación que la motivara. La Terminación en nivel medio se seleccionó en el $43 \%$ de las emisiones de tipo A contabilizadas en los datos. Este nivel de Terminación proyecta expectativas de que las intervenciones siguientes concuerden con lo manifestado en la emisión. Entendemos que, en estos casos, se impone la idea de que el tema no se da por agotado y se prevén otras intervenciones referidas al mismo. Por su 
parte, las realizaciones de Terminación en nivel alto son relativamente marginales, ya que representan un $9 \%$ de las ocurrencias. Las mismas proyectan una expectativa de que el interlocutor inicie su intervención con un Arranque alto, que manifieste oposición con otra opinión. En nuestros datos, algunas de estas emisiones son pronunciadas en una unidad simple y es posiblemente el significado de contraste, transmitido por el Arranque alto, el que se impone en la elección del hablante.

En cuanto a las elecciones realizadas en el subsistema de Tono, los hablantes optaron en todos los casos por el Tono Proclamatorio. Inversamente, en todos los casos en los que los sujetos de las pruebas perceptivas declararon que se presenta una información como nueva o como no presente en el contexto de la interacción, los locutores habían empleado el Tono Proclamatorio.

Se observa de este modo que existe una correspondencia entre nuestro análisis y la descripción efectuada por Martins-Baltar, quien atribuye la entonación descendente a la modalidad asertiva que agrega información. Desde una perspectiva que toma en cuenta el movimiento que se produce en toda la unidad, y no sólo el de su sílaba tónica, Hirst y Di Cristo describen la "declarativa básica no enfática" con una entonación ascendentedescendente. Para estos autores, el segmento que asciende es anterior a la sílaba tónica, en la cual se opera el descenso final. Si tenemos en cuenta que el modelo que tomamos como base para el análisis no atribuye un valor comunicativo sistematizable a las sílabas precedentes a la sílaba tónica vemos que hay coincidencia entre la descripción de Hirst y Di Cristo y nuestro trabajo.

En el apartado siguiente, abordaremos emisiones informativas cuyas interpretaciones difirieron en las pruebas perceptivas con respecto a las analizadas aquí. 


\subsection{Emisiones informativas de tipo B}

Dentro del conjunto de emisiones que reaccionan a elicitaciones de información, encontramos secuencias que difieren de las analizadas en el apartado 6.1, no sólo por la interpretación de los sujetos sino también por sus características entonativas. Como veremos a continuación, pese a las diferentes configuraciones sintácticas, las secuencias que nos ocupan ahora comparten la elección de una entonación final ascendente. Inversamente a lo que ocurría con las emisiones informativas de tipo A, estas emisiones generaron cierta dificultad en la interpretación, que requirió a menudo una segunda o tercera pregunta para intentar determinar los significados que los sujetos detectan. Comenzaremos este apartado con el análisis de una emisión breve, realizada en una unidad tonal.

\section{2 .1}

Al intentar establecer algunas precisiones respecto de un colegio del barrio de su infancia, un hablante solicita información a sus amigos. En reacción con este pedido, Augustin D. inicia una contribución que queda trunca (“y avait”) y está íntegramente superpuesta con la emisión que examinaremos, de Benoît D.:

P53:

O.K.: parce que c'était quelle école [A.D. : c'était infernal] qui venait euh Porque cuál era la escuela [A.D.: era infernal] que venía eh

A.D. : ah c'était euh [y avait $]$ Era eh [había ]

$\rightarrow$ B.D. : [c'était] Charlemagne?

[Era la] Charlemagne

[CFPP2000] [03-01] Ozgur_Kiliç_H_32_alii_3 ${ }^{\mathrm{e}}$ (Líneas 138-142)

Consultados por su interpretación de la emisión, los sujetos francófonos vertieron las siguientes consideraciones:

Il le dit plutôt interrogativement. Il le savait quand même.

Lo dice más bien interrogativamente. Sin embargo Lo sabía.

C'est une évidence. "On sait tous la réputation de ce collège ». Il constate, il rappelle à la mémoire de l'autre. 
Es una evidencia. "Todos sabemos la reputación de ese colegio". Constata, lo trae a la memoria del otro.

Il pose vraiment une question sans sous-entendu derrière.

Realmente hace una pregunta sin dobles intenciones.

C'est une restitution de scène de crime. "On est bien d'accord sur les lieux, l'endroit, les participants », il y a une mise au point de ça.

Es una restitución de la escena del crimen. "Estamos de acuerdo con respecto al lugar, el entorno, los participantes", se deja en claro esto.

C'est pas une question. Ou bien il pose à moitié la question [Après une réécoute] Il répond.

No es una pregunta. O bien hace la pregunta a medias [Después de volver a escuchar] Él responde.

Ce qu'il veut dire par là, c'est « Évidemment! » "C'était évident, c'était les pires du quartier. »

Lo que quiere decir con eso es "iObviamente!" "Era obvio, eran los peores del barrio."

Il a compris où se tenait ce genre de scène. Il demande de confirmer : " J'ai un doute, tu parles du lycée Charlemagne? Confirme-moi. »

Entendió dónde ocurría ese tipo de escenas. Pide que le confirmen: "Tengo una duda, ¿hablás del liceo Charlemagne? Confirmame."

En fait, ce qu'il dit c'est "C 'est connu, ça fait partie de notre cadre commun. "

En realidad, lo que dice es "Es conocido, eso forma parte de nuestro marco común."

"Tu es bien sûr que c'était Couperin, ce n'était pas plutôt Charlemagne? " Il pose la question, je pense. Il suppose que c'est Charlemagne mais il n'en est pas sûr.

“¿Estás bien seguro de que era el Couperin, no era más bien el Charlemagne?” Hace la pregunta, me parece. Supone que es Carlemagne pero no está seguro.

Il attend que le reste du groupe confirme pare que c'est un souvenir commun.

Espera que el resto del grupo confirme, porque es un recuerdo común.

Il n'est pas certain de ce qu'il propose.

No está seguro de lo que propone.

Ce collège est connu. Je ne peux pas dire ce qu'y a derrière mais, pour eux, c'est connu. "C'était Charlemagne » et c'est comme si on disait tout avec ça.

El colegio es conocido. No puedo decir lo que hay detrás pero, para ellos, es conocido. "Era el Charlemagne" y es como si eso lo dijera todo.

D’une certaine manière, il sait que c'est ça et il demande l'approbation du reste et les autres confirment.

En cierta forma, él sabe que es eso y pide la aprobación del resto y los otros confirman. 
Gráfico $n^{\circ} 31$ :

P53:

(N)

A.D. : /(M) ah c'était euh (114) / [y avait]

(R)

$\rightarrow$ B.D. : /(A) [c'était] Charlemagne (215)/

[CFPP2000] [03-01] Ozgur_Kiliç_H_32 alii_3 ${ }^{\mathrm{e}}$ (Líneas 138-142)

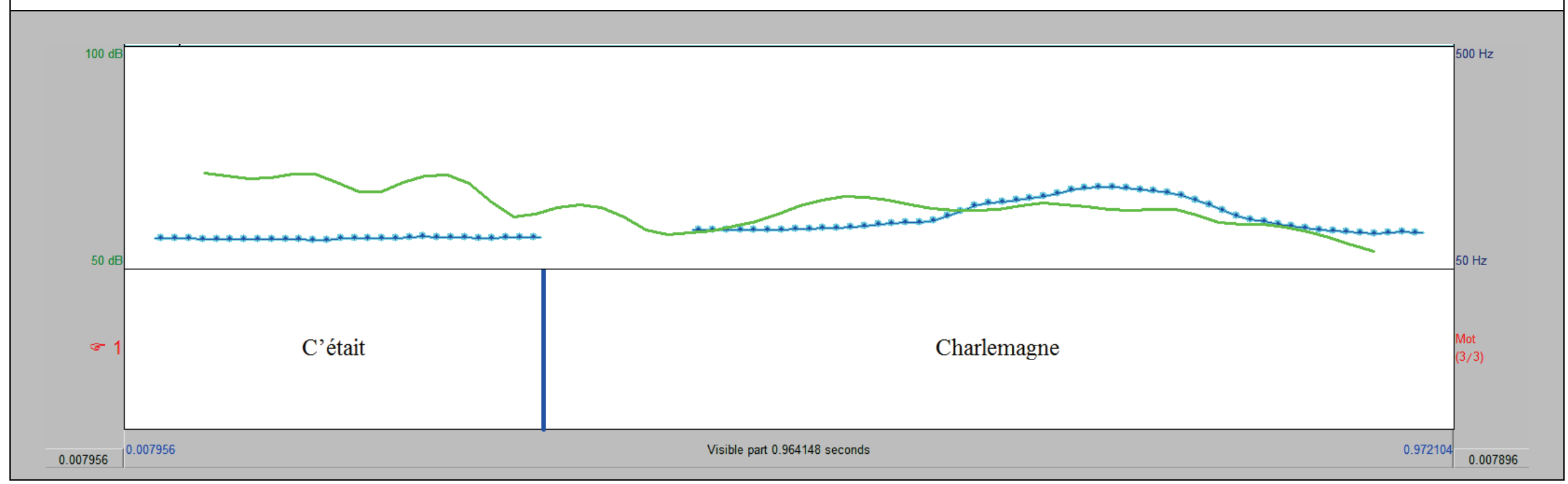


A priori, il passe l'information. Il n'est pas sûr, il a quand même un léger doute. Alors, ça peut-être aussi d'une certaine manière l'intention de voir si les autres ont les mêmes souvenirs que lui.

A priori, pasa la información. No está seguro, tiene sin embargo una leve duda. Entonces, puede ser también en cierta forma la intención de ver si los otros tienen los mismos recuerdos que él.

Se distinguen entre estos comentarios tres grandes grupos de significados que acompañan la emisión de Benoît:

a. La información que el hablante aporta no es nueva, sino que ya es compartida por más participantes en la interacción: "Il le savait quand-même. " "C'est une évidence. 'On sait tous la réputation de ce collège'. Il constate, il rappelle à la mémoire de l'autre. " «C'est une restitution de scène de crime. 'On est bien d'accord sur les lieux, l'endroit, les participants', il y a une mise au point de ça. » «... 'C'était évident, c'était les pires du quartier.' " 'C'est connu, ça fait partie de notre cadre commun.'» «... c'est un souvenir commun. » « Ce collège est connu. Je ne peux pas dire ce qu'y a derrière, mais pour eux, c'est connu. " «'C'était Charlemagne' et c'est comme si on disait tout avec ça.» «D’une certaine manière il sait que c'est ça et il demande l'approbation du reste et les autres confirment. "》

Sin embargo, lo sabía. Es una evidencia. "Todos sabemos la reputación de ese colegio". Constata, lo trae a la memoria del otro." "Es una restitución de la escena del crimen. "Estamos de acuerdo con respecto al lugar, el entorno, los participantes', se deja en claro esto." ““'Era obvio, eran los peores del barrio." Es conocido, eso forma parte de nuestro marco común."” “... es un recuerdo común." "El colegio es conocido. No puedo decir lo que hay detrás pero, para ellos, es conocido. 'Era el Charlemagne' y es como si eso lo dijera todo." "En cierta forma, él sabe que es eso y pide la aprobación del resto y los otros confirman."

b. El hablante no puede presentar la información en forma cabal por no estar plenamente seguro de ella: «Il le dit plutôt interrogativement. Il le savait quand même. " «Il demande de confirmer: 'J'ai un doute, tu parles du lycée Charlemagne ?...'» "Il pose la question, je pense. Il suppose que c'est Charlemagne mais il n'en est pas sûr. " "Il n'est pas certain de ce qu'il propose. » «A priori, il passe l'information. Il n'est pas sûr, il a quand même un léger doute. Alors, ça peut-être aussi d'une certaine manière l'intention de voir si les autres ont les mêmes souvenirs que lui. »

"Lo dice más bien interrogativamente. Lo sabía sin embargo." "Pide que le confirmen: 'Tengo una duda, ¿hablás del liceo Charlemagne?..." "Hace la pregunta, me parece. Supone que es 
Carlemagne pero no está seguro." "No está seguro de lo que propone." "A priori, pasa la información. No está seguro, tiene sin embargo una leve duda. Entonces, puede ser también en cierta forma la intención de ver si los otros tienen los mismos recuerdos que él."

c. La información que el hablante presenta puede estar sometida en forma más o menos explícita a la aprobación del resto de los participantes de la interacción: « C'est pas une question. Ou bien il pose à moitié la question [Après une réécoute : Il répond.]》 "Il a compris où se tenait ce genre de scène. Il demande de confirmer '(...) Confirme-moi.'” "Il attend que le reste du groupe confirme... » «'Tu es bien sûr que c'était Couperin, ce n'était pas plutôt Charlemagne ?' Il pose la question, je pense. Il suppose que c'est Charlemagne mais il n'en est pas sûr. » «Alors, ça peut-être aussi d'une certaine manière l'intention de voir si les autres ont les mêmes souvenirs que lui. »

"No es una pregunta. O bien hace la pregunta a medias [Después de volver a escuchar] Él responde." "Entendió dónde ocurría ese tipo de escenas. Pide confirmar '(...) Confirmame." "Espera que el resto del grupo confirme..." “¿Estás bien seguro de que era el Couperin, no era más bien el Charlemagne?' Hace la pregunta, me parece. Supone que es la Carlemagne pero no está seguro." "Entonces, puede ser también en cierta forma la intención de ver si los otros tienen los mismos recuerdos que él."

El examen acústico de la emisión permite apreciar que el hablante la realiza, como señaláramos más arriba, en una única unidad tonal (ver gráfico $\mathrm{n}^{\mathrm{o}} 31$ ). Tanto el Arranque como la Terminación se sitúan, por consiguiente, en la sílaba tónica "magne" y tienen un nivel alto situado en $215 \mathrm{~Hz}$. Precisamos que el Arranque precedente de Augustin sobre el elemento "euh" se realiza en $114 \mathrm{~Hz}$., lo cual permite determinar el nivel alto de la emisión que nos ocupa.

El gráfico permite apreciar un ascenso seguido por un descenso en la melodía (que, recordamos, está representada por el trazo azul) sobre la sílaba tónica "magne". La pendiente ascendente tiene lugar en la realización de la vocal/a/. A su vez, el descenso opera sobre el segmento /nə/. Vale destacar que este segmento no es considerado en la literatura como una sílaba plena por contener una E caduca o schwa. Del mismo modo, Brazil y Granato afirman que el descenso de la melodía está motivado fisiológicamente, ya que se trata de instancias acompañadas por un descenso consecuente de la intensidad (representada, como señaláramos, por el trazo verde).

Estas precisiones nos permiten afirmar que es el segmento ascendente de la pendiente el que ha sido significativo para los sujetos de las pruebas perceptivas. Del mismo modo, 
estimamos que es este segmento el que ha de considerarse para determinar el Tono utilizado por el hablante, que es Referido.

Presentaremos a continuación el análisis de una elicitación más prolongada realizada en dos unidades tonales.

\section{2 .2}

Luego de que Adèle mencionara que a las chicas de su distrito les gustan mucho las carteras, Francine produce una intervención, marcada asimismo por un final con melodía ascendente.

P54:

A. : et les filles c'est le le sac aussi c'est important

Y las chicas es la la cartera también es importante

\section{$\rightarrow \quad$ F. : Vanessa Bruno ?}

¿Vanessa Bruno?

[CFPP2000] [07-02] Lucie_da_Silva_F_22_7 $7^{\mathrm{e}}$

(Líneas 257-258)

Los sujetos consultados en las pruebas perceptivas expresaron las siguientes impresiones a propósito de la emisión de Francine:

Elle le dit en se posant la question.

Lo dice haciéndose la pregunta.

L'intonation à la fin c'est d'une interrogation. C'est une question, elle demande une confirmation.

La entonación al final es la de una interrogación. Es una pregunta, pide una confirmación.

Elle essaie de voir quelles références ont les autres mais c'est informatif, parce que c'est une marque.

Trata de ver qué referencias tienen las otras, pero es informativo, porque es una marca. Elle a besoin de confirmer qu'elle sait ou qu'elle fait partie du même groupe. Elle demande une corroboration.

Necesita confirmar que sabe o que forma parte del mismo grupo. Pide una corroboración. Elle pense savoir, donc elle propose. Elle sait, mais elle n'en est pas certaine, elle demande quand même une confirmation.

Cree saber, entonces propone. Sabe, pero no está segura, pide de todas formas una confirmación. Elle suggère, elle fait une suggestion parce que le ton c'est l'interrogation, mais il y a quand-même un nom pour amener la personne qu'elle interroge à plus développer. 
Gráfico $n^{\circ} 32$

P54 :

(P)

A. : / et les filles c'est le /(M) le sac (233) aussi c'est impor[tant *(M)]/

(R)

$\rightarrow \quad$ F. : /(A) [Va]nessa Bruno (357) /

[CFPP2000] [07-02] Lucie_da_Silva_F_22_7 $7^{\mathrm{e}}$ (Líneas 257-258)

* No pudo ser medido por la superposición de turnos que afecta la sílaba

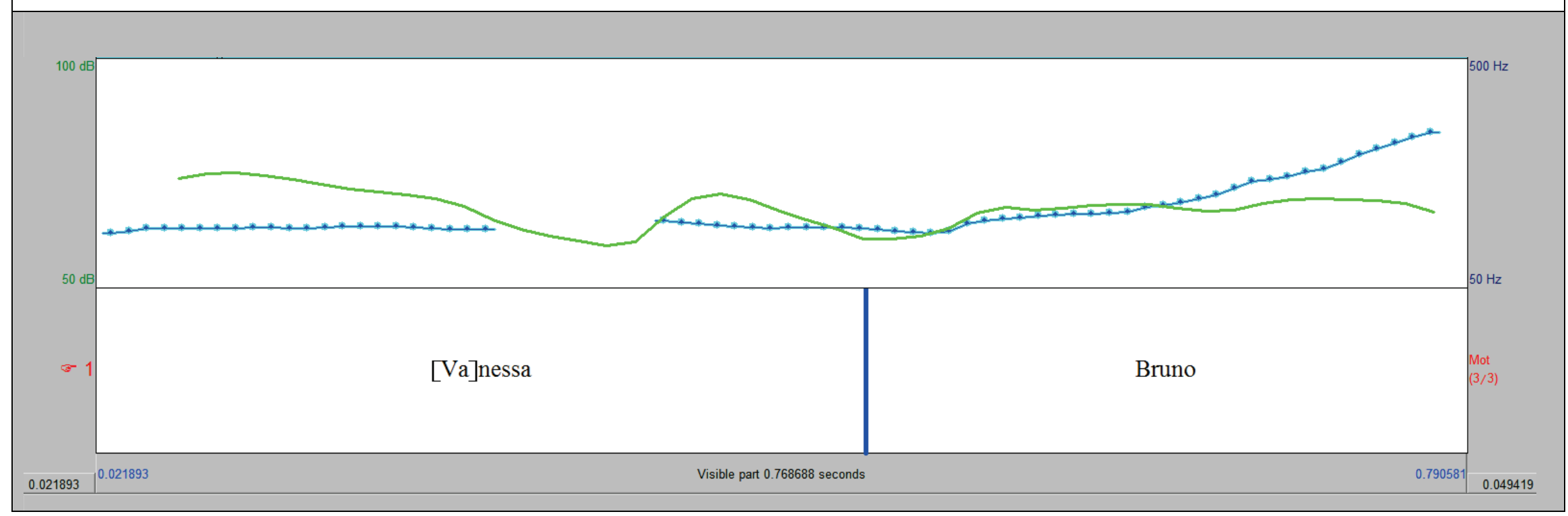


Sugiere, hace una sugerencia, porque es el tono es la interrogación, pero hay de todas formas un nombre para llevar a la persona a la que interroga a profundizar más.

Elle est informée, elle sait de quoi il s'agit et elle le dit.

Está informada, sabe de qué se trata y lo dice.

Si elle dit Vanessa Bruno, c'est qu'elle sait, mais c'est une manière pour demander

l'approbation des autres. C'est un ton semi-interrrogatif, parce qu'on le sait.

Si dice Vanessa Bruno, es que sabe, pero es una forma para pedir la aprobación de las demás. Es un tono semiinterrogativo, porque lo sabe.

Elle le dit comme si c'était une évidence. Je ne sens pas qu'elle pose une question, mais qu'elle donne une précision.

Lo dice como si fuera una evidencia. No siento que haga una pregunta, sino que da una precisión.

On sent que pour cette marque, elles sont toutes au courant. Elle sait que tout le monde va être d'accord avec sa toute petite question.

Uno siente que todas conocen esta marca. Sabe que todo el mundo va a estar de acuerdo con su preguntita.

Elle lance le nom pour confirmer qu'elle a bien compris ce que disait l'autre, pour savoir si elle est bien dans le même contexte que celle qui parle.

Larga el nombre para confirmar que entendió bien lo que decía la otra, para saber si está en el mismo contexto que la que habla.

J'ai pas eu l'impression qu'elle ignorait. "Oui ? Tu crois qu'il y a Vanessa Bruno ? "

No tuve la impresión de que lo ignorara. “¿Sí? ¿Creés que está Vanessa Bruno?”

Como vemos, estas impresiones evocan determinados aspectos de la forma en la que se presenta el contenido de la emisión:

a) La hablante aporta una información, pero la deja sujeta a corroboración: " Elle le dit en se posant la question." "Elle essaie de voir quelles références ont les autres mais c'est informatif... " «Elle a besoin de confirmer qu'elle sait ou qu'elle fait partie du même groupe. Elle demande une corroboration. " "Elle pense savoir, donc elle propose. Elle sait, mais elle n'en est pas certaine, elle demande quand même une confirmation. » «Elle suggère, elle fait une suggestion parce que le ton c'est l'interrogation, mais il y a quand-même un nom... » «Si elle dit Vanessa Bruno, c'est qu'elle sait, mais c'est une manière pour demander l'approbation des autres. " "Elle lance le nom pour confirmer qu'elle a bien compris ce que disait l'autre, pour savoir si elle est bien dans le même contexte que celle qui parle. »

"Lo dice haciéndose la pregunta." "Trata de ver qué referencias tienen las otras, pero es informativo, porque es una marca." "Necesita confirmar que sabe o que forma parte del mismo grupo. Pide una corroboración." "Piensa saber, entonces propone. Sabe, pero no está segura, pide de todas formas una confirmación." "Sugiere, hace una sugerencia, porque es el tono es la 
interrogación, pero hay de todas formas un nombre..." "Si dice Vanessa Bruno, es que sabe, pero es una forma para pedir la aprobación de las demás..." "Larga el nombre para confirmar que entendió bien lo que decía la otra, para saber si está en el mismo contexto que la que habla."

b) La hablante presenta la información como ampliamente conocida: "Elle le dit comme si c'était une évidence. Je ne sens pas qu'elle pose une question, mais qu'elle donne une précision. " «On sent que pour cette marque, elles sont toutes au courant. Elle sait que tout le monde va être d'accord avec sa toute petite question. »

"Lo dice como si fuera una evidencia. No siento que haga una pregunta, sino que da una precisión." "Uno siente que todas conocen esta marca. Sabe que todo el mundo va a estar de acuerdo con su preguntita."

Por otra parte, varios comentarios giraron en torno al conocimiento que se atribuye a la hablante acerca del contenido de su emisión. Al este respecto, es interesante prestar atención a la transcripción original del texto realizada por el equipo del CFPP2000: el final de la intervención de Francine está señalado con un signo de interrogación, que demuestra la sensibilidad del sujeto a la entonación final ascendente. En las pruebas perceptivas, una persona estimó que la hablante necesita una confirmación («L'intonation à la fin c'est d'une interrogation. C'est une question, elle demande une confirmation. $»^{18}$ ), aunque una cantidad mayor de sujetos consideraron que Francine no ignora tal contenido : «Elle est informée, elle sait de quoi il s'agit et elle le dit. » «... parce qu'on le sait. » "J'ai pas eu l'impression qu'elle ignorait. »

"Está informada, sabe de qué se trata y lo dice." "... porque lo sabe.” "No tuve la impresión de que lo ignorara."

El gráfico no 32 Expone las características entonativas de esta emisión, realizada en una unidad tonal simple. La misma cuenta con un Arranque y una Terminación en nivel alto, realizados sobre la sílaba tónica "no" (en $357 \mathrm{~Hz}$ ). Dicho nivel es, como vemos muy superior al Arranque de la unidad precedente, pronunciada por Adèle (sobre la sílaba correspondiente al ítem "sac", en $233 \mathrm{~Hz}$ ).

En cuanto a la elección de Tono que realiza Francine, se aprecia que se trata del Tono Referido.

Los apartados siguientes incluirán la presentación de emisiones más extensas, comenzando por algunas realizadas en dos unidades tonales.

18 "La entonación al final es de una interrogación. Es una pregunta, pide una confirmación." 


\section{2 .3}

Luego de una emisión presentada en el apartado anterior (6.1.5), en la que Lucie declaraba haber descubierto una fruta exótica en un comercio, la entrevistadora vuelve a realizar un pedido de información. En reacción al mismo, la joven hablante pronuncia una emisión marcada también por un ascenso melódico final:

P16 :

$$
\begin{gathered}
\text { F.L. : d'accord + autre chose } \underline{\text { non }} \\
\text { De acuerdo + otra cosa no }
\end{gathered}
$$

$\rightarrow \quad$ L.dS. : euh non les autres j'connaissais

Eh no, las otras yo las conocía

[07-02] Lucie_da_Silva_F_22_7

(Líneas 196-197)

Las pruebas perceptivas realizadas a partir de esta emisión permitieron recoger los siguientes conceptos por parte de los sujetos francohablantes consultados:

La phrase est plate, parce qu'en fait il y a avait déjà la réponse dans la question de l'intervieweuse.

La frase es chata porque, en realidad, la respuesta ya estaba en la pregunta de la entrevistadora.

Elle répond, elle n'est pas très curieuse.

Responde, no es muy curiosa.

Elle répond. Peut-être que l'intervieweuse a influencé la réponse. La réponse redit ou confirme ce que l'intervieweuse avait dit.

Responde. Quizá la entrevistadora influyó en la respuesta. La respuesta repite o confirma lo que había dicho la entrevistadora.

Elle répond en laissant sous-entendre que ça ne les intéresse pas du tout.

Responde dejando entender que eso no le interesa para nada.

Elle répond. Je pense qu'il n'y a pas d'autre intention que de dire «non».

Responde. Creo que no hay otra intención que de decir "no".

Elle répond.

Responde.

"Il n y a rien de nouveau, c'est sûr. " C'est pas une réponse avec une information que l'intervieweuse ne connaissait pas, au contraire. C'est confirmer un peu ce qu'elle lui avait dit.

"No hay nada nuevo, seguro". No es una respuesta con una información que la entrevistadora no conozca; al contrario. Es confirmar un poco lo que ella le había dicho.

Elle connaît tout. Elle n'apporte rien de nouveau dans sa réponse.

Conoce todo. No aporta nada nuevo en su respuesta.

Elle est OK pour terminer le sujet, pour terminer de parler de ça. 
Gráfico n ${ }^{\circ} 33$

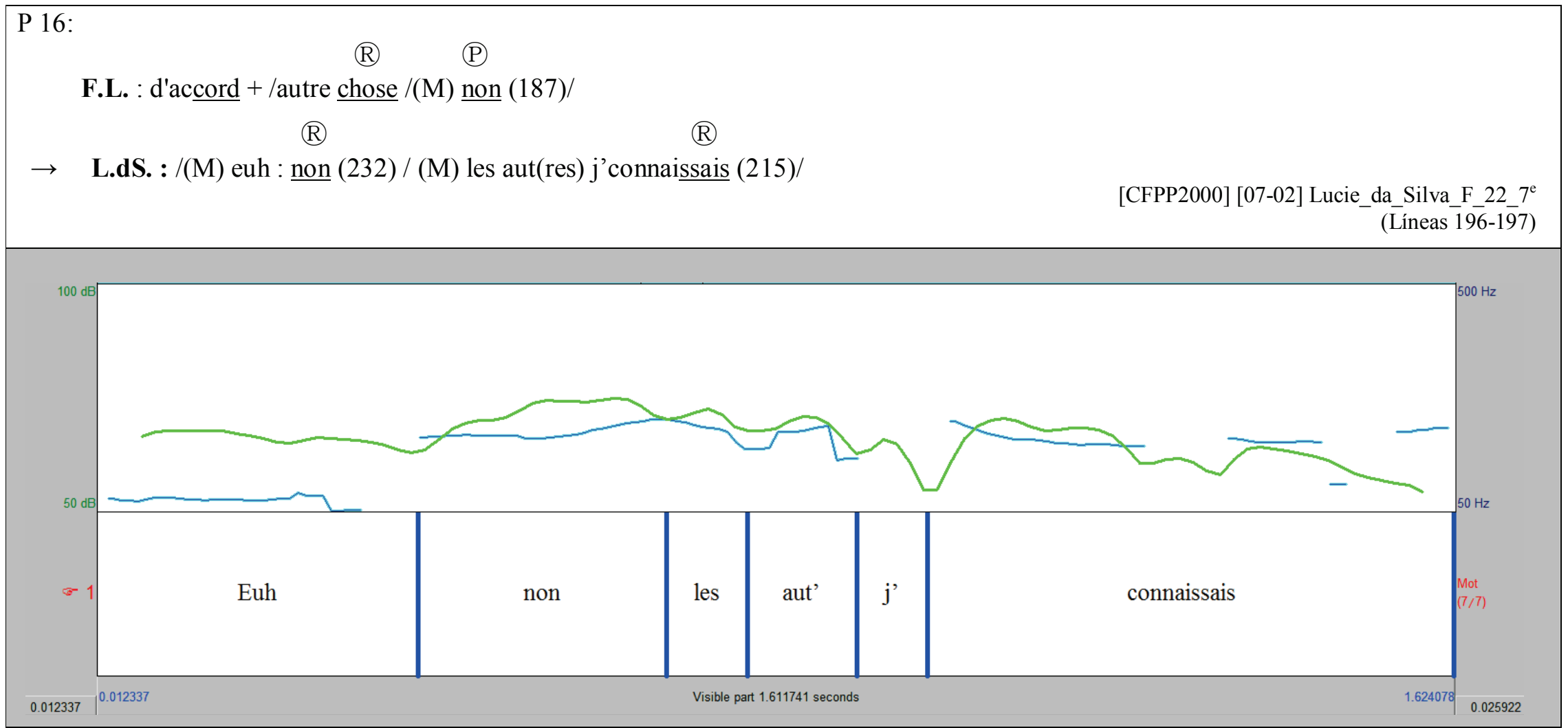


Está de acuerdo con cerrar el tema, para dejar de hablar de eso.

Je ne sais pas quoi dire, j'ai rien à dire.

No sé qué decir, no tengo nada para decir.

Elle confirme. Elle suit un petit peu ce que l'intervieweuse lui dit ; elle s'adapte.

Confirma. Sigue un poco lo que la entrevistadora le dice, se adapta.

«Non, c'est pas important d'en parler. Le plus important c'est ce que je viens de te dire. »

« No, no es importante habar de eso. Lo más importante es lo que acabo de decirte."

Là, elle est sûre. Elle confirme qu'il n'y a rien de nouveau.

Ahí está segura. Confirma que no hay nada nuevo.

Voilà, elle confirme. Je ne vois rien de particulier.

Eso es, confirma. No veo nada en especial.

C'est un peu qu'elle confirme ce que pensait l'intervieweuse. Elle n'a rien de nouveau à dire. C'est un peu aussi qu'elle met comme un doute pour ne pas paraître si catégorique.

Un poco confirma lo que pensaba la entrevistadora. No tiene nada nuevo para decir. Un poco también pone como una duda para no parecer tan categórica.

Ce n'est pas elle qui va finir la discussion, mais elle met comme des points de suspension pour dire que oui, effectivement, il n'y a pus rien à dire là-dessus.

No es ella la que va a cerrar la discusión, pero pone como puntos suspensivos para decir que sí, efectivamente, no hay nada más para decir sobre eso.

Además de la reacción al pedido de confirmación de la entrevistadora (recuperable a partir de las ocurrencias de "elle répond" "elle confirme"), los sujetos percibieron frecuentemente el hecho de que la información que proporciona la hablante no es desconocida para la rentrevistadora: "Peut-être que l'intervieweuse a influencé la réponse. La réponse redit ou confirme ce que l'intervieweuse avait dit. » « ... parce qu'en fait il y a avait déjà la réponse dans la question de l'intervieweuse. " "C'est pas une réponse avec une information que l'intervieweuse ne connaissait pas, au contraire. C'est confirmer un peu ce qu'elle lui avait dit. » «Elle n'apporte rien de nouveau dans sa réponse. » «Elle confirme. Elle suit un petit peu ce que l'intervieweuse lui dit...» «'Le plus important c'est ce que je viens de te dire.'» «... qu'elle confirme ce que pensait l'intervieweuse. Elle n'a rien de nouveau à dire. » «... pour dire que oui, effectivement, il n'y a pus rien à dire là-dessus. ${ }^{19}$

19 "Quizá la entrevistadora influyó en la respuesta. La respuesta repite o confirma lo que había dicho la entrevistadora." “..., porque, en realidad, la respuesta ya estaba en la pregunta de la entrevistadora" "No es una respuesta con una información que la entrevistadora no conozca; al contrario. Es confirmar un poco lo que ella le había dicho." "No aporta nada nuevo en su respuesta." "Confirma. Sigue un poco lo 
Vemos entonces que, si bien se trata efectivamente de una emisión que responde a la elicitación de la entrevistadora, lo que caracteriza a la forma en la que Lucie presenta la información es que la misma no se muestra como nueva, sino como ya presente en el marco de la interacción.

Las características entonativas de esta secuencia pueden observarse en el gráfico $\mathrm{n}^{\mathrm{o}} 33$. En el mismo, se aprecia que la emisión informativa está formada por dos unidades tonales simples. La primera de ellas efectúa su Arranque y su Terminación sobre la sílaba tónica correspondiente al elemento "non" y los realiza en un nivel Medio $(232 \mathrm{~Hz})$. Este nivel tonal surge por comparación con el Arranque de la unidad precedente, "non" pronunciada por Florence, situado en $187 \mathrm{~Hz}$. En la segunda unidad, “les autres j'connaissais", la hablante realiza el Arranque y la Terminación sobre la sílaba tónica "sais". Los mismos tienen también un nivel tonal medio $(215 \mathrm{~Hz})$. Precisamos además que el segmento del ítem "autres", que se encuentra entre paréntesis no tiene realización efectiva .Se trata de una caso frecuente de caída de la consonante líquida del grupo y de la e caduca que sigue.

En lo referido a las elecciones en el subsistema de Tono, las dos unidades se efectuaron con Tono Referido.

Es interesante destacar el predominio en la interpretación de una actitud colaborativa por parte de la hablante. Como detallaremos más adelante, la misma difiere de ciertos significados locales descritos por Marandin y por Morel y Danon-Boileau.

\section{2 .4}

La secuencia que veremos a continuación es posterior a los comentarios de tres jóvenes acerca de algunas expresiones frecuentes entre los adolescentes. La entrevistadora solicita una información puntual y Amélie T., una de las jóvenes, reacciona a esa solicitud. Su intervención se caracteriza también por finalizar con una entonación ascendente.

P30:
S.B. : c'est quoi déjà les veuch
¿Qué es a todo esto el veuch?

que la entrevistadora le dice...” "“Lo más importante es lo que acabo de decirte.” “... confirma lo que pensaba la entrevistadora. No tiene nada nuevo para decir." “...para decir que sí, efectivamente, no hay nada más para decir sobre eso.” 
$\rightarrow \quad$ A.T. : j'vais m' laver les veuch, les cheveux

Voy a lavarme el veuch, el pelo.

[11-04] Julie_Teixeira_F_18_Katia_Teixeira_F_15_11 ${ }^{\mathrm{e}}$

(Líneas 429-430)

En las pruebas perceptivas, los sujetos interpretaron la emisión de Amélie T. de la siguiente manera:

C'est la réponse. Il y a une explication.

Es la respuesta. Hay una explicación.

Elle répond. Pour elle, c'est évident.

Responde. Para ella es evidente.

C'est très clair pour elle.

Es muy claro para ella.

Elle met en contexte pour que l'autre comprenne.

Pone en contexto para que la otra comprenda.

Elle répond.

Responde.

Elle donne un exemple et explique.

Da un ejemplo y explica.

Elle donne une explication très claire, sans condescendance dans la réponse.

Da una explicación muy clara, sin menosprecio en la respuesta.

Elle donne un exemple et puis elle donne la réponse.

Da un ejemplo, después da la respuesta.

Elle lui donne un exemple. "Tout le monde le sait: je vais me laver les veuch, les cheveux. C'est évident. »

Le da un ejemplo. " Todo el mundo lo sabe: voy a lavarme el veuch, el pelo. Es evidente. »

Elle apporte la réponse à la curiosité de la journaliste.

Proporciona la respuesta a la curiosidad de la periodista.

Elle dit «Bon, je vais te donner un exemple bien clair pour que tu comprennes quelle langue on est en train parler. »

Dice "Bueno, voy a darte un ejemplo muy claro para que comprendas qué lengua estamos hablando."

Il y a un ton d'humour, et en même temps, de vouloir faire comprendre.

Hay un tono de humor y, al mismo tiempo, de querer hacer comprender.

Il y a un ton d'humour, et en même temps, de vouloir faire comprendre.

Hay un tono de humor $y$, al mismo tiempo, de querer hacer comprender. 
Gráfico $\mathrm{n}^{\mathrm{0}} 34$

P30:

$$
\text { (R) }
$$

S.B. : /(A) c'est quoi (313) déjà les veuch (316) (A) /

(N)

(R)

$\rightarrow$ A.T. : /(M) j' vais m' laver les veuch $(204) /+/(\mathrm{M})$ les cheveux $(218) /$

[11-04] Julie Teixeira F 18 Katia_Teixeira F $15 \quad 11^{\circ}$ (Líneas 429-430)

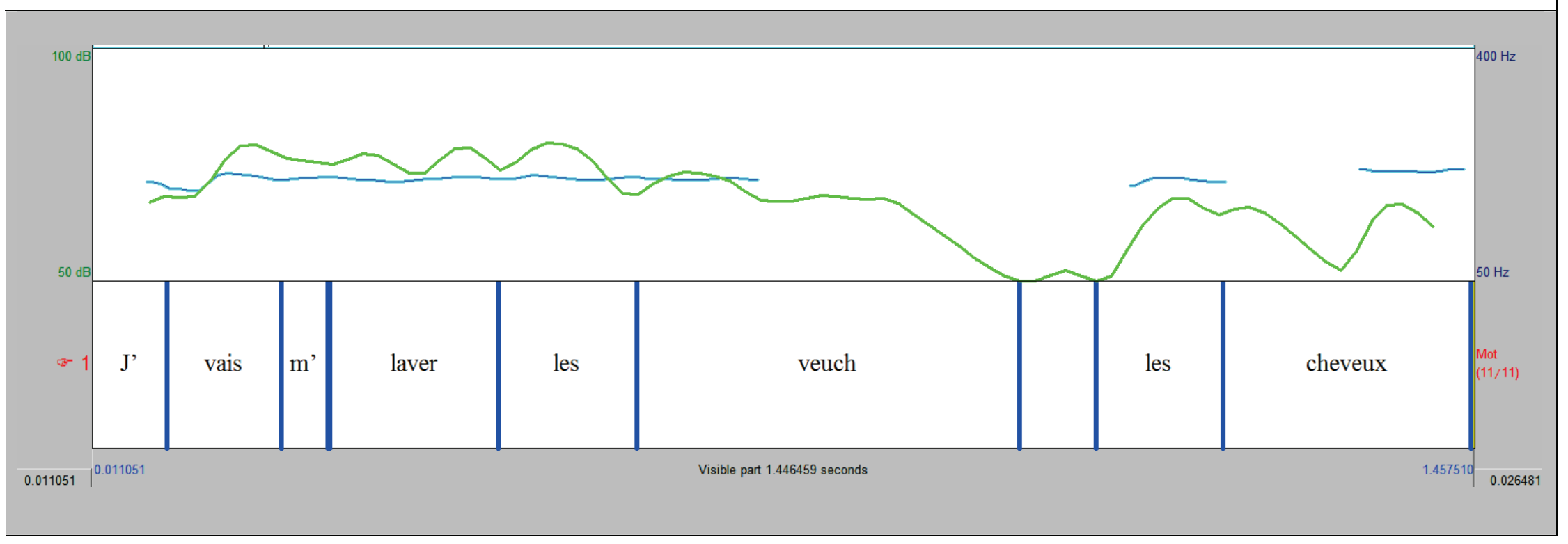


Elle explique et elle s'amuse de voir que la dame n'avait pas compris.

Explica y se divierte de ver que la señora no había entendido.

Ce qu'elle veut dire, c'est "C'est une information que toi, t'as pas. Donc, je te la donne. »

Lo que quiere decir es: "Es una información que no tenés. Entonces, te la doy."

Estos comentarios remiten fundamentalmente a los siguientes significados que transmite la emisión informativa de Amélie:

a. La hablante proporciona la respuesta requerida: «C'est la réponse. " "Elle met en contexte pour que l'autre comprenne. " "Elle donne un exemple et explique. " «Elle donne une explication très claire, sans condescendance dans la réponse. » «... puis elle donne la réponse. " "Elle apporte la réponse à la curiosité de la journaliste. " " 'C'est une information que toi, t'as pas. Donc, je te la donne.'»

"Es la respuesta." "Pone en contexto para que la otra comprenda." "Da un ejemplo y explica." "Da una explicación muy clara, sin menosprecio en la respuesta." "... después da la respuesta." "Proporciona la respuesta a la curiosidad de la periodista." "Es una información que no tenés. Entonces, te la doy."”

b. La hablante presenta la información como conocida o evidente: «Pour elle, c'est évident. " «C'est très clair pour elle. " «'Tout le monde le sait : je vais me laver les veuch, les cheveux. C'est évident.' " Elle explique et elle s'amuse de voir que la dame n'avait pas compris. »

"Para ella es evidente." "Es muy claro para ella." "Todo el mundo lo sabe : voy a lavarme el veuch, el pelo. Es evidente." "Explica y se divierte de ver que la señora no había entendido."

El análisis acústico de la emisión permite apreciar una secuencia compuesta por dos unidades tonales simples (ver gráfico $\mathrm{n}^{\circ} 34$ ). La primera de ellas “ $j$ 'vais me laver les veuch" realiza el Arranque y la Terminación sobre la sílaba tónica "veuch" en un nivel medio (204 Hz). El Arranque se determinó a través de su comparación con el Arranque de la emisión de Sonia B., realizada en $313 \mathrm{~Hz}$ sobre el ítem léxico “quoi”. La segunda unidad tonal, "les cheveux", tiene un Arranque y una Terminación realizados también en nivel medio sobre la sílaba tónica "veux”. El mismo alcanza los $218 \mathrm{~Hz}$. En cuanto a las realizaciones de Tono, en la primera unidad se percibe un Tono Neutral, mientras que en la segunda, la hablante elige un Tono Referido.

La última emisión con la que ilustraremos este capítulo está compuesta por tres unidades tonales. 
Cuando trataban las diferencias entre los distritos $16^{\circ}$ y $11^{\circ}$ de París, la entrevistadora formuló una solicitud de información puntual a Blanche D. Luego de una breve digresión, la joven proporcionó la siguiente respuesta:

P24 :

S.B. : [les façons d'par]ler aussi sont pas les mêmes? + ¿Las formas de hablar tampoco son las mismas?

Bl.D. : c'est sûr c'est sûr et de s'tenir hh j'étais impressionnée les filles elles avaient une espèce de maintien moi j'étais là complètement avachie

Claro, está claro y de desenvolverse ah yo estaba impresionada las chicas tenían como una postura yo estaba ahí completamente abatatada.

\section{S.B. : d'accord +}

De acuerdo

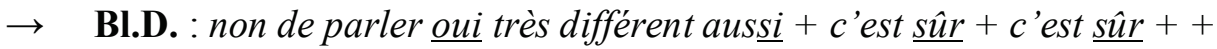
No de hablar sí muy diferente también+ seguro + seguro ++

[CFPP2000] [11-03] Blanche_Duchemin_F_25_Reine_Ceret_F_60_11

(Líneas 299-304)

Esta intervención suscitó los siguientes comentarios de los sujetos participantes en las pruebas perceptivas:

Comme elle le dit, c'est évident, ça va de soi. C'est comme si elle l'avait déjà dit avec le reste.

Como lo dice, es evidente, se da por hecho. Es como si ya lo hubiera dicho con el resto.

Elle insiste sur le maintien et, pour les façons de parler, elle le dit d'un ton très discret.

Elle en est moins surprise pour les façons de parler que pour la façon de se tenir.

Insiste en la postura y, lo de la manera de hablar, lo dice con un tono muy discreto. Está menos

sorprendida con la forma de hablar que con la forma de desenvolverse.

Elle revient pour répondre à la question posée.

Vuelve para responder a la pregunta hecha.

Elle répond mais elle ne donne pas d'argument. Il n'y a pas d'ambiguïté possible, elle en est sûre.

Responde pero no da argumento. No hay ambigüedad posible, está segura de eso.

Elle répond à la question. Elle clôture et laisse entendre que c'est évident.

Responde a la pregunta. Cierra y deja entender que es evidente. 


\section{Gráfico $\mathrm{n}^{\mathrm{0}} 35$}

P24:

(R)

S.B. : /(A) d'accord (483) /+

(R)

(R)

(R)

$\rightarrow \quad$ BI.D. : / (M) non de parler oui (293) très différent aussi (319) (A)/ + /(M) c'est sûr (276) / + /(M) c'est sûr */

[CFPP2000] [11-03] Blanche_Duchemin_F_25_Reine_Ceret_F_60_11 (Líneas 303-304)

*PRAAT no permite determinar la altura tonal debido a la débil intensidad de este segmento de elocución.

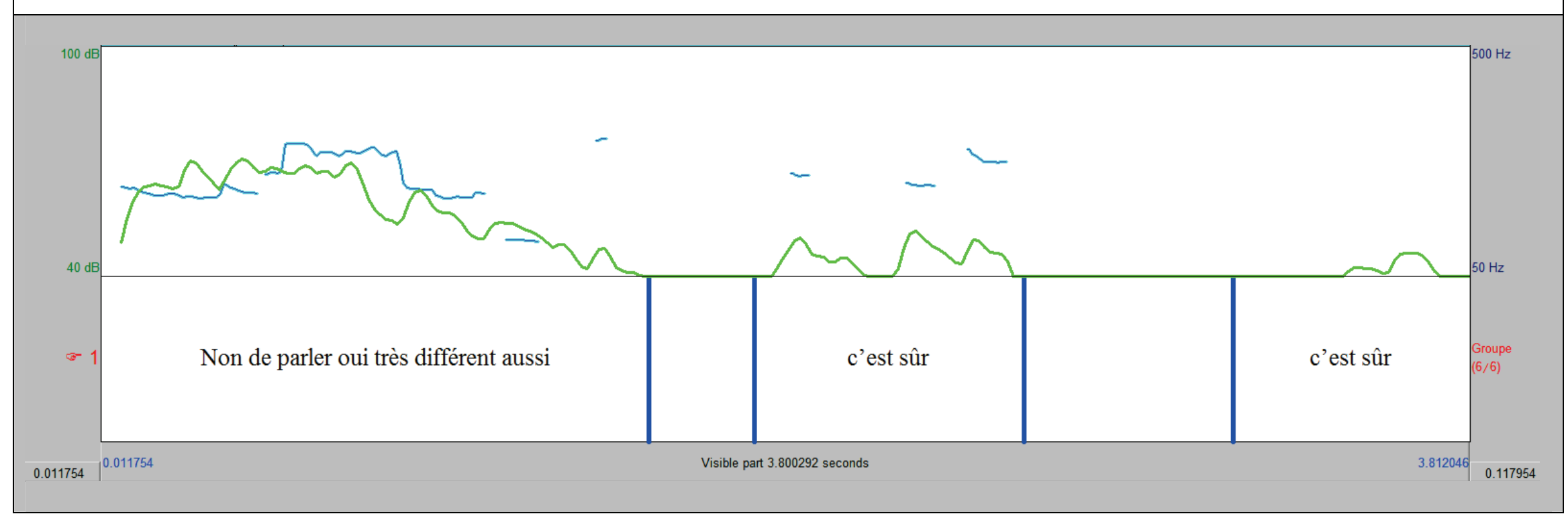


Elle répond mais elle ne donne pas d'argument. Il n'y a pas d'ambiguïté possible, elle en est sûre.

Responde pero no da argumento. No hay ambigüedad posible, está segura de eso.

Elle répond à la question. Elle clôture et laisse entendre que c'est évident.

Responde a la pregunta. Cierra y deja entender que es evidente.

Elle répond en démontrant que le sujet n'est pas passionnant, mais qu'elle n'a pas

oublié la question. Elle répond brièvement à la fin du discours, au passage.

Responde demostrando que el tema no es apasionante, pero que no se olvidó de la pregunta.

Responde brevemente al final del discurso, de paso.

Elle exprime une petite déception peut-être, un complexe d'infériorité. Le ton de sa voix décroît considérablement.

Expresa una pequeña decepción quizá, un complejo de inferioridad. El tono de su voz decrece considerablemente.

Elle répond à la question et confirme ce que dit l'intervieweuse.

Responde a la pregunta y confirma lo que dice la entrevistadora.

Elle dit « oui » mais elle sait plus quoi dire.

Dice "sí", pero no sabe qué más decir.

On sent que cette question la réconforte. Elle dit «bien sî ::r» avec du soulagement.

"Là on est d'accord. "

Se siente que esta pregunta la reconforta. Dice "cla::ro" con alivio. "En eso, estamos de acuerdo."

Elle est assez catégorique. Elle confirme que même la façon de parler est différente.

Es bastante categórica. Confirma que incluso la forma de hablar es diferente.

C'est une confirmation, elle ne doute pas qu'elle n'appartient pas à ce milieu-là.

Es una confirmación, no tiene dudas de que ella no pertenece a ese medio.

Elle confirme que la façon de parler est différente. Elle en est sûre.

Confirma que la forma de hablar es diferente. Está segura de eso.

Estas consideraciones expresan la sensibilidad de los sujetos a los siguientes significados:

a) La hablante proporciona la información requerida: « ... pour répondre à la question posée. » «Elle répond... » expresado por cuatro sujetos.

“... para responder a la pregunta hecha." "Responde..."

b) La hablante presenta su información como si fuera evidente o recuperable en el contexto: "Comme elle le dit, c'est évident, ça va de soi. C'est comme si elle l'avait déjà dit avec le reste. » «Elle en est moins surprise pour les façons de parler que pour la façon de se tenir." «Il n'y a pas d'ambiguité possible, elle en est sûre. " «laisse entendre que c'est évident.» «... et confirme ce que dit 
l'intervieweuse. " «Elle dit 'bien sîu ::r' avec du soulagement. 'Là on est d'accord.'" "Elle est assez catégorique. Elle confirme que même la façon de parler est différente." "C'est une confirmation, elle ne doute pas qu'elle n'appartient pas à ce milieu-là.» "Elle confirme que la façon de parler est différente. Elle en est sûre."

"Como lo dice, es evidente, se da por hecho. Es como si ya lo hubiera dicho con el resto." "Está menos sorprendida con la forma de hablar que con la forma de desenvolverse." "No hay ambigüedad posible, está segura de eso." “... y deja entender que es evidente.” “...y confirma lo que dice la entrevistadora." "Dice 'cla::ro' con alivio. 'En eso, estamos de acuerdo.” "Es bastante categórica. Confirma que incluso la forma de hablar es diferente." "Es una confirmación, no tiene dudas de que ella no pertenece a ese medio." "Confirma que al forma de hablar es diferente. Está segura de eso."

Como puede observarse en el gráfico $\mathrm{n}^{\circ} 35$, la emisión cuenta con tras grupos fónicos con un marcado descenso en la intensidad, que hace imposible la detección de la curva de $\mathrm{F}_{0}$ a través de PRAAT. En ese segmento, es sólo la curva de intensidad la que evidencia la realización efectiva del grupo.

La primera unidad "non de parler oui très différent aussi", es extendida. Su Arranque se realiza en nivel medio sobre el elemento "oui" (en $293 \mathrm{~Hz}$ ). La misma surge de su cotejo con el Arranque de la unidad precedente pronunciada por Sonia B. ("d'accord") que alcanza los $483 \mathrm{~Hz}$. En tanto, su Terminación, situada en la sílaba tónica "si" tiene un nivel alto $(319 \mathrm{~Hz})$.

La segunda unidad, por su parte, es simple y tiene un Arranque y una Terminación realizados sobre la sílaba "sûr" en un nivel Medio (en $276 \mathrm{~Hz}$ ). La tercera unidad es una reiteración de la segunda, tanto en su componente léxico y sintáctico como en lo referido a la entonación. La diferencia radica en la disminución marcada de la intensidad que mencionáramos. Por consiguiente, aunque entendemos que su Arranque y Terminación (situados sobre la misma sílaba "sûr") tienen un nivel medio, el mismo se determina sólo en forma perceptiva.

En lo referido al subsistema de Tono, la hablante reitera en las tres unidades la elección de Tono Referido. 
El análisis del conjunto de las emisiones informativas de este grupo permite apreciar cierta regularidad en las interpretaciones provistas por los sujetos en las pruebas perceptivas y en las características entonativas de las secuencias.

Comenzaremos por detallar las elecciones operadas en el subsistema de Arranque. El gráfico $\mathrm{n}^{\mathrm{o}} 36$ exhibe las realizaciones en los tres niveles de altura tonal.

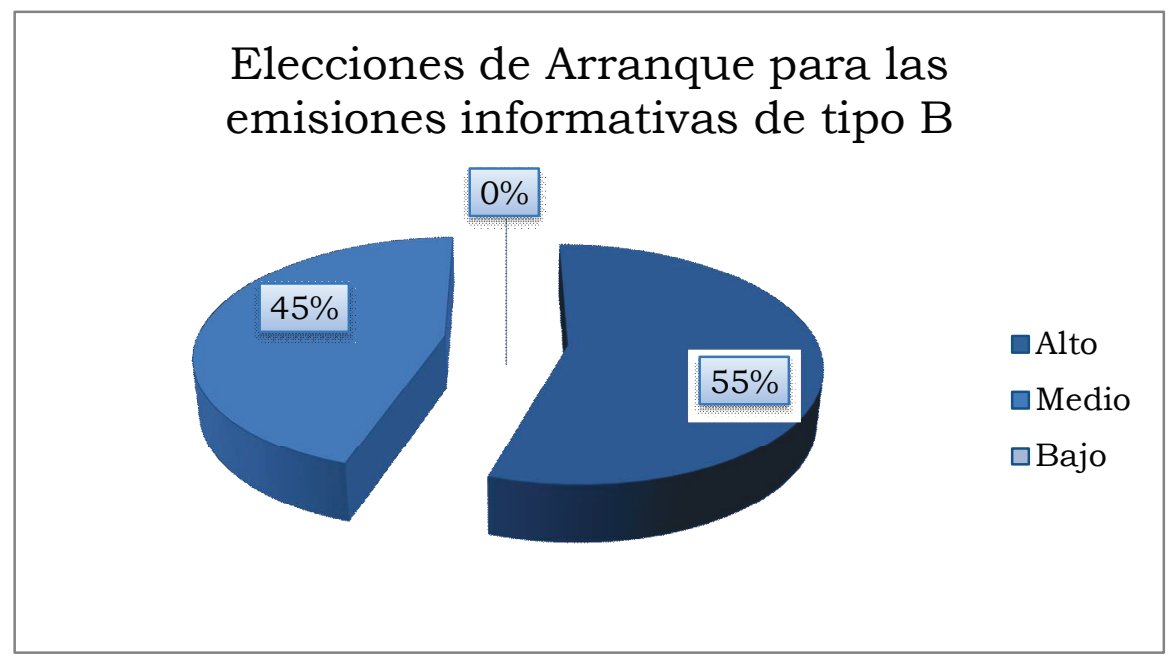

Gráfico ${ }^{\circ} 36$

Puede observarse que en la mayor parte de los casos, los hablantes efectúan un Arranque en nivel alto (el 55\% de las ocurrencias), que transmite el significado de contraste. El mismo puede tener vinculación con significados más locales, como los referidos a la conducta interaccional. Como vimos en los apartados 6.2.1 y 6.2.2, los hablantes realizan su intervención en un contexto en el que varios otros participantes están hablando y logran así imponer su emisión. No obstante, en otras emisiones informativas el contraste se vinculó con significados actitudinales como la expresión de desacuerdo o sorpresa. La elección de Arranques en nivel medio representó también un importante número: el $45 \%$ de los casos. De acuerdo con los estudios llevados a cabo por Brazil para en inglés y por Granato para el español, este nivel de Arranque se asocia con la intención de agregar información al intercambio, lo cual puede vincularse con la actitud colaborativa tan frecuentemente mencionada por los sujetos en las pruebas perceptivas. No se contabilizaron casos de Arranques en nivel bajo, que expresarían relaciones de equivalencia.

En cuanto a las elecciones operadas en el subsistema de Terminación, plasmadas en el gráfico $\mathrm{n}^{\mathrm{o}} 37$, se destaca un marcado predominio del nivel tonal alto. Las mismas 
representan el 64\% de las elecciones de Terminación, en tanto el 36\% fueron realizadas en nivel medio.

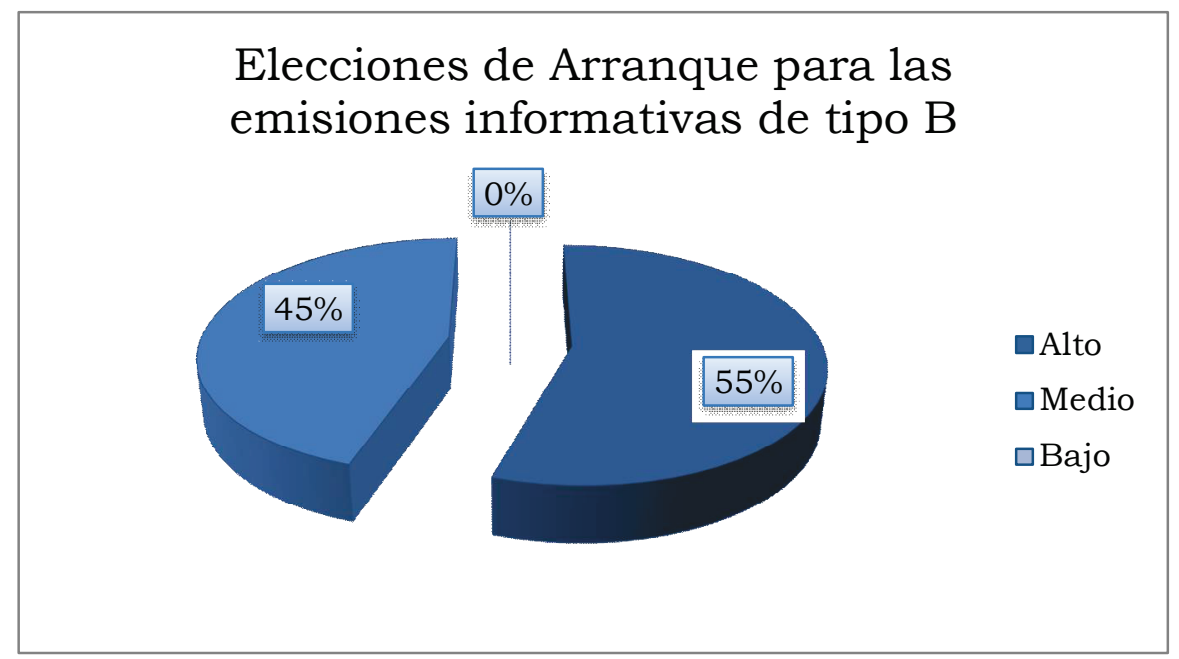

Gráfico no 37

Se pone de manifiesto una frecuencia relativamente alta del significado de “Adjudicación" mediante el cual los interactuantes anticipan una realización marcada por un Arranque alto, que expresaría contraste. Nuevamente, este significado se vinculó tanto con le intención de preservar el turno como con la previsión de que el interlocutor plantee una discrepancia. La elección del nivel medio para la Terminación tuvo una incidencia del $45 \%$ en nuestros datos. Con ella, se transmiten expectativas de que el interlocutor realice un aporte en concordancia con las expectativas planteadas por el hablante. Vemos que, como en 6.2.4, los hablantes no cierran definitivamente el ciclo iniciado con la elicitación de información. Esto puede vincularse asimismo con la ausencia de realizaciones de Terminación en nivel bajo que exhibe este grupo de emisiones informativas. Presumiblemente los locutores expresan que el tema no está agotado y esperan, por el contrario, que se realice alguna otra intervención al respecto.

Las elecciones efectuadas en el subsistema de Tono resultan nuevamente unánimes dado que, en la totalidad de los casos, los hablantes optaron por el Tono Referido, a diferencia de la realización de Tono Proclamatorio, unánime en las emisiones informativas de tipo A. Si asumimos que se tratar en estos casos de frase declarativas o asertivas, su patrón entonativo no coincide con el descrito en forma generalizada, caracterizado por un descenso final (Martins-Baltar, Rossi, Martin). 
Estos resultados pueden correlacionarse con consideraciones puntuales efectuadas por Marandin y por Morel y Danon-Boileau. Aunque se trata de perspectivas que no establecen una diferenciación funcional entre emisiones que proveen información y emisiones que la solicitan, los ejemplos que presentan estos autores muestran que sus observaciones se aplican a emisiones informativas. Como detalláramos en el Estado de la cuestión, los mismos afirman que se opera un movimiento melódico ascendente para expresar el reconocimiento de cierta diferencia en la opinión del interlocutor y la búsqueda de consenso.

Estos significados actitudinales pueden ser compatibles con una descripción de significado lingüísticos generalizables como la que nos proponemos realizar, por cuanto la Adjudicación descrita por Brazil es una invitación a que el interlocutor evalúe el contenido de lo plateado y presente esta evaluación en forma claramente contrastante con otra posible (Brazil, 1997:55). Sin embargo, sería en estos casos necesario que el Tono Referido estuviera acompañado de una Terminación en nivel Alto, que expresa Adjudicación. Al respecto, es interesante apreciar que, aunque se detectaron emisiones en las que se percibía disenso entre los participantes, este significado no fue constante. Por el contrario, la mayoría de las impresiones se refirieron a la actitud colaborativa del hablante de proveer la información requerida aun cuando esta información se presentara como evidente o ya presente de alguna manera en el contexto (ver en especial las emisiones analizadas en 6.2.2, 6.2.3 y 6.2.4).

Los significados generalizables asociados con las interpretaciones de los sujetos francófonos se refieren entonces, fundamentalmente, a la forma en que el hablante presenta la información contenida en la emisión. Los mismos permiten establecer la diferencia general entre emisiones que presentan información como no conocida por los demás interactuantes o como no negociada en el contexto del intercambio en oposición a la información que sí es conocida por los participantes o que ya ha sido negociada en la interacción en curso. Como pudimos apreciar en el apartado precedente, las emisiones de tipo A pertenecerían al primer grupo, dado que presentan la información como si fuera nueva o como que no formara parte del conocimiento común. Inversamente, las emisiones agrupadas en el tipo B, formarían parte del segundo grupo, ya que la información es presentada aquí como ya compartida, negociada o que está "en el aire" para utilizar una expresión propia de Brazil, o ya presente, de alguna manera, en el contexto. 
Al poner en relación las interpretaciones de los sujetos y las formas entonativas de ambos grupos de emisiones informativas, encontramos el siguiente correlato (ver gráfico $\mathrm{n}^{\mathrm{0}} 38$ ).

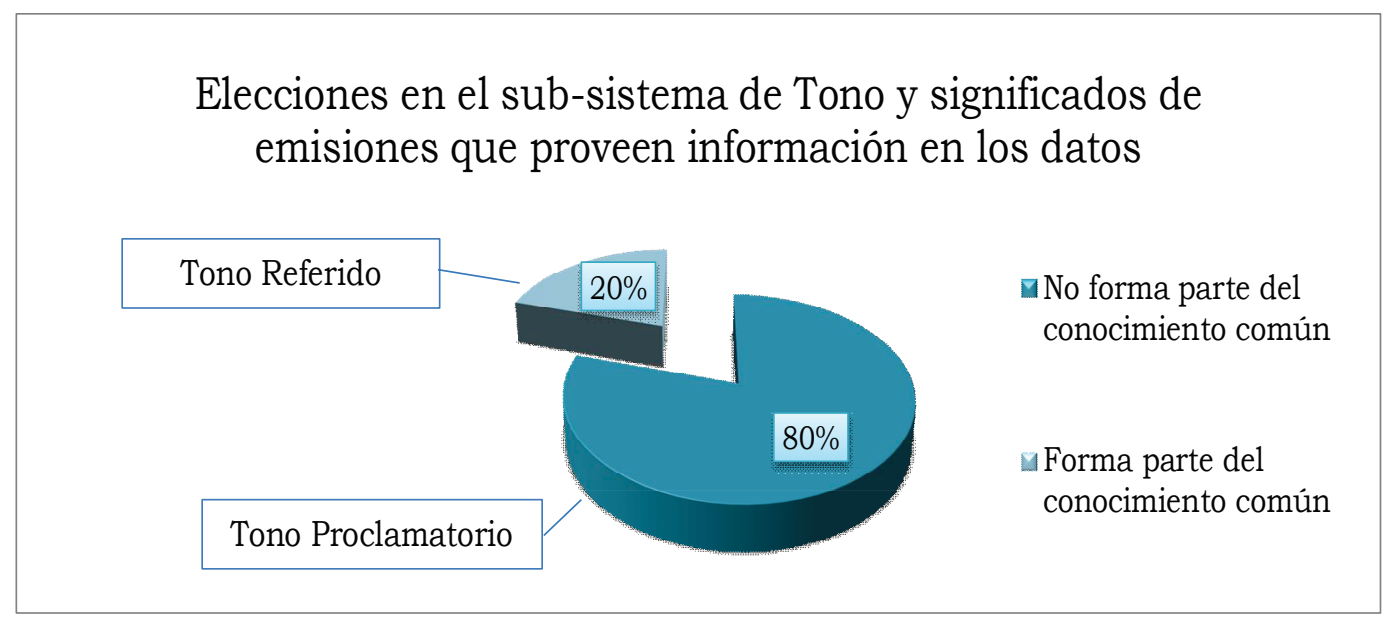

Gráfico ${ }^{\circ} 38$

Se constata también que, en las emisiones informativas, las realizaciones del subsistema de Tono han permitido distinguir los principales grupos de significados detectados por los sujetos en las pruebas perceptivas.

Los capítulos anteriores detallan características de las curvas entonativas propias del lenguaje interactivo, atendiendo a la división funcional descrita en el Marco teórico y la Metodología entre emisiones de elicitación y emisiones informativas. Se intentó dar cuenta de los significados referidos a opciones que realiza el hablante en función de cómo desea presentar su estado de conocimiento y la relación con el interlocutor. El último capítulo de nuestro análisis describirá las características entonativas de secuencias que, si bien se producen en el marco de una interacción, no están orientadas a el o los demás participantes. 


\section{Capítulo 7}

\section{El Tono no interactivo}

Las emisiones que solicitan información como las que la proveen suelen incluir secuencias que han sido significativas para los sujetos de las pruebas perceptivas aun cuando las mismas no constituyen el final de la emisión. La melodía que acompaña estos segmentos se caracteriza por ser sostenida.

Recordamos que la bibliografía consultada define este Tono como "parenthèse" o "écho" (Delattre), "contour neutralisé plat" o "contour associé à un post-fixe" (Martin). Las denominaciones propuestas por ambos autores remiten a la vinculación de la entonación con el nivel sintáctico o a la descripción fontética del movimiento melódico, para el caso del primer término utilizado por Martin. Por otra parte, Morel y DanonBoileau atribuyen a la ausencia de variación melódica una actitud de ruptura en el desarrollo discursivo del enunciado debido a una interrupción simultánea en la consideración de la coenunciación.

A través del mismo procedimiento utilizado para la descripción de los diferentes tipos de elicitaciones y emisiones informativas, presentaremos los valores que parecen prevalecer en las reacciones de los sujetos que interpretaron este grupo de emisiones. Presentaremos en primer lugar una emisión de elicitación

\section{1}

Luego de haberse agotado un tema en el intercambio, la entrevistadora inicia una nueva secuencia con la siguiente elicitación:

S23:

\footnotetext{
A. : leuh après euh/++ eh después eh

$\rightarrow \quad$ F.L. : ++ et euh $::$ dans la façon de de s'habiller + des gens est-ce qu'y a des choses que $\mathrm{xx}$ qui vous au qui vous frappent dans l'quartier ou::

Y eh:: en la forma de vestirse + de la gente ¿hay cosas que $x x$ que que los a que les sorprenden en el barrio o::
}

[CFPP2000] [07-02] Lucie_da_Silva_F_22_7

(Líneas 199-201) 
En las pruebas perceptivas, los sujetos manifestaron los siguientes comentarios a propósito de esta emisión:

Elle cherche à voir quelque chose qui les surprendrait.

Busca ver algo que las sorprendiera.

Elle essaie de les intéresser. C'est du tâtonnement, elle cherche à trouver les mots pour poser sa question.

Trata de interesarlas. Es vacilación, busca encontrar las palabras para hacer su pregunta.

Elle a fini un sujet, et elle a de la peine à retrouver la cohérence de son discours (une toute petite peine, mais voilà). La question en fait, c'est « Qu'est-ce qui sort de l'ordinaire?»

Terminó un tema y tiene dificultad para volver a encontrar la coherencia de su discurso (una muy pequeña dificultad, pero bueno). La pregunta de hecho es “¿Qué sale de lo común?"

Elle a cette façon de poser la question en utilisant un système de pauses pour apporter les éléments qui font qu'on cible.

Tiene esta forma de hacer la pregunta utilizando un sistema de pausas para aportar los elementos que hacen que se pueda focalizar.

C'est une question. Elle ouvre un débat. Elle attend une réponse justifiée.

Es una pregunta. Abre el debate. Espera una respuesta jstificada.

Elle n'a pas l'air d'être très sûre de ce qu'elle demande. C'est une question un peu étrange. Peut-être qu'elle a peur de sortir cette question.

No aparenta estar muy segura de lo que pide. Es una pregunta un poco extraña. Quizá tiene miedo de salir con esta pregunta.

On voit que la question est un peu délicate. On prend un peu des pincettes.

Se ve que la pregunta es un poco delicada. Hay que tomarlo un poco con pinzas.

Elle a un peu de mal à formuler sa question. C'est une question tout en longueur.

Tiene un poco de dificultad para formular su pregunta. Es una pregunta bien larga.

C'est une question. Elle pose des questions par rapport aux bizarreries.

Es una pregunta. Hace preguntas con respecto a las rarezas.

Elle cherche à savoir si les femmes ont quelque chose à dire sur le sujet. Elle les teste.

Busca saber si las mujeres tienen algo para decir sobre el tema. Las testea.

C'est une manière d'ouvrir le débat. Elle a une manière de dire un peu lente,

d'hésiter... Et ça c'est une stratégie des intervieweurs aussi parce qu'ils vont lentement, ils laissent le temps à la personne de réfléchir, ils hésitent un peu... Cette manière oblige les gens à développer avec un esprit critique.

Es una forma de abrir el debate. Tiene una forma de decir un poco lenta, de dudar... Y eso es una estrategia de los entrevistadores también porque van lentamente, dejan tiempo para que la persona reflexiones, dudan un poco... Esa forma obliga a la gente a desarrollar con un espíritu crítico. 


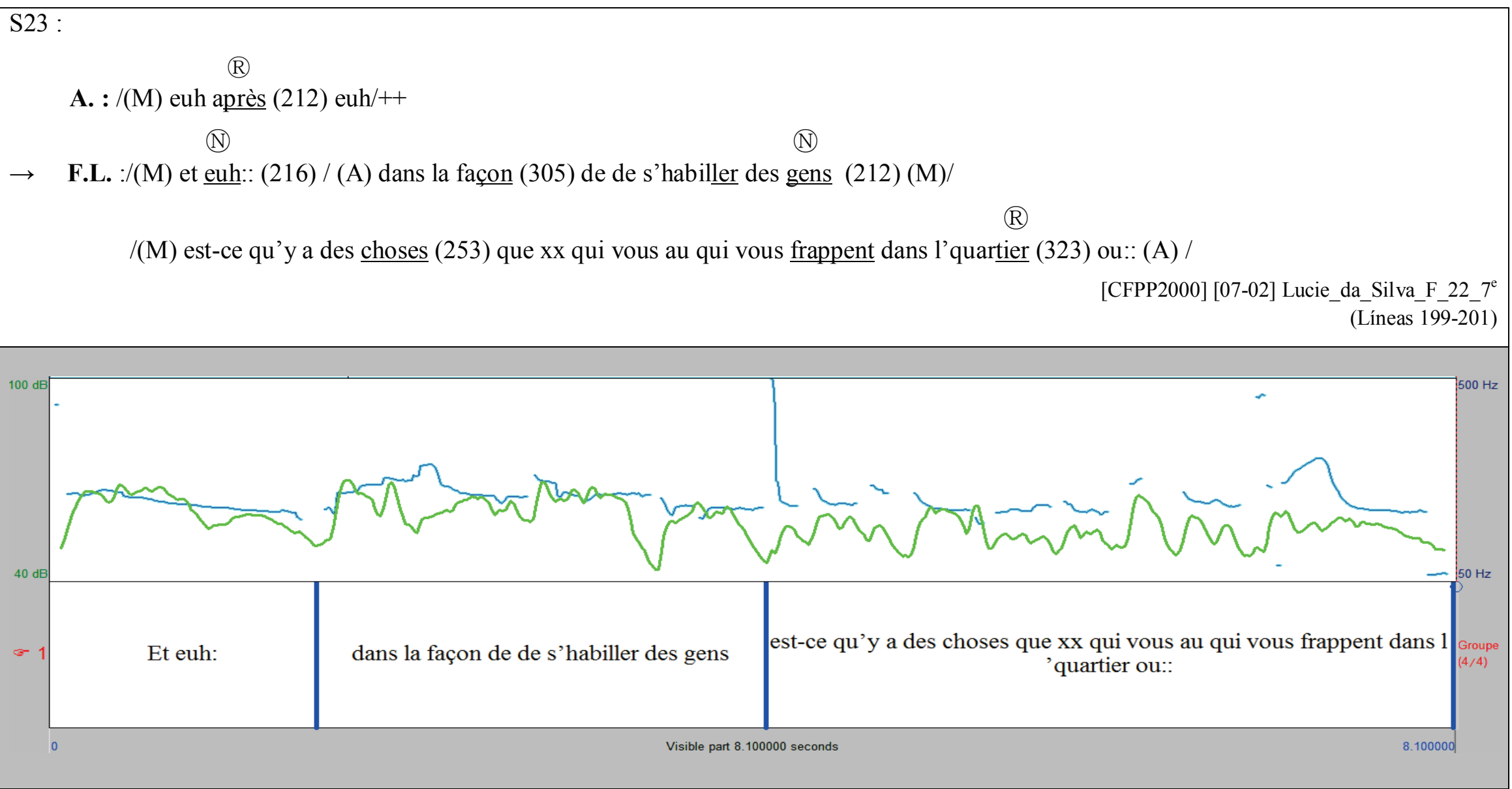


L'intervieweuse a du mal à s'exprimer. Elle veut savoir si la fille est choquée par al façon dont les gens s'habillent.

La entrevistadora tiene problemas para expresarse. Quiere saber si la chica está extrañada por la forma vestirse de los jóvenes.

Además de las abundantes referencias a la intención de obtener información, los sujetos expresaron la percepción de una instancia en la que Florence selecciona una expresión que le resulte satisfactoria: «C'est du tâtonnement, elle cherche à trouver les mots pour poser sa question.» «... elle a de la peine à retrouver la cohérence de son discours (une toute petite peine, mais voilà). " «Elle n'a pas l'air d'être très sûre de ce qu'elle demande. (...) Peut-être qu'elle a peur de sortir cette question. » "On voit que la question est un peu délicate. On prend un peu des pincettes. » «Elle a un peu de mal à formuler sa question. " «L'intervieweuse a du mal à s'exprimer. "

"Es vacilación, busca encontrar las palabras para hacer su pregunta." "... tiene dificultad para volver a encontrar la coherencia de su discurso (una muy pequeña dificultad, pero bueno)." "No aparenta estar muy segura de lo que pide. Quizá tiene miedo de salir con esta pregunta." "Se ve que la pregunta es un poco delicada. Se toma con pinzas un poco." Tiene un poco de dificultad para formular su pregunta." "La entrevistadora tiene problemas para expresarse."

Dos sujetos evocaron asimismo cierta intención específica de la persona en su rol de entrevistadora: "Elle a cette façon de poser la question en utilisant un système de pauses pour apporter les éléments qui font qu'on cible. » "Elle a une manière de dire un peu lente, d'hésiter... Et ça c'est une stratégie des intervieweurs aussi parce qu'ils vont lentement, ils laissent le temps à la personne de réfléchir, ils hésitent un peu... Cette manière oblige les gens à développer avec un esprit critique. »

«Tiene esta forma de hacer la pregunta utilizando un sistema de pausas para aportar los elementos que hacen que se pueda focalizar." "Tiene una forma de decir un poco lenta, de dudar... Y eso es una estrategia de los entrevistadores también porque van lentamente, dejan tiempo para que la persona reflexiones, dudan un poco... Esa forma obliga a la gente a desarrollar con un espíritu crítico."

En lo que hace a sus características entonativas, esta emisión está compuesta por tres unidades tonales: una simple y dos extendidas (ver gráfico $\mathrm{n}^{\circ} 39$ ). La hablante realiza el Arranque de la primera unidad sobre el elemento "euh" en nivel medio $(216 \mathrm{~Hz})$. Precisamos, para el caso específico del Arranque, que la determinación de su nivel surge de su comparación con el Arranque precedente de Adèle, "euh après euh" realizado sobre la sílaba tónica "près" en $212 \mathrm{~Hz}$. 
En la segunda unidad, "dans la façon de de s'habiller des gens", la hablante realiza un Arranque en nivel alto sobre la sílaba "çon" (305 Hz) y una Terminación en nivel medio sobre la sílaba tónica correspondiente al ítem "gens", en $212 \mathrm{~Hz}$.

Por su parte, la tercera unidad "est-ce qu'y a des choses que xx qui vous au qui vous frappent dans l'quartier ou" presenta un Arranque en nivel medio sobre la sílaba “choses" (253 Hz) y una Terminación en nivel alto sobre la sílaba tónica “tier" (323 Hz) Por último, precisamos que la hablante elige el Tono Neutral para las dos primeras unidades y finaliza con un Tono Referido. Entendemos que es la reiteración en la selección de Tono Neutral al inicio de la emisión lo que llevó a los sujetos a interpretar que la entrevistadora "busca las palabras". En cuanto a los significados vinculados con la elección del final de la unidad no difiere de lo ya interpretado en las elicitaciones de tipo A.

En los apartados siguientes, expondremos dos emisiones informativas que cuentan con secuencias cuya entonación es sostenida.

\section{2}

La secuencia que presentamos a continuación, en la que una joven describe el tipo de vestimenta usual en el $7^{\circ}$ distrito de París, permite también ilustrar los significados transmitidos por el Tono Neutral.

P18:

A.: mais habillés bien quand-même [parce que c'est un quartier aisé donc euh :]

Pero vestidos bien sin embargo porque es un barrio acomodado entonces eh:

$\rightarrow \quad$ L.dS. : [ $\underline{\text { bien }}$ sobres classiques] bien habillés + et euh:: s- une majorité euh $::$ costards euh tailleurs cos- ouais .

Bien, sobrios, clásicos, bien vestidos + y eh :: s una mayoría eh:: tragedia eh trajecito tra, se.

[CFPP2000] [07-02] Lucie_da_Silva_F_22_7

(Líneas 205 a 208)

Presentamos a continuación las reacciones de los sujetos de las pruebas perceptivas acerca de esta intervención:

Elle cherche ses mots. On vit que c'est des valeurs pour elle. Elle suit sa pensée, essaie de trouver le mot juste.

Busca sus palabras. Se ve que es importante para ella. Sigue sus pensamientos, trata de encontrar la palabra justa. 
Elle constate. Elle essaie de donner une image globale, elle cherche les mots.

Constata. Trata de dar una imagen global, busca las palabras.

Elle cherche à préciser sa pensée.

Busca precisar sus pensamientos.

Elle a un peu de mal à donner sa réponse.

Tiene un poco de dificultad para dar su respuesta.

Elle se crée peut-être une image mentale.

Quizá se está creando una imagen mental.

Elle fait presque des pauses entre chaque mot, chaque qualificatif qu'elle ajoute. Quand elle accélère c'est juste pour donner une indication. Elle est dans la description.

Hace pausas casi entre cada palabra, cada calificativo que agrega. Cuando acelera es sólo para dar una indicación. Está describiendo.

Elle réfléchit, elle cherche ses mots.

Reflexiona, busca sus palabras.

Pour moi, c'est des hésitations. Elle parle en même temps qu'elle réfléchit. Ça va vite parce qu'on est dans un dialogue.

Para mí, son vacilaciones. Habla al mismo tiempo que reflexiona. Va rápido, porque es un diálogo.

On voit que la question est un peu délicate, alors elle a un peu de mal à trouver ses mots. Elle cherche ses mots pour répondre de manière adéquate à la question.

Se ve que la pregunta es un poco delicada, entonces le cuesta un poco encontrar sus palabras.

Busca sus palabras para responder en forma adecuada a la pregunta.

Elle hésite beaucoup, peut-être qu'elle n'a pas très bien compris encore une fois la question, donc elle ne sait pas très bien ce qu'elle doit répondre, ce qu'on lui demande.

Duda mucho, quizá no entendió muy bien la pregunta otra vez, entonces no sabe muy bien lo que debe responder, lo que le preguntan.

Elle a du mal à trouver le vocabulaire adéquat.

Le cuesta encontrar el vocabulario adecuado

Je pense que c'est pas son milieu, donc elle doit réfléchir pour s'imaginer.

Creo que no es su entorno, entonces tiene que reflexionar para imaginarse.

Elle est dans la recherche des mots, elle hésite.

Está buscando palabras, duda. 


\section{Gráfico $\mathrm{n}^{\circ} 40$}

P18:

\section{(P)}

A.: /(M) mais habillés bien (206) quand même (172) / [parce que c'est un quartier aisé donc euh :]

(R)

(R)

(R)

(R)

(N)

$\rightarrow$ L.dS. : [/(A) bien (272) / (A) sobres (314) / (A) classiques (306)/] (A) bien habillés (340) / (M) et euh:: s (203)/

(N)

(N)

(P)

(P)

/(A) une majorité (249) euh ::(200) (M) / (M) costards euh (201)/(B) tailleurs (148)/(B) cos- ouais (91)/

[CFPP2000] [07-02] Lucie_da_Silva_F_22_7 (Líneas 205 a 208)

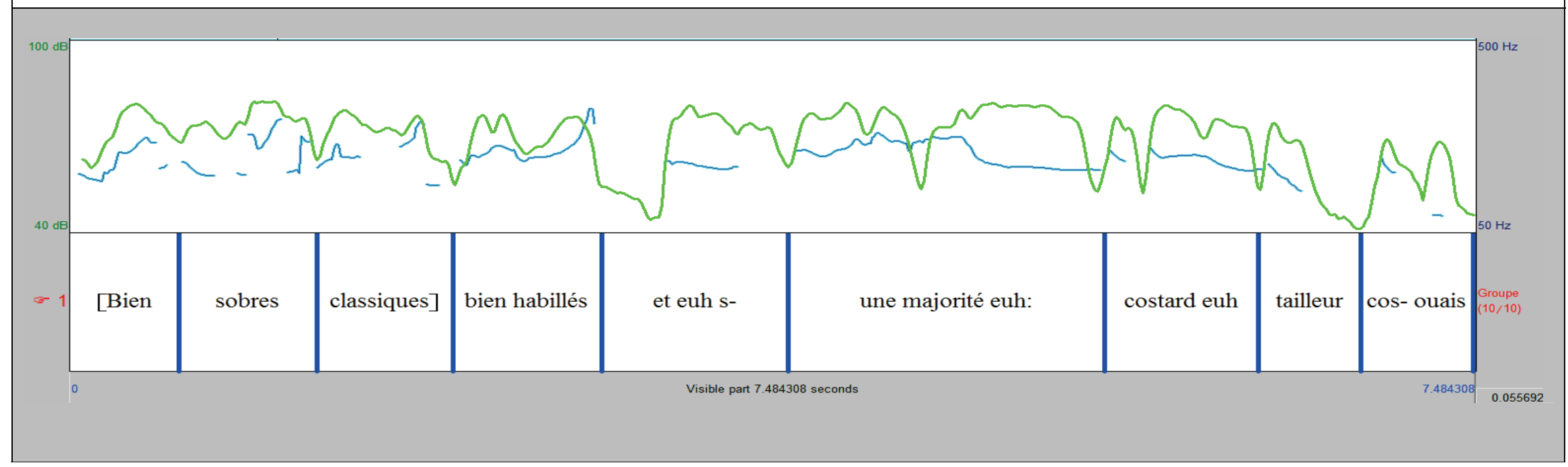


Los comentarios muestran que los sujetos relacionan la forma de la emisión y los procesos mentales que realiza el hablante para formularla. Los mismos se remiten a:

a) La dificultad de la hablante para encontrar expresiones que le resulten satisfactorias: "Pour moi, c'est des hésitations. " «Elle hésite beaucoup... » «Elle a du mal à trouver le vocabulaire adéquat.» «Elle a un peu de mal à donner sa réponse.» «... elle a un peu de mal à trouver ses mots. » «Elle est dans la recherche des mots, elle hésite. "

"Para mí, son vacilaciones." "Duda mucho..." "Le cuesta encontrar el vocabulario adecuado" "Tiene un poco de dificultad para dar su respuesta." "...le cuesta un poco encontrar las palabras." "Está buscando palabras, duda."

b) La voluntad de proveer una descripción correcta: «Elle suit sa pensée, essaie de trouver le mot juste. » "Elle cherche ses mots. » en dos oportunidades «Elle cherche à préciser sa pensée. " «Elle cherche ses mots pour répondre de manière adéquate à la question. »

"Sigue sus pensamientos, trata de encontrar la palabra justa." "Busca sus palabras." "Busca precisar sus pensamientos." "Busca sus palabras para responder en forma adecuada a la pregunta."

c) La simultaneidad de la reflexión y la puesta en palabras: «Elle se crée peut-être une image mentale. " «Elle réfléchit, elle cherche ses mots. " "Elle parle en même temps qu'elle réfléchit. » « ... elle doit réfléchir pour s'imaginer. »

"Quizá se está creando una imagen mental." "Reflexiona, busca sus palabras." "Habla al mismo tiempo que reflexiona." "...tiene que reflexionar para imaginarse."

El análisis acústico, expuesto en el gráfico $n^{\circ} 40$, permite visualizar una emisión compuesta por 9 unidades tonales. Las cuatro primeras son simples y reiteran la elección del nivel tonal alto para su Arranque y Terminación. Los mismos se realizan, sucesivamente, sobre las sílabas tónicas "bien" (272 Hz), "sobres" (314 Hz), "siques" (306 Hz) y "llés" $(340 \mathrm{~Hz})$. Recordemos que el nivel tonal de Arranque se determina por su cotejo con el Arranque precedente. Para el caso de la primera secuencia, es necesario mencionar que el Arranque de la unidad previa pronunciada por Adèle ("mais habillés bien quand.même") tiene una altura de $206 \mathrm{~Hz}$. El Arranque alto parece entonces acompañar la búsqueda de la retención del turno, puesto que, de estas cuatro unidades, las tres primeras se encuentras efectuadas por un encabalgamiento con el final de la emisión de Adèle. Al tratarse de grupos fónicos simples, las Terminaciones tienen el mismo novel tonal alto. 
En cuanto a las elecciones en el subsistema de Tono, esta secuencia de cuatro grupos repite la realización de Tono Referido. En las emisiones informativas, este Tono acompaña también el deseo de conservar el turno de habla, como señala para el español Granato (1999).

En las tres unidades siguientes, se opera un descenso en las alturas tonales y un cambio en las elecciones de Tono: la quinta unidad "et euh $s^{-}$" es simple. Lucie realiza el Arranque y la Terminación en un nivel tonal medio sobre la sílaba tónica "euh s" (en $203 \mathrm{~Hz}$ ). La sexta unidad, “une majorité euh”, es extendida. Su Arranque, realizado en la sílaba " $m a$ ", tiene nivel tonal alto $(249 \mathrm{~Hz})$, mientras que su Terminación, situada en la sílaba tónica "euh" tiene un nivel medio $(200 \mathrm{~Hz})$. La séptima unidad, "costard euh" es simple y cuenta con un Arranque y una Terminación también en nivel medio, situados en la sílaba tónica "euh" $(201 \mathrm{~Hz})$. En esta secuencia de tres unidades, la hablante reitera el uso del Tono Neutral. Una interpretación factible para el cambio en la elección de niveles tonales es que, una vez lograda la retención del turno, Lucie se aboca simplemente a proporcionar la información - el nivel medio en el arranque acompaña la adición de información -. En tanto, el predominio del Tono Neutral manifestaría que la hablante está centrada en la búsqueda de la expresión deseada sin expresar, en este momento, ningún significado orientado a los demás participantes de la interacción.

Finalmente, las dos últimas unidades tienen también en común que ambas son simples e incluyen realizaciones de Arranque y Terminación en nivel bajo. Los mismos se ubican en las sílabas tónicas "lleurs" (148 Hz) y “ouais" (91 Hz) respectivamente. Entendemos que el nivel bajo vehiculiza aquí la idea de finalidad ya que la joven ha encontrado la formulación que deseaba para aportar la información. Paralelamente, se reiteran las elecciones de Tono, pero en este caso, se trata del Tono Proclamatorio cuyos significados coinciden con los ya tratados en el capítulo Emisiones informativas de tipo A.

Es notorio, en este caso, que la elección de Tonos permite interpretar la dilación que se produce en la emisión hasta el momento en que Lucie logra tomar una posición determinada respecto de la información que brinda a sus interlocutoras.

Si bien el Tono neutral no demuestra una consideración del interlocutor, las elecciones de Arranque y Terminación, parecen señalar cierto grado de interactividad. Como 
señala Brazil, el discurso no interactivo y el interactivo se ubican en extremos de un continuo que incluye discursos con diferentes grados de consideración del interlocutor. En las emisiones analizadas, el Tono Neutral indica la no consideración del otro, mientras que las diferencias en las elecciones de Arranque y Terminación serían constituirían una señal de que, de alguna manera, sí se lo tiene en cuenta.

\section{3}

Para concluir, presentaremos una emisión informativa muy extensa. La misma está realizada en 13 unidades tonales y tiene una duración de casi medio minuto. En ella, Gabriel P. reacciona al pedido de información de Florence L., acerca de las escuelas del barrio.

P38:

F.L. : et euh + en c'qui concerne l'école là tu tu m'as parlé du lycée Rodin est-ce que [G.P. : ouais] qu'est qu'est-ce que tu penses des écoles du quartier des collèges des lycées? euh

En lo referido a la escuela recién me me hablaste del liceo Rodin es [G.P.: sí] ¿qué qué pensás de las escuelas del barrio, de los primarios, de los secundarios? eh:

$\rightarrow \quad$ G.P. : euh ++ bah je pense qu'a priori enfin + de c'qu'on en entend c'est pas ++ on n'est pas dans une zone défavorisée + (F.L. : mm) hein + euh à savoir que les choses ont l'air de s'passer à peu près bien sauf que bon ++ j'pense que comme dans tout lycée euh y a des problèmes un petit peu à la sortie (F.L. : mm) de drogue de machin choses comme ça mais bon c'est l'adolescence hein

Eh ++ este pienso que a priori enfin por lo que se escucha no es ++ no estamos en una zona desfavorecida + (F.L.: $\mathrm{mm}$ ) eh + a saber que las cosas parecen andar más o menos bien salvo que bueno ++ creo que como en cualquier liceo eh hay problemas un poco a la salida (F.L.: $\mathrm{mm}$ ) de droga de qué sé yo de cosas así pero bueno es la adolescencia eh

[CFPP2000] [13-01] Gabriel_Pujade_H_40_13 ${ }^{\mathrm{e}}$ (Líneas 627-634)

En las pruebas perceptivas, se obtuvieron los siguientes comentarios a propósito de esta emisión informativa:

Il cherche ses mots. Il a l'air de bien réfléchir à ce qu'il dit.

Busca sus palabras. Parece reflexionar bien en lo que dice.

Il hésite.

Vacila.

Il cherche les mots, il prend le temps de réfléchir.

Busca las palabras, se toma tiempo para reflexionar. 
Il est sûr de lui, mais il doute beaucoup.

Está seguro de sí mismo, pero duda mucho.

Il réfléchit toujours pour donner sa réponse.

Piensa siempre para dar su respuesta.

Il réfléchit à ce qu'il va dire, il y a une volonté de bien exposer clairement ce qu'il est en train de dire, mais il y a aussi peut-être un peu d'inquiétude.

Reflexiona en lo que va a decir, hay una voluntad de exponer claramente lo que está diciendo, pero quizá hay también un poco de preocupación.

C'est une réponse avec beaucoup de bonne volonté Mais il y a beaucoup de distance quand-même, il y a un désir d'objectivité.

Es una respuesta con mucha buena voluntad. Pero sin embargo hay mucha distancia, hay un deseo de objetividad.

Il prend tout son temps pour répondre, pour bien répondre. Il prend un peu de temps au début pour bien choisir ses mots, pour bien formuler ses idées, trouver le mot juste.

Se toma todo el tiempo para responder, para responder bien. Toma un poco de tiempo al principio para elegir sus palabras, para formular bien sus ideas, encontrar la palabra justa.

Il est calme, il réfléchit, cherche ses mots... Il est dépassionné, mais très soucieux de donner une réponse juste.

Está tranquilo, reflexiona, busca sus palabras... Está desapasionado, pero muy preocupado por dar una respuesta justa.

Il hésite, il y a des silences et des pauses dans la voix.

Vacila, hay silencios y pausas en la voz.

Il n'est pas très sûr de lui, en fait. Il doute un peu de sa réponse. J'ai l'impression qu'il ne sait pas trop si c'est bien ou si c'est pas bien.

No está muy seguro de sí mismo, en realidad. Duda un poco de su respuesta. Tengo la sensación de que no sabe demasiado si está bien o no está bien.

Il n'est pas très à l'aise sur le sujet. Au départ il hésite. Il a un ton relativement hésitant. No está muy a gusto con el tema. Al principio, duda. Tiene un tono realmente dubitativo.

Il a peur de tomber dans le cliché, donc il réfléchit beaucoup avant de parler et pour se donner du temps, il multiplie les pauses, les 'euh', les aspirations.

Tiene miedo de caer en el cliché, entonces piensa mucho antes de hablar y, para darse tiempo, multiplica las pausas, los 'eh', las aspiraciones.

Como pudo observarse, nuevamente los sujetos son sensibles al proceso de búsqueda de la formulación satisfactoria que lleva a cabo el hablante al mismo tiempo que efectúa la respuesta. El mismo se atribuye en algunas interpretaciones a la una actitud cooperativa que lleva a buscar una respuesta lo más adecuada posible: «Il cherche ses 
mots. Il a l'air de bien réfléchir à ce qu'il dit. » «Il cherche les mots, il prend le temps de réfléchir. " «Il réfléchit toujours pour donner sa réponse. " «Il réfléchit à ce qu’il va dire, il y a une volonté de bien exposer clairement ce qu'il est en train de dire... » " C'est une réponse avec beaucoup de bonne volonté Mais il y a beaucoup de distance quand-même, il y a un désir d'objectivité. » «Il prend tout son temps pour répondre, pour bien répondre. Il prend un peu de temps au début pour bien choisir ses mots, pour bien formuler ses idées, trouver le mot juste. » «Il est calme, il réfléchit, cherche ses mots... (...) très soucieux de donner une réponse juste. " «ll a peur de tomber dans le cliché, donc il réfléchit beaucoup avant de parler et pour se donner du temps, il multiplie les pauses, les 'euh', les aspirations. »

"Busca sus palabras. Parece reflexionar bien en lo que dice." "Busca las palabras, se toma tiempo para reflexionar." "Piensa siempre para dar su respuesta. Reflexiona en lo que va a decir, hay una voluntad de exponer claramente lo que está diciendo..." "Es una respuesta con mucha buena voluntad. Pero sin embargo hay mucha distancia, hay un deseo de objetividad." "Se toma todo el tiempo para responder, para responder bien. Toma un poco de tiempo al principio para elegir sus palabras, para formular bien sus ideas, encontrar la palabra justa." "Está tranquilo, reflexiona, busca sus palabras... (...) muy preocupado por dar una respuesta justa." "Tiene miedo de caer en el cliché, entonces piensa mucho antes de hablar y, para darse tiempo, multiplica las pausas, los 'eh', las aspiraciones." 
Gráfico $\mathrm{n}^{\circ} 41$ - segmento 1

P 38:

(R)

F.L. : qu'est qu'est-ce que tu penses des écoles du quartier /(M) des collèges (165) des lycées (187) euh (M)/ (N)

$\rightarrow \quad$ G.P. : /(M) euh (123)/++

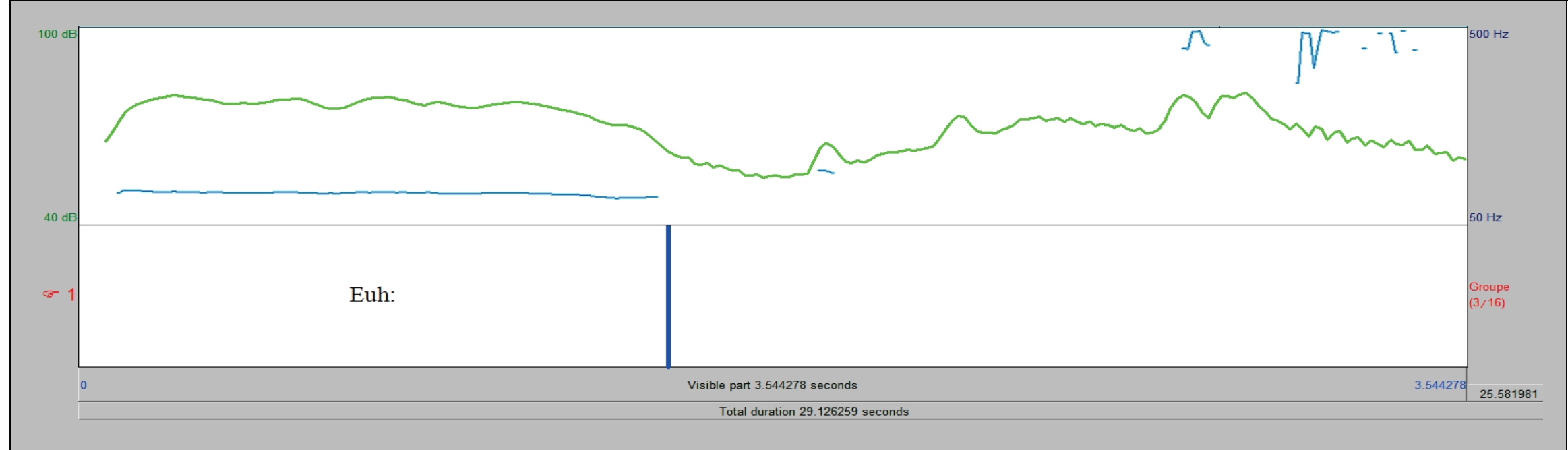


Gráfico $n^{\circ} 41-$ segmentos 2 y 3

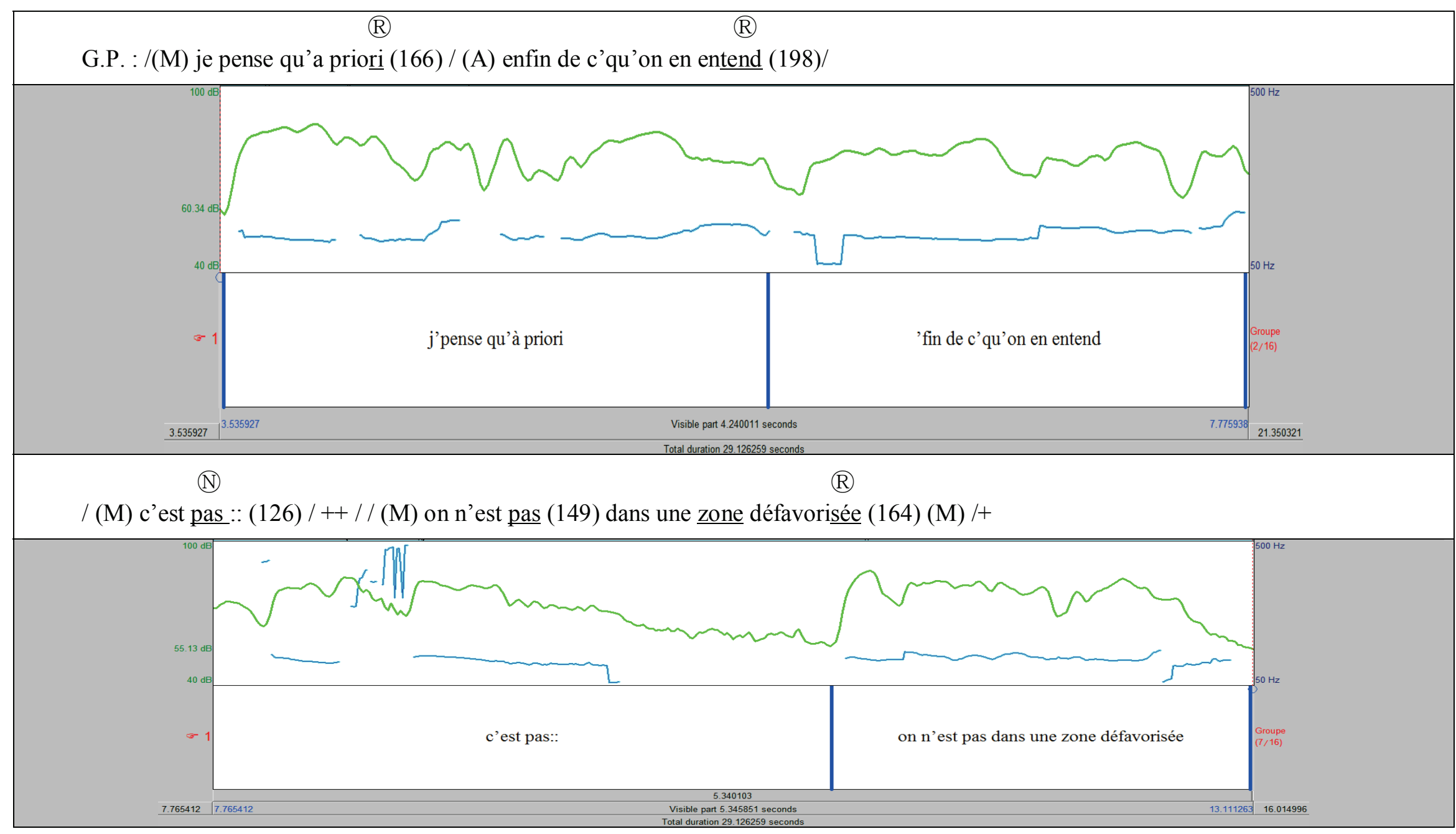




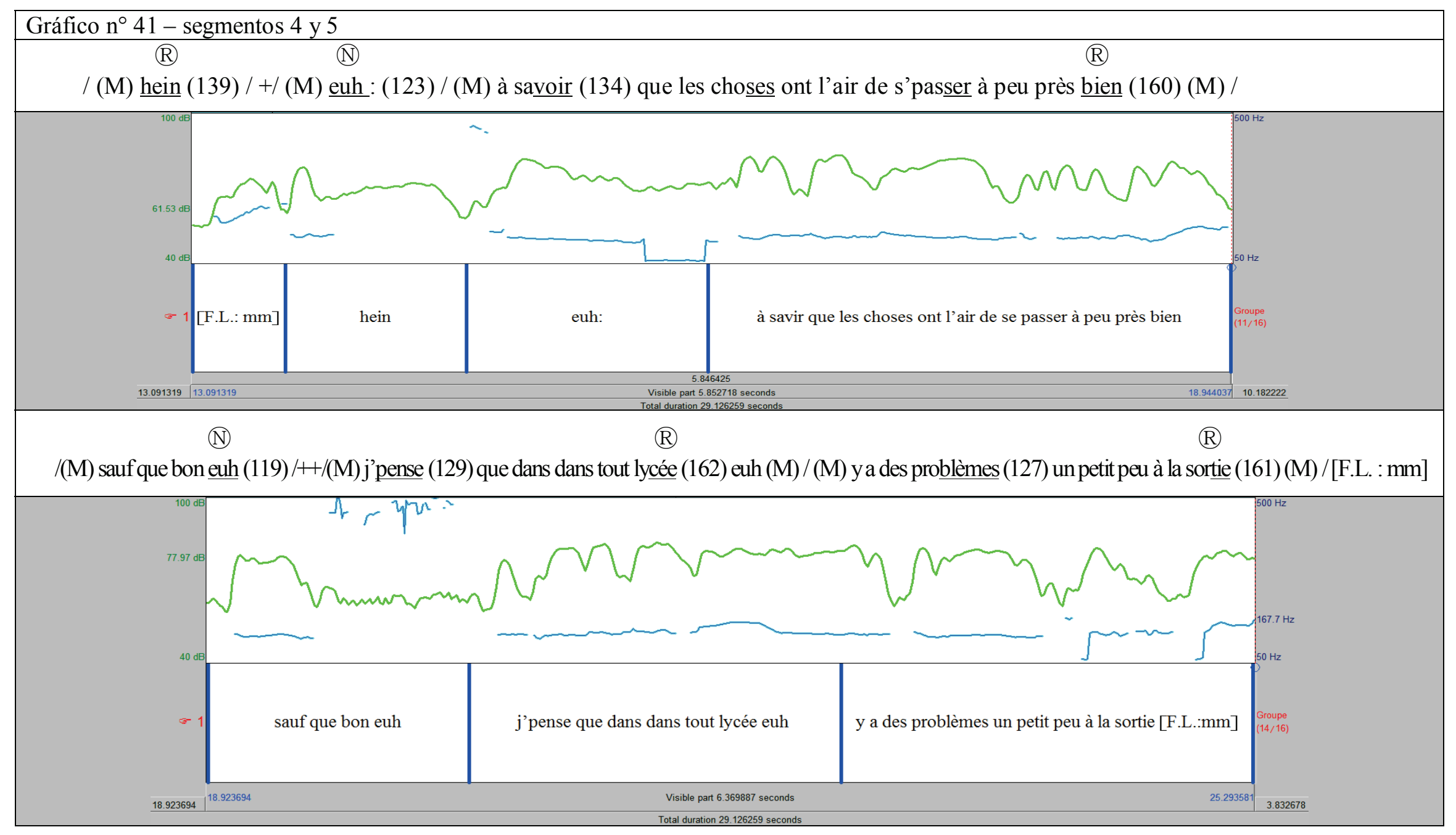


Gráfico $n^{\circ} 41$ - segmento 6

(R)

/(M) de drogue (117) de machin choses comme ça (146) (M) / (A) mais bon c'est l'adolescence (178) hein/

[CFPP2000] [13-01] Gabriel_Pujade_H_40_13

(Líneas 627-634)

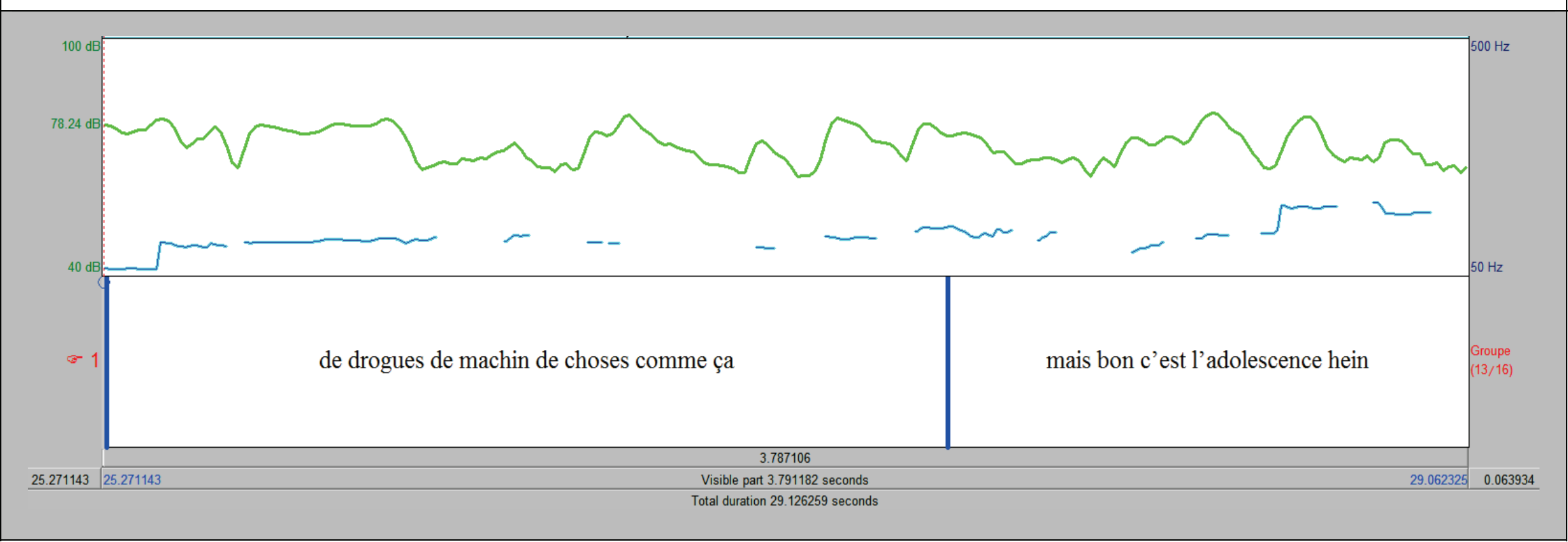


Por su parte, otros sujetos estimaron que la emisión pone de manifiesto la falta de certeza del hablante, atribuida ya sea a su carácter, ya sea al tema abordado: «Il hésite. » « ... mais il doute beaucoup. » «Il hésite, il y a des silences et des pauses dans la voix. » «Il n'est pas très sûr de lui, en fait. Il doute un peu de sa réponse. J'ai l'impression qu'il ne sait pas trop si c'est bien ou si c'est pas bien. 》 «Il n'est pas très à l'aise sur le sujet. Au départ il hésite. Il a un ton relativement hésitant. »

"Vacila." “... pero duda mucho." "Vacila, hay silencios y pausas en la voz." "No está muy seguro de sí mismo, en realidad. Duda un poco de su respuesta. Tengo la sensación de que no sabe demasiado si está bien o no está bien." "No está muy a gusto con el tema. Al principio, duda. Tiene un tono realmente dubitativo."

En cuanto a sus características entonativas, la emisión está realizada, como mencionáramos, en 13 unidades tonales. Se trata de una emisión extensa y pausada $\left(29,13\right.$ segundos), como puede apreciarse en el gráfico $n^{\circ} 41$, que ha sido dividido en 6 segmentos para facilitar la visualización del movimiento de $\mathrm{F}_{0}$. A fin de simplificar la presentación, nos limitaremos a la especificación de las realizaciones de Arranque y Terminación que vinculan a la emisión con las secuencias previa y siguiente. Del mismo modo, detallaremos sólo las elecciones de Tono Neutral.

La primera unidad es simple y tanto su Arranque como su Terminación se realizan sobre la sílaba tónica "euh" en un nivel medio $(123 \mathrm{~Hz})$. Respecto del Arranque, precisamos que el Arranque precedente de la emisión de Florence (“des collèges des lycées euh") tiene asimismo un nivel medio $(165 \mathrm{~Hz})$ y se efectúa en la sílaba "lèges". Puede interpretarse que, con la elección de este nivel tonal, Gabriel desea simplemente aportar la información que le ha sido solicitada.

Entre los aspectos de las realizaciones de Arranque y Terminación, se destaca la escasa variación melódica a lo largo de todo el segmento. La misma se restringe a un rango de entre $117 \mathrm{~Hz}$ y $198 \mathrm{~Hz}$. La elección del nivel tonal Medio se impone en los 13 grupos fónicos con sólo dos excepciones: el Arranque y la Terminación de la tercera unidad efectuado en nivel alto ("enfin de c'qu'on en entend", que alcanza los $198 \mathrm{~Hz}$ ) y el Arranque y la Terminación de la última unidad de la secuencia, también en nivel alto ("mais bon c'est l'adolescence hein" que alcanza los $178 \mathrm{~Hz}$ ). Entendemos que en esta secuencia, la elección de nivel Alto invita efectivamente a la Adjudicación: el hablante considera posible que su interlocutora intervenga con una opinión divergente -iniciada con un Arranque también alto-- 
En lo referido a las elecciones de Tono, Gabriel P. alterna, en su emisión el Tono Referido, utilizado en nueve oportunidades y el Tono Neutral, presente en los cuatro grupos restantes. Los grupos realizados con este último Tono están frecuentemente acompañados por alargamientos vocálicos y limitados por pausas: tres ocasiones en que las unidades finalizan el ítem cuasi léxico "euh" (en la primera, la séptima y la novena unidad) o la cuarta unidad tonal, “c'est pas:”. Las unidades acompañadas por Tono Referido pueden vincularse con el deseo de preservar el turno de habla, como señala Granato (1999) en su estudio sobre le español. Inversamente, la última elección de Tono Referido, coincidente con la última unidad de la secuencia intenta, a nuestro entender, presentar la información como natural o ya presente en el contexto "mais bon c'est l'adolescence hein". En tanto, entendemos que son las realizaciones de Tono Neutral lo que manifiesta la orientación oblicua del significado del discurso. Los sujetos de las pruebas perceptivas expresaron esta orientación con la búsqueda de las palabras y la reflexión acerca de lo que se va a decir.

El análisis presentado hasta aquí permite constatar que las realizaciones de Tono Neutral son significativas tanto para el hablante como para los oyentes. Las mismas ponen de manifiesto la simultaneidad de su proceso mental de búsqueda de la expresión que desea y de la verbalización.

Recordamos que, entre los autores consultados, Morel y Danon-Boileau observan, desde una perspectiva enunciativa, que la ausencia de variación melódica manifiesta un repliegue monológico y una ruptura en la consideración de la coenunciación. Asimismo, en las descripciones efectuadas por Brazil y por Granato para el inglés y para el español, los autores subrayan el carácter no interactivo de esta elección de Tono. Contrariamente a lo que ocurre con el Tono Proclamatorio y el Referido, con los cuales el hablante proyecta significados hacia los interlocutores, el Tono Neutral no establece ninguna actitud interactiva. Por su parte, este Tono expresa la implicación del hablante con el contenido de lo que dice.

Es interesante notar que los participantes de las pruebas perceptivas interpretaban estas instancias como pausas, aunque no considerasen posible que otro participante pudiera tomar la palabra en esos momentos. 
Parte III

Reflexiones finales 


\section{Capítulo 8}

\section{Conclusiones}

Los resultados obtenidos confirman la hipótesis general del trabajo - Es posible encontrar valores sistematizables en relación con los significados que la entonación agrega - por cuanto se ha podido plantear una primera aproximación al análisis de la entonación como sistema independiente y desde una perspectiva socio-pragmática y sistemática. Se ha puesto de manifiesto que un estudio que parte de los significados detectados por los sujetos hablantes de una lengua posibilita la descripción de los aportes que la entonación realiza al contenido del discurso. Tales contribuciones pueden analizarse independientemente de aquellas que realizan las diferentes configuraciones léxicas y sintácticas de las emisiones a fin de dar cuenta de los valores funcionales de la entonación.

La atención se centró de este modo en la búsqueda de características comunes en los significados evocados por los sujetos francohablantes a fin de esbozar un sistema con variables generales que se manifestaron en forma relativamente estable en nuestros datos. Recordamos que existen numerosos trabajos referidos al rol de la entonación en la expresión de significados vinculados con las actitudes y emociones. No obstante, estimamos que aunque tales significados pueden describirse, los mismos no son sistematizables, dado que un mismo patrón puede proyectar valores diferentes.

Pudo detectarse que, en muchos, casos los sujetos que participaron de las pruebas perceptivas atendieron al significado que otorgan otras elecciones lingüísticas que nos son los patrones entonativos. Teniendo en cuenta, siempre desde una perspectiva funcional y sistémica, que las elecciones efectuadas por los hablantes son siempre significativas y que las mismas se realizan también en otros planos del lenguaje, pensamos que los interactuantes pueden atender a diferentes significados y que algunos pueden ser predominantes sobre otros.

El estudio llevado a cabo determinó, en lo que atañe al subsistema de Arranque, que los sujetos son sensibles a la elección de diferentes niveles tonales. En particular, se observó la vinculación constante entre elecciones de nivel alto y significados vinculados 
con la idea general de contraste. La misma se evidenció con gran frecuencia en emisiones informativas, pero también en emisiones de elicitación.

Los significados transmitidos por las opciones en el subsistema de Terminación no fueron evocados con frecuencia en las pruebas perceptivas. Esto se debe a que, posiblemente, los sujetos se centraban principalmente en el contenido proposicional o en el significado aportado por la elección de Tono. Sin embargo, en todos los casos en que las respuestas se refirieron a las elecciones de Terminación, los significados percibidos coincidieron con aquellos descritos para el inglés y para el castellano.

Por su parte, los significados vinculados con las opciones en el subsistema de Tono fueron los evocados con mayor regularidad en las pruebas perceptivas. Los mismos permitieron determinar las distinciones iniciales operadas en las emisiones de elicitación y en las emisiones informativas. Asimismo, en el interior de cada grupo de emisiones, fueron las opciones de Tono las que permitieron identificar pasajes de discurso no interactivo en el interior de los intercambios de nuestro corpus.

El cuadro $n^{0} 13$ reúne los valores generales atribuidos en forma constante a cada opción en el subsistema de Tono.

\begin{tabular}{|c|c|c|c|}
\hline $\begin{array}{l}\text { Instancias de } \\
\text { lenguaje }\end{array}$ & Función & Tono & Significado \\
\hline \multirow{4}{*}{ Interactivo } & \multirow{2}{*}{ Elicitaciones } & (R) & Se ignora la respuesta \\
\hline & & (P) & No se ignora la respuesta \\
\hline & \multirow{2}{*}{$\begin{array}{l}\text { Emisiones } \\
\text { informativas }\end{array}$} & P & $\begin{array}{l}\text { La información no es } \\
\text { compartida }\end{array}$ \\
\hline & & (R) & $\begin{array}{l}\text { La información es } \\
\text { compartida }\end{array}$ \\
\hline \multicolumn{2}{|c|}{ No interactivo } & (N) & $\begin{array}{l}\text { El mensaje no se dirige a un } \\
\text { interlocutor in mente }\end{array}$ \\
\hline
\end{tabular}

Cuadro $n^{\circ} 13$

Estas opciones permiten identificar diferentes tipos de elicitaciones y de emisiones informativas. En el caso de las emisiones que solicitan información, la elección del Tono Referido acompaña las elicitaciones en las que el hablante desconoce la respuesta que solicita. Inversamente, con el Tono Proclamatorio, el hablante solicita una información con una determinada respuesta in mente. 
En lo que respecta a las emisiones informativas, se distinguen tipos de información en relación con su presencia en el contexto o con su carácter novedoso. Con el Tono Proclamatorio, el hablante expresa la información como compartida por los demás participantes del intercambio, mientras que el Tono Referido describe esta información como presente, de alguna manera, en el contexto de la interacción.

Asimismo, dentro de los dos tipos de emisiones, el Tono Neutral permitió identificar segmentos en los que la atención del hablante está momentáneamente dirigida al contenido de lo que está expresando y no a sus interlocutores, motivo por el cual, se lo considera no interactivo.

Reiteramos, además, que los significados expuestos tienen relación con intenciones comunicativas específicas del hablante en el momento de la interacción. Como señala Brazil y como se puntualizó en las pruebas perceptivas, hay instancias en las se pone de manifiesto la intención del hablante de explotar el sistema para proyectar un determinado estado de cosas, independientemente del carácter efectivo o no del mismo.

Entendemos que este trabajo constituye un primer aporte en la descripción de la contribución que realiza la entonación al discurso en lengua francesa, dado que no existen, según nuestro conocimiento, trabajos que aborden el mismo objeto desde esta perspectiva socio-pragmática y sistémica.

Dicho aporte puede describirse atendiendo a un aspecto teórico, específicamente en lo referido a la contribución al estudio del funcionamiento de la lengua en uso y de los significados en el ámbito del discurso.

Asimismo, se destaca un aspecto aplicado orientado, en primer lugar a la enseñanza del francés como lengua extranjera en todos los niveles, incluido el de la formación de formadores $y$, en segundo lugar, a la formación de intérpretes cuya tarea atañe la circulación oral de significados.

Estimamos, además, que este primer estudio tiene un carácter exploratorio y que sería posible, sobre la base teórica adoptada, de la metodología utilizada y de los elementos analizados aquí, profundizar el estudio de determinados temas, específicamente, el tratamiento de los subsistemas de Arranque y Terminación. Del mismo modo, puede extenderse el análisis a otros aspectos que impliquen:

a. Abordar el análisis de las características de las elecciones de Prominencia y de sus valores sistematizables. 
b. Analizar la ocurrencia de emisiones con el mismo valor funcional en otros tipos de discursos, diferentes en cuanto a género y registro a los textos de este trabajo.

c. Detallar el aporte de la entonación en la determinación de valores funcionales en otros tipos de emisiones. En especial, la profundización del examen de secuencias o discursos no interactivos como la lectura, tan frecuentemente examinada en la entonación del francés.

d. Comparar los valores de los patrones entonacionales atribuidos al español con los descritos en este trabajo, lo cual resultaría pertinente en el ámbito de la enseñanza del francés como lengua extranjera en todos los niveles.

Es nuestra intención completar nuestro análisis en estudios posteriores, a fin de analizar otros tipos de interacciones verbales en situaciones con diferentes grados de formalidad, de participación de los interactuantes y de ritualización. 


\section{Bibliografia}

- Angouri, J. (2010) “Quantitative, qualitative or both”. In Lotosseliti, L. (ed.) Research Methods in Linguistics. London: Continuum.

- Aubergé, V. (2002) «Prosodie et émotion » En Actes des Deuxièmes Assises Nationales du GdR, 2002 - irit.fr Disponible en : http://www.irit.fr/GDRI3/fichiers/assises2002/papers/15-ProsodieEtEmotion.pdf. Consultado el 17 de diciembre de 2013.

- Blanche-Benveniste, C. et al. (1992) «Actualité de l'enquête et des études sur l'oral » en Langue française, Volume 93, nº 1 pp. $94-119$.

- Blanche-Benveniste, C. et P. Martin (2011) «Structuration prosodique, dernière réorganisation avant énonciation ». Dans Langue française $\mathrm{n}^{\circ}$ 170. pp. 127-142.

- Boffi, A. y L. Granato (1994) "La entonación en la comunicación verbal” en Serie Pedagógica 1. pp. 47-58.

- Bouvet, D. y M.-A. Morel (2001) Le ballet et la musique de la parole: Le geste et l'intonation dans le dialogue oral en français. Paris: Ophrys.

- Branca-Rosoff S., Fleury S., Lefeuvre F., Pires M. (2012) Discours sur la ville. Présentation du Corpus de Français Parlé Parisien des années 2000 (CFPP2000) Disponible en http://cfpp2000.univ-paris3.fr/CFPP2000.pdf. Consultado el 17 de diciembre de 2013.

- Brazil, D. ([1985]1997) The Communicative Value of Intonation in English. London: University of Birmingham/Cambridge University Press.

- Brazil, D. (1984) “Tag questions”. In Ilha do Desterro, V/11. PP. 28-44.

- Brazil, D. (1992) “Listening to people reading”. In R. M. Coulthard ed. Advances in discourse analysis. London: Routledge.

- Brazil, D. (1995) A Grammar of Speech. Oxford: Oxford University Press

- Candea, M. y M.-A. Morel (2002) « La gestion de l'indicible à l'aide de différents types d'allongements en français oral ». Dans Représentations du sens linguistique, Lagorgette, D. y Larrivée, P. (Ed.) Munich : Lincom Europa.

- Carton, F. (1974). Introduction à la Phonétique du français. Paris : Bordas.

- Chomsky, N. (1981) Lectures on Government and Binding: The Pisa Lectures. Berlin and New York: Mouton de Gruyter.

- Chomsky, N. (1987) La nouvelle syntaxe. Paris : Seuil.

- Delattre, P. (1966) «Les dix intonations de base du français ». In The French Review $\mathrm{n}^{\circ} 40$, American Association of Teachers of French. Illinois. pp. 1-14. 
- Delattre, P. (1969) «L'intonation par les oppositions ». Dans Le Français Dans Le Monde $\mathrm{n}^{\circ}$ 64. Paris. pp. 6-13.

- Di Cristo, A. (1998) “Intonation in French". In Hirst, D. et A. Di Cristo (1998). Intonation systems: a survey of twenty languages. Cambridge: Cambridge University Press.

- Di Cristo, A. (2003) « De la métrique et du rythme de la parole ordinaire : l'exemple du français », Semen [En ligne], 16, mis en ligne le 06 mai 2007, consulté le 14 décembre 2013. URL : http://semen.revues.org/2944.

- Di Cristo, A. y D. Hirst (1997) «L'accentuation non emphatique en français : stratégies et paramètres » en Perrot, D. (coord.). Polyphonie pour Ivan Fónagy. Paris : L'Harmattan.

- Eggins, S. y D. Slade (1997) Analysing Casual Conversation. London: Cassell.

- Fairclough, N. (1992) Discourse and Social change. Cambridge: Polity Press.

- Fónagy, I. (1983) La vive voix. Paris: Éditions Payot.

- Fónagy, I. (2000) « Mes rencontres avec l'intonation ». Dans Guimbretière, E. (ed.) La prosodie au coeur du débat. Rouen: Publication de l'Université de Rouen.

- Fónagy, Ivan (2003) « Des fonctions de l'intonation : Essai de synthèse » en Revue annuelle de la section française, Université des Langues Étrangères de Tokyo. Flambeau 29 pp.1 -20. Disponible en : http://ed268.univParís3.fr/lpp/pages/EQUIPE/vaissiere/fonagy/articles/fontions $\% 20 \mathrm{de} \% 201 \% 27$ intona tion.pdf. Consultado el 17 de diciembre de 2013.

- Garde, P. (1968) L'accent. Paris : Presses Universitaires de France.

- Granato de Grasso, L. (1997) "Dominio lingüístico: un estudio de fonología discursiva" en Bolívar, A y P. Bentivoglio (eds.) Actas del I Coloquio de Analistas del Discurso. Caracas: Universidad Central de Venezuela.

- Granato, L. (1999) La entrevista radial telefónica: un estudio de pragmática discursiva. Tesis no publicada.

- Granato, L. (2005). "Aportes de la entonación al significado del discurso" en: $R A S A L$, diciembre de 2005 vol. $\mathrm{n}^{\mathrm{o}} 1$. pp. 85-109.

- Grasso, M. y K. Ibañez (2010) "Evaluaciones simultáneas en conversaciones entre jóvenes". En La renovación de la palabra en el bicentenario de la Argentina. Los colores de la mirada lingüistica. Castel y Cubo (eds.). Mendoza: Editorial de la FFL UnCuyo. ISBN 978-950-774-193-7.

- Gumperz, J. (1982) Discourse Strategies. Cambridge: Cambridge University Press.

- Halliday, M.A.K. and C.M.I.M. Matthiessen (2004) Introduction to Functional Grammar. ${ }^{\text {rd }}$ Edition, London: Edward Arnold.

- Halliday, M.A.K. and R. Hasan (1989) Language, Context, and Text: Aspects of language in a social-semiotic perspective. Oxford: Oxford University Press. 
- Ibañez, K. (2007) "Prosodia en el texto y apreciación. Un estudio de sus configuraciones". VII Congreso Latinoamericano de Estudios del Discurso ALED. Horizontes de Sentido Bogotá, Colombia.

- Ibañez, K. (2008) "La descripción en la conversación informal: un análisis del uso y de la configuración de ítems valorativos". Actas del III Congreso internacional Transformaciones culturales. Debates de la teoría, la crítica y la lingüística. ISBN 978-987-1450-53-4.

- Ibañez, K. (2010) "Didáctica de la entonación y realizaciones entonativas en los textos para la enseñanza de francés como lengua extranjera (FLE): primeras aproximaciones”. Segundas jornadas internacionales de formación e investigación en lenguas extranjeras y traducción. ISLV Juan Ramón Fernández. Buenos Aires.

- Ibañez, K. (2012) "Perspectivas actuales en la enseñanza de la prosodia del francés: algunas reflexiones a propósito de la noción de sistemas entonativos y su aplicación”. II Jornadas internacionales de didáctica de la fonética de las lenguas extranjeras. UNSAM.

- Ibañez, K. (2013) "Entonación y solicitud de información: Reflexiones acerca de las características entonativas del discurso en francés" Actas de las III Jornadas internacionales de Fonética y Fonología. Mar del Plata, 26-28 de Septiembre. En prensa.

- Jefferson, G. (1974) "Error correction as an interactional resource". In Language in Society, 3(2). pp. 181-199.

- Kawag, Y., I. Fónagy y T. Moriguchi (2006) Prosody and Syntax. Amsterdam: John Benjamins.

- Kerbrat-Orecchioni, C. $(1986,1990,1992)$ Les Interactions verbales. Paris : Armand Colin.

- Kerbrat-Orecchioni, C. (1996) La conversation. Paris : Seuil.

- Kerbrat-Orecchioni, C. et V. Traverso (2004). «Les genres de l'oral : Types d'interaction et types d'activité », ICAR, Université Lumière Lyon 2, Institut Universitaire de France.

- Labov, W. (1972) Sociolinguistic Patterns. Philadelphia: University of Pennsylvania Press.

- Labov, W. (1996) Principles of Linguistic Change. Volume 1: Internal Factors. Oxford: Basil Blackwell.

- Lacheret, A. (2008) Projet ANR Rhapsodie. http://www.projetrhapsodie.fr/plus/presentation.html . Consultado el 17 de diciembre de 2013.

- Lacheret-Dujour, A. (2003) La prosodie des circonstants. Louvain : Peeters.

- Lacheret-Dujour, A. et F. Beaugendre (1999) La prosodie du français. Paris: CNRS Éditions. 
- Léon, P. (1971) Essais de phonostylistique. Studia Phonetica n 4. Montréal : Didier.

- Léon, P. (1993) Précis de phonostylistique : parole et expressivité. Paris: Nathan.

- Marandin, J-M. (2006) “Contours as constructions" in Schoenefeld, D. (ed.) Constructions all over: case studies and theoretical implications. Disponible en: www.constructions-online.de/articles/specvol1/. Consultado el 17 de diciembre de 2013.

- Martin, J.R. and D. Rose (2003) Working with Discourse: Meaning Beyond the Clause. London: Continuum.

- Martin, P. (2004) «Intonation de la phrase dans les langues romanes : l'exception du français ». Dans Langue française. $\mathrm{N}^{\circ} 141$. pp. 36-55.

http://www.persee.fr/web/revues/home/prescript/article/lfr_0023-

8368_2004_num_141_1_6587

Consultado el 17 de diciembre de 2013.

- Martin, P. (2006) «Intonation du Français : parole spontanée et parole lue ». Dans EFE No XV, pp. 133-162. Disponible en: http://www.ub.es/labfon/XV-9.pdf. Consultado el 17 de diciembre 2013.

- Martin, P. (2008) «L'intonation du français : le vilain petit canard parmi les langues romanes? » en Language Design. Journal of Theoretical and Experimental

Linguistics Special Issue $\mathrm{N}^{\circ}:$ 2, 2008. pp. 1-13. http://elies.rediris.es/Language_Design/LD-SI-2/indice_vol_SI_2.html. Consultado el 17 de diciembre de 2013.

- Martin, P. (2009) Intonation du français. Paris : Armand Colin.

- Martins-Baltar, M. (1977) De l'énoncé à l'énonciation : une approche des fonctions intonatives. Paris : Didier.

- Mertens, P. (1997) «De la chaîne linéaire à la séquence de tons ». Dans revue de l'Association pour le T.A.L. (Traitement Automatique des Langues) n ${ }^{\circ}$ 38/1. pp.2751. Paris: Klincksieck.

- Mertens, P. (2002) "Synthesizing Elaborate Intonation Contours in Text-to-Speech for French". In Bel, B. e I. Marlien (eds.) Proceedings of the Speech Prosody 2002 conference, 11-13 April 2002. Aix-en-Provence: Laboratoire Parole et Langage. p. 499-502 http://bach.arts.kuleuven.be/pmertens/publications.html. Consultado el 17 de diciembre de 2013.

- Mertens, P. (2004) "The Prosogram: Semi-Automatic Transcription of Prosody based on a Tonal Perception Model”. In B. Bel \& I. Marlien (eds.) Proceedings of Speech Prosody, Nara (Japan), 23-26 March. (ISBN 2-9518233-1-2). Disponible en http://bach.arts.kuleuven.be/pmertens/papers/sp2004.pdf. Consultado el 17 de diciembre de 2013.

- Mertens, P. (2006) "A Predictive Approach to the Analysis of Intonation in Discourse in French" en Kawaguchi, Y.; Fonagy, I.; Moriguchi, T. (eds.) Prosody and Syntax. 
Amsterdam: John Benjamins. pp. 64-101.

- Mertens, P. (2009) «Prosodie, syntaxe, discours : autour d'une approche prédictive. » Dans Actes du colloque IDP2009 (Interface Discours Prosodie), Paris, 9-11 septembre 2009. Disponible en http://bach.arts.kuleuven.be/pmertens/papers/PMertens_IDP2009.pdf. Consultado el 17 de diciembre de 2013.

- Morel M.-A. (2007) « Un thème, deux thèmes, un préambule ? Intonation, geste et morphosyntaxe dans le dialogue oral en français ». Dans Elalouf, M.-L. (coord.) LINX n55 Thème et thématisation. pp. 133-152.

- Morel, M.-A. (2004) «Intonation, Regard et Genres dans le dialogue à bâtons rompus ». Dans Languages, $\mathrm{n}^{\circ} 153$. pp. 15-27.

- Morel, M.-A. y L. Danon Boileau (1998) Grammaire de l'intonation. Paris: Ophrys.

- Pierrel, J.-M. (dir.) (2013) Centre National de Ressources textuelles et lexicales. Dictionnaire en ligne. Disponible en http://www.cnrtl.fr/. Consultado el $17 \mathrm{de}$ diciembre de 2013.

- Quivy, R. et L. Van Campenhoudt (1995) Manuel de recherche en sciences sociales. Paris : Dunod.

- Rossi, M. (1980), «Le français, langue sans accent ?» Dans Studia Phonetica $n^{\circ} 15$. pp. $13-51$.

- Rossi, M. (1987) «Peut-on prédire l'organisation prosodique du langage spontané ? » Dans Etudes de Linguistique Appliquée n 66. pp. 20-48.

- Rossi, M. (1999) L’intonation, le système du français : description et modélisation. Paris : Orphys.

- Sacks, H., Schegloff, E. A. \& Jefferson, G. (1974) "A Simplest Systematics for the Organisation of Turn-Taking for Conversation". In Language $\mathrm{n}^{\circ}$ 50. pp. 696-735.

- Searle, J. (1965): “¿Qué es un acto de Habla?” en Valdés Villanueva, L.M. (comp.) La búsqueda del significado. Madrid: Tecnos y Universidad de Murcia.

- Silverman, D. (2001) Interpreting Qualitative Data: Methods for Analysing Talk, Text and Interaction. London: Sage.

- Sinclair, J. McH. y Coulthard, R.M. ([1975]1978). Towards an Analysis of Discourse. The English used by teachers and pupils. Great Britain: Oxford University Press.

- Vaissière, J. (2006) La phonétique. Paris : Presses Universitaires de France.

- Warnant, L. (1987) Dictionnaire de la prononciation française dans sa norme actuelle. Paris : Duculot. 


\section{Anexo 1}

Selección de fragmentos del CFPP2000 (Corpus de français parlé parisien des années 2000) Datos de los hablantes - Transcripción

\begin{tabular}{|c|c|c|c|c|}
\hline \multicolumn{5}{|c|}{ Hablantes } \\
\hline Iniciales & Nombre $^{1}$ & Edad & Profesión & Procedencia $^{2}$ \\
\hline S.B. & $\begin{array}{l}\text { Sonia Branca } \\
\text { (encuestadora) }\end{array}$ & 62 & $\begin{array}{l}\text { Docente universidad } \\
\text { de París III }\end{array}$ & $\begin{array}{l}\text { Inf. no } \\
\text { disponible }\end{array}$ \\
\hline O.K. & Ozgur Kiliç & 32 & Ingeniero de sonido & $3^{\circ}$ distrito \\
\hline B.D. & Benoît Dubreuil & 32 & Ebanista & $3^{\circ}$ distrito \\
\hline A.D. & Augustin Dubreuil & 34 & $\begin{array}{l}\text { Supervisor de call } \\
\text { center }\end{array}$ & $3^{\circ}$ distrito \\
\hline M.C. & Michel Chevrier & 31 & $\begin{array}{l}\text { Músico, compositor, } \\
\text { profesor de piano }\end{array}$ & $3^{\circ}$ distrito \\
\hline E.S. & Etienne Salvegas & 32 & $\begin{array}{l}\text { Empleado } \\
\text { temporario }\end{array}$ & $3^{\circ}$ distrito \\
\hline F.L. & $\begin{array}{l}\text { Florence Lefeuvre } \\
\text { (encuestadora) }\end{array}$ & 41 & $\begin{array}{l}\text { Docente universidad } \\
\text { de París III }\end{array}$ & Toulouse \\
\hline L.dS. & Lucie da Silva & 22 & Empleada bancaria & $7^{\circ}$ distrito \\
\hline A. & Adèle & $\begin{array}{l}\text { Inf. no } \\
\text { disponible }\end{array}$ & Conserje & $7^{\circ}$ distrito \\
\hline F. & Francine & $\begin{array}{c}\text { Inf. no } \\
\text { disponible }\end{array}$ & Inf. no disponible & $7^{\circ}$ distrito \\
\hline J-P. & $\begin{array}{l}\text { Jean-Pierre } \\
\text { Duchemin }\end{array}$ & 60 & $\begin{array}{l}\text { DEA Ciencias de la } \\
\text { Educación }\end{array}$ & $11^{\circ}$ distrito \\
\hline R.C. & Reine Céret & 60 & Dra. en Sociología & $11^{\circ}$ distrito \\
\hline Bl.D. & Blanche Duchemin & 25 & Médico residente & $11^{\circ}$ distrito \\
\hline J.T. & Julie Teixeira & 17 & $\begin{array}{c}\text { Estudiante de } \\
\text { Preparatoria letras }\end{array}$ & $11^{\circ}$ distrito \\
\hline K.T. & Katia Teixeira & 15 & $\begin{array}{l}\text { Estudiante de } \\
\text { colegio }\end{array}$ & $11^{\circ}$ distrito \\
\hline A.T. & Amélie Tourette & 28 & $\begin{array}{c}\text { Doctoranda } \\
\text { universidad de París } \\
\text { III }\end{array}$ & $11^{\circ}$ distrito \\
\hline G.P. & Gabriel Pujade & 40 & $\begin{array}{l}\text { DESS (disciplina no } \\
\text { consignada) }\end{array}$ & $13^{\circ}$ distrito \\
\hline J.M. & Jeanne Mallet & 75 & $\begin{array}{c}\text { Empleada de } \\
\text { comercio jubilada }\end{array}$ & Saint-Ouen \\
\hline L.L. & Louise Liotard & 88 & $\begin{array}{l}\text { Ama de casa } \\
\text { jubilada }\end{array}$ & Saint-Ouen \\
\hline
\end{tabular}

1 Los nombres verdaderos de los entrevistados han sido reemplazados por seudónimos a fin de garantizar su privacidad.

2 Se trata del lugar acerca del cual han sido interrogados los hablantes. En el caso de los dos primeros fragmentos, se trata del lugar de nacimiento y residencia durante la infancia. En el resto de los fragmentos, se refiere al lugar de residencia al momento de la entrevista. 


\begin{tabular}{|c|c|c|c|c|}
\hline Iniciales & Nombre $^{3}$ & Edad & Profesión & Procedencia $^{4}$ \\
\hline M.P. & $\begin{array}{c}\text { Mat Pires } \\
\text { (encuestador) }\end{array}$ & $\begin{array}{c}\text { Inf. no } \\
\text { disponible }\end{array}$ & Inf. no disponible & $\begin{array}{c}\text { Inf. no } \\
\text { disponible }\end{array}$ \\
\hline An. & Anne & $\begin{array}{c}\text { Inf. no } \\
\text { disponible }\end{array}$ & Inf. no disponible & $\begin{array}{c}\text { Inf. no } \\
\text { disponible }\end{array}$ \\
\hline F. & Farah & $\begin{array}{c}\text { Inf. no } \\
\text { disponible }\end{array}$ & Inf. no disponible & $\begin{array}{c}\text { Inf. no } \\
\text { disponible }\end{array}$ \\
\hline
\end{tabular}

\section{Participantes :}

\section{Fragmento 1}

\section{[CFPP2000] [03-01] Ozgur_Kiliç_H_32_alii_3}

1.O.K. : Ozgur Kiliç

2.S.B. : Sonia Branca

3.B.D. : Benoît Dubreuil

4.A.D. : Augustin Dubreuil

5.M.C. : Michel Chevrier

6.E.S. : Etienne Salvegas

$1 \quad$ S.B. : euh y avait des animaux qui ont compté dans le quartier + pour vous?

2 B.D. : ouais ceux d'Michel

3 M.C. : ouais

4 O.K. : ouais

5 O.K.-B.D. : ah moi j'avais j'avais deux lapins aussi et ceux et ceux + d'Etienne

$6 \quad$ M.C. : ah ses lapins tes lapins

7 B.D.-S.B. : t'avais un chat ah - ça c'est chez vous

8 O.K.-M.C. : ouais - ouais

9 M.C. : c'est chez nous

10 S.B.-O.K. : des lapins - on voulait dire

11 S.B. : des chats des singes euh non pas d'singes

12 O.K. : non des singes c'est nous qui jouions aux singes

13 M.C. : qui jouions aux singes

14 O.K. : est-ce qu'y avait des animaux vous voulez dire dans l'quartier?

15 S.B. : oui

16 O.K. : euhl- non

17 B.D.-O.K. : ah si des - de

18 B.D. : souris $+y$ en avait des

19 O.K.-B.D. : ouais mais bon $-X X$

20 B.D. : ah attends

21 O.K. : moi ça m'a pas marqué hein

3 Los nombres verdaderos de los entrevistados han sido reemplazados por seudónimos a fin de garantizar su privacidad.

4 Se trata del lugar acerca del cual han sido interrogados los hablantes. En el caso de los dos primeros fragmentos, se trata del lugar de nacimiento y residencia durante la infancia. En el resto de los fragmentos, se refiere al lugar de residencia al momento de la entrevista. 
B.D. : parce que ta mère elle t'a jamais t'a jamais dit qu'elle allait déménager si elle voyait encore une fois des souris quoi (rires de quelques interviewés)

24 A.D. : j'ai jamais entendu

25 O.K.-A.D. : non ma mère elle les soignait les souris - les cris d'notre mère hein

26 B.D. : "tiens prends un caillou"

S.B. : mais grosso modo les animaux euh dans la ville ça + vous convient ça vous dérange ça y en a qui vous plaisent y en a qu'vous regardez?

M.C. : bah, ces merdes de chien dans certaines rues

30 S.B. : oui

31 M.C.-S.B. : et euh - c'est ça qu'je

O.K.- S.B. : ah -voulais

O.K.-M.C. : oui moi moi - moi XX la rue d'Braque

M.C. : $y$ avait des chiens

35 O.K. : ouais

36 A.D. : atroce certaines petites rues c'était

37 O.K. : $m o i$

38 M.C.-O.K. : X chez - ma rue

39 M.C. : Steve aussi d'ailleurs

40 O.K. : la rue Portefoin j'l'appelais la rue Portemerde

41 M.C. : ah ouais non la rue Portefoin là où habitait Ozgur c'était euh c'était vraiment euh 42 d'ailleurs

43 O.K. : on jouait dans la rue

44 M.C.- O.K. : ouais ou jouait dans la rue c'est clair - on jouait beaucoup nous nous on 45 jouait

46 O.K. : m- moi je jouais beaucoup dans dans la rue en bas d'chez moi avec euh + mon 47 voisin du dessous et et mes deux

$48 \quad$ M.C. : les courses de poubelle

49 O.K. : potes de gardien mais ça c'était plus tard non on jouait vraiment beaucoup on 50 jouait au foot on jouait euh $(\mathrm{mm} \mathrm{mm})$ ah y avait très peu d'passages de voitures on jouait 51 à on jouait à quoi on jouait à des jeux où on s'cachait derrière les voitures

52 M.C. : du skate

53 O.K. : ou du skate voilà on et euh c'est vrai que : quand on s'cachait derrière les voitures 54 on prenait rapidement l'réflexe de regarder où est-ce qu'on s'cachait

55 S.B. : d'accord

56 O.K. : parce que ça nous est arrivé de

57 O.K.-M.C. : de tomber euh - on a joué au foot

58 M.C. : là le nombre de fois où $X X$

59 O.K. : bah oui

60 M.C. : tombés dans la merde

61 S.B. : donc chiens + merde

62 O.K. : ouais chiens égal euh ouais à Paris oui

63 A.D. : dans dans les petites rues surtout

64 M.C. : ouais bah ouais mais euh

65 E.S. : rue d'Beauce ça $X$ dit rien

66 O.K. : moi c'est pour ça d'ailleurs qu'j'aurai jamais d'chien euh à Paris hein j'aurai

67 j'aurai envie d'avoir un chien à Paris

68 S.B. : et les pigeons?

69 O.K.-B.D. : $m m-c ̧ a$

70 B.D. : s'mange? (rires de quelques interviewés)

71 S.B. : non j'crois pas 
B.D. : $X X$

O.K. : les pigeons on s'est pas amusés à tirer dessus un jour? + peut-être?

B.D. : ouais mais on était jeunes

O.K. : quand on avait des + pistolets à billes

M.C. : euh j'pensais aux aux merdes $+X X$ quand on était gamins XX la petite la petite rue qui à côté d'la rue Saint-Merri on mettait des pétards dedans aussi

78 O.K. : ah ouais

79 B.D. : ah ouais

80 O.K. : oui

81 A.D. : moi aussi j'ai fait ça

82 O.K. : ah oui ça on l'a tous fait

83 E.S. : moi $X X$ des canards peut-être

84 A.D. : des canards

85 B.D. : canards + au square?

86 E.S. : toujours au square du Temple

87 O.K. : ah c'est vrai qu'y avait des canards et des cygnes au square du Temple

88 E.S. : ouais mais à part les canards euh

89 O.K. : mais t'y allais souvent toi au square du Temple?

90 E.S. : bah j'étais tout le temps fourré là-bas mais moi c'est différent parce que j'avais une 91 cour en fait là où j'habitais + où j'pouvais faire du tennis du foot (mm) j'étais aussi

92 souvent dans la cour mais j'étais très peu dans la rue

93 S.B. : avec des voisins qui trouvaient ça normal que la cour soit + occupée par les enfants

94 E.S. : bah t'avais pas d'voisins

95 B.D. : ils étaient pas là les voisins

96 E.S. : si y avait des gens qui voyaient au-dessus enfin l'immeuble en face (mm) mais y

97 avait pas d'voisins effectivement

98 B.D. : il habitait un hôtel particulier hein

99 E.S. : ah c'était un ancien château donc c'est une école euh $X$ une école

100 S.B. : oui

101 E.S. : puis donc y avait un cour et c'est vrai qu'des fois l'week-end y avait euh quinze

102 enfants avec des tracteurs à + à pédales des kartings + enfin bon c'était euh c'était un un 103 centre aéré quoi ++ mais non personne XXX

104 S.B. : d'accord mais c'était assez particulier comme logement oui ?

105 E.S. : ah oui oui

106 B.D. : il porte pas plainte contre les impôts en général (rires deO.K.)

107 E.S. : jamais

108 B.D. : c'est un peu

109 E.S.-B.D. : on fait gaffe - difficile quoi

110 B.D. : ouais

111 E.S. : et c'était l'école des impôts ++

Fragmento 2

112 B.D. : ah si y avait mardi gras

113 M.C. : ah oui

114 B.D. : et les guerres de collège et des lycées ah ah

115 A.D. : ça les les sor-

116 O.K. : les guerres de collèges de mardi gras y avait que

117 B.D.-O.K. : ouais - ça ouais

118 A.D.-O.K. : les sorties d'collèges - c'est vrai en 
A.D. : étaient violentes hein

120 O.K. : ouais les guerres de collège de mardi gras ouais ça c'est vrai qu'

121 A.D.-O.K. : ouais + les oufs et farine - y avait ça + toi t'en as eu des comme ça non?

122 E.S. : ben? pas vraiment moi j'ai toujours un souvenir

123 O.K. : à Turgot euh

124 S.B.-O.K. : X collège était - ils venaient pas

125 S.B. : Victor Hugo

126 E.S. : $n o n$

127 O.K.-A.D. : t'en as eu ? - moi j'étais à C

128 A.D. : Couperin moi

129 O.K. : toi t'étais à Couperin

130 B.D.-O.K. : t'as raté ta jeunesse - ouais ouais

131 B.D. : ou quoi?

132 E.S. : ouais j'ai raté

133 B.D.-E.S. : mais t'étais où? - quelque chose donc

134 E.S. : non non non j'étais $X X X$

135 A.D. : ah ça si moi je j'me rappelle de de Couperin où euh et on on ouvrait la porte avec

136 cinq oufs qui arrivaient d'un d'un coup en même temps $(\mathrm{mm})+i l s$ étaient obligés d'faire

137 sortir par une sortie d'secours dans une petite rue derrière

138 O.K.-A.D. : parce que c'était quelle école - c'était infernal

139 O.K. : qui venait euh

140 A.D. : ah c'était euh

141 B.D.-A.D. : c'était - y avait

142 B.D. : Charlemagne?

143 A.D. : $y$ avait Charlemagne mais y avait aussi un en face Sophie euh

144 M.C. : Sophie-Germain?

145 A.D. : Sophie-Germin ouais + un peu moins parce que c'était des lycéens mais euh plus 146 mais euh + ah c'était + violent quoi la rue la rue du collège c'était euh à la fin d'la d'la 147 d'la journée elle était blanche et euh + on pouvait faire des crêpes quoi

148 S.B. : farine et oufs

149 O.K. : ouais

150 A.D. : farine et æeufs

151 O.K. : farine et oufs ouais

152 B.D. : et mousse à raser

153 O.K. : et mousse à raser

154 B.D. : et dentifrice et tout c'qui colle et tout c'qui tâche enfin

155 S.B. : c'est un peu fini non?

156 O.K. : j'en sais rien

157 B.D. : moi j'ai arrêté hein (rires de tous) ++ perso ça fait longtemps qu'j'ai pas fait quoi

158 A.D. : mais j'ai X ouais vraiment, j'ai plus l'impression qu'ça s'fasse beaucoup ça

159 B.D. : moins

160 A.D. : ouais

161 B.D. : c'est la crise 
Fragmento 3

[CFPP2000] [07-02] Lucie_da_Silva_F_22_7 $7^{\mathrm{e}}$

\section{Participantes :}

1.F.L. : Florence Lefeuvre (enq.)

2.L.dS. : Lucie da Silva

3.A. : Adèle

4.F. : Francine

162 F.L.-L.dS. : est-ce que pour aller faire des courses par exemple vous ça vous arrive de prendre - euh: alors

164 L.dS. : si on reste c'qu'est marrant c'est que comme on a tout à côté si on reste dans

165 l'quartier on est tout l'temps avec nos chiens +

166 F.L.-L.dS. : d'accord + vous vous sortez avec eux - ouais avec eux c'est ça-ouais ouais - d'accord - mmh mmh

168 F.L.-A. : d'accord ouais c'est marrant-ouais

169 F. : toi tu sors pas avec ton hamster hein?

170 A. : $n o n$

171 F.L. : (rires) ça $x$

172 A.-L.dS. : ouais - c'est marrant moi j'ai emmené mon hamster quand j'étais petite

173 partout hein même à la banque +

174 F.L. : (rires) + est-ce qu'il y a des des aliments qu'vous avez découvert chez les chez les commerçants: $x y$ a des des courses

176 L.dS. : euh: pas du tout (rires)

177 A.-F.L. : est-ce que quoi vous avez des quoi ? - des aliments des fruits un peu exotiques 178 ou des euh:

179 A. : des choses nouvelles? + +

180 L.dS.-F. : euh non - ça aurait pu +

181 L.dS.-A. : non - de quoi des choses nouvelles dans

182 F. : oui

183 A.-F.L. : les magasins ? - oui +++

184 F.L. : non

185 A.-L.dS. : qu'est-ce qu'y a d'nouveau? - ah si attends le le mélange entre l'al l'ananas et

186 le:: et euh:: mmh + et l'pamplemousse là le pomélo ou j'sais pas comment ça s'appelle

187 pamélo pomélo

$188 \quad$ F. : le gros machin là?

189 L.dS. : ouais l'truc là

190 F.-A. : ah oui j'en ai vu - quoi?

191 L.dS. : ça j'connaissais pas

192 F. : on en a goûté mais ils on a pas aimé +

193 F.-L.dS. : c’t espèce de de truc énorme là - si ça je si j'ai découvert ça dans

194 A.-L.dS. : c'est quoi un fruit? - un supermarché ouais

195 F.L.-F. : $m m h$ mmh - ouais

196 F.L. : d'accord + autre chose non

197 L.dS. : euh non les autres j'connaissais

198 F.L. : $m m h \mathrm{mmh}$

199 A. : euh après euh ++

200 F.L. : ++et euh:: dans la façon de de s'habiller + des gens est-ce qu'y a des choses que

201 qui vous au qui vous frappent dans l'quartier ou:: 
L.dS. : pas du tout + non non + les gens sont: + re- en généralement euh: habillés euh:: soit euh très so- sobres dans l'quartier comparé à certains quartiers ils sont très sobres +

204 très classiques +

205 A.: mais habillés bien quand même

206 L.dS. : bien

207 A.-L.dS. : parce que c'est un quartier aisé donc euh: - sobres classiques bien habillés + 208 et euh:: souv-une majorité euh :: costards euh tailleurs cos- ouais

209 F.L. : d'accord +

210 A.-F.L. : et euh - c'est c'qui vous frappe

211 L.dS. : $m m h$

212 A.-F.L. : ouais - vous aussi?

213 A. : bah y a y a beaucoup d'bureaux dans l'coin donc euh c'est pour ça qu'y a beaucoup

214 de

215 F.L. : $m m h$

216 A. : personnes: ouais en costard ouais

$217 \quad$ F. : et les jeunes +

218 F.L. : et les jeunes alors?

219 A. : et les jeunes? alors les jeunes ça dépend + mais euh + bah ils s'habillent un peu

220 comme tous les jeunes quoi bah + la mode des jeunes

221 A.-F. : tous - c'est-à-dire?

222 A.-L.dS. : bah c'est-à-dire euh - bah c'est très on va dire que - ça dépend des - non j'suis désolée mais dans l'septième c'est très rare de voir euh: un groupe de jeunes en jogging

225 A. : de quoi + c'est très?

226 L.dS. : de voir un groupe de jeunes en jogging c'est très rare dans l'septième hein

227 F.-A. : ah ils ont tous le jean les Converses hein Adèle - si les Adidas

228 F.-L.dS. : vous avez quoi tous le jean les Converses - ils sont tous voilà-

229 et l'petit sac $x$ - voilà alors

230 L.dS. : ils ont tous le les filles elles ont toutes le sac Longchamp + le slim euh: de chez Le

231 Temps des Cerises les Converses + le tee-shirt avec des paillettes de chez H\&M et la veste

232 treillis + voilà

233 F.L. : d'accord (rires)

234 A. : ouais ouais ça dépend ouais (rires)

235 L.dS. : c'est le modèle de base

236 F.L.- L.dS. : ça c'est le modèle de base - c'est l'standard

237 F.L. : et + et les les garçons?

238 L.dS. : les garçons c'est alors le pantalon euh:: slim sous les fesses avec le calçon qui

239 dépasse

240 F. : ah non pas tous non quand même là j'en vois pas beaucoup hein (rires) t'exagères

241 A.-L.dS. : non mais mainte(nant) maintenant les slims c'est moins à la mode - non

242 maintenant ça redevient ça redevient plus les jeans plus classique maintenant j 'trouve

243 aussi ouais j'trouve qu'y a une tendance au

244 L.dS.-F. : plus classique - non les garçons c'est le jean

245 L.dS.-A. : c'est jean jean baskettes Converses - euh - voilà

246 A.-L.dS. : les Schmooves aussi là les chaussures ouais un peu pointues - les schmooves

247 ouais

248 F.L. : ouais

249 A.-L.dS. : euh bah ils peuvent mettre tee-shirt une chemise - tee-shirt chemise un tee-shirt 250 ouais ouais

251 L.dS. : tee-shirt chemise 
F.L. : comment ça s'appelle ces chaussures?

L.dS. A. : les Schmooves - c'est des chaussures un peu pointues F.L. : d'accord

256 A.-L.dS. : donc ça pourrait être même des chaussures de bureau-mais euh ouais +

257 A. : ouais + et les filles c'est le le sac aussi c'est important-

258 F. : Vanessa Bruno?

259 A. : Vanessa Bruno euh Gérard Darel: tout ça.

\section{Fragmento 4 \\ [CFPP2000] [11-03] Blanche_Duchemin_F_25_Reine_Ceret_F_60_11 ${ }^{\mathrm{e}}$}

\section{Participantes :}

1.S.B. : Sonia Branca

2.J-P. : Jean-Pierre Duchemin

3.R.C. : Reine Céret

4.Bl.D. : Blanche Duchemin

260 R.C. : comment tu connais au fond le par exemple comment comment toi t'as tu connais

261 j'sais pas les quartiers chics par exemple co- comment tu les connais finalement?

262 BI.D. : ben alors

263 R.C.-Bl.D. : t'y vas jamais moi j'ai été étudiante à la Sorbonne - c'est c'est complètement ponctuel c'est des trucs complètement

R.C.-BI.D. : mais toi t'es - ponctuels enfin on se fait

\section{R.C. : oui c'est ça}

BI.D. : inviter à une soirée euh et cetera des choses comme ça et + enfin bon ben voilà O.K. anecdote + attention + euh y a un mois j'ai été invitée à une soirée d'un type qui faisait son anniversaire + ce mec habite dans un triplex il a vingt-neuf ans donc on va pas s'le cacher c'est pas avec son travail qu'il s'est payé cet appartement + et l'adresse de l'appartement était dix place du Trocadéro +

R.C.: comme quartier chic + t'es sûre que c'était chic ? (rires)

Bl.D. : quand on m'a dit l'adresse j'étais là "non mais tu t'trompes on a rendez-vous place du Troca- non non c'est dix place du Trocadéro c'est l'adresse où" voilà +

277 J-P.-BI.D. : un triplex - un triplex oui

278 Bl.D. : un triplex euh pas très très large

279 BI.D.-R.C. : pas très grande surface- il est

280 R.C. : c'est pas qu'il est logé par le + (rires) le T.N.P xxx j'plaisante

BI.D. : et franchement et ben ++ c'est pas mon monde + c'est pas mon monde je je $+c ̧ a$ me voilà et même être dans les rues enfin c'est tout vide c'est large c'est grand y a pas d' magasins c'est tout euh + ah la la j'aime pas du tout j'aime pas l'ambiance mais c'est

284 vraiment j'aime pas + hhh $+j$ 'peux pas décrire

BI.D.-S.B. : mais c'est $++-t u$ en dirais autant des gens ? + +

BI.D. : ah oui oui oui j'aimais pas du tout la soirée non plus (rire) franchement j'ai trouvé les gens hyper guindés hyper pas tous j'ai j'ai quand même parlé avec quelques personnes mais enfin globalement les gens euh c'était tous beaucoup sur l'apparence enfin c'qui 289 paraît logique hein la consommation euh ++ ça va pas c'est pas comme ça moi qu'je vis 290 quoi alors je les méprise pas du tout et je les juge pas ils ont été élevés comme ça et cetera 291 mais disons que je me sens une vraie appartenance envers effectivement l'est de Paris voilà 
R.C. : oui

B1.D. : je j'veux pas dire plus

BI.D.-S.B. : c'est pas - ah non

S.B.-BI.D. : c'est très clair - c'est voilà

BI.D. : mais mon appartenance elle est clairement là et tous les + quasiment tous mes amis vivent dans l'est de Paris + et ont ce mode de vie de plutôt euh + soirée "allez on va dans un bar" euh "ah il est trois heures y a plus plus d'métro on prend

299 S.B.-Bl.D. : les façons d'parler aussi sont pas les mêmes ? + - le vélib enfin

300 S.B. Bl.D. : (rire puis toux) -c'est sûr c'est sûr et de s'tenir hh j'étais impressionnée les

301 filles elles avaient une espèce de maintien moi j'étais là complètement avachie

302 S.B. : d'accord +

BI.D. : non de parler oui très différent aussi + c'est sûr + c'est sûr ++

S.B. : mais en même temps tu n'parles pas comme les petits gamins qui ratent leurs études de ton quartier +

306 Bl.D. : non + + d'ailleurs j'comprends pas forcément c'qu'ils disent parfois (rires) + non + c'est vraiment l'côté j' pense là enfin c'est y a vraiment une tranche d'âge j'sais pas entre ++ le moment où tu deviens étudiant vers vingt ans jusqu'à à peu près trente-cinq ça pousse peut-être un peu maintenant vers quarante le côté bobo c'est pas c'est vraiment pas c'est pas l'côté racaille c'est pas ++ euh + à la rigueur $++j$ 'pense qu'il y a plus une différence dans ce dont on va parler + c'est-à-dire qu'il faut toujours parler culture il faut toujours parler tu vois c'que j'veux dire que + cinéma politique on a vraiment des discussions très + que la façon les mots qu'on va employer y a une différence dans les mots qu'on emploie elle est certaine mais + encore plus profond y a le le fond

S.B.-Bl.D. : les thèmes - je pense

B1.D. : oui je pense +

R.C.-BI.D. : $m m$ c'est assez juste - dans cette soirée là tu vois

BI.D. : c'était très euh + enfin malgré tout c'était très euh ++ les conversations +++ euh faisaient rentrer l'argent dans la conversation + je raconte mon dernier voyage je raconte mon travail où j' gagne tant d'argent euh ou au contraire raconte que j' n' ai pas besoin d' travailler euh des choses comme ça + ça c'est quelque chose enfin nous j'veux pas dire qu'y a un tabou avec l'argent + mais ça ça vient des catégories socioprofessionnelles moyennes parce que c'est aussi quelque chose qu'on m'a transmis mais malgré tout + bon moi avec des amis j'peux très bien leur dire "ben vas-y dis-moi combien tu gagnes j'te dis combien j'gagne" c'est pas c'est pas c'est pas

BI.D.-R.C. : comme ça mais il y a un-oui c'est pas qu'c'est

S.B.-BI.D. : XXX ostentatoire ostentatoire - tabou à étaler son argent c'est c'est

BI.D. : ça n'se fait pas de dire euh

R.C. : c'est pas une valeur c'est pas une valeur qui vient en premier

BI.D. : voilà

R.C.-BI.D. : $X X X$ j' $^{\prime}$ crois qu'c'est ça-et et quand

Bl.D. : quelqu'un part en vacances on lui dit "c'était bien? - oui c'était bien + et sinon t'as $v u$ tel film?" + et là on part sur une vraie conversation + et + ça enfin ça peut être jugé euh par d'autres gens comme mais justement tu t'intéresses pas vraiment aux gens ou j'en sais rien hein mais $+y$ a vraiment c' côté là je je et ça j'pense que c'est vraiment quelque chose très très Est ${ }^{o}$ de Paris euh + dans le dans l'mode de vie dans l'côté 
S.B. : alors c'est quoi les bons restos et les cafés?

R.C.-BI.D. : oh quand tu veux on t'les fait connaître - ben l'resto non parce que resto t'as pas

BI.D. : d'argent j'te rappelle (rires) t'as d'l'argent pour boire plein d'verres tous les soirs mais t'auras jamais assez d'argent pour faire un resto

R.C. : oh quand même l'Express Bar tu te

BI.D. : ben y a que quand vous m'le payez hein

R.C. : ah bon j'croyais

Bl.D.-R.C. : ah non sinon j'vais boire des verres ah non j'vais boire des verres $++-q u e$ tu étais allée y dîner

Bl.D. : euh ben les The place to be non mais ça c'est parce que c'est des trucs que moi j' connais qui sont tout petits qui sont boui-boui hein enfin je j'veux bien t'dire si tu veux qu'j' te donne les adresses

R.C. : non mais donner une idée

R.C.-BI.D. : donner une idée de qu'est ce que vous faites j'sais pas ++- non mon bar préféré

BI.D.-S.B. : c'est un bar qui s'appelle le Zéro Zéro XX - ton bar préféré

BI.D. : c'est un bar qui est tenu par deux mecs qui ont un an d' moins qu' moi qui + sont plus ou moins D.J. enfin ils sont plus ou moins dans la musique et en fait un jour un d'eux a hérité un bar je crois de son grand-père ou je sais plus enfin + de par sa famille il a hérité vraiment d'ce bar et il s'est dit "qu'est c' que j'fais ?"et lui et son copain ils se sont dit “allez on s'lance +écoute on a rien à perdre c'est tout petit euh + il faut qu'on mette du un fond mais l'autre avait d'l'argent je crois euh qu'il voulait plutôt à la base garder pour s'acheter un appart ou quelque chose comme ça mais enfin oui ils se sont lancés + euh et c' qui était rigolo c'est que la même semaine y a une copine à moi qui m'dit "oh j'ai rerencontré un mec avec qui j'étais super amie au collège qui est génial écoute c'est extraordinaire comme histoire il vient d'ouvrir un bar bla bla" elle me raconte toute l'histoire et me dit "c'est juste à côté d' chez toi il faut absolument qu'on y aille la semaine prochaine" + deux jours plus tard je croise moi-même par ha-par hasard un ami d'enfance qui était Nathan Micheli le fils d'Emmanuelle qui me dit "écoute j'ai un ami mon meilleur pote il a ouvert un bar jusqu'à côté d'chez toi il faut absolument qu'tu viennes" R.C.: ah j'savais pas

Bl.D.-R.C. : j'lui dis - ça

BI.D.-R.C. : "mais comment ça" et il connaît l'autre mec + (rires de tous) voilà donc donc déjà d'emblée - et il est où ce bar ma fille?

BI.D. : c'est rue Amelot

R.C. : ah oui

BI.D. : donc déjà d'emblée ça commençait bien

\section{Fragmento 5 \\ [CFPP2000] [11-04] Julie_Teixeira_F_18_Katia_Teixeira_F_15_11 ${ }^{\mathrm{e}}$}

\section{Participantes:}

1.S.B. : Sonia B.-R. (Enq.)

2.J.T. : Julie Teixeira

3.K.T. : Katia Teixeira

4.A.T. : Amélie Tourette

379 S.B. : et les langues alors? comment vous réagissez à tout ce ce bain d' langues qu'on a

380 autour de nous? 
K.T. S.B. : c'est marrant - ça vous

S.B. : plaît?

K.T.-S.B. : oui c'est marrant

K.T. : c'est marrant oui $(\mathrm{mh})$ d'entendre de plein d'expressions par rapport avec des gens avec qui on est (mh) puis ouais y a des mots

386 S.B. : vous en avez appris? + +

387 K.T. : oh ben plein oui mais enfin maintenant ça rentre dans le vocabulaire

388 quand on parle $y$ a des mots qui sort

389 S.B. : euh par exemple?

390 K.T. : + beuh genre bolosse + euh voilà tout ça $++(\mathrm{mh})$ j'sais pas + y a quoi d'autre ? +

391 J.T. : non je moi j"hallucinais, avais $X X$

392 K.T.-J.T. : ouais ça sort maintenant encore c'est - l'autre jour moi j'étais

393 S.B. : oui

394 J.T. : non parce qu'en fait j'étais à la cantine donc à la enfin à Saint-Ouen et j'étais avec 395 une amie et c'est vrai que enfin à côté + on avait des filles de collège qui parlaient + et on 396 comprenait rien mais vraiment rien rien rien enfin elles avaient inventé des mots + et ben 397 enfin j'trouve ça vraiment marrant d'voir parce que enfin pour moi dans mon lycée tout l' 398 monde parlait enfin normalement on s'comprenait $(\mathrm{mh})$ et là elles parlaient mais c'était 399 euh indéchiffrable mais enfin j'trouve ça marrant que + + enfin j'sais pas j'ai l'impression $400 q$ qu'ils X qu'ils ont développé une nouvelle langue mais c'est enfin parce que la langue elle 401 évolue d'toute façon elle est pas figée (mh) mais euh

402 S.B. : oui oui oui

403 J.T. : mais c'est marrant d'voir que enfin + en banlieue enfin là ils parlent vraiment d'une 404 façon où

405 A.T.-J.T. : c'est vrai que ouais - nous on comprend pas

406 A.T. : vous avez pas l'accent en plus

407 J.T. : non

408 A.T. : euh parce que nous on l'avait par exemple (mh) même à Meudon qu'est bourge XX+ 409 on avait l'accent d'banlieue +

410 J.T. : ah ouais ++

411 A.T. : ouais mais ouais mais c'était mais c'est bizarre ouais (mh) mais c'était l'accent du 412 quatre-vingt-treize qui allait dans l'quatre-vingt-douze $(\mathrm{mh})$ juste pour

413 S.B. : et l'accent du quatre-vingt-treize à S-à Saint-Ouen-prépa les gens ont l'accent?

414 J.T. : non moi j' trouve pas + enfin c'est juste qu'ils parlent de façon très saccadée et +

415 S.B. : quand même

416 J.T. : ouais

417 S.B.-J.T. : pas l'même rythme - c'est saccadé

418 J.T. : oui pas l'même rythme mais euh sur- c'est surtout les mots quoi c'est + +

419 A.T.-J.T. : ah + + c'est quoi comme mots ?- enfin c'est drôle quoi c'est

420 J.T. : ah mais j'p-j'suis incapable

421 K.T.-J.T. : ouais $-j$ 'ai

422 J.T. : j'enfin on on écoutait

423 A.T. : mais euh

424 J.T. : incapable de dire de quoi elles parlaient

425 A.T. : est-ce que par exemple euh euf mince euh les ch-chev ou les non les veuch

426 J.T. : oui les veuch mais ça encore j' comprends

427 A.T.-J.T. : ça encore j' comprends - mais euh

428 J.T. : enfin comme elles enchaînent

429 S.B. : c'est quoi déjà, les veuch? +

430 A.T. : j'vais m'laver les veuch + les cheveux 
431 S.B.-J.T. : ah! - ah d'accord les cheveux

432 K.T. : ah moi j'aurais genre tu fais crari + genre tu t'la pètes et cetera

433 J.T. : mais ça ça va encore mais

434 K.T. : ouais mais bon

435 J.T. : c'est c'est c'est marrant

436 S.B. : crari?

437 A.T. : daron ça

438 S.B.-A.T. : crari $-X X X$

439 S.B. : crari c'est quoi ?

440 J.T. : daron

441 K.T.-A.T. : c'est euh se - daron daronne

442 K.T.-J.T. : la jouer - daron daronne oui

443 K.T. : ça fait crari

444 S.B. : et ça vient d'où ça vous savez?

445 S.B.-K.T. : aucune idée - on veut pas savoir

446 S.B.-A.T. : c'est là ça arrive un jour-Mimi Cracra

447 K.T. A.T. : ouais - crade peut-être

448 A.T. : ouais euh (mh) ça m'paraît bizarre quand même tout est beau euh

449 A.T.-K.T. : crari c'est cras $(\mathrm{mh})$ - maintenant y a plein d' mots on sait pas d'où

450 S.B. : oui daron c'est

451 S.B.-K.T. : plus ancien X c'est un mot-oui + oui c'est revenu

452 S.B. : $d u$ vieil argot +

453 A.T. : oui mais euh je enfin

454 K.T.-A.T. : daron daronne - ouais c'est revenu ouais

455 A.T. : parce que ouais c'est du vieil argot?

456 S.B. : oui ++

457 A.T. : parce moi mon frère il dit ça enfin

458 J.T. : ouais

459 A.T. : enfin quand j' lui présente une fille qui est un peu qui a mon âge il dit "oh on dirait 460 une daronne ! elle est daronne ++ "

461 S.B. : euh et sinon + alors vous par rapport à + à notre génération vous avez vous êtes

462 frappées par des différences de + façons d'parler?

463 K.T.-S.B. : oui de façons d'par XX trouve-pas pas plus que ça

464 A.T. : par rapport à la sienne, $X X$ tu veux dire ++

465 S.B. : oui un peu mélangé $X X X$

466 A.T. : j'pense que j'vais plonger d'ce côté (rires)

467 K.T. : ben oui des façons d'parler pas trop la façon d'être oui enfin ça ça a énormément 468 évolué enfin c'est fou enfin

469 S.B. : ah oui quoi par exemple?

470 K.T. : ben tout enfin la façon d'parler la façon enfin + on dit des mots maintenant on 471 utilise des mots beaucoup plus crus enfin entre amis y a aucune gêne on s'dit tout et puis 472 euh + les filles ça couche beaucoup plus vite voilà c'est plus y a plus les règles d'avant 473 aujourd'hui sortir avec un gars ça veut pff-ça veut dire vite fait enfin c'est

474 A.T.-K.T. : quoi! - pas

475 K.T. : grand chose sortir avec un garçon c'est plus grand chose c'est plus alors qu'à

476 l'époque c'était beaucoup plus moi j'sais qu' ma mère son premier copain elle l'a eu à dix-

477 sept ans (rire) ça m' paraît vieille quoi quand même

478 A.T.-K.T. : c'est jeune tout ça-dix-sept ans ++

479 K.T. : ben ouais (rire) c'est bizarre + ça dépend

480 A.T. : mais toi t'as déjà des chagrins d'amour hein 
K.T. : hein

482 A.T.-K.T. : des grands des chagrins non ? - oh non ++ oh non non

483 A.T. : non?

K.T. : non non non mais j'ai

S.B. : justement c'est c'qu'elle dit

K.T.-S.B. : voilà c'est justement - c'est pas important

487 K.T. : c'est pour ça (mh) j'ai pas envie d'être amoureuse à mon âge je j'aurais peur d'être 488 amoureuse à mon âge moi j' vois des amies à qui ça arrive et hh supporte pas non mais +

489 mais t'es pas formée à XX tu peux pas tu peux pas recevoir un sentiment aussi fort

490 S.B. : non mais ça s'choisit pas

491 K.T.-S.B. : non ça s' choisit pas - ça vous dégringole dessus

492 K.T. : ben oui je sais mais moi j'les vois y en a plein qu'ont + mal tourné enfin à cause de 493 ça

494 A.T. : à cause des chagrins d'amour

495 K.T. : ouais ++ et oui hein + Amélie elle prend ça à la rigolade

496 A.T. : ben non non mais euh

497 S.B.-A.T. : et euh-ouais ouais j'sais pas

498 A.T. : enfin moi y avait des chagrins d'amour euh quand j'étais j'avais douze treize

499 quatorze ans $+y$ avait des gros chagrins

500 K.T. : ah bon?

501 A.T. : ah oui carrément

502 K.T.-A.T. : et on embrassait les garçons? -j' connaissais des filles

503 A.T. : elles se sont mises à fumer à cause de chagrins d'amour vraiment hein + ah oui non 504 on pleurait et tout non mais tu t'rends pas compte hein en quatrième XX c'était horrible 505 parce qu'un tel

506 A.T.-S.B. : $X X-$ Katia

507 S.B. : ne pleure jamais

508 K.T. : non

509 S.B. : elle prend les garçons et elle les jette

510 K.T. : c'est plus drôle

511 S.B. : mais peut-être que + eux pleurent $+d u$ coup

512 K.T. : bof mmh chacun son malheur ++

513 S.B. : et + alors + plus cru + par exemple les blagues les blagues euh les blagues

514 cochonnes

515 T.-S.B. : oui - ça s'

516 S.B. : raconte

517 K.T.-S.B. : non - qu'on soit fille

518 S.B. : qu'on soit garçon $(\mathrm{mh})$ ?

519 K.T. : non c'est plus enfin quand on parle de sexe soit on utilise des mots très enfin voilà 520 ( $\mathrm{mh}$ ) très crus et on en parle vraiment librement entre nous

521 A.T.-K.T. : $m$ h + comme Fun radio - quoi +

522 K.T. : hein?

523 A.T. : comme Fun radio y a longtemps

524 K.T. : oui oui (mh) enfin oui mais c'est entre nous alors qu'avant

525 S.B.-K.T. : ce c'est - mais vous

526 S.B. : avez écouté Fun Radio pour apprendre?

527 K.T. : ah non du tout non non c'est entre amies qu'on apprend tout ça enfin + parce qu'on 528 raconte et donc voilà c'est pas avec notre famille qu'on l'apprend + et non ma mère elle

529 m'a pas dit euh + donc voilà ++ 
530 S.B. : d'accord ++ et vous aussi ? + quand on est en prépa on parle cru on

531 J.T. : ben oui enfin c'est oui c'est la même chose oui $(\mathrm{mh})++m h++$

532 S.B. : d'accord + euh +++ est-ce que vous pouvez me décrire vos déplacements $++(\mathrm{mh})$

533 avec beaucoup d'précisions ++ pour un jour de la journ- de de la semaine + l'une et puis

534 l'autre + un + un jour où vous bougez un peu ++ alors 'j'suis sortie d'la maison (mh mh)

535 à telle heure j'ai fait comme ça

536 J.T. : ben alors jour de semaine ou : le week-end?

537 S.B. : comme vous voulez +++

538 J.T. : ben (rire)

539 K.T. : ben le week-end XXj'me lève

540 S.B. : alors dimanche dernier

541 K.T.-S.B. : samedi-par exemple

542 K.T. : pardon le dimanche je n'bouge presque pas

543 S.B.-K.T. : donc +++++ O.K. - ou alors j'vais prendre un café mais c'est tout

544 S.B. : donc samedi dernier

545 S.B.-K.T. : hein pour qu'ça soit très concret-samedi oui O.K.

546 K.T. : donc samedi dernier j'ai été en cours ++

547 S.B. : oui

548 K.T.-S.B. : de huit-alors

549 K.T. : à onze heures j'ai eu trois heures de maths le samedi matin

550 S.B. : donc pour pour faire ça vous quittez la maison ++ vous arrivez donc sur la Place

551 Voltaire +

552 K.T. : euh non non j'a-j'vais oui enfin si sur la Place Voltaire j'prends l'métro + j'

553 descends Cours de Vincennes donc à Ravel + euh après je rentre chez moi tout d'suite je

554 déjeune parce que j'l'ai pas fait l'matin (mh) et je dors pour récupérer + après j'me lève

555 vers quatorze heures j'me lave j'm 'habille j'me prépare je sors

556 A.T.-K.T. : tu t'es pas lavée en fait? -j'retrouve les gens

557 K.T. : ben oui c'matin j'me suis pas lavée non plus j'me suis lavée en rentrant là et donc j'

558 rejoins des gens à chaque fois devant la Fnac Bastille

559 S.B. : alors pour aller à la Fnac Bastille c'est à pieds ?

560 K.T. : oui à pieds

561 S.B. : vous passez par où?

562 K.T. : + oh j'sais pas comment on dit par là

563 J.T.-K.T. : la rue d'la Roquette? - comment ça s'appelle

564 K.T. : rue d'la Roquette donc voilà rue d'la Roquette + après j'ai été me poser bien

565 justement au fond des quais d'Bastille + parce qu'il y a un petit tremplin en fait qu'est sur

566 l'eau enfin on peut escalader

567 K.T.-S.B. : pour y aller - comment on fait?

568 K.T. : mais c'est interdit (rire) + mais c'est sur l'eau et

569 A.T.-K.T. : c'est où ça $X X$ - quand on est posés

570 K.T. : c'est c'est ben quand tu marches sur les quais d'Bastille quand tu descends

571 A.T. : ouais

572 K.T. : tu sais tu marches + à la fin t'as une énorme place + tu passes sous l'métro et là

573 t'as un tremplin qu'est sur l'eau en bois

574 S.B.-K.T. : ah ouais - et donc

575 K.T. : faut escalader et on y a été +

576 S.B.-K.T. : y a personne qui vous déloge après ? - y a la police

577 S.B.-K.T. : de là ? si

578 S.B. : si si? 
579 K.T. : y a la police qu'est passée qui nous a demandé de remonter + donc on a remonté + 580 après on a été se poser ben chez Oscar le café à un euro vingt

581 S.B. : $m$ h + c'est où ça Oscar?

582 J.T.-K.T. : c'est avenue Beaumarchais - oui c'est à Bastille

583 K.T. : ouais rue Beaumarchais juste à côté donc voilà c'est très bien + et après on s'est 584 quittés j'suis rentrée chez moi je suis ressortie le soir + j'ai été prendre un café avec des 585 amis à Bastille au Café des Phares + et après j'ai été à une soirée euh vers Nation + +

586 S.B. : et tout ça à pattes ou tout ça

587 K.T. : euh non à pieds souvent +

588 S.B. : oui

589 K.T. : ouais

590 K.T. : enfin les soirées bon

591 S.B.-K.T. : donc -j'y vais en métro

592 S.B. : Bastille Nation ça c'est agréable à faire à pieds

593 K.T. : oui oui ça j'le fais oui $(\mathrm{mh})$ donc voilà puis j'suis rentrée à la maison 'ai dormi

594 S.B. : et vous? +

595 S.B. : ben moi samedi dernier j'me suis levée à à onze heures à mi-non ouais enfin à midi

596 j'étais Place de Clichy + non à midi j'étais à Anvers (mh) et en fait j'de j'devais aller faire

597 les boutiques avec une amie donc on a marché on a fait Anvers Barbès + on est revenues

598 Place de + Clichy on a + pris l'métro + on a été jusqu'à euh Hôtel de Ville Hôtel de Ville

599 on a marché jusqu'à Châtelet

600 A.T.-J.T. : c'est le après à Châtelet - ouais

601 S.B.-J.T. : quand vous dites Châtelet - ah non ça a été non non on a été

602 S.B. : c'est la rue

603 J.T.-S.B. : là j'me suis trouvée oui - d'Rivoli?

604 J.T. : la rue d'Rivoli mais avant on est passées

605 S.B.-J.T. : donc c'est les boutiques qui vous intéressent? - par Saint-Maur ouais

606 A.T. : mais quand t'es à la Place de Clichy t'es allée à à Guerissol ?

607 J.T. : ouais voilà

608 A.T.-K.T. : j'en étais sûre et voilà

609 J.T. : non en fait de Place de Clichy après j'ai été à $++a ̀++$ à rue rue Saint-Maur (mh)

610 on a repris l'métro + de rue Saint-Maur après on a pris l'bus pour aller à Châtelet à Hôtel

611 de Ville après on a été à Châtelet à pieds + et après j'suis retournée à Hôtel de Ville après

612 j'suis rentrée chez moi en passant par Bastille

613 A.T.-J.T. : à pieds ? - ah non non avec le métro + non

614 J.T. : et euh et le soir j'suis repartie ben j'étais à Bastille + on s'était donné rendez-vous

615 devant la Fnac + pour aller à Hoche donc on a pris l' métro +

616 A.T. : c'est où Hoche? +

617 J.T. : c'est euh

618 S.B.-J.T. : c'est à XX non? + + - à vers Porte de Pantin

619 A.T.-S.B. : ah d'accord non non-d'accord

620 A.T.-S.B. : ah mais c'est près - ah mais la Fnac c'est le

621 A.T. : le point d'rendez-vous euh

622 J.T. : ouais non mais

623 K.T.-J.T. : ouais devant la Fnac oui la Fnac XX rendez-vous devant la Fnac - la Fnac

624 c'est

625 K.T. : oui

626 J.T. : c'est vrai 


\section{Participantes :}

1.F.L. : Florence Lefeuvre

2.G.P. : Gabriel Pujade

627 F.L. : et euh + en c'qui concerne l'école là tu tu m'as parlé du lycée Rodin est-ce que

628 G.P.-F.L. : ouais - qu'est

629 F.L. : qu'est-ce que tu penses des écoles du quartier des collèges des lycées? euh

630 G.P. : euh ++ bah je pense qu'a priori enfin + de c'qu'on en entend c'est pas ++ on n'est

631 pas dans une zone défavorisée + (F.L. : $\mathrm{mm}$ ) hein + euh à savoir que les choses ont l'air de

632 s'passer à peu près bien sauf que bon $++j$ 'pense que dans dans tout lycée euh y a des

633 problèmes un petit peu à la sortie (F.L. : $\mathrm{mm}$ ) de drogue de machin choses comme ça mais

634 bon c'est l'adolescence hein + j'pense que c'est ça un peu partout pareil + euh au niveau

635 des écoles y a quand même un souci j'pense c'est que + les écoles ont tendance à fermer

636 des classes ++ (F.L. : $\mathrm{mm} \mathrm{mm}$ ) ++ parce que les familles s'en vont d'Paris parce que les

637 loyers sont trop chers et que ++ et que bah à l'école qu'est vraiment juste à côté d'chez

638 nous y a une classe qui s'est fermée l'année dernière l'école où sont les enfants donc qui

639 est l'école dont on dépendait avant mais ils sont restés là-bas + une classe s'est fermée

640 quand ils sont arrivés enfin quand l'premier est arrivé ++ euh

641 F.L. : e- elle est où cette école (ou, où)?

642 G.P.: boulevard Arago

643 F.L. : boulevard Arago?

644 G.P.-F.L. : ouais $-m m$

645 G.P. : donc ce sont des écoles où franchement en tant qu'parents y a pas +

646 d'problèmes + tout tout l'monde il est beau tout le monde il est gentil en gros c'est c'est

647 l'quartier qui veut un peu ça aussi (F.L. : $\mathrm{mm} \mathrm{mm}$ ) puisque on est + quand même dans les

648 coins du treizième où y a pas trop de + de soucis quoi (F.L. : $\mathrm{mm} \mathrm{mm}$ )

649 F.L.-G.P.: $X$ - les écoles

650 G.P. : qui sont plus en périphérie (F.L. : $\mathrm{mm} \mathrm{mm}$ ) ont peut-être plus mauvaise presse que +

651 que les écoles qui sont vraiment là dans l'milieu du treizième quoi

652 F.L. : ils sont + d'accord ils sont + ils sont en quelles classes c'est en à l'école primaire

653 c'est ça?

654 G.P.-F.L. : ouais $-c$ 'est

655 G.P. : $C P$ et $C M 2$

656 F.L. : d'accord ++ et donc par exemple pour l'année prochaine alors comment + ça va

657 s'passer pour le collège?

658 G.P. : et bah le collège euh ça va être a priori celui qui est à côté d'la maison + on dépend

659 d'un collège qui est rue ++ je sais plus l'nom d'la rue + qui est juste à côté + (F.L. : $\mathrm{mm}$ )

660 donc collège et puis après ce sera l'lycée Rodin et l'collège apparemment on (n') rien

661 entendu de+ d'alarmant

662 F.L. : d'accord

663 G.P. : donc euh pour l'instant on s'fait pas trop de

664 F.L. : donc tu + tu t'inquiètes pas de

665 G.P. : non

666 F.L. : la structure publique

667 G.P. : non

668 F.L. : par-...? + d'accord et le lycée Rodin non plus?

669 G.P. : le lycée Rodin euh n'est + pas réputé pour être le meilleur lycée du treizième ++

670 (F.L. : mm) puisque c'est a priori Claude Monnet qui a (F.L. : $\mathrm{mm}$ ) meilleure réputation 
671 dans l'treizième ++ bon maintenant le lycée Rodin ça a pas l'air d'être un catastrophe non 672 plus donc on (n') y est pas (F.L. : $\mathrm{mm}$ mm) encore j'ai dit (F.L. : $\mathrm{mm}$ ) CM2 mais c'est peut673 être CMI + (F.L. : $\mathrm{mm}$ ) parce que c'est pas l'année prochaine qu'il rentre au lycée

674 F.L. : ah oui alors c'est peut-être CM1 alors oui d'accord

675 G.P. : euh donc on s'est pas encore inquiétés d'ces choses-là mais euh + j'sais pas les

676 écoles ont l'air assez tranquilles c'est pas ++ XX enfin la population (F.L. : $\mathrm{mm}$ mm) c'est

677 quand même relativement des gens + qui ont pas d'problèmes et d'ailleurs ça s'ressent au

678 niveau des profs qui (F.L. : $\mathrm{mm}$ ) ++ qui font pas trop d'sorties par exemple parce qu'ils

679 considèrent que c'est l'boulot des parents parce qu'ils ont le temps et

680 F.L. : d'accord

681 G.P. : et l'argent et le niveau intellectuel (F.L. : $\mathrm{mm} \mathrm{mm}$ ) suffisant pour sortir leurs enfants

$682+$ c'qui avait fait un peu débat dans certaines réunions d'parents (F.L. : $\mathrm{mm} \mathrm{mm}$ ) ++ euh

683 donc c'est peut-être trop pépère

684 F.L. : $\mathrm{mm} \mathrm{mm}$

685 G.P.-F.L. : trop - d'accord

686 G.P. : c'est peut-être trop axé sur justement euh les cours l'apprentissage + tout c'qui est

687 F.L.-G.P. : ah ouais annexe

688 G.P. : passe un peu en arrière plan (F.L. : $\mathrm{mm} \mathrm{mm}$ ) parce qu'ils considèrent que + que ça

689 peut être fait à la maison

690 F.L. : et toi-même tu tu as été à quelle école?

691 G.P. : école Arago où sont mes enfants

692 F.L. : ah où sont les

693 G.P.-F.L. : puisque j'hab - enfants

694 G.P. : j'habitais avec mes parents donc

695 F.L.-G.P. : oui oui c'est ça-dans l'appartement

696 G.P. : dans lequel on était voilà donc euh voilà

697 F.L. : tu as retrouvé des des enseignants ou

698 G.P.-F.L. : non - X ou ...?

699 G.P. : non non + non (rire)

700 G.P.- F.L. : non non -ça aurait pu?

701 G.P. : ouais ouais ça aurait pu mais non non ils sont tous partis ils sont ils sont ils sont plus 702 là-bas + mais j'ai discuté avec la concierge très longuement et + elle s'rappelle d'un

703 certain nombre certains sont partis certains sont morts certains ++ sont dans d'autres

704 écoles ++ (F.L. : $\mathrm{mm} \mathrm{mm}$ ) donc j'ai eu des nouvelles (rires)

705 G.P.-F.L. : de mes anciens profs - tu as eu des nouvelles

706 F.L. : tu avais de-tu avais demandé euh

707 G.P.-F.L. : ouais - il y en avait un

708 F.L. : qui t'avait marqué plus

709 G.P.-F.L. : je pense que tous - spécialement...?

710 G.P. : m'ont marqué dans cette école $+j$ 'ai v-j'avais vraiment eu des instits +++ à forte

711 personnalité et vraiment $+j$ 'en n'ai que de bons souvenirs de cette école $+($ F.L. : $\mathrm{mm})+$ et

712 ça s'est vraiment toujours bien passé et non non je $+m$ 'souviens des noms d'tous mes profs

$713++$ et j'en ai même rencontré plusieurs de longues années après qui connaissaient encore

714 mon nom c'qui m'avait assez surpris + (F.L. : $\mathrm{mm} \mathrm{mm})+$ non vraiment + très très bien 


\section{Fragmento 7 \\ CFPP2000 [SO-01] Louise_Liotard_F_85_et_Jeanne_Mallet_F_75_SO}

\section{Participantes :}

1. J.M. : Jeanne Mallet

2. L.L. : Louise Liotard

3. M.P. : Mat Pires

4. An. : Anne

5. F. : Farah

715 J.M. : mais + lui l'Algérien + il le fait que pour moi toute seule la nuit +

716 M.P. : ah oui + mais il fait quoi?

717 J.M. : pour que moi j'entende

718 J.M.-M.P. : ah ben il il roule s - la musique?

719 J.M. : il roule sa banquette j'sais pas quoi + il fait tomber des bouts d'bois il fait tomber

720 des billes + euh voyez + il a + il doit avoir un appareil qui fait tac tac tac tac tac tac + tac

721 tac tac tac tac tac tac + san-s- arrêt

722 M.P. : ah oui +

723 J.M. : si vous saviez ce que c'est énervant

724 An.-M.P. : oui je sais $+m m \mathrm{~mm}$

725 J.M.-L.L. : qu'est-ce que c'est que cet appareil? ++ - c'est une vidéo j'en sais rien j'sais

726 pas quoi je sais pas $+d u$ bruit la nuit oui $+X X$

727 J.M. : alors je l'ai signalé là je l'entends plus il y a il a d̂̀ être + plusieurs fois qu'il est

728 appelé à la loge + par madame Jacques +

729 M.P.-J.M. : $\mathrm{mm}+++$ est-ce que vous avez fait connaissance euh: enfin des des + des ah-

730 mais je suis montée l'voir il m'a reçue comme un chien dans un jeu d'quilles +

731 M.P.-J.M. : ouais oh la la - comme on dit ah ben oui + et il m'a dit que si j'étais pas une

732 femme + en mettant son poing comme ça j'ai dit oh: attention jeune homme (rires Marc) oh

733 attention +

734 F.-J.M. : c'est un Arabe? + c'est un Algérien? - regardez ++ oui oui +

735 J.M. : faites bien attention à qui vous parlez hein +

736 An.-M.P. : c'est un violent $-m m+$

737 M.P- J.M. : oh la la - parce que:

738 An. : c'est un un violent +

739 F. : c'est un vieux?

740 An. : un violent

741 F.-J.M. : un violent c'est un + oui c'est

742 An.-J.M. : un violent oui + et pourtant c'est un jeune - XXX (brouhaha)

\section{Fragmento 8}

743 M.P. : et vous madame Pollet votre: votre école: ça s-

744 M.P.-J.M. : ça s'est bien passé dans la Nièvre là ? + ouais + vous avez de: - ah ben non 745 moi j'étais à l'école dans la Nièvre + les monts d'Morvan vraiment

746 J.M.-An. : vraiment les monts du Morvan - XXX (rires Marc)

747 J.M. : euh: je suis venue j'avais neuf ans + mais une grand-mère à: + Champigny-sur-

748 Marne

749 M.P.-J.M. : ah ouais - mais comme c'était en pleine guerre je n'suis pas restée longtemps

750 parce que moi: descendre tout l'temps à la cave: les bombardements +

751 M.P. : $m m+$ 
J.M. : c'est pas fait pour moi j'ai préféré retourner chez ma mère (rires) à la campagne j'étais plus tran- plus tranquille + et puis donc euh non: +

J.M.-M.P. : ben j'ai fait mes écoles: dans l'Morvan ça s'est bien passé +- est-ce que vous vous souvenez d'une d'un enseignant qui vous a marquée euh? +++

J.M. : madame Legris elle s'appelait + euh elle m'a elle m'a fait pra-pratiquement toutes mes classes + de la maternelle à:

J.M.-M.P. : il y avait trois écoles quand même dans ce bourg c'était un bourg important$\mathrm{mm}++$ ouais ouais +

J.M. : où est enterré Paul d'ailleurs

An. : ah oui +

J.M. : cimetière on avait: boulanger épicier euh mairie: enfin tout quoi

M.P.-J.M. : $m m++$ ah oui - c'était vraiment un bourg important

J.M.-L.L.: maintenant dans: j'y suis allée - et vous êtes dans le Loiret non? +

J.M.-An. : non dans l'Morvan - dans la Nièvre

L.L.-J.M. : dans la ah dans les monts d'Morvan + ah oui - cinquante-huit

J.M. : $j$ 'y suis allée donc lundi dernier

L.L. : $(X X X)$

An. : mais ça a dû changer hein depuis

L.L.-J.M. : hein? - ah il y a plus rien

An.-L.L. : ah ben oui hein-parce que: X c'est l'pays à Mitterrand la Nièvre

J.M. : oui tout à fait $X X$

L.L. : oui c'est pour ça que vous vous êtes:

J.M. : oui + oui oui ++

L.L. -J.M. : vous l'avez connu non? + - j'étais très bien avec Mitterrand

J.M. : mes parents étaient très bien il venait chez nous euh: comme moi j'étais reçue en hiver; X euh: chez Mitterrand

L.L. : j'ai été euh ++

J.M. : et c'est pour ça que: ++

L.L.-J.M. : il ét- on déjeunait au même: restaurant le vieux Morvan + à: Chateau-Chinon + il était maire de Chateau-Chinon-j'ai bien regretté euh Mitterrand euh ++ parce que certainement

An.-M.P. : oui il était maire oui - ouais c'est ça ouais

L.L.-J.M. : je l'ai vu là + on a parlé ensemble ++ oui ++ Chateau-Chinon il a son musée là-bas à Chinon + - il y a l'musée là + de tout: de beaucoup d'objets qu'il ramenait de: + qu'on lui offrait quoi

F.-M.P. : mais il paraît que sa femme a mis en vente ses euh ses: ses affaires; X ouais c'est $c ̧ a+-m m+m m$

J.M.-An. : (brouhaha) elle a vendu tous ses vêtements - oui ça y est c'est vendu hein

J.M. : (brouhaha) XXX mais ça s'est vendu cher hein

L.L.-An. : au moins trente mille costumes - oui hein ça fait XX

J.M.-An. : (brouhaha) enfin c'est pour son association c'est pour euh: oui oui oui + oui oui oui

M.P.-J.M. : mm + - oui c'est ça c'est pas pour elle elle a pas besoin de

An.-L.L. : X c'est pas pour elle bien sûr hein-mais moi quand je l'ai vu il était pas président de la République +

L.L.-F. : et j'me rappelle: X et j'av- euh oui ben il était: - il devait être ministre non?

L.L.-An. : déjà + euh: député: maire de son patelin X oui il a été pas mal ministre hein + oui 
800 L.L.-J.M. : j'avais acheté une carte postale + petite X deviendra grande + alors je lui dis 801 vous pouvez me signer une car-ah ben oui mais Chateau-Chinon XX-à partir du moment 802 que: Mitterrand est: ++ n'a plus été président

803 L.L. :j'dis + avant + lisez ce qu'il y a dessus + j'dis j'vous souhaite la même chose ah ben 804 ça c'est gentil (rires Marc)

805 An.-M.P. : il était ministre sous De Gaulle (brouhaha) vous êtes très bien X (rires)

806 J.M.-M.P. : mais moi je sais j'ai beau-beaucoup regretté comme comme monsieur Lefort 807 d'ailleurs toutes les deux $+++-m m$

808 J.M.-An. : comme disent les bons copains + hein ben voilà ben voilà ouais $+-c ̧ a$ n'a rien 809 à voir hein

810 F.-J.M. : mais il est décédé ce monsieur Lefort? ben voilà

811 L.L.-An. : il y a longtemps - ah:oui:

812 J.M.-An. : oh ben oui ça fait un moment Fernand Lefort euh:

813 L.L. : quarante ans

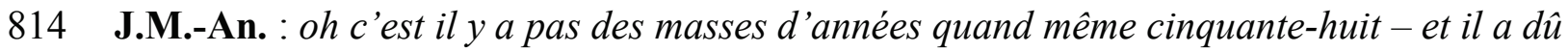
815 décéder vers dans les années soixante

816 L.L.-An. : oh oui il y a une quarantaine d'années - oui à peu près +

817 L.L. : oui

818 J.M.-M.P. : tant que ça? - $\mathrm{mm}$

819 An. : après

820 L.L.-An. : oh oui - oh oui oui oui +

821 An.-L.L. : dans les années soixante après c'était Paulette après $m m+-$ ah oui ?

822 F. : oui oui + oui +

823 J.M.-L.L. : pas tant que ça quand même ++ il y a pas oh non: Paulette elle a fait + trois 824 mandatures ++- ah si ah si

825 J.M.-F. : il y a pas quarante ans qu- oh non:- euh : peut-être pas soi-soixante cinq? +

826 An.-L.L. : dans les années soixante quand même hein monsieur Lefort ++ oh oui oui + oui 827 oui + oui ++ oui oui + oui + puis après c'est: - oui mais il y a au moins trente ans quand 828 même hein + parce que son fils il a t-soixante-quatre ans ++ et: il était déjà marié 
Anexo 2

\section{Sujetos participantes de las pruebas perceptivas}

1. Aline Boudeville. 30 años. Profesora de FLE. Rouen. Francia.

2. Angélique Demouiller. 21 años. Estudiante de traductorado. Louviers. Francia.

3. Aurélie Meignan. 32 años. Traductora francés-español. Angers. Francia.

4. Béatrix Carruel. 60 años. Operador de viajes y turismo. Annecy. Francia.

5. Catherine Larriva. 64 años. Profesora de lengua y literatura jubilada. Nantes. Francia.

6. Claire Ruhier. 25 años. Estudiante. Grenoble. Francia.

7. Clément Beury. 38 años. Profesor de FLE. Chinon. Francia.

8. Florianne Verrecchia. 23 años. Traductora. Marseille. Francia.

9. Frédéric Faivre. 43 años. Publicista. París. Francia.

10. Gilles Jamin. 57 años. Director de colegio. Le Mans. Francia.

11. Laetitia Mayer. 40 años. Ingeniero químico. La Rochelle. Francia.

12. Monique Tuteau. 48 años. Profesora de español. Luçon. Francia.

13. Nadine Calvez. 50 años. Animadora de centro recreativo y colonia de vacaciones. Brest. Francia.

14. Nathalie Collomb. 44 años. Enfermera. Lyon. Francia.

15. Nicolas Durieux. 26 años. Sociólogo. Brest. Francia.

16. Ophélie Pain. 23 años. Traductora. Caen. Francia.

17. Roger Rousseaux. 50 años. Profesor de tecnología. Fontenay le Comte. Francia.

18. Samantha Larriva. 33 años. Actriz. Nantes. Francia. 


\section{Anexo $n^{\circ} 3$}

\section{Detalles de la modalidad utilizada para las pruebas perceptivas}

A- Etapas de las entrevistas:

1) Presentación de la actividad: se describe la actividad que se va a realizar y los objetivos de la misma. La actividad se describe como un análisis de las interpretaciones que los sujetos realizan de los fragmentos grabados que van a escucharse. Se explica que van a escuchar cada fragmento en forma integral y que luego se escuchará con pausas en las que se les preguntará por el sentido de secuencias puntuales. Se evita en todo momento dar más detalles del objetivo. Cuando es necesario, se explica que se busca entender lo que el hablante quiere decir por la forma como lo dice. Asimismo, suele ser necesario aclarar que el significado léxico ya ha sido elucidado, puesto que los sujetos tienden a focalizarse en ese aspecto.

2) Se describe el fragmento que se escuchará: participantes (sexo, edad, relación entre ellos) y temas tratados.

3) Se hace escuchar el fragmento.

4) Se anuncia en qué parte del fragmento se pausará la grabación. Se hace escuchar el fragmento pausándolo luego de cada emisión sobre la que se desea indagar.

5) Se pregunta por el significado de esa emisión.

6) De ser necesario, se vuelve a focalizar sobre la forma en que se dice la emisión y se pregunta si esa forma condiciona el significado de lo dicho.

7) Se continúa del mismo modo con las siguientes emisiones, siguiendo la progresión del fragmento, sin saltar partes ni aislar emisiones.

8) Se procede del mismo modo con los demás fragmentos.

B- Preguntas efectuadas:

Obligatorias:

1- Quelle est la signification de ce fragment?

Comment tu interprètes/vous interprétez cette phrase ? 
Qu'est-ce qu'il/elle veut dire avec cette phrase ?

2- Qu'est-ce que tu penses /vous pensez de la façon dont on pose la question/on répond à la question?

La façon de poser la question / de répondre te/vous suggère quelque chose ?

Opcionales :

3- Y aurait-il une différence s'il/elle avait dit [ + la misma secuencia con una pendiente melódica inversa]

Pourquoi pensez-vous /tu penses que la personne a prononcé $[+$ secencia con la entonación original] au lieu de [ + secuencia con entonación inversa] 